

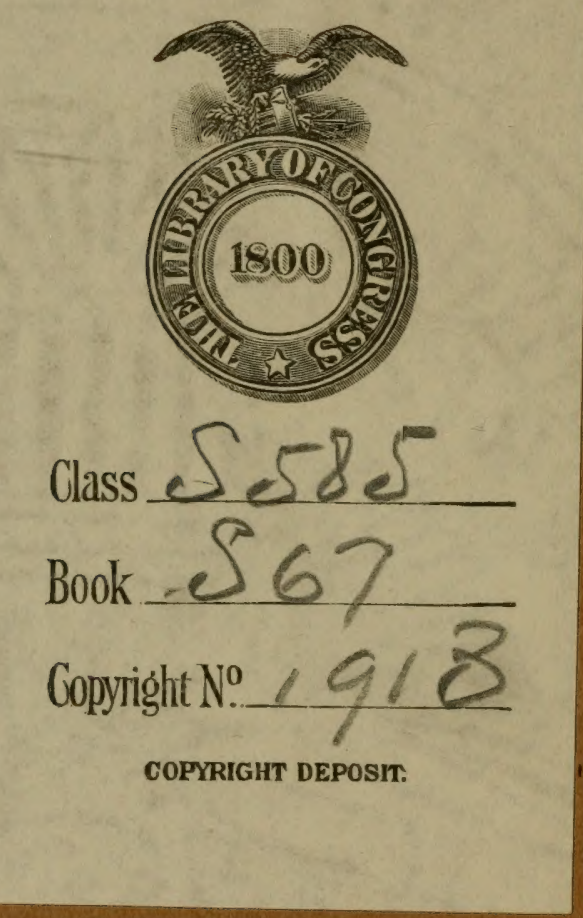





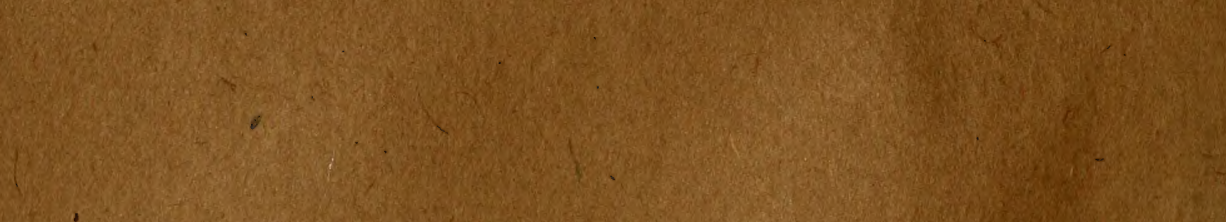

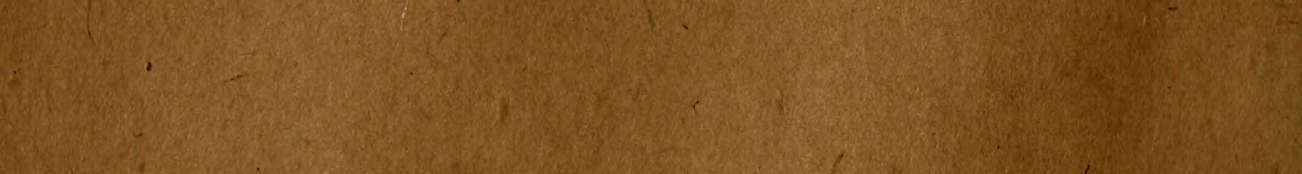

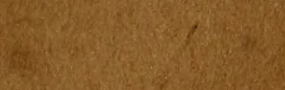

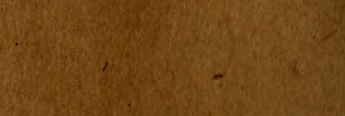

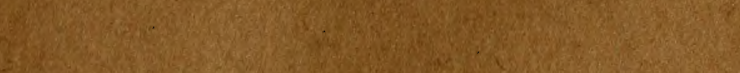

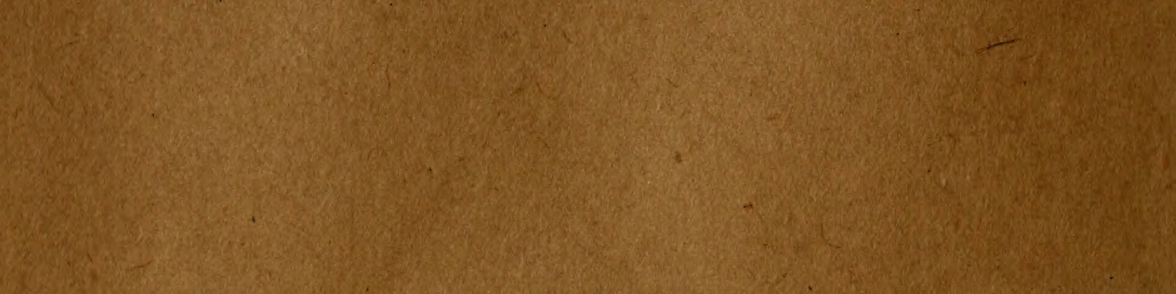

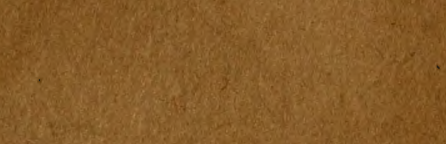

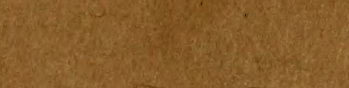

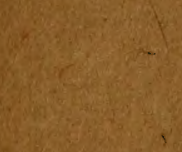

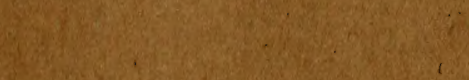

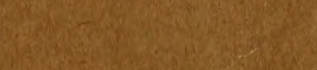

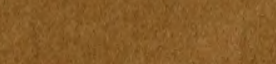

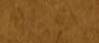

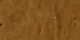

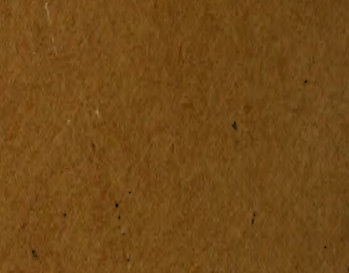
S.

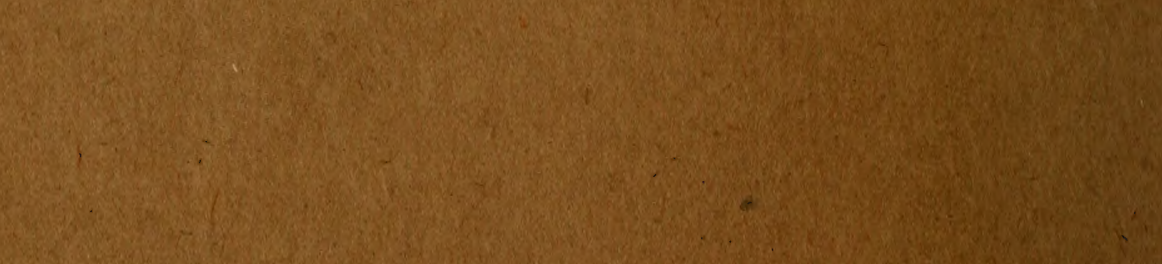


THE CHEMISTRY

OF

PLANT AND ANIMAL LIFE 


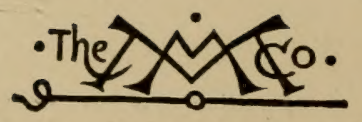

THE MACMILLAN COMPANY

NEW YORK - BOSTON - CHICAGO - DALLAS

ATLANTA - SAN FRANCISCO

MACMILLAN \& CO., Limited

LONDON - BOMBAY - CALCUTTA

THE MACMILLAN CO. OF CANADA, LtD. TORONTO 


\section{THE CHEMISTRY}

\section{OF \\ PLANT AND ANIMAL LIFE}

BY

HARRY SNYDER, B.S.

THIRD REVISED EDITION

New 洫ark

THE MACMILLAN COMPANY

I9I 3

All rights reserved 


\section{5 \\ .567 \\ 1913}

COPYRIGHT, 1903,

BY HARRY SNYDER.

COPYRIGHT, I9०3 AND 1913,

BY THE MACMILLAN COMPANY.

First published elsewhere.

New edition set up and electrotyped. Published December, 1903. Reprinted December, 1905; October, 1907; January, 1909.

Third revised edition, September, rgr3.

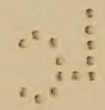

Norwood 招rsss

J. s. Cushing Co. - Berwick \& Smith Co.

Norwood, Mass., U.S.A.

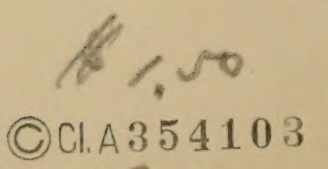




\section{PREFACE TO FIRST EDITION}

THIS book is the outgrowth of instruction in chemistry given in the School of Agriculture of the University of Minnesota. At first the classes were small, and individual work with blackboard exercises and references to the literature in the school library was possible. With increased number of students, mimeographed notes were supplied, until finally the size of the classes and the volume of the notes have necessitated their publication in book form. The work was first given, in $189 \mathrm{I}$, to a class of seven students, while in 1903 they numbered 150 .

The students to whom this instruction has been given have been mostly earnest workers who attended school mainly from personal choice and who desired to make as much progress as possible. Numerous questions have been asked by them relating to the application of chemistry to farm and everyday life, and for a number of years the author kept a box in which were placed the more important of these questions together with notes of the difficulties experienced in the laboratory: and in developing the work from year to year these questions and difficulties have been considered.

This work was originally outlined as Agricultural Chemistry, but as special features have been developed and published, as "Soils and Fertilizers," and "The Chemistry of Dairying," this part of the subject has gradually developed into "The Chemistry of Plant and Animal Life," and includes the composition of plant and 
animal bodies, the chemistry of the plant and of its food and growth, the chemistry of human foods and animal nutrition, the digestibility and value of foods and the laws governing their economic use. A few topics of an industrial nature but closely related to plant and animal life are also included.

Before taking up the parts relating to the chemistry of plant and animal bodies, the elements and the simpler compounds present in plants and animals, together with the laws governing their combinations, are considered so as to prepare the way for a more intelligent study of the subject, and to show the relation which exists between chemistry and plant and animal life. Laboratory practice forms an important feature, and questions are asked in connection with each experiment. Many of the experiments and problems are given to illustrate some special phase of the composition of plant and animal bodies. The illustrations, with the exception of a few as noted, are original.

It has been the aim throughout to present the topics in such a way that they would be easily understood and to develop the reasoning powers of the student so that he would be able to make the best use of his chemistry in everyday life affairs.

HARRY SNYDER.

St. Anthony Park, St. Paul, Minn.

First edition, March I, 1903.

Second edition, Nov. II, 1903. 


\section{PREFACE TO REVISED EDITION}

IN revising this work it has been the aim to retain the individuality as expressed in the preface of the first edition, with such changes and additions as are in accord with recent investigations.

It has been deemed best to make a sharper division between the first part, which deals with the elementary principles of chemistry from an agricultural viewpoint, and the second part, dealing more distinctively with the chemistry of plant and animal life.

Many colleges in which this subject is taught give more extended courses in general chemistry than is presented in Part I of this work, in which case the student is already prepared, with a special review, to begin Part II. In other institutions the time allotted to chemistry is so limited as to necessitate a brief course, and then Part I or its equivalent should be given before undertaking Part II.

The problems, laboratory practice, and collateral reading as suggested, are essentials of the work, and sufficient time should be allotted in the curriculum, to permit a rational study of the subject. It should be the aim to master the principles which form the basis of the subject so as to intelligently apply them to the solution of the new problems which continually present themselves.

Minneapolis, Minn.

HARRY SNYDER.

May, I9I3. 



\section{CONTENTS}

\section{INTRODUCTION}

Chemistry in its relation to plant and animal life; Relation to other sciences; How to study chemistry; Reference books and how to use them; Importance of chemistry. Pages xix-xxii.

\section{PART I \\ CHAPTER I}

Composition of Matter. - Physical and chemical changes; Indestructibility of matter; Molecules; Atoms; Elements; Compounds; Chemical affinity; Mechanical mixtures; Chemical analysis and synthesis; Summary. Pages 3-8.

\section{CHAPTER II}

Properties of Elements and Compounds. - Physical properties; Chemical properties; Symbols of the elements; Formulas of compounds; Atomic weights; Molecular weights; Law of definite proportion; Valence; Combination of elements; Problems on combination of elements; Experiments and questions. Pages 9-r8.

\section{CHAPTER III}

Laboratory Manipulation. - Importance of laboratory practice; Names and uses of apparatus; Cutting glass tubing; Bending glass tubing; Perforating corks; Weighing; Measuring liquids; Obtaining reagents from bottles; Filtering; Laboratory notebook; Breakage of apparatus; Care of sinks and plumbing; How to accomplish the best results in the laboratory. Pages r9-29.

\section{CHAPTER IV}

Oxygen. - Occurrence; Preparation; Properties; Importance; Problems, experiments, and questions; Part taken in plant and animal life. Pages 30-35. 


\section{CHAPTER V}

Hydrogen. - Occurrence; Preparation; Properties; Importance; Problems, experiments, and questions; Part taken in plant and animal life. Pages $36-40$.

\section{CHAPTER VI}

Nitrogen. - Occurrence; Preparation; Properties; Importance; Problems, experiments, and questions; Part taken in plant and animal life. Pages $4 \mathrm{I}-44$.

\section{CHAPTER VII}

Carbon. - Occurrence; Preparation; Properties ; Coal ; Allotropism; A reducing agent; Combustion;'Spontaneous combustion; A decolorizer and deodorizer; Products of combustion; Compounds of carbon; Importance; Experiments and questions; Part taken in plant and animal life. Pages $45-53$.

\section{CHAPTER VIII}

Water. - Chemical composition; Physical properties; Water of crystallization; Natural waters; Impurities and relation to diseases; Location of wells; Mineral impurities; Contamination of drinking water; Methods of improving drinking waters; Water filters; Experiments and questions. Pages 54-62.

\section{CHAPTER IX}

Air. - A mechanical mixture; Carbon dioxid; Ammonium compounds; Moisture; Atmospheric constituents present in small amounts; Liquid air; Organic impurities and ventilation of rooms ; Air, a source of plant food; Sources of contamination of air ; Experiments and questions; Importance of air in plant and animal life. Pages 63-68. 
CHAPTER $\mathrm{X}$

Acids, Bases, Salts, and Neutralization. - Classification of elements; Acids; Bases; Salts; Radicals; Naming of acids; Naming of bases; Naming of salts; Double salts; Acid salts; Basicity of acids; Two series of salts. Pages $69-75$.

\section{CHAPTER XI}

Hydrochloric Acid, Chlorin, and Chlorids. - Occurrence; Preparation; Properties; Preparation of chlorin; Properties; The chlorin group of elements; Chlorids; Problems; Experiments and questions. Pages $76-8 \mathrm{r}$.

\section{CHAPTER XII}

Nitric Acid and Nitrogen Compounds. - Occurrence; Preparation; Properties; Importance; Ammonia; Occurrence; Preparation; Properties; Uses; Oxids of nitrogen; Anhydrids; Law of multiple proportion; Utilization of atmospheric nitrogen; Importance of the nitrogen compounds; Problems; Experiments and questions. Pages $82-88$.

\section{CHAPTER XIII}

Phosphorus and its Compounds. - Occurrence; Preparation; Properties; Oxids; Phosphoric acid and phosphates; Compounds of phosphorus; Importance of phosphorus and its compounds; Problems; Experiments and questions. Pages 89-9I.

\section{CHAPTER XIV}

Sulfur and its Compounds. - Occurrence; Preparation; Properties; Uses; Sulfur dioxid; Sulfuric acid; Properties of $\mathrm{H}_{2} \mathrm{SO}_{4}$; Sulfates; Sulfids; Problems; Experiments and questions. Pages 92-97.

\section{CHAPTER XV}

Silicon and its Compounds. - Occurrence; Preparation and properties; Silicic acid; Dialysis; Silicates; Importance of compounds of silicon; Problems; Experiments and questions. Pages 98-ror. 


\section{CHAPTER XVI}

Oxids of Carbon, Carbonates, and Carbon Compounds. - Carbon dioxid; Carbon monoxid; Marsh gas; Hydrocarbons; Petroleum; Use of gasoline; Illuminating gas; Mineral oils; Oil of turpentine ; Creosote; Benzene or benzol ; Aliphatic and aromatic series of compounds; Carbon disulfid; Cyanids; Carbids; Fuels; B. T. U. value of fuels; Foods; Production of organic compounds in plants; Decay of organic compounds; Experiments. Pages Io2-II4.

\section{CHAPTER XVII}

Writing Equations. - Importance; Common errors in writing equations; Impossible reactions; A knowledge of reacting compounds and products necessary; Equations for classroom work. Pages II5-I 20.

\section{CHAPTER XVIII}

Potassium, Sodium, and their Compounds. - Occurrence of potassium; Potassium hydroxid; Potassium nitrate; Potassium carbonate; Potassium chlorate; Potassium sulfate; Miscellaneous potassium salts; Occurrence of sodium; Sodium chlorid; Sodium nitrate; Sodium carbonate; Sodium hydroxid; Sodium phosphate; Miscellaneous sodium salts; Experiments. Pages I 2 I-I 27.

\section{CHAPTER XIX}

Calcium, Magnesium, and their Compounds. - Occurrence of calcium; Calcium carbonate; Calcium oxid; Calcium hydroxid; Calcium sulfate; Calcium chlorid; Bleaching powder; Calcium phosphate; Mortar; Glass; Occurrence of magnesia; Magnesium salts ; Experiments. Pages $\mathrm{I} 28-\mathrm{I} 32$.

\section{CHAPTER XX}

Iron, Aluminum, and their Compounds. - Occurrence of iron; Reduction of iron ores; Wrought iron; Steel; Rusting of iron; Iron Compounds; Occurrence of aluminum; Alums; Pottery ; Experiments. Pages I33-I40. 


\section{CHAPTER XXI}

Copper, Zinc, Lead, Tin, Arsenic, Mercury, their Compounds and Alloys. - Commercial importance; Occurrence of copper and its metallurgy; Copper sulfate; Bordeaux mixture; Occurrence of zinc; Compounds of zinc; Galvanized iron; Occurrence of tin ; Tin salts; Occurrence of lead; Oxids of lead; Lead carbonates; Lead salts; Uses of lead; Occurrence of arsenic; Paris green; Occurrence of mercury; Compounds of mercury; Experiments. Pages I $4 \mathrm{I}-\mathrm{I} 46$.

\section{PART II \\ CHAPTER XXII}

The Water Content and Ash of Plants. - Water; Dry matter; Plant ash; Form of the ash elements; Amount of ash in plants; Importance of ash elements; Water culture; Sand culture; Occurrence and function of ash elements ; Potassium; Sodium; Calcium ; Magnesium; Aluminum; Iron ; Phosphorus ; Sulfur ; Silicon; Chlorin; Experiments; Problems. Pages I49-167.

\section{CHAPTER XXIII}

The Non-nitrogenous Organic Compounds of Plants. - Organic matter; Non-nitrogenous and nitrogenous organic compounds; Classification of non-nitrogenous compounds; Carbohydrates; General characteristics; Cellulose; Occurrence; Physical properties; Chemical properties; Function and value; Food value; Amount of cellulose in plants; Crude fiber; Starch; Occurrence; Physical properties; Chemical properties; Function and value; Food value of starch; Amount of starch in plants; Dextrin ; Structural formulas; Sugar; Classification of sugars; Occurrence of sucrose; Physical and chemical properties of sucrose; Milk-sugar; Maltose; Inversion of sucrose; Refining of sugar; Occurrence of dextrose; Chemical and physical properties; Levulose; Miscellaneous sugars; Optical properties of sugar; Sugar-beets; Food value of sugar; Gums; Pentosans; Pectin bodies; Nitrogen-free extract; Fats; Presence in plants; Physical properties; Chemical composition; Stearin; Palmitin; Olein; Miscellaneous fats; Sa- 
ponification; Fatty acids; Waxes; Food value of fat; Amount of fat in plants and foods; Ether extract; Organic acids; Occurrence in plants; Tartaric acid; Malic acid; Succinic acid; Oxalic acid; Citric acid; Tannic acid; Function and food value of the organic acids; Essential oils; General properties; Occurrence; Chemical composition and properties; Essential oils of agricultural crops; Synthetic production of essential oils; Amount of essential oils in plants; Food value; Miscellaneous compounds in plants; Relationship of non-nitrogenous compounds of plants; Food value of the non-nitrogenous compounds; Experiments and questions. Pages I68-203.

\section{CHAPTER XXIV}

Nitrogenous Organic Compounds of Plants. - Amount of nitrogenous matter in plants; Different terms applied to nitrogenous compounds; Complexity of composition; Classification of nitrogenous compounds; Proteids; General composition; Occurrence; Physical properties; Chemical properties; Classification of proteids; Albumins; Globulins; Albuminates; Peptones and proteoses; Insoluble proteids; Food value of proteids; Amount in plants; Crude protein; Albuminoids; Composition; Nuclein; Gelatin; Mucin; Elastin; Food value of albuminoids ; Amides and amines; Composition and properties; Formation and Occurrence in plants; Formation and occurrence of amides in animals; Food value; Amount in foods; Protein production and disintegration; Alkaloids; General composition; Plant alkaloids; Animal alkaloids; Food value and production; Mixed nitrogenous compounds; Lecithin; Nitrogenous glucosides; General relationship of the nitrogenous organic compounds of foods; Problems and experiments. Pages 204-223.

\section{CHAPTER XXV}

Chemistry of Plant Growth. - Seeds; Ash; Non-nitrogenous compounds; Nitrogenous compounds; Chemical changes during germination; Change of starch to soluble forms; Change of fats to starch; Change of insoluble proteids to soluble forms; Germination of seeds and digestion of food compared; Necessary conditions for germination; Heavy- and light-weight seeds; Movement of 
plant juices; Joint action of chemical and physical agents; Porosity of tissues; Osmosis; Chlorophyl and protoplasm; Chemical action in leaves of plants; Production of chlorophyl; Function; Production of organic matter; Experiments. Pages 224-234.

\section{CHAPTER XXVI}

Composition of Plants at Different Stages of Growth. - Composition and stage of growth; Assimilation of mineral food by the wheat plant; Assimilation of nitrogen by the wheat plant; Clover ; Rapidity of growth; Flax; Rapidity of growth; Maize (corn); Importance; Roots; Stalks; Leaves; Tassel; Husks; Ripening period. Pages $235^{-244}$.

\section{CHAPTER XXVII}

Factors which influence the Composition and Feeding Value of Crops. - Seed; Soil; Climate; Stage of maturity; Method of preparation as food; Improving the feeding value of forage crops. Pages $245^{-249 .}$

\section{CHAPTER XXVIII}

Composition of Coarse Fodders. - Coarse fodders; Straw; Timothy hay; Hay similar to timothy; Oat hay; Hay similar to oat hay; Bromus inermis; Clover hay; Alfalfa and fodders similar to clover; Rape; Pasture grass; Corn fodder and stover; Silage. Pages $250-258$.

\section{CHAPTER XXIX}

Wheat. - Structure of kernel; Proteids of wheat; Relation of nitrogen in wheat to nitrogen content of flour; Influence of fertilizers upon composition of wheat; Variations in composition of wheat; Storage in elevators; Manufacture of flour; Composition of unsound wheat; Composition of different varieties; American and foreign wheats; Wheat as animal food; As human food; Experiments and questions. Pages $259-272$. 


\section{CHAPTER XXX}

Maize (Indian Corn). - Structure of the kernel; Composition; Proteids; Nitrogenous and non-nitrogenous corn; Varieties; Moisture content of corn ; Corn products ; Corn as a food ; Experiments. Pages $273^{-278 .}$

\section{CHAPTER XXXI}

Oats, Barley, Rye, Buckwheat, Rice, and Miscellaneous Seeds. Structure of the oat kernel; Composition of oats; Oats as human and animal foods; Barley; Rye; Rice; Buckwheat; Millet seed; Peas and beans; Grading of grains; Experiments. Pages 279-290.

\section{CHAPTER XXXII}

Mill and By-products. - Sources; Wheat by-products; Wheat bran; Wheat shorts; Wheat germ; Wheat screenings; Linseed meal; Cottonseed cake and meal; Oat feed; Gluten meal; Malt sprouts; Miscellaneous by-products; Inspection of feeding stuffs; Problems and experiments. Pages 29I-298.

\section{CHAPTER XXXIII}

Roots, Tubers, and Fruits. - General composition ; Potatoes; Carrots; Parsnips; Mangel wurzels; Apples; Oranges; Lemons; Strawberries; Grapes; Olives; Dried fruits; Miscellaneous fruits; Food value. Pages 299-303.

\section{CHAPTER XXXIV}

Fermentation. - Insoluble ferments; Soluble ferments or enzymes; Aërobic and anaërobic ferments; Conditions necessary for fermentation; Soil ferments ; Ferments in seeds ; Ferments in breadmaking; Ferment action and food digestion; Ferments and food preservation; Ferments in butter- and cheese-making; Diseaseproducing organisms; Beneficial organisms; Experiments. Pages 304-310.

\section{CHAPTER XXXV}

Chemistry of Digestion and Nutrition. - Digestion, a biochemical process; Digestion experiments; Caloric value of foods; Available 
energy of foods; Net energy of foods; Digestion of proteids; Digestion of the carbohydrates; Digestion of fats; Oxygen necessary for digestion; Factors influencing digestion; Mechanical condition; Combination of foods; Amount of food consumed; Palatability; Individuality; Miscellaneous factors influencing digestibility; Application of digestion coefficients; Digestible nutrients of foods; Problems. Pages 3II-327.

\section{CHAPTER XXXVI}

Rational Feeding of Animals. - Balanced rations; A maintenance ration; Standard rations; Food requirements of animals; Food supply at different stages of growth; Food requirements of horses; Selection of food for horses; Foods required for beef production; Selection of foods for beef production; Food requirements of dairy cows; Selection of foods for dairy cows; Food requirements of swine; Food requirements of sheep; Calculation of balanced rations; Nutritive ratio; Comparative cost and value; Caloric value of rations; Sanitary conditions; Problems. Pages 328-347.

\section{CHAPTER XXXVII}

Composition of Animal Bodies. - Water and dry matter; Mineral matter; Fat; Nitrogenous matter; Proteids of meat; Albumin; Myosin; Syntonin; Hemoglobin; Insoluble proteids; Peptones ; Keratin; Albuminoids; Gelatin; Influence of food upon the composition of animal bodies; Composition of human body. Pages $348-355$.

\section{CHAPTER XXXVIII}

Rational Feeding of Men. - Similarity of the principles of human and animal feeding; Dietary standards; Amount of food consumed per day; Calculating a balanced ration; Comparative cost and value of foods; Factors influencing digestibility; Requisites of a ration; Dietary studies; Chemical changes in the cooking of foods; Refuse and waste matters; Loss of nutrients in the preparation of foods; Mineral matter in a ration; Digestibility of foods; Digestibility of animal foods; Digestibility of vegetable foods; Relation of food to health; Tables of composition of human foods. Pages $356-380$. 


\section{CHAPTER XXX}

Maize (Indian Corn). - Structure of the kernel; Composition; Proteids; Nitrogenous and non-nitrogenous corn; Varieties; Moisture content of corn ; Corn products ; Corn as a food; Experiments. Pages $273^{-278 .}$

\section{CHAPTER XXXI}

Oats, Barley, Rye, Buckwheat, Rice, and Miscellaneous Seeds. Structure of the oat kernel; Composition of oats; Oats as human and animal foods; Barley; Rye; Rice; Buckwheat; Millet seed; Peas and beans; Grading of grains; Experiments. Pages 279-290.

\section{CHAPTER XXXII}

Mill and By-products. - Sources; Wheat by-products; Wheat bran; Wheat shorts; Wheat germ; Wheat screenings; Linseed meal; Cottonseed cake and meal; Oat feed; Gluten meal; Malt sprouts; Miscellaneous by-products; Inspection of feeding stuffs ; Problems and experiments. Pages 29I-298.

\section{CHAPTER XXXIII}

Roots, Tubers, and Fruits. - General composition; Potatoes; Carrots; Parsnips; Mangel wurzels; Apples; Oranges; Lemons ; Strawberries; Grapes; Olives; Dried fruits; Miscellaneous fruits; Food value. Pages 299-303.

\section{CHAPTER XXXIV}

Fermentation. - Insoluble ferments; Soluble ferments or enzymes; Aërobic and anaërobic ferments; Conditions necessary for fermentation; Soil ferments; Ferments in seeds; Ferments in breadmaking; Ferment action and food digestion; Ferments and food preservation; Ferments in butter- and cheese-making; Diseaseproducing organisms; Beneficial organisms; Experiments. Pages 304-310.

\section{CHAPTER XXXV}

Chemistry of Digestion and Nutrition. - Digestion, a biochemical process ; Digestion experiments; Caloric value of foods; Available 
energy of foods; Net energy of foods; Digestion of proteids ; Digestion of the carbohydrates; Digestion of fats; Oxygen necessary for digestion; Factors influencing digestion; Mechanical condition; Combination of foods; Amount of food consumed; Palatability; Individuality; Miscellaneous factors influencing digestibility; Application of digestion coefficients; Digestible nutrients of foods; Problems. Pages $311-327$.

\section{CHAPTER XXXVI}

Rational Feeding of Animals. - Balanced rations; A maintenance ration; Standard rations; Food requirements of animals; Food supply at different stages of growth; Food requirements of horses; Selection of food for horses; Foods required for beef production; Selection of foods for beef production; Food requirements of dairy cows; Selection of foods for dairy cows; Food requirements of swine; Food requirements of sheep; Calculation of balanced rations; Nutritive ratio; Comparative cost and value; Caloric value of rations; Sanitary conditions; Problems. Pages $328-347$.

\section{CHAPTER XXXVII}

Composition of Animal Bodies. - Water and dry matter; Mineral matter; Fat; Nitrogenous matter; Proteids of meat; Albumin; Myosin; Syntonin; Hemoglobin; Insoluble proteids; Peptones; Keratin; Albuminoids; Gelatin; Influence of food upon the composition of animal bodies; Composition of human body. Pages $348-355$.

\section{CHAPTER XXXVIII}

Rational Feeding of Men. - Similarity of the principles of human and animal feeding; Dietary standards; Amount of food consumed per day; Calculating a balanced ration; Comparative cost and value of foods; Factors influencing digestibility; Requisites of a ration; Dietary studies; Chemical changes in the cooking of foods; Refuse and waste matters; Loss of nutrients in the preparation of foods; Mineral matter in a ration; Digestibility of foods; Digestibility of animal foods; Digestibility of vegetable foods; Relation of food to health; Tables of composition of human foods. Pages $35^{6}-380$. 



\section{INTRODUCTION}

PLANT life and animal life are dependent upon the changes which are continually taking place in nature. The laws of nature, as far as they are known, are set forth in the various sciences, among which chemistry occupies a prominent place. In everyday life affairs, chemistry takes an important part because it is the science which treats of the composition and uses of substances found in nature. Plant and animal foods which are essential for life are simply mechanical mixtures of various forms of matter which are constantly undergoing changes and exemplifying the laws of chemistry. In agriculture, chemistry takes an important part, the term Agricultural Chemistry being applied to that branch of the science which concerns itself with the practical application of the laws of chemistry to the science of agriculture.

In the cultivation of the soil, production of crops, feeding of animals, manufacture of farm products, preparation and use of human foods, and in all life processes, numerous chemical changes take place, and it is in part the province of chemistry to investigate these changes so as to assist nature in rendering the plant food of the soil more available, and to produce crops of the highest nutritive value, as well as to indicate ways in which the best possible use can be made of farm products in the feeding of animals and men. Before these subjects can xix 
be considered in an intelligent way, a fundamental knowledge must be obtained of some of the basic principles and laws of chemistry, since they are as essential to future work along special lines as is a good foundation to a building, or a scaffold during its construction. In the household, arts, industries, and professions, constant use is made of products formed from the soil, air, and water. In order to understand more perfectly the nature of the substances dealt with so as to make the most intelligent use of them, it is necessary to have a practical knowledge of some of the laws of chemistry and of the properties of the elements and the compounds which enter into the composition of plant and animal bodies.

To the student who begins the study of chemistry, it is imperative that the first part of the subject should be thoroughly mastered. Chemistry is different in its nature from many subjects. It cannot be studied in disconnected parts, but must be undertaken systematically. It cannot be absorbed by listening to lectures, but must be studied. If the first part of the work is neglected, failure is almost inevitable. If particular attention is given to the elements and their combinations, to the composition of matter, to laboratory manipulations, and to the classification of the elements, and if the experiments are performed regularly, the student experiences a keen enjoyment in the subject, the work ceases to be drudgery and becomes a pleasure.

Should it be desired to begin the laboratory practice with the classroom study, Sections I 5 to 2 I of Chapter 2 may be deferred or studied with Chapters 4, 5, and 6.

The student should make an effort to learn how to study; the memorizing of chemical formulas and equations is not studying chemistry; he should master the 
principles governing the combination of elements and then the memorizing of chemical formulas becomes unnecessary. In the preparation of the lessons, there are a number of reference books which should be consulted occasionally. For example, if difficulty is experienced with the subject of valence and radicals, the interesting chapter upon these topics in Ellen H. Richards' " Chemistry of Cooking and Cleaning " should be read. Remsen's "Chemistry," Hart's " Chemistry for Beginners," Storer and Lindsay's "Elementary Manual of Chemistry," as well as many others, will be found valuable. In studying the parts relating to foods, crops, and animal feeding, Henry's "Feeds and Feeding," Jordan's "Feeding of Farm Animals," Armsby's "The Principles of Animal Nutrition," Johnson's "How Crops Grow," and "How Crops Feed," and the bulletins of the U. S. Department of Agriculture and of the several stations should be available. The student should early acquire the habit of consulting other works, as frequently a topic is presented more clearly in one work than in another.

He who studies chemistry from the professional point of view, as medical chemistry, pharmaceutical chemistry, or agricultural chemistry, should remember that because of the limited time for the subject in professional schools, he is receiving at the best only a very abridged course in the science. Hence the necessity of supplementing it by collateral reading and study; otherwise he comes in contact with but one phase of the subject, and while he receives a technical education, he may obtain only a limited and narrow view of the science of chemistry.

In the study of the "Chemistry of Plant and Animal Life," it is the aim to bring the student into close contact with nature. This is one of the requisites for perfect agri- 
culture. Although not all of the laws relating to the chemistry of plant and animal life have been discovered, many of those relating to soils and foods, particularly human foods, are known and can be applied to everyday life affairs. 
PART I 



\section{CHAPTER I}

\section{Composition of Matter}

\section{Physical and Chemical Changes. - All substances}

in nature are subject to change in form and composition. At a low temperature water is converted into ice, and by the application of heat, into steam. The three forms which water assumes, solid, liquid, and vapor, are merely the different conditions in which it is capable of existing. When water is changed to steam or ice, nothing is added to or taken from the particles of water, simply a change of form or a physical change takes place. When, however, an electric current is passed through water, the water is decomposed and two gases are produced. When such a change occurs the water particles are subjected to a change in composition called a chemical change.

Limestone may be pulverized until it is as fine as wheat flour, and when examined with a microscope, each fragment is in all respects like the original piece, except in size. The crushing has resulted merely in dividing the limestone into a large number of particles. If, however, a piece of limestone is burned in a lime kiln, the product is entirely different in its properties from the original lime rock. When water is added to burned lime, the lime slakes, heat is generated, and steam is given off, while, when water is added to lime rock, no appreciable change takes place.

Changes which affect the form but not the composition 
of matter are known as physical changes. The production of steam from water, the freezing of water, the pulverizing of limestone, and similar changes which do not affect the composition of the material are physical changes. When milk sours, fruits decay, or wood is burned, a different kind of change takes place. The smallest particles of which the material is composed undergo change in composition. The products formed are entirely different in character from the original substances. Such changes affect the identity or individuality of a material, and are chemical changes.

2. Physics is the science which concerns itself with the changes which matter undergoes when the ultimate particles of a material retain their identity or individuality.

Animal and plant life are to a great extent dependent upon the physical changes which take place in the soil. Rain is the result of the action of physical agencies, as is also the pulverization of rocks and soils. In all manufacturing operations, and as the result of all kinds of manual labor, particularly upon the farm and in the workshop, physical changes are continually taking place.

3. Chemistry is the science which deals with the changes which matter undergoes when the ultimate particles lose their identity or individuality, and the products formed are entirely different from the original material.

Chemical changes are continually taking place, and plant growth and animal life are dependent largely upon the chemical changes as well as upon the physical changes which occur in the soil and in the air. Life processes are intimately associated with chemical changes. Chemical and physical changes are closely related; a chemical change is often dependent upon a physical change, and a physi- 
cal change is, in turn, often dependent upon a chemical change. A chemical change necessarily brings about a physical change. While the sciences of chemistry and physics are, to a certain extent, closely related, each nevertheless deals with a different phase of change which matter undergoes.

4. Indestructibility of Matter. - When either a chemcal or a physical change takes place, no matter is destroyed or produced. It is not possible either to create or destroy matter. This is known as the law of indestructibility of matter.

Whenever a chemical change takes place, the parts which make up the substance are rearranged in a new and different way, or they are combined with other materials. When wood is burned, it is changed into gaseous products and ashes; the materials which composed the wood are not lost to nature, they simply assume a different form. The law of indestructibility of matter is one of the foundation principles of chemistry. It was believed, at one time, that metals, as copper, could be changed to gold, and other substances to different forms of matter. After many centuries of experimenting, it was found that this could not be done, and as the result, the law of indestructibility of matter was established.

5. Molecules. - It is possible, by mechanical means, as pulverizing, to reduce substances to a very fine state of division, and it is believed that if this division could be carried on by more refined methods, particles of matter could finally be obtained that would not be susceptible to further division by purely physical methods. The smallest particle of a material that can exist and have all of the properties of the original material is called a molecule. Molecules, however, have never been separated as 
individuals. All forms of matter are composed of molecules. The proof that matter is composed of molecules is founded upon the laws of physics. The reasons for the acceptance of the molecular structure of matter cannot profitably be studied by the student of elementary chemistry, but properly form a very important part of advanced chemistry. The molecular structure of matter has been sufficiently well established to warrant the use of the term molecule by the student of elementary chemistry.

6. Atoms. - Whenever a chemical change takes place, the molecule is changed in composition. When an electric current is passed through water, the molecules of water are split up into simpler forms of matter. It is evident that the molecule is not the simplest form of matter, and that while the molecule is the smallest part of a substance, it is, in fact, made up of still smaller parts. These parts of matter which form a molecule are called atoms. An atom is the smallest part of an elementary substance that can enter into combination to form a molecule. Atoms never exist in nature in a free or uncombined state, but unite to form molecules, and molecules unite to form masses.

7. Elements. - The simplest forms of matter, as iron, copper, and sulfur, from which it is impossible to extract or obtain simpler bodies, are called elements. The element is the simplest form in which matter can exist. All substances found in nature, as plant and animal bodies, rocks and soils, are composed of compounds which, in turn, are composed of elements. There are about 74 of these elementary forms of matter, although only about I8 take any important part directly or indirectly, as far as is known, in either plant or animal life processes. 
There are a few substances found in nature in elementary form, as iron, copper, gold, and sulfur, but most of the elements are in combination with others, forming compounds.

8. Compounds. - The substances found most abundantly in nature are compounds. A compound is formed by the chemical union of two or more elements. All compounds are made up of a definite amount, by weight, of separate elements which unite according to the laws of chemical combination. Water, for example, is a compound formed by the union of two elements, hydrogen and oxygen. Sugar is a compound of three elements, hydrogen, carbon, and oxygen. When elements unite to form a compound, the elements lose their identity and the compound that is produced has entirely different and distinct chemical and physical properties from those of the elements of which it is composed.

9. Chemical Affinity. - The force or power which causes elements to combine to form compounds is called chemical affinity, and about this comparatively little is known. Whenever a compound is separated into its elements, chemical affinity or the force which holds the elements together is overcome. When elements combine to form compounds, it is because of the chemical affinity which the elements have for one another. Some elements have a stronger affinity for certain elements than for others.

I0. Mechanical Mixtures. - When two or more substances mix, but fail to unite chemically, a mechanical mixture is obtained. When iron and sulfur are mixed, a mechanical mixture is the result, and the iron and the sulfur can, by purely physical methods, be separated. If, however, a mixture of iron and sulfur is heated, a 
chemical change takes place and it is impossible by physical methods, as by the use of a magnet or by solvents, to separate the iron from the sulfur. Compounds as well as elements may form mechanical mixtures.

II. Chemical Analysis and Synthesis. - Whenever a substance or a compound is separated into simpler compounds or elements, the process is called chemical analysis. When only the kinds of elements or simpler compounds are determined, the process is called qualitative analysis. If the percentage amounts are determined, it is called quantitative analysis. When elements or simpler compounds are united, the process is called synthesis. Synthesis and analysis are directly opposite processes. When substances are produced in the laboratory from simpler elements or compounds, it is called a synthetical process. Many useful compounds are produced synthetically.

I2. Summary. - Substances may undergo either physical or chemical changes. A physical change does not destroy the identity or change the composition of the molecule. When a chemical change occurs, the atoms are combined in a different way and a new molecule is produced. The molecule is the smallest particle of matter that can exist and retain its identity or individuality. Compounds are composed of molecules, and molecules are composed of atoms. Atoms never exist free, but unite to form molecules. If a substance contains in its molecule atoms of only one kind, it is an element. If there are present atoms of more than one kind, it is a compound. Physics and chemistry are closely related sciences, but each deals with a different kind of change. Life processes are dependent largely upon the physical and chemical changes continually taking place in nature. 


\section{CHAPTER II}

\section{Properties of Elements and Compounds}

I3. Physical Properties. - In order to determine the value of any element or compound, a knowledge of its chemical and physical properties is necessary, and it is important that a clear idea be obtained as to what is meant by the terms chemical and physical properties of elements and compounds. Each element and compound has its own characteristic properties, which are different in a number of ways from those of other elements and compounds. The physical properties of a substance include :

I. Form or state of the material, as solid, liquid, or gas, which depends upon the temperature to which the substance is subjected. Many substances which are solid under ordinary conditions are, at higher temperatures, converted into liquids or vapors; and substances which are gases are in turn converted into liquids and solids at low temperature and under high pressure.

2. Weight or specific gravity. The weight or specific gravity of a material depends upon its molecular structure and upon the character of its individual molecules. Some of the elements and compounds have molecules of greater weight than have others. Liquids and gases are characterized as light or heavy according to their weight, compared with some material taken as the standard.

3. Color. The color of a compound is a physical property which is due to its chemical composition. Many of 
the elements, as copper, silver, and gold, have characteristic colors. Some compounds owe their value entirely to their color, and are used for paints and dyes.

4. Odor and taste. Odor and taste of an element or a compound are physical properties which are characteristic of the element or compound.

5. Electrical characteristics. Elements and compounds have definite electrical properties. They are either good or poor conductors of electricity, and offer a large or a small amount of resistance to the passing of an electric current.

The way in which a substance responds to pressure, water, heat, and cold depends upon its physical properties, and the physical properties in turn are modified by these agencies.

In a study of the elements and their compounds, the physical properties are also included because our knowledge of chemistry would be incomplete without considering the physical as well as the chemical properties of substances.

I4. Chemical Properties. - In addition to the physical properties, each element and compound has definite chemical properties. This is because the molecules of the different elements are unlike in character, and some of the elements and compounds are more readily affected by chemical agencies than are others. The molecules of compounds are made up of atoms of different kinds which impart different properties to the molecule. Copper, for example, has different chemical properties from gold. It will dissolve more readily in acids, tarnish in the air, and be acted upon more rapidly by other bodies than will gold. When iron is exposed to moisture and air it rusts, while aluminum is not readily affected by these agents. This is because iron and aluminum have different chem- 
ical properties. The chemical properties of a substance include the way in which it combines or produces chemical change when brought into contact with other elements or compounds. Some elements are characterized as chemically active or inactive. An active element is one that readily unites or combines with other elements, while an inactive or passive element is one that does not readily unite or combine. Some elements are active under certain conditions and with some of the elements, and inactive under other conditions and with other elements. The various elements require different conditions for producing chemical changes. In studying an element, the way in which it deports itself in producing chemical changes, the ability with which it combines with other elements, and the products which are formed as the result of the chemical changes are some of the important chemical properties considered.

A study of the chemical and the physical properties of elements and their compounds is important in many ways, as the value of a substance depends entirely upon its propertics. In the growing and cultivation of crops, the production, preparation, and the economic use of foods, the treatment of diseases, and in all manufacturing operations, as the smelting and refining of metals, the chemical and physical properties of the elements and their compounds are constantly made use of.

I5. Symbols of the Elements. - In the study of chemistry, a characteristic system of notation is used. The name of an element, as oxygen, is not written in full, but a symbol or sign, denoting the element, is employed. In the case of oxygen, the symbol is $O$. The symbol of an element is either the first letter of the name of the element, or the first with some characteristic letter, as $\mathrm{Cl}$ 
for chlorin. In some cases, the symbols are derived from the Latin names of the elements, as Fe (Ferrum) for iron. By use, the student soon becomes familiar with the symbols most commonly used.

\begin{tabular}{|c|c|c|c|c|}
\hline Name & Symbol & $\begin{array}{l}\text { Approximate } \\
\text { atomic weight }\end{array}$ & $\begin{array}{l}\text { Va- } \\
\text { lence }\end{array}$ & $\begin{array}{l}\text { Kind of } \\
\text { element }\end{array}$ \\
\hline Aluminum. & Al & 27 & & Base-forming \\
\hline Antimony. & $\mathrm{Sb}$ & 120.5 & 3,5 & \\
\hline Arsenic... & As & 75 & 3,5 & \\
\hline Barium. . & $\mathrm{Ba}$ & I 37.5 & 2 & Base-forming \\
\hline Bismuth. & $\mathrm{Bi}$ & 208 & 3,5 & \\
\hline Boron. ... & B & II & 3 & Acid-forming \\
\hline Bromin.. & $\mathrm{Br}$ & 80 & I & Acid-forming \\
\hline Calcium. & $\mathrm{Ca}$ & 40 & 2 & Base-forming \\
\hline Carbon. . & $\mathrm{C}$ & $\mathrm{I}_{2}$ & 2,4 & Acid-forming \\
\hline Chlorin... & $\mathrm{Cl}$ & $35 \cdot 5$ & I & Acid-forming \\
\hline Chromium. & $\mathrm{Cr}$ & $5^{2}$ & 4,6 & \\
\hline Cobalt.... & Co & 59 & 2,4 & Base-forming \\
\hline Copper. . & $\mathrm{Cu}$ & 64 & $\mathrm{I}, 2$ & Base-forming \\
\hline Fluorin: . & $\mathrm{F}$ & I9 & I & Acid-forming \\
\hline Gold.... & $\mathrm{Au}$ & 197 & 3 & Base-forming \\
\hline Hydrogen. & $\mathrm{H}$ & I & I & \\
\hline Iodin..... & I & I 27 & I & Acid-forming \\
\hline Iron. . & $\mathrm{Fe}$ & $5^{6}$ & $2,3,4$ & Base-forming \\
\hline Lead. . . . & $\mathrm{Pb}$ & 207 & 2,4 & Base-forming \\
\hline Lithium. . . & $\mathrm{Li}$ & 7 & I & Base-forming \\
\hline Magnesium & $\mathrm{Mg}$ & 24 & 2 & Base-forming \\
\hline Manganese & $\mathrm{Mn}$ & 55 & $2,4,6$ & \\
\hline Mercury.. & $\mathrm{Hg}$ & 200 & $\mathrm{I}, 2$ & Base-forming \\
\hline Nickel... & $\mathrm{Ni}$ & 59 & 2,4 & Base-forming \\
\hline Nitrogen: & $\mathrm{N}$ & $I_{4}$ & 3,5 & Acid-forming \\
\hline Oxygen... & $\mathrm{O}$ & 16 & 2 & Acid-forming \\
\hline Phosphorus & $P$ & $3 x$ & 3,5 & Acid-forming \\
\hline Platinum . & Pt & 195 & 4 & Base-forming \\
\hline Potassium. & $\mathrm{K}$ & 39 & I & Base-forming \\
\hline Silicon.... & $\mathrm{Si}$ & 28 & 4 & Acid-forming \\
\hline Silver... & $\mathrm{Ag}$ & 108 & I & Base-forming \\
\hline Sodium. & $\mathrm{Na}$ & 23 & I & Base-forming \\
\hline Sulfur. . & $\mathrm{S}$ & 32 & 2,4 & Acid-forming \\
\hline & $\mathrm{Sn}$ & II & 2,4 & Base-forming \\
\hline Zinc. & $\mathrm{Zn}$ & 65.5 & 2 & Base-forming \\
\hline
\end{tabular}


I6. Formulas of Compounds. - Since compounds are composed of elements, it is possible, by means of combination of symbols, to express the formula of a compound. The formula of a compound denotes the number and kinds of elements contained; as, for water, the formula $\mathrm{H}_{2} \mathrm{O}$ designates that the compound is composed of the two elements hydrogen and oxygen; and for sugar, the formula $\mathrm{C}_{12} \mathrm{H}_{22} \mathrm{O}_{11}$ denotes that the compound is made up of three elements, carbon, hydrogen, and oxygen. The formula always expresses the composition. In the formulas of compounds, figures are made use of, as 2 in $\mathrm{H}_{2} \mathrm{O}$, at the right of the $\mathrm{H}$ and partially below the line. In this formula, the 2 indicates that there are two atoms of $\mathrm{H}$ in the molecule. In the case of sugar, the figures used mean that in one molecule of sugar there are 12 atoms of $\mathrm{C}, 22$ atoms of $\mathrm{H}$, and II of $\mathrm{O}$. The formula of a compound always represents one molecule of the compound unless some figure is placed to the left of the formula, as $2 \mathrm{H}_{2} \mathrm{O}$. When placed in this position, the 2 shows that there are two molecules of water. Figures placed at the left of a formula and on the same line indicate the number of molecules, while figures at the right of the individual element represent the number of atoms of elements in each molecule. Hence the formula of a compound always designates the composition of the molecule, and the number and kind of atoms contained. Further study of the formulas of compounds will show that additional facts, as composition by weight and volume, are also represented.

Exercise. - Name the elements, the number of molecules, and the number of atoms in each molecule in the following formulas: $\mathrm{NaCl}, \mathrm{CaCl}_{2}, 2 \mathrm{KCl}, 2 \mathrm{~K}_{2} \mathrm{SO}_{4}, \mathrm{Al}_{2} \mathrm{O}_{3}, 5 \mathrm{~N}_{2} \mathrm{O}_{5}, \mathrm{H}_{2} \mathrm{SO}_{4}$, $\mathrm{NaOH}, \mathrm{HPO}_{3}$. 
I7. Atomic Weights. - An atom is the smallest part of an element present in a molecule. Atoms have definite properties, as weight. Hydrogen is the lightest material known. An atom of hydrogen, or the smallest part of hydrogen which can enter into chemical combination, is considered as having a weight of $\mathrm{I}$. The weight of the atom of any element is the number of times heavier that atom is than hydrogen, which is the standard. Oxygen, for example, has an atomic weight of $\mathrm{I} 6$; that is, an atom of oxygen weighs 16 times as much as an atom of hydrogen. Carbon has an atomic weight of $\mathrm{I} 2$; that is, an atom of carbon is I 2 times as heavy as an atom of hydrogen. The way in which the atomic weights are obtained cannot, at this stage of the work, be profitably considered. Atomic weights are, however, obtained with a high degree of accuracy, and while the individual atoms and molecules are not susceptible, at the present time, to separation and weighing, the comparative weight, or the number of times heavier or lighter a definite number of molecules is than a similar number of molecules, in other forms of matter, can be accurately determined. While the absolute weight of a molecule or atom cannot be determined, its comparative weight can be. When chlorin, for example, combines with hydrogen, it is known that 35.45 times as much, by weight, of chlorin as of hydrogen has entered into combination. Hence the smallest part by weight of chlorin which can combine must weigh at least 35.45 times as much as the weight of the smallest particle of hydrogen which enters into combination. The atomic weights of the more common elements are given in the table on page $\mathrm{I} 2$.

I8. Molecular Weights. - Since the molecules of compounds are composed of a definite number of atoms of 
elements, and each atom has a definite weight, it necessarily follows that a molecule has a definite weight. In the case of water, the formula $\mathrm{H}_{2} \mathrm{O}$ represents one molecule of water, composed of two atoms of hydrogen and one of oxygen. As the atoms have definite weights, the weight of the molecule $\mathrm{H}_{2} \mathrm{O}$ is the sum of the weights of the atoms in the molecule. Since hydrogen is taken as the standard and weighs $\mathrm{I}$, and there are two atoms of hydrogen, and one atom of oxygen weighing 16 , the weight of the molecule will be $2+16$ or 18 ; that is, the molecule of water, $\mathrm{H}_{2} \mathrm{O}$, is I 8 times heavier than one atom of hydrogen.

Excrcise. - Compute the molecular weights of the compounds given in the exercise following the formulas of the compounds, Section 16.

19. Law of Definite Proportion. - A study of the combination of elements shows that when elements unite to form compounds, a definite weight of each element enters into the composition. This is known as the law of definite proportion. Chemical combination always takes place between definite weights of the elements, and a chemical compound always contains the same elements in exactly the same proportion by weight. The law of definite proportion is one of the fundamental principles of modern chemistry, and has enabled the chemist to determine the composition of bodies. This law is founded upon fact independent of any hypothesis, and the accuracy of the law has been demonstrated by many investigators.

The theories relating to the composition of matter, particularly to atoms and molecules, are in harmony with this law of definite proportion. It is believed, since chemical combination occurs between definite masses 
of elements, it must also occur between the smallest particles of the substances. Since the smallest particles which enter into chemical composition are the atoms, then chemical combination must take place between the atoms. The atoms all possess definite weights. Hence it can readily be understood why chemical combination takes place between definite weights of the elements. The next step in the study of the composition of matter is the way in which the elements combine, or the power of combination; this is known as valence.

20. Valence. - The valence of elements is the power which an atom of one element has of holding in chemical combination a definite number of atoms of other elements. Carbon, for example, has the power of uniting with or holding in chemical combination four hydrogen atoms; carbon is said, therefore, to have a valence of 4 . Elements which have power to hold only one atom of hydrogen in combination are called monovalent. Hydrogen is a monovalent element. Bivalent, trivalent, tetravalent, and pentavalent elements are those whose atoms have the power of uniting with 2, 3, 4, and 5 atoms of hydrogen or other monovalent elements. The valence of an element is spoken of as its combining power. Some of the elements have more than one valence. The valences of some of the elements are given on page $\mathrm{I} 2$.

21. Combination of Elements. - The combination of two elements to form compounds is always governed by the valence of the elements. When calcium and chlorin combine, the combination takes place in a definite way; calcium has a valence of 2 ; chlorin has a valence of $\mathrm{I}$; hence, in order to make a chemical combination, it will take one atom of $\mathrm{Ca}$, having a valence of 2 , to combine with two atoms of $\mathrm{Cl}$, each $\mathrm{Cl}$ atom having a valence 
of I. $\mathrm{CaCl}_{2}$ is the formula. Calcium could not combine with three atoms of chlorin, because compounds composed of two elements are always formed according to the valence of the elements. The valence of calcium, 2, limits the number of atoms of chlorin with which it can combine. If one of the elements, as oxygen, has a valence of 2 , and the other element, as carbon, has a valence of 4,2 atoms of oxygen, each atom having a valence of 2 , will be required to combine with $\mathrm{I}$ atom of carbon, having a valence of 4 . The formula is $\mathrm{CO}_{2}$. In the formulas of compounds, the valences of the atoms uniting are always balanced or satisfied.

When two elements combine, and one of them has an odd valence, as phosphorus, which has a valence of 3 , two atoms of the element with the odd valence are always required for combination. For example, two phosphorus atoms, each having a valence of 3 , making a total valence of 6 , require, in order to combine with $O$, whose valence is 2 , three atoms of $\mathrm{O}$, which make the valence of 6 . The two atoms of phosphorus combine with the three atoms of oxygen, making a balanced compound, and the valences of the phosphorus and oxygen are satisfied. The compound is $\mathrm{P}_{2} \mathrm{O}_{3}$.

Combine according to the lowest valence the following elements, and give the formulas of the compounds produced:

Zinc and oxygen

Calcium and oxygen

Tin and oxygen

Iron and oxygen

Potassium and oxygen

Silicon and oxygen
Sulfur and oxygen

Sodium and chlorin

Potassium and chlorin

Carbon and oxygen

Phosphorus and oxygen

Iron and sulfur

Potassium and sulfur

Manganese and sulfur

C 
Phosphorus and hydrogen

Calcium and chlorin

Aluminum and oxygen

Phosphorus and oxygen

Problem $x$. - How much hydrogen is required to combine with 20 grams of $\mathrm{O}$ to form $\mathrm{H}_{2} \mathrm{O}$ ? When hydrogen and oxygen unite to form water, the combination takes place according to valence, as follows: 2 atoms of $\mathrm{H}+\mathrm{I}$ atom of $\mathrm{O}$ equal $\mathrm{I}$ molecule of water, or $2 \mathrm{H}+\mathrm{O}=\mathrm{H}_{2} \mathrm{O}$. An atom of $\mathrm{O}$ weighs $\mathrm{I} 6$ times as much as an atom of $\mathrm{H}$. Two atoms of $\mathrm{H}$ and $\mathrm{I}$ atom of $\mathrm{O}$ weigh $\mathrm{I} 8$ times as much as an atom of $\mathrm{H}$. The molecular weight of water is I8. Sixteen of these 18 parts, by weight, are $\mathrm{O}$, or $1 \frac{6}{18}$ are oxygen, which is 88.88 per cent; $\frac{2}{18}$, or II.I 2 per cent, being H. In the production of water, $\mathrm{H}$ and $\mathrm{O}$ always unite in this proportion. If, for example, 20 grams of $\mathrm{O}$ and 2 grams of $\mathrm{H}$ were brought together, only I 6 grams of $\mathrm{O}$ would enter into chemical combination with the 2 grams of $\mathrm{H}$, and 4 grams of $\mathrm{O}$ would be left uncombined. The amount of $\mathrm{H}$ required to combine with 20 grams of $\mathrm{O}$ would be obtained from the following proportion, $-2: 16:: x: 20$, or $x=2.5$ grams of $\mathrm{H}$.

Problem 2. - ( $\mathrm{I}$ ) Calculate the per cent by weight of $\mathrm{C}$ and $\mathrm{O}$ in $\mathrm{CO}_{2}$. (2) Calculate the per cent of $\mathrm{Fe}$ and $\mathrm{O}$ in $\mathrm{Fe}_{2} \mathrm{O}_{3}$. (3) Calculate the per cent of $\mathrm{O}$ in $\mathrm{KClO}_{3}$. 


\section{CHAPTER III}

\section{LABORATORY MANipUlation}

22. Importance of Laboratory Practice. - Laboratory practice is an essential part of the study of chemistry. It assists in developing more perfect ideas in regard to the composition of substances, and many of the important facts and laws of chemistry may be demonstrated by the student. The hand, the eye, the nose, and, to a less extent, the ear are all called into use in the laboratory, and this results in a balanced education of the senses. Neatness is absolutely necessary for success in laboratory work. An experiment performed in a slovenly way, with dirty and poorly connected apparatus, and poor mechanical manipulation, fails to give the right impression or result.

When laboratory work is in progress it should receive the student's entire attention. The directions for the experiments should be carefully followed. The apparatus should always be put together as directed, and because of the danger of accident, the student should never take the risk of connecting apparatus in an original way, or of using for the experiment materials other than those directed. The student should never attempt to experiment for himself in combining chemicals.

23. Names and Uses of Apparatus. - The various pieces of apparatus used in the experiments are shown in Plates I and II. Number 23 shows the common Bunsen burner, and, at the right, the wing-top attachment, used 
in bending glass tubes. Number 24, Plate II, is an iron ring stand with three rings, and No. 25 is a single clamp. The iron stand with rings is used for supporting apparatus, particularly the sand bath (I9) in which there is a thin layer of sand. Evaporating dish (5), beaker (I2), and flask (26) are all supported in the various experiments upon the sand bath and iron ring stand. In cutting glass tubes and perforating corks, the two files ( $I$ and 2 ) are employed. Test tube (I3) is used extensively in the laboratory, and when heated, is supported with the testtube clamp (I8). This test-tube clamp is held in the hand. The test tube is cleaned with the test-tube brush (I7), and when not in use is placed in the test-tube rack (I4). When solutions are filtered, the funnel (I5) is used, and is supported in the wooden stand (2I). Substances are pulverized or mixed in the mortar (I6), which is supplied with a pestle. The various gases, as oxygen, hydrogen, and nitrogen, are collected in the small cylinder (IO), and in some of the experiments the large cylinder (I I) is used. The iron spoon (8) is used for ignition of substances. Crucible tongs (3) are for handling pieces of apparatus when hot. Other pieces of apparatus, Woulff bottle (7), water bath (4), tripod (22), Hessian crucible (20), wide-mouthed bottle (9), and ground glass plate with hole, are used in various ways in the different experiments. Glass rods, thistle tube, pneumatic trough (27), of galvanized iron with pocket to receive excess of water when cylinders are filled with gas, and small squares of plain glass complete the set of apparatus. A few pieces, used only occasionally, are obtained from the instructor or supply clerk at the time the experiments are performed.

The student should take an inventory of his apparatus 

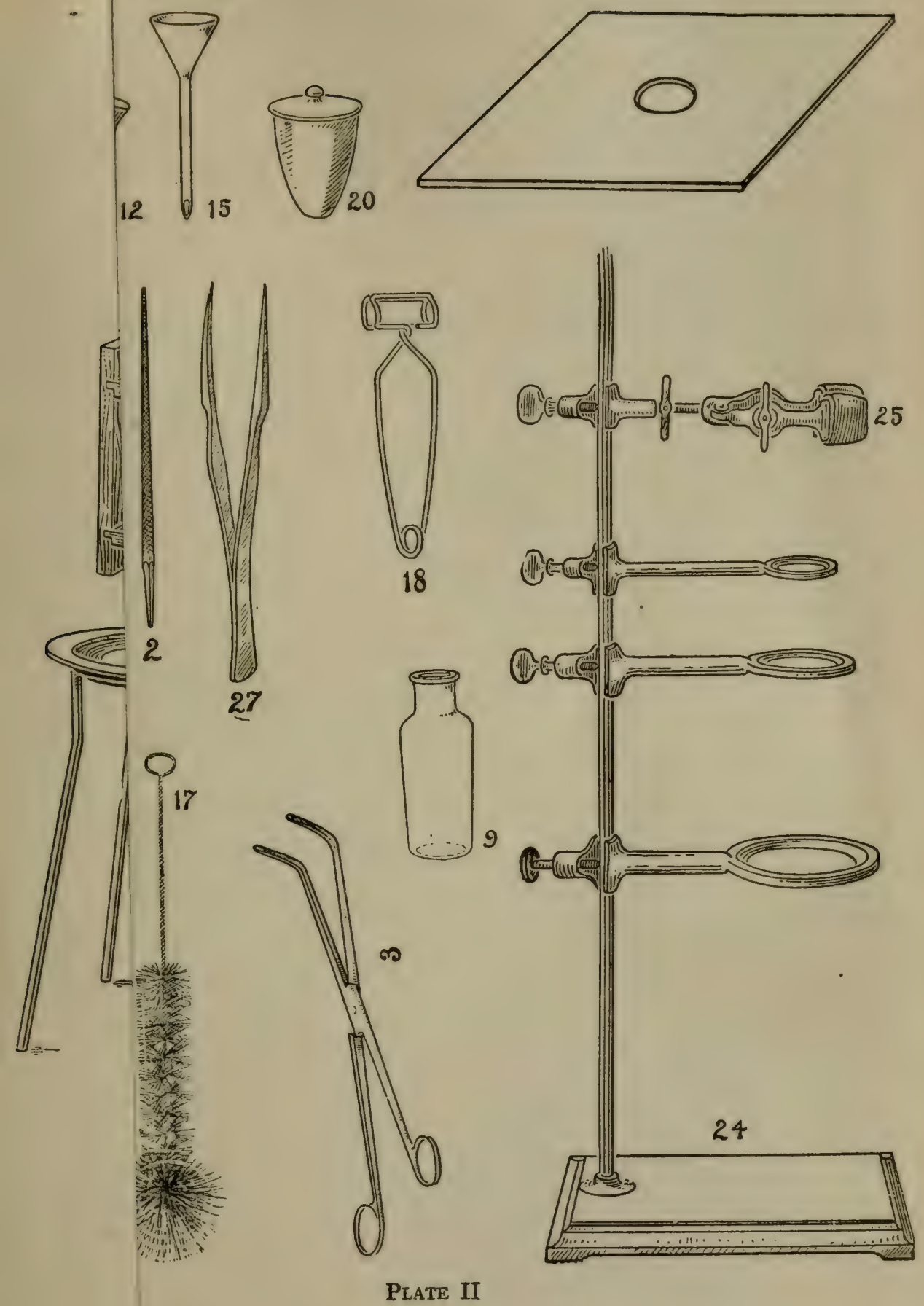



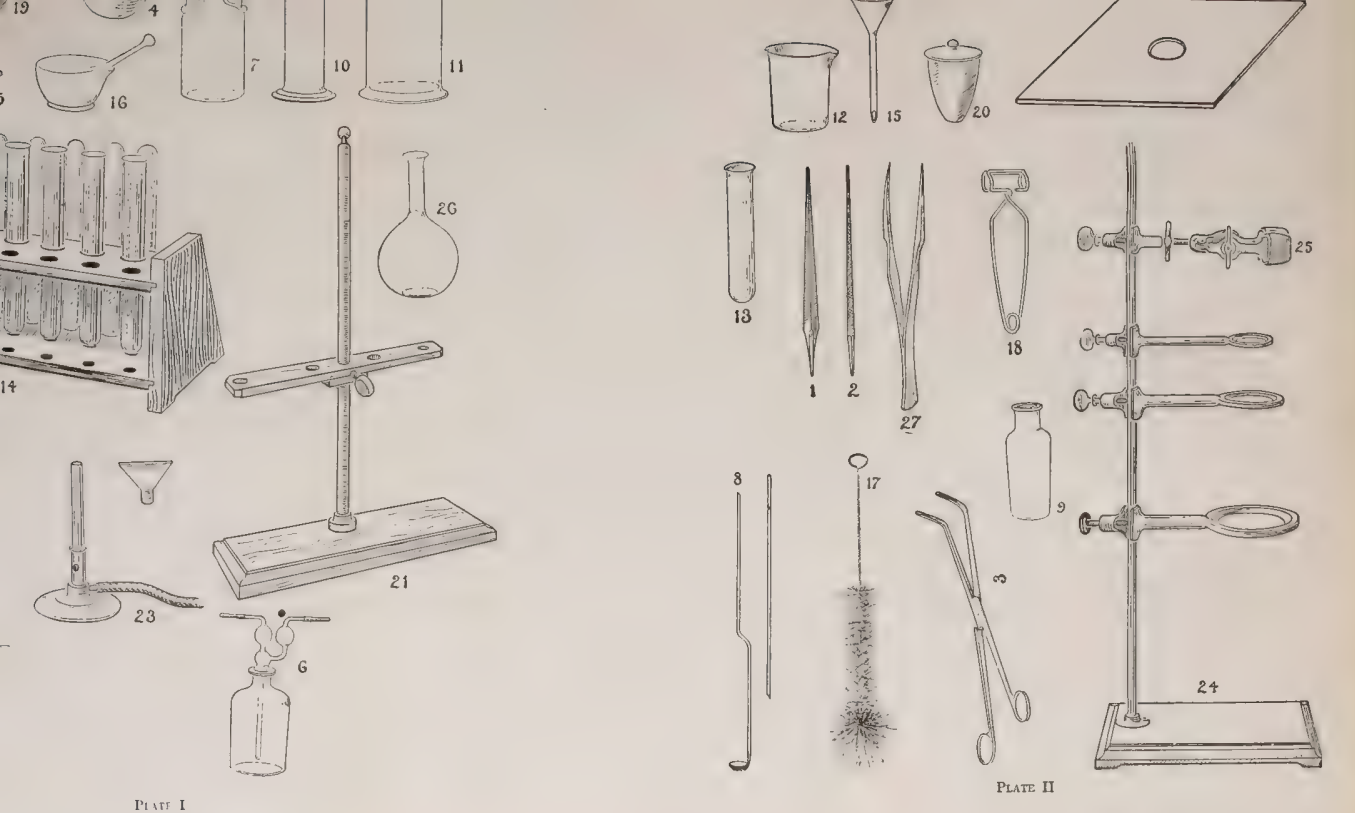



as soon as assigned a place in the laboratory. In case any of the pieces are broken or missing, the attention of the instructor should be called to them. Always, at the close of each day's work, the apparatus should be cleaned, placed in the desk, and the desk locked. The apparatus and desk should be kept in a neat and orderly condition. Untidiness is a frequent cause of failure in laboratory work; neatness and careful attention to details are necessary to success.

24. Cutting Glass Tubing. - Lay the glass tubing on the top of the desk or on any other flat surface. Draw a sharp three-cornered file across it two or three times, always on the same place at which it is to be broken, until a scratch is made through the annealed surface of

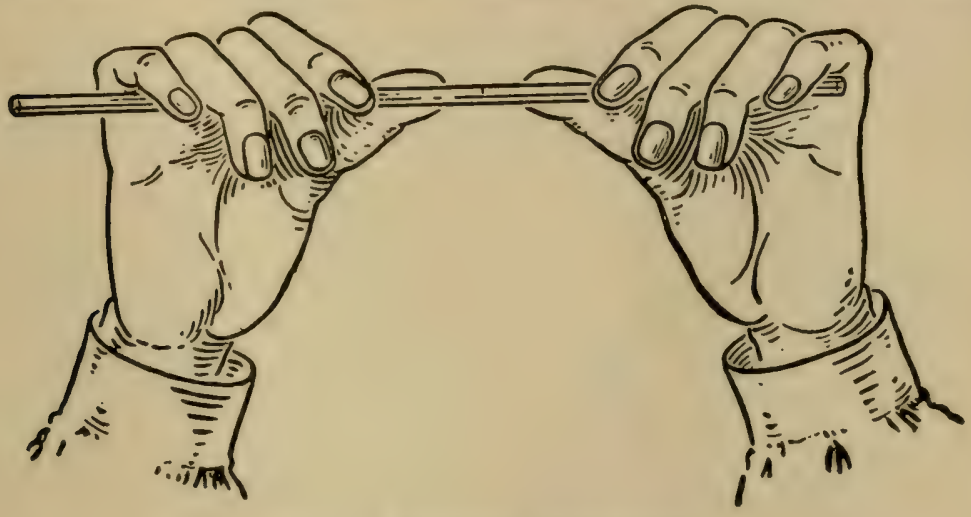

Fig r. - Breaking glass tubing.

the tubing. Take the tubing in the hands with fingers and a thumb on each side of the scratch (see Fig. I). The scratch should be nearly between and on the side opposite the thumbs. Pull the hands toward the body as if bending the tubing and at the same time press outward with the thumbs. This causes a square break of the tubing. The cut ends of the tubing should then be held in the outer portion of a flame until the rough edges are fused. 
25. Bending Glass Tubing. - Place the wing-top attachment on the burner. Hold the tubing in the upper part of the flame as shown in the illustration (Fig. 2),

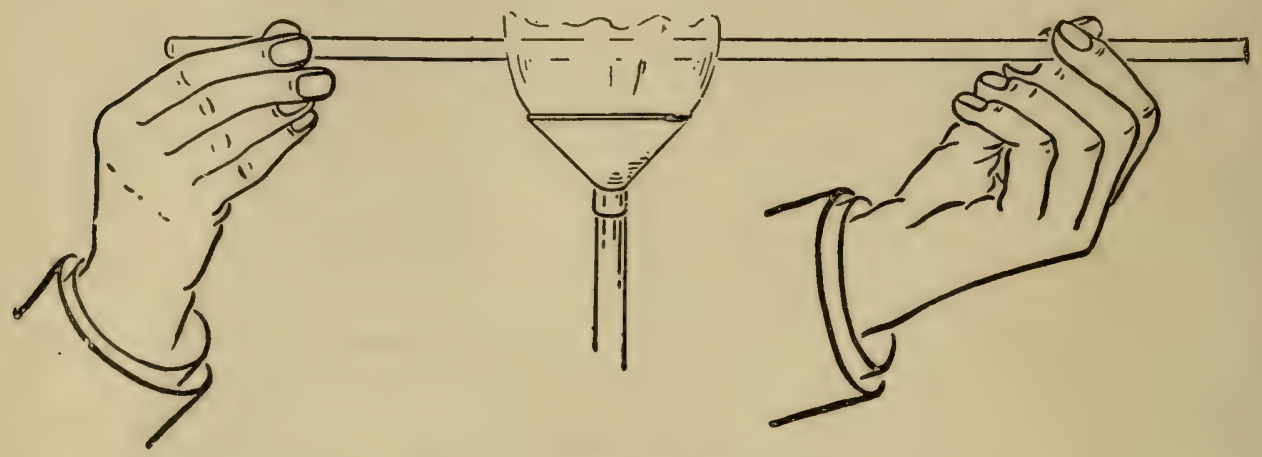

FIG. 2. - Bending glass tubing.

and rotate so that all parts are heated alike. When the tubing becomes pliable it can be bent in almost any form desired, but if overheated it becomes too soft and collapses.

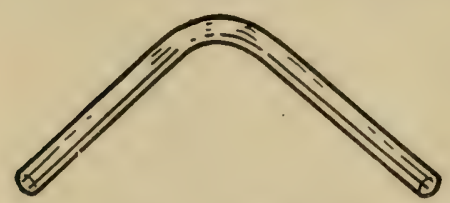

Fig. 3.- Bent tube.

It is always best to bend without removing from the flame. A little practice with pieces of old tubing will soon give the necessary experience. Avoid twisting or rapid bending of the tube. Make all bends on the same plane and aim to make well-rounded joints as shown in Fig. 3 .

26. Perforating Corks. - Select a cork of suitable size for the test tube or flask used. New corks should always be rolled in the cork press. With the small pointed end of the round file make a hole through the center of the cork, or a little to one side if directed to do so. This hole should be perpendicular to the surface of the cork. In making a hole, the cork should be held in the left hand, and the larger end should be placed against the edge of 
the desk. The file should be held in the right hand, and only enough pressure exerted to perforate the cork. The opening thus made may be enlarged with the round file until the desired size is obtained. The hole should be a suggestion smaller than the tube it is to receive, which can be inserted easily if well annealed and wet. When inserting a tube in a cork, never push the tube toward the palm of the hand, or use too much pressure, as severe cuts may be received from breaking the glass. Hold the cork in Fig. 4.-Inserting glass the left hand as shown in Fig. 4, then

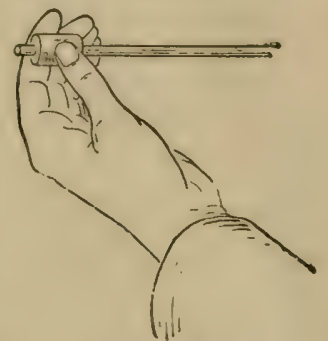
with the right hand carefully insert the tube. Perforated rubber stoppers of the requisite size may be used in nearly all of the experiments in place of cork stoppers, and while the initial cost is morc, a saving of time is effected.

27. Weighing. - In this work, the metric system is employed, and it is taken for granted that the student is familiar with the system; if he is not, he should review the subject as given in any ordinary arithmetic.

$$
\begin{aligned}
\text { Note. - I kilo } & =2.2046 \mathrm{lbs} . \text { (avoirdupois). } \\
\text { I oz. } & =28.45 \mathrm{gms} . \\
\text { I lb. } & =453.59 \mathrm{gms} . \\
\text { I liter } & =\mathrm{I} .05708 \mathrm{U} . \mathrm{S} . \text { quarts. } \\
\text { I inch } & =2.54 \text { centimeters. } \\
\text { I meter } & =39.3808 \text { inches. }
\end{aligned}
$$

The small balance used for weighing materials in these experiments is shown in Fig. 5. In case 5 grams of a material are to be weighed, prepare counterpoised papers, about 3 by 4 inches in size; that is, two pieces of paper of exactly the same size to be placed on opposite sides of the balance. If they do not weigh alike, remove 
small pieces of the paper from the heavier pan, until the needle moves nearly as many divisions on one side of

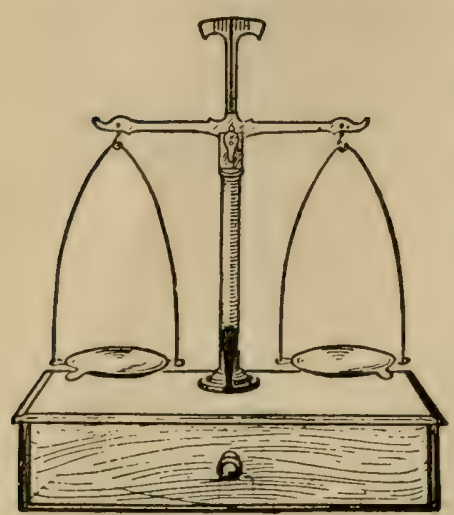

FIG. 5. - Balance. the scale as on the other. Then place, with the forceps, the 5gram weight on the right-hand pan of the balance. Do not handle the weights with the fingers. By means of the scoop or spoon provided for the purpose, add to the paper in the left-hand pan of the balance enough of the material that is to be weighed to counterpoise the 5-gram weight. If any of the substance has been spilled, it should be cleaned up at once. The weight should be replaced in the weight box and the forceps returned to their proper place. No substance except a piece of metal, as copper or lead, should ever be placed in direct contact with the balance pan. Liquids are never weighed, but always measured. Too much care and neatness cannot be exercised in weighing.

28. Measuring Liquids. - For purposes of measuring, cylinders or graduates are employed (Fig. 6). A large test tube, when filled with water, holds from 60 to $65 \mathrm{cc}$. In a measuring cylinder or graduate (Fig. 6), measure out 5 .cc. of water, and transfer to a large test tube. Note the quantity, and then pour it out. Now draw water directly into the test tube until you have ap-

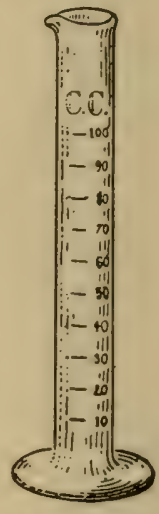

Fig. 6. Measuring cylinder. proximately the same amount, then measure it. Repeat this operation until you can judge with a fair 
degree of accuracy the part of a test tube filled by 5 cc. Repeat the operation, using IO, I5, 20, and 25 cc. portions, until the eye has become reasonably familiar with the approximate and relative amounts; so that, if at any time a graduate is not at hand, the amounts can be estimated with the eye accurately enough for practical purposes.

29. Obtaining Reagents from Bottles. - Take the bottle from the shelf, remove the stopper, holding it between the first and second fingers of the right or left hand (Fig. 7). Hold the test tube or vessel that is to receive the reagent in the other hand. Pour the liquid slowly until the desired amount is obtained. Because of danger of contaminating the reagents, it is always better to pour the liquid slowly and secure the right amount at first rather

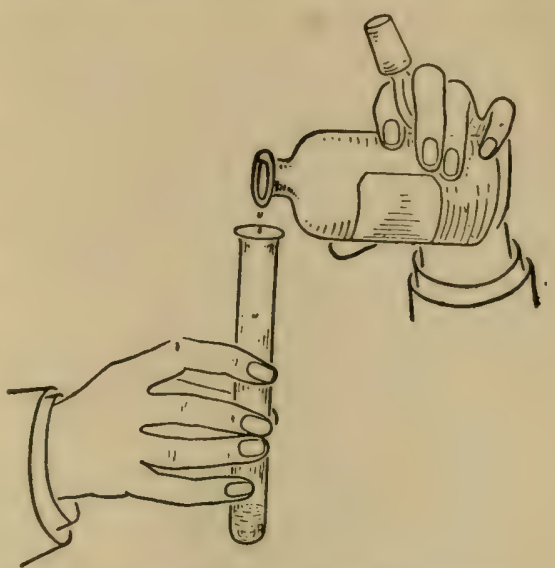

Fig. 7. - Pouring liquid from bottle. than to pour back from the receiving vessel. Replace the test tube in the stand or receiver on the desk; then, before inserting the stopper, touch it to the neck of the bottle to catch the few drops on the edge, to prevent them from dripping down the sides of the bottle, and on to the shelf. Be sure to replace the bottle on the shelf in its proper place. Much annoyance and delay are caused by not returning the bottles to their proper places.

30. Filtering. - Place the funnel on the arm of the wooden stand. Fold a filter paper so as to make a semi- 
circle (see Figs. 8 and 9). Fold the paper again, forming a quadrant (Fig. Io). Then open it as shown in Fig.

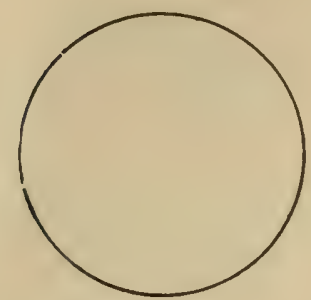

FIG. 8.

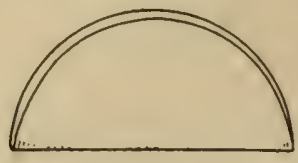

FIG. 9.

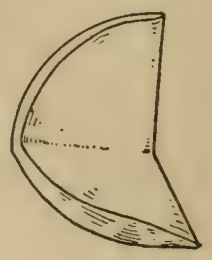

FIG. IO.

Folding filter paper.

Ir. Place the filter paper in the funnel, using a little water to make it adhere to the sides. Place a beaker or cylinder under the funnel so as to collect the filtrate, or liquid which passes through the filter paper (Fig. I2). Pour the material to be filtered into the filter paper in the funnel. Do not fill the filter too full. An eighth of an inch or so should always be left between the surface of the liquid and the edge of the paper. The stem of the funnel should touch the side of the

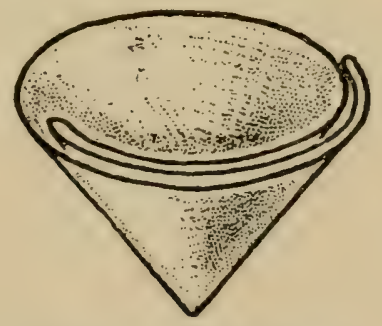

FIG. Ir - Folded filter paper.

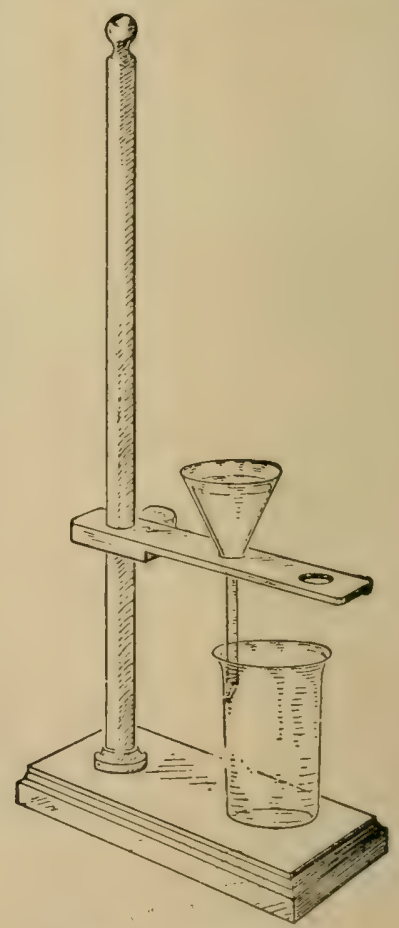

FIG. I2.- Filtering. 
beaker or cylinder so as to avoid spattering. The material left on the filter paper is called the precipitate or residue.

3I. Laboratory Notebook. - Each student should keep a careful record of his laboratory work. The notebook should be complete and should represent the student's individual work. With each experiment a number of questions are asked, and the record of the experiment should cmbody the answers to these questions. Do not make short answers, as "yes" and "no," but make a complete statement, giving an intelligent answer to the question. Do not copy the laboratory directions into your notebook, but state briefly and conciscly, (I) what the experiment is about, (2) the matcrials used, (3) the apparatus employed, (4) what you have observed in making the experiment, (5) the chemical and other changes that have taken place, and finally what the experiment proves. In writing up the notebook, it is not necessary to separate the topics, but all the questions should be numbered and answered in the order asked. Write out each experiment at the time it is performed, and while the work is in progress, watch it and think about it. Do not leave or neglect an experiment. When the experiments are performed as called for from day to day, the labor of preparing the daily recitation is considerably lessened, and less effort is required to obtain a clear idea of the subject. The notebook should be kept in a neat and orderly way. Careful attention should be given to spelling, English, and punctuation. Always have the notebook in condition for examination if the books are called for without notice. The instructor will mark all errors, and the student should correct them. A notebook with errors that have been corrected, representing 
the student's individual work, is much to be preferred to a notebook copied from some other student, and having but few errors. Each student has an individuality which always marks his work, and whenever copying of experiments is resorted to, it can be detected by the instructor. The student who copies from some one else only cheats himself, and usually fails to pass his examinations.

32. Breaking of Apparatus. - If due care is taken in performing the experiments, there will be but little breakage of apparatus. In case an accident occurs, clean up the broken pieces at once and place them in the waste jar. If a liquid is spilled, wipe it up with a sponge, using plenty of water. If a strong acid is spilled, a little dilute ammonia should be used in the final washing. No combustible materials should be placed in the desk, and the student should throw burned matches and splinters into the receptacles provided for the purpose.

33. Care of Sinks and Plumbing. - Do not throw waste matter of any description, as paper, glass, matches, etc., into the sinks. Large waste jars, for such materials, are provided under every sink and elsewhere. Everything liable to clog the drains must be thrown into these jars. Liquids containing acids may be safely thrown into the sinks, provided a stream of water is kept running at the same time to dilute and wash down the acids. When acids are poured into the sinks, care should be taken to prevent spattering of the liquid, as severe burns are sometimes received when the liquid is not properly poured from the vessel. If directions are followed, no accidents can occur. Do not fill the sinks too full. The water should never be allowed to come to within 2 inches of the top of the 
sinks. If the sinks overflow, they cause much damage to the rooms below. Students who disregard the regulations in regard to plumbing and the use of sinks will be held responsible and must pay for any damage caused by carelessness or negligence.

\section{How to Accomplish the Best Results in the Lab-} oratory. - In order to accomplish the best results, the student, while in the laboratory, should endeavor to use his time profitably and economically. He should obtain a clear idea of what he is to do, and then do it to the best of his ability. If the experiment is not a success, repeat the work. Never pass over an experiment that offers difficulties in performing. Much valuable time can be saved by a brief study of the day's work before going into the laboratory. While the work is in progress, the student should give it undivided attention, and make an effort to learn as much as possible from the experiments performed. 


\section{CHAPTER IV}

\section{OXYGEN}

35. Occurrence. - Oxygen is the most abundant element in nature. About seventy-seven per cent of the air, by weight, is free or uncombined oxygen. It enters into the composition of water, rocks, and minerals, and

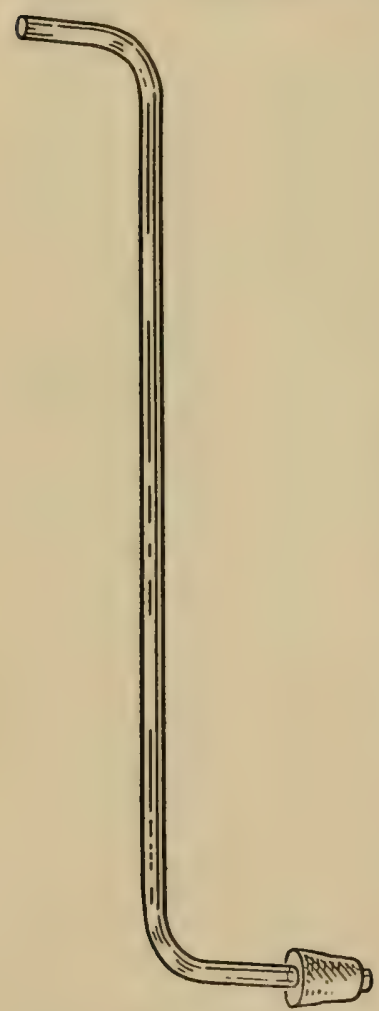

FIG. I3.-Delivery tube. plant and animal bodies. Eight ninths of water and one half of the solid crust of the earth are oxygen in combination with other elements. Oxygen is also present in all animal and plant tissue, making up a large portion of the weight of these bodies.

36. Preparation. - Oxygen can be prepared from a number of materials, as oxid of mercury and potassium chlorate. When made in small amounts in the laboratory, it is generally prepared by heating potassium chlorate, a compound composed of the elements potassium, chlorin, and oxygen. The oxygen is separated by means of heat, the process being as follows:

Experiment $1 .-$ Fuse the end of a piece of glass tubing, $2 \frac{1}{2}$ or 3 feet long. Make a bend nearly at right angles to the tube, about 3 inches from one end. Then make a second bend of $2 \frac{1}{2}$ or 3 inches on the opposite end of the tube nearly at right angles, and 
in an opposite direction from the first bend (Fig. I3). Fit to the test tube a cork, as directed in Section 26 , and insert the delivery tube. Fill the pneumatic trough nearly full of water, and place in it the free end of the delivery tube (Fig. I 4). Weigh out 5 grams each of potassium chlorate $\left(\mathrm{KClO}_{3}\right)$ and manganese dioxid $\left(\mathrm{MnO}_{2}\right)$. Mix

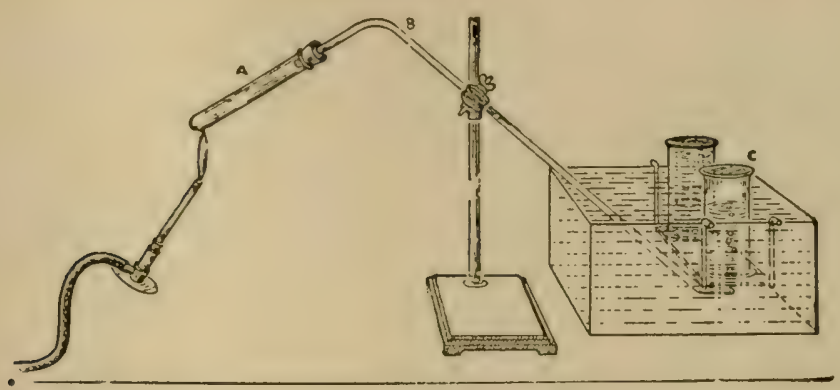

FIG. I4. - Preparation of oxygen. Pneumatic trough.

on a sheet of paper, and place the mixture in a test tube. See that the test tube is perfectly dry, both inside and out. Fill the cylinders with water, cover with glass plates, and place them inverted on the shelf of the pneumatic trough. With a medium-sized flame, apply heat cautiously to the test tube. The flame should be moved from time to time, and not allowed to strike just one part of the test tube, otherwise the glass will melt, and the test tube collapse. As soon as bubbles of gas are given off freely from the water, place the end of the delivery tube so that the gas is collected in one of the cylinders. When a cylinder is filled, cover it with a glass plate, while the mouth of the cylinder is still under water. The cylinder can then be placed upright upon the desk, and another filled with $\mathrm{O}$. After collecting three or four cylinders of gas, remove the end of the delivery tube from the water, and then remove the flame. Do not remove the flame while the end of the delivery tube is under water, or a vacuum will be formed, and the water will rush back into the test tube. Tests should be made with $\mathrm{O}$ as follows:

(I) Light a splinter and place it for a moment in one of the cylinders of oxygen (see Fig. I 5); remove it; extinguish the flame, and while the splinter is still glowing, thrust it again into the cylinder. Observe the result in each case. (2) Put a small piece of sulfur, a little larger than a grain of wheat, into the iron or deflagration 
spoon; ignite in the flame, and thrust into the second cylinder of O. Observe the result. (3) Take a piece of bright fine iron wire or watch-spring, and make it into a spiral with a loop at one end.

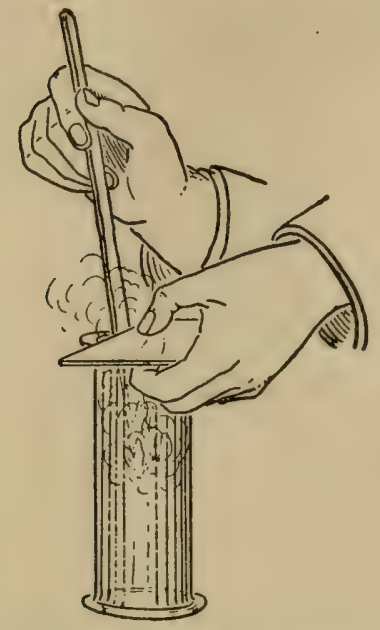

FIG. I5. - Testing oxygen with burning splinter.

Warm the wire by holding it near the flame, then hold the-loop for an instant in the flame and dip it into some sulfur which has been placed on a piece of paper. Hold again in the flame for a moment and then place at once in the third cylinder of $\mathrm{O}$. In order to insure the success of this experiment, the wire should be very fine, free from rust, and held in the flame only long enough to start ignition, and then placed in the cylinder.

Questions. - (I) Where does the $\mathrm{O}$ in the cylinder come from? (2) What caused it to separate from the compound? (3) What is the appearance of $\mathrm{O}$ ? (4) Compared with air, is it a light or a heavy gas?

(5) What caused the splinter to burn and to rekindle? (6) What product was formed when the splinter was burned? (7) What caused the sulfur to burn? (8) What product was

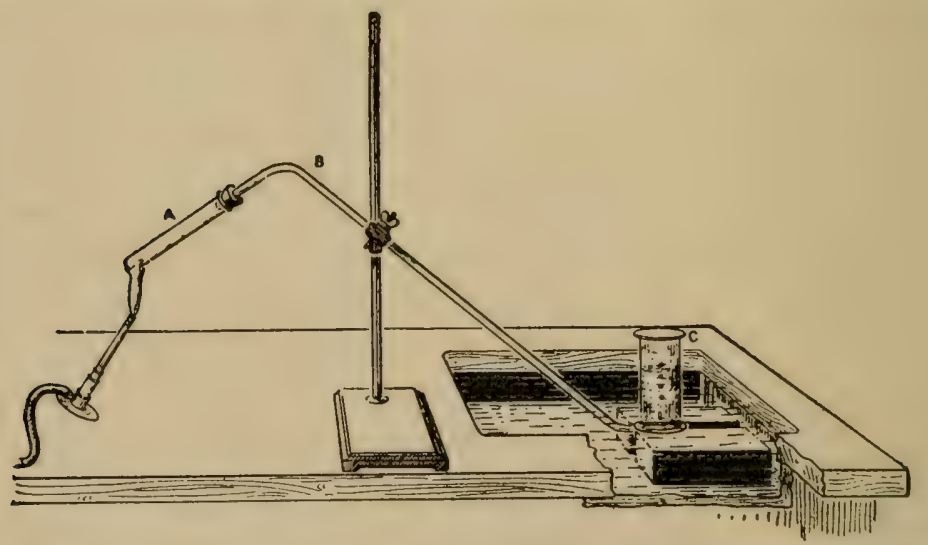

FIG. 16. - Preparation of oxygen, using sink in place of pneumatic trough.

formed when the $\mathrm{S}$ was burned? differently in $\mathrm{O}$ than in air? (ro) What caused the iron to burn, and 
what was formed? (I I) Is O combustible? (I 2) Is O a supporter of combustion? (I3) What compounds are always formed by the union of $\mathrm{O}$ with an element? (I4) Give the properties and characteristics of $\mathrm{O}$ as observed from this experiment.

The oxygen in potassium chlorate is not held in firm chemical combination, and when the substance is heated, first a part, and finally all, of the oxygen is given off. Manganese dioxid is used because of its physical action upon potassium chlorate, enabling the oxygen to be given off more easily. The change which takes place is expressed by the equation: $\mathrm{KClO}_{3}=\mathrm{KCl}+3 \mathrm{O}$. The products of the reaction are potassium chlorid and oxygen. The oxygen is collected in the cylinders, while the potassium chlorid remains with the manganese dioxid in the test tube.

37. Properties of Oxygen. - Physically considered, oxygen is a colorless, odorless, and tasteless gas, about I6 times as heavy as hydrogen. It is slightly soluble in water, and, when subjected to low temperature and high pressure, it is liquefied. Chemically, oxygen unites with all common elements to form oxids. It is not combustible, but is a supporter of combustion. When the burning splinter was thrust into the cylinder of oxygen, the carbon and hydrogen of the wood united with the oxygen in the cylinder, forming carbon dioxid and water. When substances unite with oxygen they are oxidized; that is, oxygen is added to the material. An oxid is a compound of oxygen and any other element. When sulfur is burned, it unites with oxygen, forming sulfur dioxid, $\mathrm{SO}_{2}$. Other elements, as phosphorus and iron, also unite with oxygen, forming oxids. Different elements unite with oxygen at different temperatures. Phosphorus and sulfur combine with oxygen at a comparatively low temperature, while carbon and iron require a higher temperature. The sulfur and the splinter of wood burned more brilliantly in the oxygen than in the air because air 
is diluted with other gases and elements and is not pure oxygen. Oxygen is more active at a high than at a low temperature.

Oxidation of some of the elements and compounds results in the production of light and heat, and this is commonly called combustion, although it does not necessarily follow that when a substance contains oxygen it is combustible, because it may be the product of combustion, as carbon dioxid or sulfur dioxid. Oxygen forms stable compounds with many of the elements. It has such affinity for some elements, as aluminum and carbon, that it is separated from them with difficulty. With other elements it forms less stable compounds. When an element, as oxygen, enters into chemical combination, it loses its identity or individuality as an element. The oxygen in the minerals forming the crust of the earth, and in plant and animal tissues, is not free, but combined with other elements.

38. Importance. - Oxygen takes an important part in life affairs, and is necessary to the existence of plant and animal bodies. The combustion of wood, coal, and other fuel is due to the oxygen of the air. The production of heat in the body is due to oxidation of food, and many of the chemical changes which take place in the soil are dependent upon this element. Because of its wide distribution in nature, it is not given such economic consideration as are other elements, but it is one of the most important, and is as necessary for life as other food.

Problem 1. - How many pounds of oxygen are required to combine with 25 pounds of pure carbon? When carbon is burned, I part of $\mathrm{C}$ (called an atom) unites with 2 parts of $\mathrm{O}$ ( 2 atoms of $\mathrm{O}$ ) to form the compound $\mathrm{CO}_{2}$. This is expressed by the equation $\mathrm{C}+{ }_{2} \mathrm{O}=\mathrm{CO}_{2}$. The atomic or least combining weight of carbon 
is $\mathrm{I} 2$ and of $\mathrm{O}$ is $\mathrm{I} 6$; one part by weight of $\mathrm{C}$ weighing $\mathrm{I} 2$ unites with 2 parts by weight of $\mathrm{O}$, each part weighing 16 ; or 12 parts by weight of $\mathrm{C}$ unite with 32 parts by weight of $\mathrm{O}$. If the parts are designated pounds, then 25 pounds of $\mathrm{C}$ will require proportionally as much $\mathrm{O}$ as do $\mathrm{I} 2$ pounds of $\mathrm{C}$. This amount can be determined by a simple proportion.

$$
\begin{gathered}
\mathrm{C}: \mathrm{O}:: \mathrm{C}: \mathrm{O} \\
\mathrm{I} 2: 32:: 25: x
\end{gathered}
$$

By solving this proportion, $x$, or the required amount of $\mathrm{O}$ to combine with 25 pounds of $\mathrm{C}$, is found to be $66 \frac{2}{3}$.

In the solving of chemical problems some of the most common errors are: (I) Failure to write properly the formulas of the compounds used, or the equation representing the chemical reaction that takes place. This error causes the wrong number of parts of elements or compounds to be taken in the proportion. (2) Failure to make proper use of the combining weights of the elements. (3) Failure to combine properly the weights so as to form a true proportion. It should be remembered that after the writing of the equation and weights, the problem becomes simply one of arithmetic.

Problem 2. - How many pounds of $\mathrm{CO}_{2}$ are produced when 25 pounds of carbon are burned?

Problem 3. - How many pounds of carbon are necessary to combine with 25 pounds of $\mathrm{O}$ in forming $\mathrm{CO}_{2}$ ? 


\section{CHAPTER V}

\section{HYdROGEN}

39. Occurrence. - Hydrogen is found in nature in combination with other elements, entering into the composition of water, animal and plant tissues, and some minerals. It is never in a free state, except as given off in traces with volcanic gases. Hydrogen is an essential part of all acids and of many other compounds.

40. Preparation. - In the laboratory, hydrogen is usually prepared by treating a metal with an acid which contains hydrogen; the metal replaces the hydrogen of the acid, and the hydrogen is then liberated as a free gas. When zinc and hydrochloric acid are employed, the reaction which takes place is as follows: $\mathrm{Zn}+2 \mathrm{HCl}=$ $\mathrm{ZnCl}_{2}+2 \mathrm{H}$. Two molecules of hydrochloric acid are required in the reaction because zinc has a valence of 2 and whenever zinc enters into chemical combination, it must take the place of two monovalent atoms. The compound, $\mathrm{ZnCl}_{2}$, zinc chlorid, contains one atom of zinc and two atoms of chlorin.

Experiment 2. - Arrange the apparatus as shown in Fig. I7. Use a small two-necked Woulff bottle, and in one of the necks insert a tight-fitting cork with a thistle tube. In the other neck insert a cork carrying a delivery tube. Place about 20 grams of zinc, $\mathrm{Zn}$, and $25 \mathrm{cc}$. of water in the Woulff bottle. The thistle tube should pass below the surface of the water to prevent the escape of gas. Fill two or three cylinders with water for collecting the gas. The corks carrying the delivery tube and the thistle tube should fit tightly, otherwise the $\mathrm{H}$ is easily lost. When all is ready, add, 
through the thistle tube, about I $_{5} \mathrm{cc}$. concentrated hydrochloric acid $(\mathrm{HCl})$, and then sufficient water to carry the acid out of the trap of the thistle tube. Do not apply any heat whatever. Do not collect any gas until the generator has been going for about two minutes, and do not attempt to light the gas as it issues from the generator. Collect one or two cylinders of gas, adding more acid if necessary, always keeping the cylinders covered, mouth downward, because

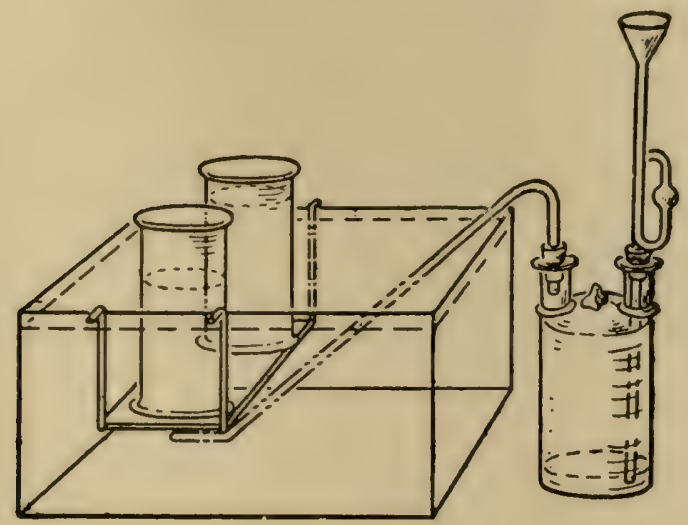

FIG. I7. - Apparatus for preparation of hydrogen.

$\mathrm{H}$ is a light gas, and will readily escape if the cylinders are placed right side up.

When working with hydrogen in the laboratory, the student should always exercise care, because mixtures of hydrogen and oxygen are very explosive. Only a spark or a near-by flame is necessary to bring about an explosion.

Make the following test with hydrogen: Thrust a burning splinter into the mouth of the cylinder of hydrogen, as shown in Fig. I8.

Questions. - (I) What is the color of H? (2) Odor? (3) Is it a light or heavy gas? (4) Does it support combustion? (5) Is it combustible? (6) What is formed when $\mathrm{H}$ is burned? (7) How do you know that this product is formed? (8) From what com- 
pound was the $\mathrm{H}$ obtained? (9) What caused the $\mathrm{H}$ to be liberated. from this compound? (Io) Why are mixtures of $\mathrm{H}$ and $\mathrm{O}$ very explosive? (II) What other acids could be used in the preparation of $\mathrm{H}$ ? (I 2) What other metals could be used in the preparation of $\mathrm{H}$ ? (13) Give the equation for the reaction of $\mathrm{Zn}$ and $\mathrm{HCl}$. (I4) What do these tests prove in regard to the character and properties of the element $\mathrm{H}$ ?

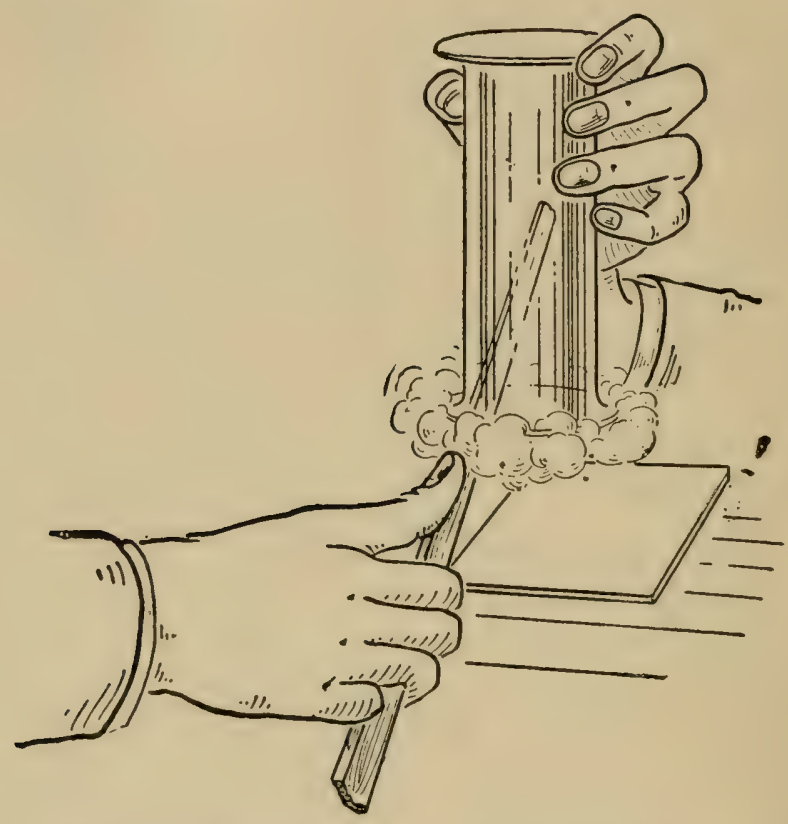

Fig. I8. - Thrusting burning splinter into hydrogen.

4I. Properties. - Physically, hydrogen is characterized as a colorless, odorless, and tasteless gas. It is the lightest in weight of any of the elements, and for that reason is taken as the standard for the atomic weights. At a low temperature, and under pressure, hydrogen can be liquefied, with greater difficulty, however, than any other element. Hydrogen is $\mathbf{4} 4.43$ times lighter than air. A liter of hydrogen, under standard conditions of temperature and pressure, weighs 0.0896 I gram. Chemically, 
hydrogen is characterized as combustible, but not a supporter of combustion. It readily combines with many other elcments, particularly oxygen, with which it forms water. When hydrogen and oxygen unite to form water, a reaction takes place which causes a contraction in volume. Two volumes of hydrogen and one volume of oxy-

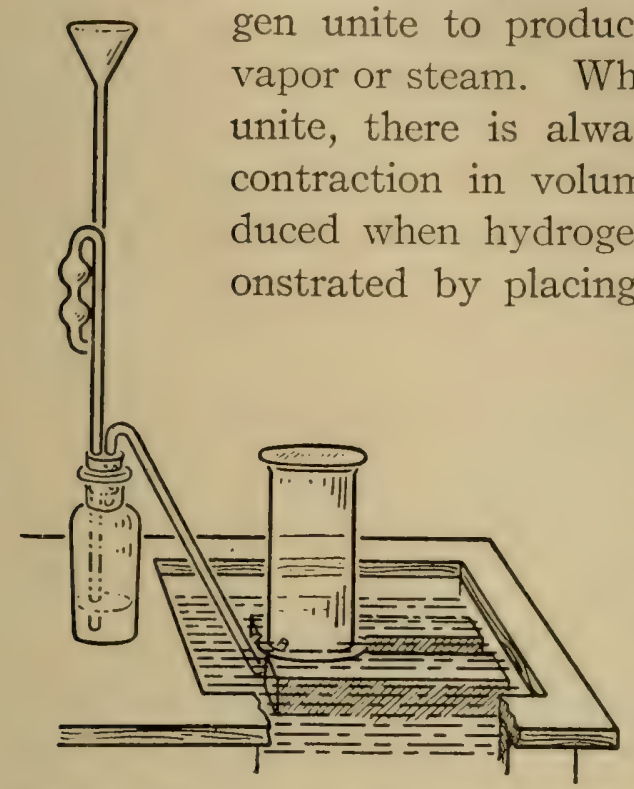

Fig. 10. - Preparation of hydrogen, using a wide-mouthed bottle and sink in place of a Woulff bottle and pneumatic trough. duce two volumes of water

When hydrogen and oxygen an explosion, due to That water is prois burned, can be dema dry test tube over a flame of hydrogen. The interior of the test tube will become covered with moisture. Hydrogen does not unite with all elements as readily as does oxygen. When hydrogen is burned, the flame is nearly colorless because combustion is complete, and there are in the flame no solid particles heated to incandescence. Hydrogen produces a very hot flame, and, when mixed with oxygen in the right proportion, as in the oxyhydrogen blowpipe, a high temperature is secured.

42. Importance. - Hydrogen is one of the essential elements for the formation of compounds in plant and animal tissues, but because of its extreme lightness it never makes up a large portion by weight of a material. As a free element, it takes no part in life processes, but 
when combined with water, and in other forms, as in food materials where it is united with carbon and oxygen, it is an essential part of compounds which are of much importance for animal and plant life.

Problem I. - How many pounds of $\mathrm{H}$ will roo pounds of $\mathrm{Zn}$ liberate when it is acted upon by $\mathrm{H}_{2} \mathrm{SO}_{4}$ ?

Problem 2. - How much $\mathrm{ZnCl}_{2}$ is formed when roo pounds of $\mathrm{Zn}$ are acted upon by $\mathrm{HCl}$ ? 


\section{CHAPTER VI}

\section{NitROGEN}

43. Occurrence. - Nitrogen occurs abundantly in a free state in the air, nearly 23 per cent by weight being uncombined nitrogen. It also forms a part of some of the compounds which make up animal and plant tissues, where it is in chemical combination with carbon, hydrogen, and oxygen. Nitrogen is present also in the soil, forming a part of the decaying organic matter. It is one of the elements of ammonia gas and ammonium compounds, and is in combination with other elements, as in nitrates.

44. Preparation. - Nitrogen is usually prepared from air by removing the oxygen with which it forms a mechanical mixture. Since air is composed of both oxygen and nitrogen, if the oxygen in a given volume of air, as in a cylinder, is chemically united with phosphorus or carbon, forming soluble products, there is a residue of nitrogen left in the cylinder. Nitrogen produced in this way is not pure, but contains traces of other elements and compounds. For experimental purposes, it may, however, be considered nitrogen. Nitrogen can also be produced from its compounds, as by the removal of the hydrogen from ammonia gas. The method of preparation in the laboratory is as follows:

Experiment 3. - Insert a long pin through the center of a large flat cork. Fasten a short piece of candle to the cork by means of the pin. Nearly fill the pneumatic trough with water. Light the candle and float it upon the surface of the water. Invert a large cylinder over the candle, having the mouth of the cylinder just 
below the surface of the water, as shown in Fig. 20. After the candle is extinguished, remove it with the hand, reaching through the water into the cylinder without admitting any air. While the cylinder is still under water, cover it with a glass plate and remove from the trough. Then make the following tests:

(I) Insert a burning splinter into the cylinder of N. Observe the result. (2) Place a little sulfur in the deflagration spoon, ignite, and insert in the cylinder of N. Observe the result. (3) With a

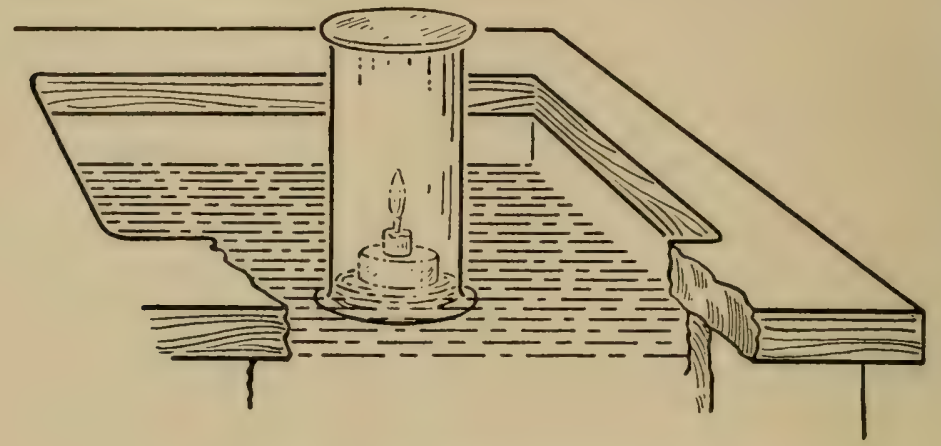

FIG. 20.-Preparation of nitrogen.

ruler, measure the height of the cylinder and the amount of water left in the cylinder.

Questions. - (I) What is the color of N? (2) Odor? (3) Compared with air is it a heavy or a light gas? (4) Is it combustible? (5) Does $\mathrm{N}$ support combustion? (6) Is $\mathrm{N}$ an active element? (7) What portion of the cylinder is filled with water in the preparation of $N$ ? (8) What portion of the cylinder is filled with $N$ ? (9) What portion of the cylinder did the O occupy? (Io) What becomes of the products of combustion of the candle? (I I) What do these experiments prove in regard to the element N? (I2) Complete the following table:

Name of Symbol. Combin- Color. Taste. Combus- Supporter of Where $\begin{array}{ccccc}\text { element. Symbol. } & \text { ing wt. } & \text { Color. Taste. } & \begin{array}{c}\text { Combus- } \\ \text { tible. }\end{array} & \begin{array}{c}\text { Supporter of } \\ \text { combustion. }\end{array} \text { found. } \\ \text { found }\end{array}$

Oxygen

Nitrogen

Hydrogen

When the candle is burned, the oxygen of the air in the cylinder unites with the carbon and hydrogen from the candle and forms 
carbon dioxid and water. The $\mathrm{CO}_{2}$ is soluble in water, and the gas that is left is mainly nitrogen. The combination of the oxygen with the carbon causes a partial vacuum to form, and this results in the water rising in the cylinder. If great care is taken in performing the experiment, it will be found that the water fills about one fifth of the cylinder, occupying the space of the oxygen which has been combined with the carbon. When all of the oxygen in the cylinder is combined with the carbon, the candle is extinguished because of lack of oxygen for.combustion.

45. Properties of Nitrogen. - In general, the physical properties of nitrogen, except weight, are somewhat like those of hydrogen and oxygen, inasmuch as when pure, it is colorless, tasteless, and odorless. It is about I4 times as heavy as hydrogen, and only slightly soluble in water. At a low temperature and under pressure, it is liquefied, and at a still lower temperature and under higher pressure, it is solidified.

Chemically, nitrogen is unlike either hydrogen or oxygen. It is an inactive gas; it is neither combustible nor a supporter of combustion. When in the free state, it is one of the most inactive of all the elements, and will combine directly with only a ferv. When nitrogen enters into combination with other elements, particularly with carbon and hydrogen, forming the organic compounds, it has a tendency to make a weak link in the combination, and will readily split off to form simpler products. In the air, it serves the purpose of diluting the oxygen. No other element could perform this function so well as nitrogen. If the air were composed of pure oxygen, all combustion would be carried on in a rapid and wasteful manner. Nitrogen is not a poisonous gas, but if an animal were compelled to breathe pure nitrogen, it would die for need of oxygen. Some of the compounds of nitrogen decompose with violence, causing explosions. Nearly 
all the explosives, as gunpowder, nitroglycerin, and guncotton, are compounds of nitrogen.

46. Importance. - The compounds of nitrogen take an important part in animal and plant life. In combination with carbon, hydrogen, and other elements, nitrogen forms the nitrogenous compounds of plant and animal bodies. These compounds are called organic nitrogenous compounds because they are capable of undergoing combustion, and they produce volatile and gaseous products when burned.

In the study of foods, and of soils and fertilizers, the element nitrogen is given a prominent place. This is because it is one of the most expensive elements in commercial fertilizers, and foods which contain nitrogenous compounds are the most expensive. Although nitrogen is found uncombined in the air, it is made use of as a plant food by only a limited number of plants, and then in an indirect way. Nitrogen forms a large number of important compounds, as ammonia, nitrates, nitrites, amids, and the complex organic compounds, proteids. Some of these will be studied more in detail in future chapters. To the agricultural student, nitrogen is one of the most important elements because of the rôle which it plays in plant and animal economy.

Problem I. - Calculate the per cent of $\mathrm{N}$ in $\mathrm{NaNO}_{3}$.

Problem 2. - Calculate the per cent of $\mathrm{N}$ in $\mathrm{NH}_{3}$.

Problem 3. - Calculate the per cent of $\mathrm{N}$ in $\left(\mathrm{NH}_{4}\right)_{2} \mathrm{SO}_{4}$. 


\section{CHAPTER VII}

CARBon

47. Occurrence. - Carbon is found in the free state in limited amounts only, but is mainly in combination with other elements. With the metals and oxygen, it forms carbonates, such as calcium carbonate or limestone. With hydrogen and oxygen, and a few other elements, it forms a large number of compounds of which plant and animal tissues are composed. All substances which char or blacken when burned contain carbon in combination. Diamonds, coal, and graphite are forms of this element in various degrees of purity. With oxygen, it is present in the air in small amounts as carbon dioxid. About half of the dry substance of wood and animal tissue is carbon. It occurs in nature in a great variety of forms.

48. Preparation. - In the form of charcoal, carbon can be prepared from wood, by application of heat in the absence of air or oxygen, when a change known as destructive distillation takes place. The hydrogen, oxygen, and nitrogen of the wood are expelled, and a black mass of impure carbon and mineral matter is left. To make charcoal, wood is piled and burned in suitable pits, which, after the combustion is well started, are covered with turf to protect the burning mass from the air. Charcoal can be produced on a small scale in the laboratory, in the following manner: 
Experiment 4. - Place two or three small pieces of wood in a Hessian crucible, and cover with sand. Heat the crucible until smoking ceases (see Fig. 2I). Remove and examine the charcoal.

Questions. - (I) What are the principal elements in wood? (2) What becomes of these various elements when the material is

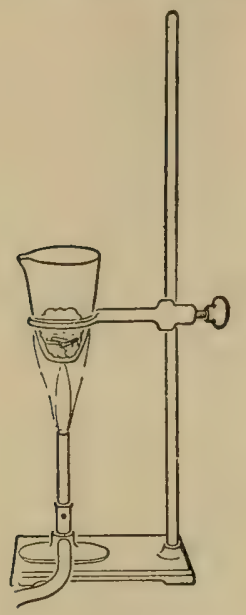

Fig.21.-Preparation of charcoal. heated? (3) Why was sand used in this experiment? (4) What becomes of the ash or mineral matter in the process of charcoal making? (5) What is charcoal, and of what element is it principally composed? (6) Does charcoal have a crystalline structure? (7) What would be the result if sand were not used in the experiment? Give the equation for the combustion of carbon. (9) How can charcoal be made on a large scale?

Particles of carbon may also be obtained from a gas, candle, or lamp flame, by holding a piece of cold porcelain a little above the flame. Carbon, in the form of soot, is deposited in chimneys when fuel is burned with a poor draft. When combustion is complete, the carbon is oxidized, forming carbon dioxid. If a fire gives off a large amount of dense black smoke, the carbon is not completely oxidized, and consequently there is a loss of fuel value.

49. Properties. - Carbon is found in three forms in nature: as diamond, graphite, and amorphous carbon. The diamond is a pure form of crystallized carbon. It can be burned like any other form of the element, and produces carbon dioxid. Diamonds of small size are produced artificially by the cooling of graphite from molten iron. Graphite also is a crystalline form of carbon, but the crystals are of different shape and color from diamond crystals. Graphite is soft, and is used extensively as a lubricant. As it does not burn as readily as other forms of carbon, it is used, too, for making crucibles and for the linings of furnaces. It is a natural product and also is produced artificially by dissolving carbon in iron. 
There are a great many uncrystallized or amorphous forms of carbon, as lignite and soft coal, lampblack, and charcoal.

50. Coal. - All the conditions under which coal has been produced are not known. It is supposed to be the result of the joint action of heat and pressure upon prehistoric forms of vegetation. Hard or anthracite coal is the purest form known, and yields the least ash and unoxidized volatile products. Bituminous or soft coal is less pure, as more of the carbon is in chemical combination with the other elements, and when burned, the carbon is not as completely oxidized under ordinary conditions as is that of hard coal. Coal may contain a number of impurities, as sulfur and mineral matter. Cannel coal is a variety which contains a large amount of mineral oils.

Lignite is vegetable matter which has only partially undergone the coal-forming process. It is less pure than soft coal, and is supposed to be an intermediate stage in its formation. Peat is vegetable matter which has undergone chemical changes under water. It has a lower fuel value than lignite.

5I. Allotropism. - An element which has the power to take on so many different physical forms as has carbon is called an allotropic element. Only a few elements have the properties of allotropism.

52. Carbon as a Reducing Agent. - Carbon is used extensively for the reduction of minerals. It unites with the oxygen of minerals and ores to form carbon dioxid. In the reduction of iron ore, the oxide of iron is heated with carbon in the form of coke. The ore is reduced by giving up its oxygen to the carbon. When reduction takes place oxygen is removed by a reducing agent, while oxidation is the chemical union of oxygen 
with a substance. The action of carbon as a reducing agent may be observed from the following experiment:

Experiment 5. - Mix thoroughly 2 or 3 grams of copper oxid ( $\mathrm{CuO}$ ) and an equal bulk of charcoal (animal charcoal). Place the mixture in a small test tube and apply heat. Observe the result.

Questions. - (I) What is the bright red material produced in the test tube? (2) What was the source of this material? (3) What caused the $O$ to be separated from this compound? (4) What did it unite with? (5) What was formed as the product? (6) Write the reaction. ( 7 ) Why is carbon called a reducing agent? (8) What kind of an agent would $\mathrm{CuO}$ be called? (9) Why is carbon useful in separating minerals from their ores?

53. Combustion. - Combustion, in the ordinary sense, is simply the union of carbon with oxygen, and, as a result, light and heat are given off. If the process is
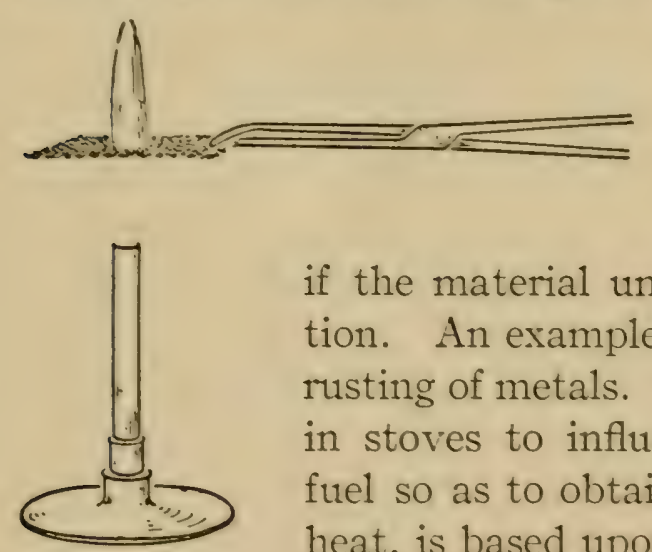

FIG. 22.-Com-

bustion. combustion of carbon. slow, and heat without light is evolved, it is slow oxidation, and the total amount of heat generated is the same as if the material underwent direct combustion. An example of slow oxidation is the rusting of metals. The regulation of drafts in stoves to influence the combustion of fuel so as to obtain the largest amount of heat, is based upon the simple laws of the

A candle or gas flame well illustrates the laws of combustion. The outer portion of the flame is a non-luminous envelope of gases undergoing perfect combustion; within this is a layer of gases undergoing partial combustion, and constituting the light-giving part of the 
flame; while in the center is a zone which is more perfectly cut off from the air, and little or no combustion is taking place. The combustion of a gas or candle flame may be studied from the following experiment:

Experiment 6. - Structure of the flame. Unscrew the top of a Bunsen burner ancl make a drawing showing how the burner works, and the workings of the ori-

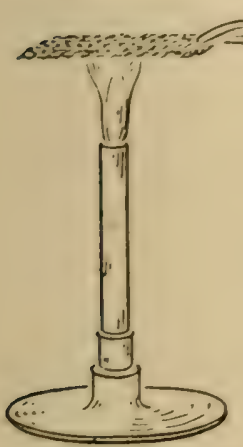

Fig. 23. - Combustion. fices at the bottom of the burner. Replace the parts of the burner, open the airholes at the base, and light the gas. Hold a sheet of paper back of the flame and try to distinguish the three parts: (I) the outer non-luminous envelope of perfect combustion; (2) the inner luminous zone of partial combustion; (3) the central blue cone of unburned gas. Make a drawing of the flame. Press a piece of card board or paper down upon the flame for an instant and remove it before it takes fire. Observe the result. Hold a piece of wire close to the burner and observe that at first the wire does not become red at the center of the flame. Thrust the head of a match into the center of the flame for an instant and then remove it. If this is done quickly, the match can be removed before combustion takes place. Place a piece of wire gauze above the flame as shown in Fig. 23. Observe the result. Extinguish the gas. Hold the wire gauze about an inch above the burner, then light the gas above the gauze (Fig. 22).

Questions. - (I) Why was a charred circle formed when the piece of paper was pressed down upon the flame? (2) Why did the wire first redden near the outer portions of the flame and not at the center? (3) Why did the flame refuse to burn above the wire gauze when the gauze was pressed down upon the flame? (4) When the gas was lighted above the gauze, why did it refuse to burn below? (5) What is kindling temperature? (6) What are the three conditions necessary for combustion? (7) What condition was lacking when the gauze was placed in the flame? (8) Why does a flame give light when air is excluded from the burner, and give but little light when the air vent is open? (9) Does the amount of light which 
a flame produces indicate the amount of heat produced? Why? (Io) What causes a flame to give light? (Ix) Why do some materials, when burned, produce more flame than others? (I2) What is spontaneous combustion? (I3) Explain how it is possible for clover or fodder to undergo spontaneous combustion in a barn. (I4) What can be done to prevent spontaneous combustion? (I5) Carbon, when burned, produces heat; limestone, $\mathrm{CaCO}_{3}$, contains carbon; why is it not possible to use limestone for fuel?

54. Spontaneous Combustion. - In order for a substance to undergo combustion, it is not always necessary for a match or a flame to be applied to it. As soon as it is heated to its kindling temperature, that is, the temperature at which it unites with oxygen, if in the presence of air, combustion takes place, called spontaneous combustion. Clover, when stored in a damp condition, may undergo spontaneous combustion. The fermentation which takes place produces combustible gases which,

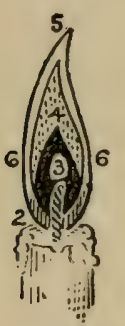

Fig. 24.-Candle flame. 3. Nonluminous cone. 4. Luminous line. 5,6. Outer non-luminous envelope. at suitable temperature, ignite, and the burning gases, in turn, ignite the carbon of the material. Substances containing a great deal of oil and materials of low kindling temperature, as carbon bisulfid, phosphorus and sulfur, under suitable conditions of temperature and air, readily undergo spontaneous combustion.

In case of fire, the laws governing combustion should be taken advantage of. If the fire is a small one, cut off the supply of air, and the fire is extinguished. This can be accomplished by the use of sand, wet blankets, or any material that will cut off the supply of air. In order for spontaneous combustion to take place, there must be (I) a combustible substance, which (2) is heated 
to its kindling temperature, (3) in the presence of air.

55. Carbon a Decolorizer and Deodorizer. - Wood and animal charcoal have the power of absorbing gases and coloring materials from solutions. In the manufacture of sugar, a part of the impurities are removed by boneblack or animal charcoal filters, and in purifying water, charcoal filters are often used. The power of carbon to abstract gases and coloring matter is largely a physical property. In the soil, the carbon compounds decay and produce humus, which has some of the power of charcoal to absorb gases and soluble bodies.

Experiment 7. - Place in a cylinder 2 grams of animal charcoal and about I cc. cochineal solution diluted with ro cc. water. Cover the cylinder with a glass plate and shake; then pour the contents of the cylinder into a filter. If the first of the filtrate is not clear, pass it through the filter a second time.

Repeat the experiment, using $2 \mathrm{cc}$. potassium sulfid solution, 2 cc. hydrochloric acid, and ro cc. water in place of the dilute cochineal solution.

Questions. - (I) What effect did the animal charcoal have upon the color of the solution? (2) What property of animal charcoal does this show? (3) What was the result of filtering the potassium sulfid solution? (4) What property of animal charcoal does this show?

56. Products of Combustion. - The carbon dioxid gas given off from either a candle or a gas flame can be collected by arranging an apparatus like that shown in Fig. 25. A metal funnel is connected with a delivery tube which

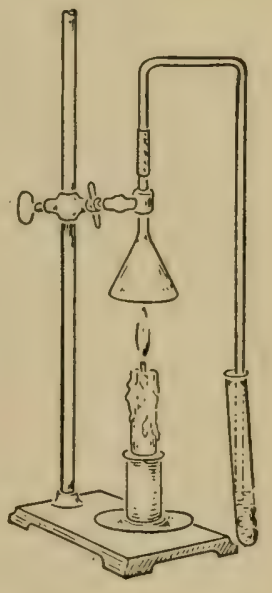

IG. 25.- Collecting carbon dioxid from candle. passes near the surface of a solution of lime water, $\mathrm{Ca}(\mathrm{OH})_{2}$, in a test tube. The carbon dioxid given 
off from the flame passes into the lime water, and, by forming calcium carbonate, causes it to become cloudy. $\mathrm{Ca}(\mathrm{OH})_{2}+\mathrm{CO}_{2}=\mathrm{CaCO}_{3}+\mathrm{H}_{2} \mathrm{O}$. The carbon comes

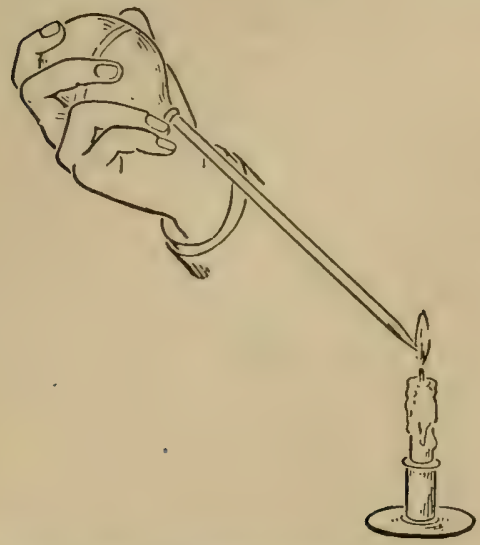

Fig. 26. - Obtaining unburned gas from candle. from the gas, which undergoes combustion, and is combined with hydrogen as hydrocarbons. That a candle produces its own combustible gases can be proved by collecting some of the gas with a glass tube and rubber bulb as shown in Fig. 26. This gas can then be burned as indicated in Fig. 27. The hydrogen of gas or a candle forms $\mathrm{H}_{2} \mathrm{O}$ during combustion, and can be collected by passing the products of combustion through suitable absorbents. If a dry test tube is held above the flame, a little moisture will collect on the sides of the test tube.

57. Compounds of Carbon. - Chemically, carbon forms a very large number of compounds, more, in fact, than any other element. The carbon compounds in plant and animal tissues are studied in a division of chemistry known as organic chemistry, while those compounds of carbon which are in combination with the mineral elements, as calcium, sodium, and potassium, are studied in a division termed inorganic chemistry. No well-defined bound-

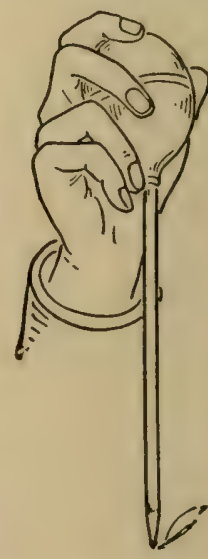

Fig. 27.- Combustion of gas from candle. ary line, however, can be established between these two divisions of chemistry. 
58. Importance of Carbon. - The carbon compounds take a very important part in animal and plant growth. And commercially, they are of great importance, as they are found in foods, fuels, and in all animal and plant products. Carbon is present in plant and animal bodies in larger amounts than any other element. Carbon is the element essential for the production of heat when fuels and foods are oxidized.

Carbon is in the air in the form of carbon dioxid in sufficient amounts for the production of crops. It is also in human and animal foods in large amounts; but because of its abundance, and its distribution in balanced form, it has not been considered of so much importance economically in the production of plants as nitrogen. It is, however, equally important, although its natural distribution is such that it does not require so much effort, on the part of man, to obtain it as it does other forms of plant food materials. Nevertheless, the carbon compounds, particularly in food materials, should not be disregarded or considered of little or no importance because of their abundance. In studying foods and soils and fertilizers the student will find some of the compounds of carbon considered more in detail. 


\section{CHAPTER VIII}

\section{WATER}

59. Chemical Composition. - That water is composed of hydrogen and oxygen in approximately the proportion of 2 volumes of $\mathrm{H}$ to $\mathrm{I}$ of $\mathrm{O}$ can be demonstrated by pass-

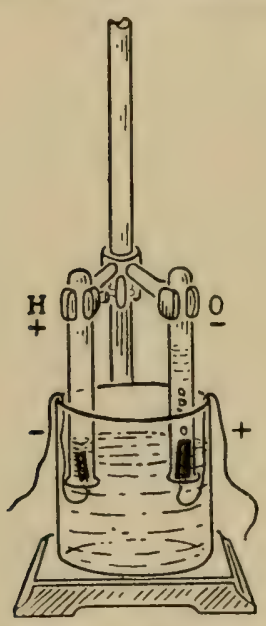

FIG. 28. - Electrolysis of water. ing a current of electricity through water and collecting the escaping gases. Oxygen is liberated at the positive electrode, while hydrogen is liberated at the negative electrode. That water is composed of 16 parts, by weight, of oxygen, to 2 parts, by weight, of hydrogen, can be demonstrated by passing hydrogen gas over copper oxid heated in a tube. The reaction which takes place is $\mathrm{CuO}+$ $2 \mathrm{H}=\mathrm{H}_{2} \mathrm{O}+\mathrm{Cu}$. If suitable provisions are made for weighing the oxid of copper used, and the water produced, it will be found that the weight of the water bears definite relation to the amount of oxid of copper reduced. For every loss of 16 grams of oxygen from the copper oxid, I8 grams of water are obtained, showing that water is eight ninths, by weight, oxygen.

Experiment 8.-Distillation of water. Connect flask $A$ (Fig. 29) with the bent tube $B$ to the condensing apparatus issued for this experiment. Place the distilling flask upon the sand bath and in position as shown in Fig. 29. Fill the tank of the distilling apparatus, and half fill the flask, with water. Apply heat to the 
flask, and reject the first portion of water that is distilled. Distil about 25 or $30 \mathrm{cc}$. of water.

Tests. - ( I) Thoroughly clean your porcelain evaporating dish, if necessary using a little white sand for scouring, rinse with distilled water, and then by placing the evaporator upon a sand bath, evaporate some of the distilled water to dryness. Carefully regulate the heat so that as the water evaporates there will be less and less heat. This is to prevent the breaking of the evaporating dish by too much heat at the close. Examine the evaporating dish. See if there is any residue. (2) Evaporate to dryness a similar amount of ordinary water, and observe the residue

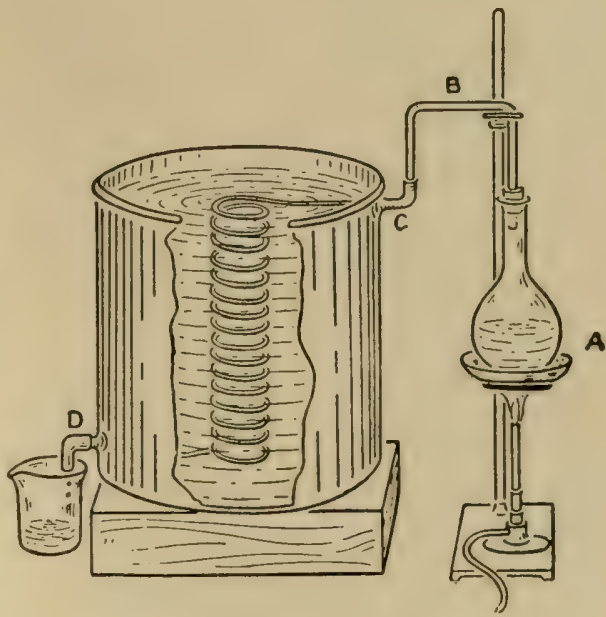

Fig. 29. - Distillation of water.

Questions. - (I) Why do the contents of flask $A$ become cloudy after boiling and cooling? (2) Why was the residue obtained by one test and not by the other? (3) What became of the residue when the water was distilled? (4) How could you distil water on a larger scale for drinking purposes, if necessary to do so?

6o. Physical Properties. - When water cools, it reaches its maximum density at $4^{\circ} \mathrm{C}$.; below this point, it expands, and hence ice has a lower specific gravity than water. All natural waters contain more or less impurities in the form of mineral and vegetable matter and gases. Pure water can be prepared only by distillation. When a substance, as salt, is dissolved in water, a solution is obtained. The particles of the material are separated in the process of solution, and every part of the solution, even though dilute, contains some of the dis- 
solved substance. When a substance is dissolved, ions are produced. They are small parts of the material that have undergone changes due to the action of the solvent. The ions possess definite electrical properties. When a substance goes into solution, the process is both physical and chemical. In some cases a change of temperature occurs, as when ammonium nitrate solution is made.

61. Water of Crystallization. - Many substances contain, in chemical combination, water necessary for the formation of crystals. This is what is meant by water of crystallization. Without this water, crystals could not be formed. The amount of water required bears a definite relation to the composition of the crystals. When copper sulfate crystallizes, 7 molecules of water of crystallization are added to the substance. In purchasing some materials, as sulfate of soda, there is a large amount of water included, as this compound contains ro molecules of water of crystallization. When the substance is heated in an oven to a sufficiently high temperature, usually above $100^{\circ} \mathrm{C}$., the water of crystallization is expelled and the anhydrous substance is obtained. Water of crystallization is entirely different from hydroscopic moisture or moisture absorbed from the air. Some chemical compounds, when exposed to the air, give up their water of crystallization. This is called efflorescence. Other compounds, as $\mathrm{KOH}$ and $\mathrm{CaCl}_{2}$, absorb moisture from the air. Such substances are called deliquescent. Water takes an important part in chemical reactions; in fact, many of the reactions expressed in the form of equations could not take place without the presence of water.

62. Natural Waters. - Rain, spring, lake, river, and sea waters are some of the principal forms in which water is found in nature. Some waters contain enough dissolved 
salts to give them definite characteristics and are known as mineral waters. The most common impurities in water are lime, magnesia, potash, soda, and iron compounds. These substances give properties to the water which cause them to be characterized as hard or soft, according to the nature and amount of minerals dissolved. All natural waters are liable to contamination, and the organic impurities serve as food for disease-producing organisms. The sanitary condition of the water supply

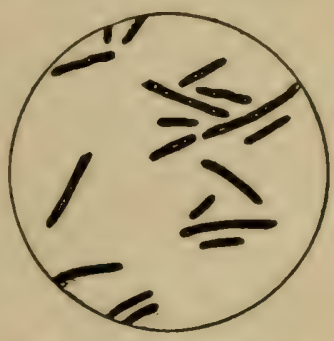

FIG. 30.-Typhoid bacillus. has an important bearing upon health. Typhoid fever, cholera, and other bacterial diseases are frequently caused by poor drinking water. The spores of the organisms present in the water are taken into the body, where they rapidly multiply. Surface wells, particularly when near barns and dwellings, and in thickly settled regions, are frequently in an unsanitary condition.

63. Impurities in Water. - The nature of the impurities in the soil through which water flows determines the kinds of impurities in the water. If a soil is polluted with decaying animal and vegetable refuse matter, the soluble portions of these, along with the countless organisms which they contain, become a part of the drinking water. The impurities in well waters are (I) organic matter and (2) mineral salts. When water is charged with an excessive amount of organic matter, the solids obtained by evaporating the water to dryness blacken when ignited. The carbon compounds in a liter of some waters require $20 \mathrm{mgs}$. or more of oxygen for oxidation. The organic matter may decompose and become harmless, but it is liable, in times of epidemics, to furnish food for disease germs. 
Water that is comparatively free from organic matter is not nearly so apt to convey disease germs as one that contains a large amount of such material, as this is the best kind of food for the development of the germs which cause many of the most fatal diseases. Vegetable matter, as a rule, is not as harmful in a water as animal matter. The organic refuse dissolved in waters is constantly decaying, and this decomposition is the result of the workings of minute organisms known as bacteria, which may be the disease-producing ones as well as the harmless kinds. The history of the water supply of large cities shows that a water which is comparatively free from organic matter is the best for household purposes. The source of the nitrogenous organic matter in drinking waters is often sewage or surface drainage, as from. a swamp. Deep well waters are less liable to be contaminated than surface wells, but a deep well is not above

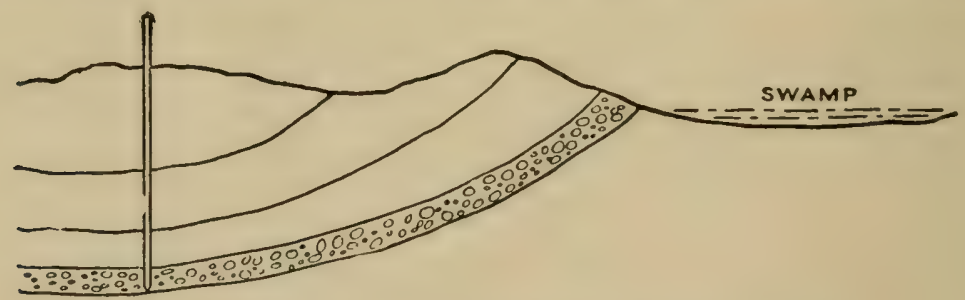

FIG. 31. - Well contaminated with drainage from swamp.

suspicion, because the layers of soil are subject to changes in slope, and the water from a deep well may receive surface drainage from some distant place, as indicated in the illustration (Fig. 3I). Although the soil would remove a portion of the impurities and the organic matter would be partially oxidized, the water would not be entirely free from contamination.

64. Location of Wells. - Wells should be remote 
from barns and cesspools. Large trees about wells are objectionable because the water is fouled by waste matter thrown off by the roots. The top of the well for 6 or 8

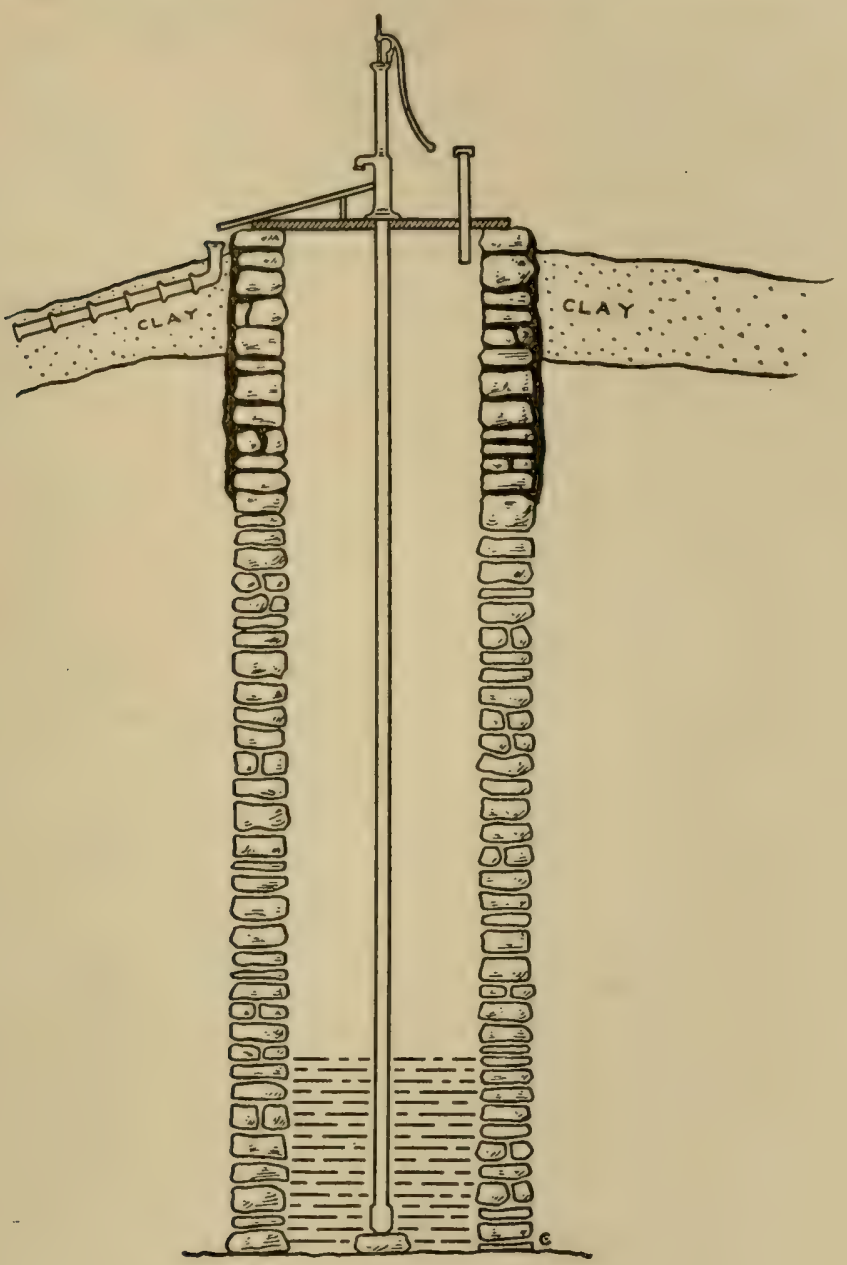

FIG. 32.-Construction of well.

feet should be laid with cement. The well platform should be tight so that small animals are kept out. Drain water from the spout should be carried away from 
the well platform, and the watering trough should not be directly over the well. The land should slope away from the well and the surfacing should be of clay. The well

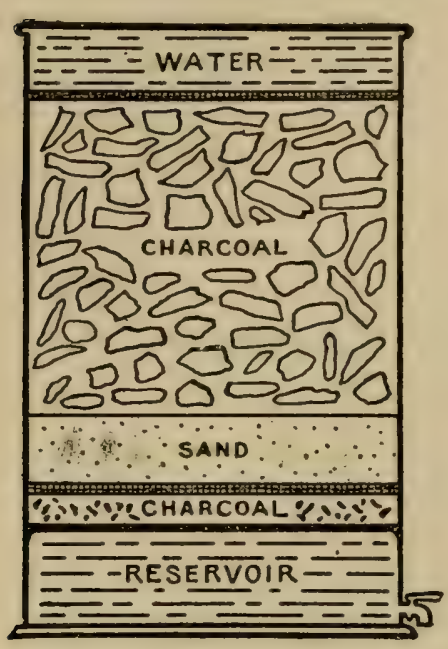

FIG. 33.-Charcoal water filter. should have ventilation, and should occasionally receive a cleaning.

65. Mineral Impurities.-Calcium carbonate, calcium sulfate, sodium chlorid, and sodium sulfate are the most common minerals present in water. In alkali waters the mineral impurities are sodium or potassium compounds, often in large amounts, and there is no way of improving such waters except by distillation. Different kinds of minerals, if in excessive amounts, may impart medicinal properties; magnesium sulfate (Epsom salts) acts as a purgative, while calcium sulfate causes costiveness. Strong alkaline waters can generally be detected by their salty taste. An excess of some forms of alkaline salts in waters renders them unsafe for irrigation purposes, as the salts are destructive to plant life.

Limestone in waters is not so serious as are other minerals. Waters sometimes contain limestone to such an extent that when boiled they become cloudy, which is because of the removal of the carbonic acid

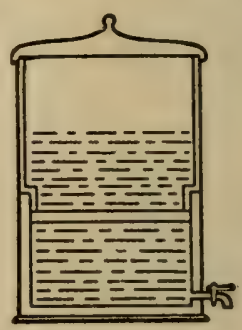

FIG. 34. - Unglazed porcelain filter. gas which causes the limestone to remain in solution. Some waters that contain limestone are not considered injurious to health, although they are not so satisfactory for 
cleaning purposes because the lime acts upon the soap and forms a scum of insoluble lime soap. A large amount of limestone, gypsum, etc., causes waters to be hard. Some waters contain iron compounds, as carbonate of iron which, upon contact with the air, forms hydrate of iron, and is deposited as a brownish red sediment. Sometimes there is so much mineral matter in waters that when used for generating steam they produce a large amount of boiler scale. This can often be partially prevented by the use of materials as trisodium phosphate, soda ash and graphite, which form a sludge instead of a hard scale.

66. Methods of Improving Drinking Waters. (I) By boiling, which destroys disease-producing organisms. Boiled or sterilized water, however, is not free from the poisonous compounds which many organisms produce. In cases of pestilential diseases, water should always be boiled.

(2) By filtering through charcoal or through disks of unglazed porcelain-like material, which results in

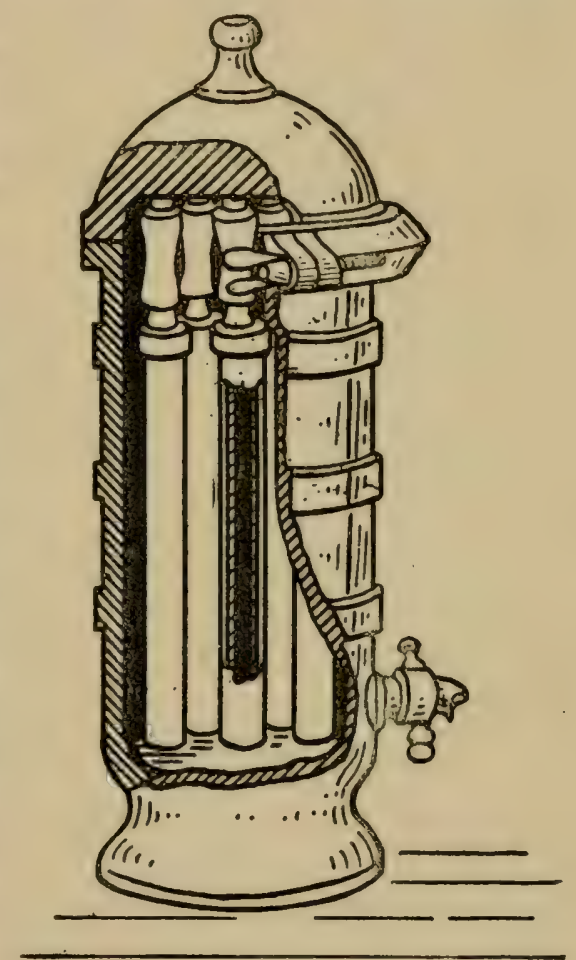

FIG. 35. - Pasteur water filter. removing a large part of the organic matter. Special care, however, should be taken to keep the filter clean, otherwise it will be a source of contamination. Boiling the water 
before filtering also improves its sanitary condition. One of the most efficient forms of water filters is the Pasteur filter, where the water passes through a series of tubes which present a large surface area for filtering.

(3) By distilling, which removes all mineral impurities, and also purifies the water from organic matter. It is the best way of removing all kinds of impurities and rendering the water free from organisms, and safe for use.

Chemical precipitation and filtration plants are often used for improvement of the water supply of cities. The suspended matter along with the dissolved organic impurities are coagulated and precipitated by small amounts of iron and aluminum compounds, then enough lime or other substance is added to precipitate the excess of iron or aluminum salts. After precipitation the impurities are removed by filtration. Such plants are under supervision of chemists, and the reagents used vary with the amount and nature of the impurities contained in the water. Water of high sanitary quality can be secured by chemical precipitation and filtration methods. 


\section{CHAPTER IX}

AIR

67. Air a Mechanical Mixture. - Air is a mechanical mixture of a number of gases and compounds in about the following proportions: (I) nitrogen, 79 per cent; (2) oxygen, 20 per cent; (3) carbon dioxid, 0.04 per cent; (4) ammonium compounds in small amounts ; (5) moisture; (6) ozone; (7) hydrogen peroxid; (8) argon; (9) dust, organic matter, and microörganisms. That air is a mechanical mixture is shown by its not having a constant chemical composition, which is necessary for all compounds, and when nitrogen and oxygen are mixed in the same proportion as in air, there is no evidence of a chemical reaction, as change of volume or temperature. The air that is dissolved in water is of different composition from atmospheric air, due to the fact that oxygen is more soluble in water than is nitrogen. The occurrence of nitrogen and oxygen in the air, and the chemical and physical properties of these gases, have been discussed in Chapters IV and V.

68. Carbon Dioxid. - The amount of carbon dioxid in the air is small, about 0.04 per cent, and it is supposed to remain fairly constant. It is produced from: (I) combustion of carbon-containing materials, as fuels ; (2) decaying of organic matter; and (3) respiration of animals. The carbon dioxid of the air serves as food for plants and is used for the construction of plant tissue. The amount produced and that used by vegetation 
nearly balance each other, so that the carbon dioxid in the air remains fairly constant. While the percentage amount in the air is small, the total amount is quite large; it is estimated that over each acre of the earth's surface there are about 30 tons of carbon dioxid at the disposal of plant bodies. Carbon dioxid itself is not such a poisonous gas, but it is usually associated in

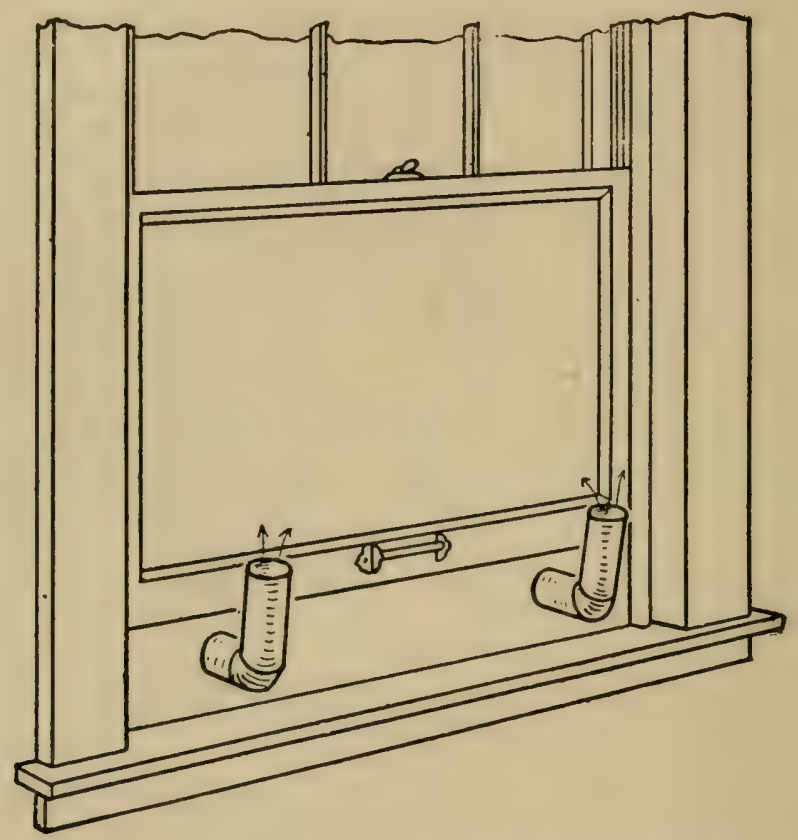

FIG. 36. - Ventilating board in window for obtaining fresh air.

respired air with noxious and poisonous products thrown off by the lungs. Hence the carbon dioxid in a room is taken as the index of the completeness of ventilation, and when it exceeds O.I per cent, the poisonous products associated with it are considered to be too much for sanitary conditions. While carbon dioxid is a product of respiration, and is of no direct economic importance 
to animals, it is indirectly of great importance because of its serving as food for plants. It is a heavy gas, but in a room it diffuses and is quite evenly distributed. Its presence in pure and in respired air can be shown by the following experiment:

Experiment 9. - Pour ro cc. of lime water (calcium hydrate) into a test tube, and blow through it, using for the purpose a clean glass tube. Observe the precipitate of calcium carbonate. Expose about to cc. of lime water in a beaker for twenty-four hours, and observe the result. The reaction which takes place between the lime water and the carbon dioxid of the air is as follows:

$$
\mathrm{Ca}(\mathrm{OH})_{2}+\mathrm{CO}_{2}=\mathrm{CaCO}_{3}+\mathrm{H}_{2} \mathrm{O} \text {. }
$$

Questions. - (I) What caused the precipitate to form? (2) What was produced? (3) Is $\mathrm{CaCO}_{3}$ soluble in water? (4) How do you determine whether or not a gas is $\mathrm{CO}_{2}$ ? (5) How does the product from this experiment compare with that from the burning candle?

In the ventilation of dwellings, barns, and stables, it is necessary that the products of respiration be removed as completely as possible and not allowed to accumulate and endanger health. Pure air is as important as pure food or water. Impure air is frequently the cause of disease, and indirectly it may, by lowering the vitality of the individual, prepare the way for disease. When gasoline or kerosene is used as fuel, more thorough ventilation is necessary than when wood or coal is used, because the products of combustion from the gasoline and kerosene are given off into the room instead of being carried out through the chimney. The subject of ventilation, which forms a part of sanitary chemistry, is, as a rule, given too little attention.

69. Ammonium Compounds. - When nitrogenous organic compounds decay, ammonia gas, $\mathrm{NH}_{3}$, is given off. Since nitrogenous animal and vegetable matters are con- 
stantly undergoing decay, some ammonia is always in the air. The ammonia gas unites with the carbon dioxid and forms ammonium carbonate. In barns and stables

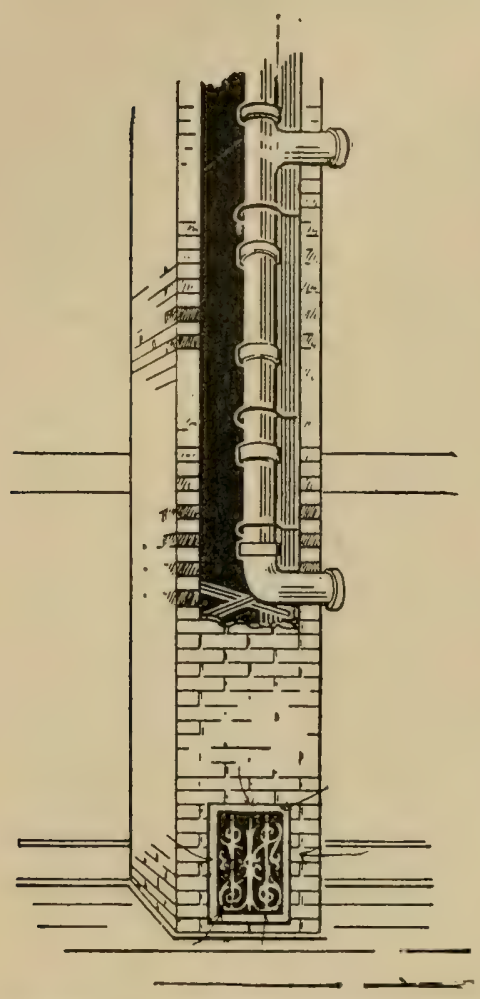

FIG. 37. - Ventilating flue in chimney for removing foul air. where the ventilation is poor, abnormal amounts of carbon dioxid and ammonia are formed from the respiration and waste products of animals. When carbon dioxid forms to such an extent that it produces a white coating upon stones and boards, it shows enough ammonium carbonate to be injurious to animals. Nitrogen, in traces, in the form of ammonium nitrate and nitrite, is also present in the air. The amount of combined nitrogenous compounds in the air is small and not sufficient to furnish food for plants.

70. Moisture. - The amount of moisture in the air ranges between wide limits, from complete saturation to desert conditions. When the air contains all the moisture it can hold, it is said to be saturated. In temperate climates, the humidity, or per cent of saturation, ranges between 60 and 85 . The amount of moisture in the air has an influence upon plant growth, rather because it modifies the conditions of the atmosphere than because it furnishes moisture directly to plants. The humidity of the air also influences many farm operations, as the 
curing of cheese, which is best effected in an atmosphere containing about 85 per cent of moisture.

\section{Atmospheric Constituents Present in Small} Amounts. - Ozone and hydrogen peroxid are oxidizing agents, present in the air only in traces. Ozone is a modified or allotropic form of oxygen. It is more active than ordinary oxygen. Hydrogen peroxid $\left(\mathrm{H}_{2} \mathrm{O}_{2}\right)$ readily gives up one of its atoms of oxygen for oxidation purposes. $\mathrm{H}_{2} \mathrm{O}_{2}=\mathrm{H}_{2} \mathrm{O}+\mathrm{O}$. Argon, krypton, neon, and penon are elements which are in the air in small amounts. Argon makes up about I per cent of the volume of the air, and is like nitrogen in many of its chemical characteristics, but is even more inactive and inert than nitrogen; it is the most inactive element known. When argon is liquified it is not supposed to take any direct part in animal or plant life.

72. Liquid Air. - As both nitrogen and oxygen can be liquefied, and air is a mechanical mixture of these elements, it necessarily follows that air can be liquefied. To accomplish this, air is cooled and then subjected to a pressure of 2500 pounds per square inch. Liquid air may vary in its nitrogen and oxygen content. It is a colorless liquid, and boils at - I9 $\mathrm{I}^{\circ}$.

73. Organic Impurities. - Dust, dirt, and impurities in the air vary with conditions, as rainfall, local influences, and sources of contamination. Fine particles of dust, containing decaying vegetable matter, are carried long distances by the wind. This decaying vegetable matter often contains spores of disease germs. The dust and impurities in the air can be observed when a beam of sunlight finds its way into a room; then the particles of dust will be seen floating in the air. When the air in a room is not in motion, the dust particles separate and 
settle very much as fine clay separates from water which is not disturbed. There are many different kinds of organic impurities in the air. The most objectionable are decayed refuse matters, particularly of animal origin. The air which passes over swampy, undrained land is often contaminated with impurities.

74. Air as a Source of Food. - In both animal and plant life, air plays an important rôle. It contains oxygen necessary for the existence of animals and carbon dioxid essential as food for plants. Over 90 per cent of the total food of our agricultural and useful plants is obtained from the air as carbon dioxid, or from rain which finds its way into the soil. Food which is oxidized in the body requires oxygen for combustion. Hence it will be seen that the air is the source of the larger portion of the total food of both plants and animals. 


\section{CHAPTER X}

\section{Acids, Bases, Salts, and Neutralization}

75. Classification of Elements. - Elements are divided into two classes: (I) acid-forming elements, and (2) base-forming elements. This division is made according to the properties of the elements.

The basic elements are commonly called metals : iron, copper, silver, and lead are examples. The basic elements form, with $\mathrm{H}$ and $\mathrm{O}$, bases or hydroxids, as $\mathrm{KOH}$ and $\mathrm{NaOH}$. A base is a compound composed of a metal in combination with $\mathrm{OH}$, the hydroxyl radical. This radical can be replaced by an acid-forming element.

An acid is a compound containing hydrogen which can be replaced by a metal. In the preparation of hydrogen, the $\mathrm{H}$ of $\mathrm{HCl}$ is replaced with zinc. The acidforming elements, with hydrogen, and with $\mathrm{H}$ and $\mathrm{O}$, form acids.

Bases and acids are opposite in character and properties. Acids color blue litmus red, bases color red litmus blue. For purposes of study, the different acid- and base-forming elements are subdivided into families and groups which have definite relationships and common characteristics.

76. Salts. - When an acid and a base are brought together, a chemical reaction takes place, known as neutralization. The product is a salt. A salt is an acid in which the hydrogen has been replaced by a metal. It is formed by the union of acid-and base-forming elements. Salts are 
neutral compounds. In the study of acids, bases, and salts, the character of the compound can always be determined from the formula as $\mathrm{Ca}(\mathrm{OH})_{2}$. Calcium hydrate is a base because it contains the hydroxyl radical $\mathrm{OH}$. $\mathrm{CaCl}_{2}$ is a salt because it is composed of the acid-forming element $\mathrm{Cl}$ and the base-forming element $\mathrm{Ca} . \mathrm{HCl}$ is an acid because it is composed of hydrogen and the acid-forming element $\mathrm{Cl}$ and the $\mathrm{H}$ can be replaced by a metal. Acids and bases do not exist as such to any appreciable extent in nature. Salts are neutral compounds and the materials most extensively found. In the table, Section I5, the characteristic properties of some of the elements, as acid- or base-forming, are given. A few elements, as will be discussed later, have both acid and basic characteristics.

77. Radicals. - A radical is a group of elements which enters into chemical combination like a single element. When three elements combine to form a compound the combination is made in the following way: Two of the elements first form a radical, and then this radical combines with the third element. Every radical has its own valence, which is independent of that of its separate atoms. A radical can exist only in chemical combination; it cannot be separated. Its individuality as a radical exists only when in combination. The elements which unite to form a radical do not do so according to the law of valence. Example: When $\mathrm{H}, \mathrm{S}$, and $\mathrm{O}$ combine, the $\mathrm{S}$ and $\mathrm{O}$ first form a radical, $\mathrm{SO}_{4}$, which has a valence of 2. Two atoms of $\mathrm{H}$ combine with one $\mathrm{SO}_{4}$ radical and form $\mathrm{H}_{2} \mathrm{SO}_{4}$. $\mathrm{NH}_{4}$ is the ammonium radical, with a value of $\mathrm{I}$, and deports itself as a metal, forming ammonium salts with acid radicals as $\left(\mathrm{NH}_{4}\right)_{2} \mathrm{SO}_{4}$. There are only a few of the more common radicals which require special study at this 
stage of the work. Some of the more common radicals are :

$\begin{array}{lcll}\begin{array}{l}\text { Radi- } \\ \text { cal. }\end{array} & \text { Valence. } & \begin{array}{c}\text { Compounds formed } \\ \text { with } \mathrm{H} .\end{array} & \begin{array}{c}\text { Compounds formed } \\ \text { with metals. }\end{array} \\ \mathrm{CO}_{3} & 2 & \text { Carbonic acid } & \text { Carbonates } \\ \mathrm{ClO}_{3} & \text { I } & \text { Chloric acid } & \text { Chlorates } \\ \mathrm{NO}_{3} & \text { I } & \text { Nitric acid } & \text { Nitrates } \\ \mathrm{PO}_{4} & 3 & \text { Phosphoric acid } & \text { Phosphates } \\ \mathrm{OH} & \text { I } & \text { Water } & \text { Hydroxids } \\ \mathrm{SiO}_{3} & 2 & \text { Silicic acid } & \text { Silicates } \\ \mathrm{NO}_{2} & \text { I } & \text { Nitrous acid } & \text { Nitrites } \\ \mathrm{SO}_{3} & 2 & \text { Sulfurous acid } & \text { Sulfites } \\ \mathrm{SO}_{4} & 2 & \text { Sulfuric acid } & \text { Sulfates }\end{array}$

78. Naming of Acids. - Acids are named according to the characteristic acid element or radical present, as sulfuric acid, $\mathrm{H}_{2} \mathrm{SO}_{4}$, in which $\mathrm{S}$ is the characteristic acid element. The most common acids have the ending $i c$. Some acids have an ous ending, as $\mathrm{H}_{2} \mathrm{SO}_{3}$, sulfurous acid. The acid which has the smaller amount of oxygen has the ending ous, while the acid with the larger amount of oxygen has the ending $i c$.

Name the following acids: $\mathrm{HNO}_{3}, \mathrm{HNO}_{2}, \mathrm{H}_{2} \mathrm{SO}_{4}$, $\mathrm{H}_{2} \mathrm{SO}_{3}, \mathrm{H}_{3} \mathrm{PO}_{4}, \mathrm{H}_{3} \mathrm{PO}_{3}, \mathrm{H}_{3} \mathrm{AsO}_{4}, \mathrm{H}_{3} \mathrm{AsO}_{3}$.

79. Naming of Bases. - Bases are named according to the characteristic base element which they contain. All bases are called hydroxids, as calcium hydroxid, $\mathrm{Ca}(\mathrm{OH})_{2}$, and potassium hydroxid, $\mathrm{KOH}$.

The rule in regard to the endings ic and ous applies in the case of bases as well as in that of acids; that is, when an element forms two hydroxids, the ending $i c$ is applied to the one with the larger amount of hydroxyl, and the ending ous to the one with the smaller amount.

Name the following bases: $\mathrm{Mg}(\mathrm{OH})_{2}, \mathrm{NH}_{4} \mathrm{OH}, \mathrm{NaOH}$, $\mathrm{Fe}(\mathrm{OH})_{2}, \mathrm{Fe}(\mathrm{OH})_{3}, \mathrm{Al}(\mathrm{OH})_{3}, \mathrm{CuOH}, \mathrm{Cu}(\mathrm{OH})_{2}$. 
8o. Naming of Salts. - Salts are named according to the acid and base elements which they contain, as $\mathrm{K}_{2} \mathrm{SO}_{4}$, potassium sulfate, composed of potassium, $\mathrm{K}$, and the sulfate radical, $\mathrm{SO}_{4}$. Most salts have an ending ate. A few have an ending ite. The salts derived from the acids with the $i c$ ending always have the ate ending, as sulfuric acid, which produces sulfates, phosphoric acid, phosphates, and nitric acid, nitrates. The acids ending with ous produce salts which end in ite, as nitrous acid produces nitrites, and sulfurous acid, sulfites. Salts that are composed of only two elements always have an ending of $i d$, as sodium chlorid, $\mathrm{NaCl}$, and sodium sulfid, $\mathrm{Na}_{2} \mathrm{~S}$.

8I. Double Salts. - A double salt is one that is composed of two base elements in combination with one acid radical, as $\mathrm{NaKSO}_{4}$, sodium potassium sulfate. Double salts are formed from acids which contain two replaceable hydrogen atoms, as $\mathrm{H}_{2} \mathrm{SO}_{4}$, by replacing one of the $\mathrm{H}$ atoms with one base element and the remaining $\mathrm{H}$ atom with another base element. This is represented graphically as follows:

$$
\left.\left.\mathrm{H}_{2} \mathrm{SO}_{4}={ }_{\mathrm{H}}^{\mathrm{H}}\right\rangle \mathrm{SO}_{4}={ }_{\mathrm{K}}^{\mathrm{Na}}\right\rangle \mathrm{SO}_{4} \text {. }
$$

82. Acid Salts. - An acid salt is one in which only a part of the $\mathrm{H}$ of the acid has been replaced. An acid salt always contains $\mathrm{H}$, a metal, and a radical. $\mathrm{HNaSO}_{4}$ is acid sodium sulfate, as only one $\mathrm{H}$ atom has been replaced with $\mathrm{Na}$. A normal salt contains no replaceable $\mathrm{H}$.

83. Basicity of Acids. - Acids with one replaceable $\mathrm{H}$ atom are called monobasic acids, as $\mathrm{HCl}$ and $\mathrm{HNO}_{3}$. Acids with two replaceable $\mathrm{H}$ atoms are dibasic, as $\mathrm{H}_{2} \mathrm{SO}_{4}$, 
$\mathrm{H}_{2} \mathrm{SiO}_{3}$, and $\mathrm{H}_{2} \mathrm{CO}_{3}$. When an acid contains three replaceable $\mathrm{H}$ atoms, it is tribasic, as $\mathrm{H}_{3} \mathrm{PO}_{4}$.

84. Two Series of Salts. - When a base element has more than one valence, it forms two series of salts. For example, $\mathrm{Fe}$ has a valence of 2 and 3. The first series of salts is known by the ending ous. The second series has an $i c$ ending. The one ending means that the compound is formed from the lower valence of the element, as $\mathrm{FeCl}_{2}$, ferrous chlorid, while $\mathrm{FeCl}_{3}$ is ferric chlorid. There are two series of copper salts ; $\mathrm{CuCl}$ is called cuprous chlorid, and $\mathrm{CuCl}_{2}$, cupric chlorid.

Name the following salts: $\mathrm{FeCl}_{2}, \mathrm{FeCl}_{3}, \mathrm{FeSO}_{4}, \mathrm{Fe}_{2}\left(\mathrm{SO}_{4}\right)_{3}$, $\mathrm{Fe}\left(\mathrm{NO}_{3}\right)_{2}, \mathrm{Fe}\left(\mathrm{NO}_{3}\right)_{3}, \mathrm{Fe}(\mathrm{OH})_{2}$, $\mathrm{Fe}(\mathrm{OH})_{3}, \mathrm{HgCl}, \mathrm{HgCl}_{2}, \mathrm{SmCl}_{2}$, $\mathrm{SnCl}_{4}, \mathrm{MnCl}_{4}, \mathrm{MnCl}_{2}$.

Experiment io. - Neutralization and preparation of salts. Obtain two burettes for these experiments. Measure out $5 \mathrm{cc}$. of concentrated $\mathrm{HCl}$ and $95 \mathrm{cc}$. of water; after mixing, fill one of the burettes with this diluted $\mathrm{HCl}$ (Fig. 38). Use your funnel for filling the burette, and then carefully wash the funnel. Prepare

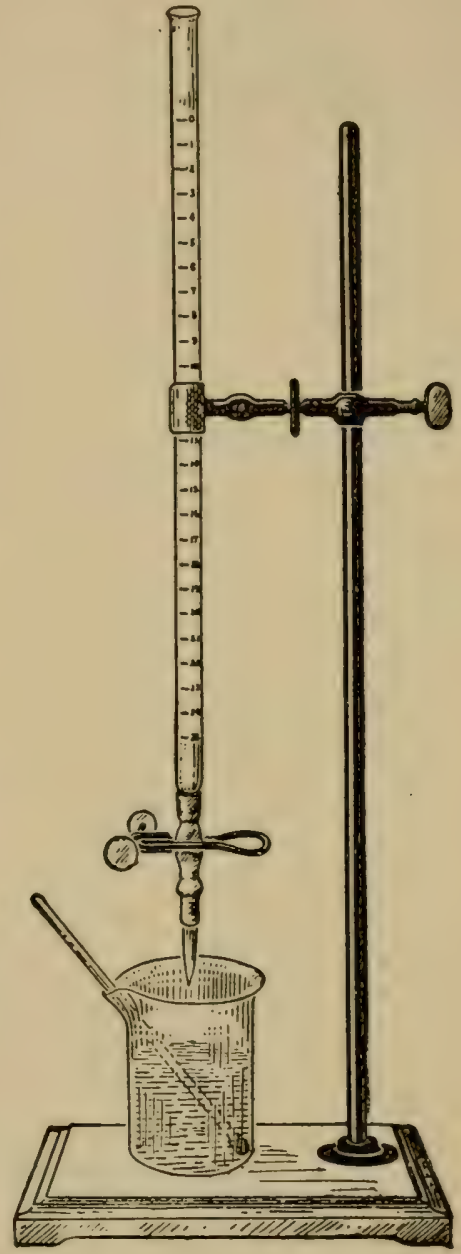

Fig. 38.-Burette. a dilute solution of $\mathrm{NH}_{4} \mathrm{OH}$, using $90 \mathrm{cc}$. of water and Io cc. of the shelf $\mathrm{NH}_{4} \mathrm{OH}$. After mixing, fill the second burette with this preparation of diluted $\mathrm{NH}_{4} \mathrm{OH}$. Before using the solution in the burette, 
it should be lowered to the zero point by carefully opening the pinchcock. Always allow the tip of the burette to be filled with the solution before beginning the experiment.

Into a small beaker, measure from the burette exactly $20 \mathrm{cc}$. $\mathrm{NH}_{4} \mathrm{OH}$, with Io or I 2 drops of cochineal solution, which is changed to a deep purplish color by the alkali; then slowly add $\mathrm{HCl}$ from the other burette, constantly stirring the solution in the beaker until a decided change in color is observed. When all of the $\mathrm{NH}_{4} \mathrm{OH}$ has been neutralized, the solution has a yellowish red color. Note the number of cubic centimeters of $\mathrm{HCl}$ used for neutralizing the $20 \mathrm{cc}$. of $\mathrm{NH}_{4} \mathrm{OH}$ solution. Add a drop or two from the $\mathrm{NH}_{4} \mathrm{OH}$ burette and note if there is a change of color. When the solution is neutralized, one or two drops of $\mathrm{HCl}$ or $\mathrm{NH}_{4} \mathrm{OH}$ should give a decided change of color. If too much acid has been used, add a measured amount from the $\mathrm{NH}_{4} \mathrm{OH}$ burette until the solution is neutralized. Finally note the total quantity of $\mathrm{HCl}$ and $\mathrm{NH}_{4} \mathrm{OH}$ used. Repeat this experiment, using $20 \mathrm{cc}$. of the $\mathrm{HCl}$ solution.

Questions. - (I) What was formed when the $\mathrm{HCl}$ neutralized the $\mathrm{NH}_{4} \mathrm{OH}$ solution? (2) Write the reaction. (3) What would be the result if the neutralized solutions were evaporated to dryness? (4) Calculate the amount of $\mathrm{HCl}$ required to neutralize I cc. of $\mathrm{NH}_{4} \mathrm{OH}$.

Experiment II. - Neutralization. Repeat Experiment Io, using dilute $\mathrm{H}_{2} \mathrm{SO}_{4}$ and $\mathrm{NaOH}$ solutions that have been prepared for this experiment. After completing the experiment, clean the.burettes thoroughly.

Questions. - (I) What was formed when $\mathrm{H}_{2} \mathrm{SO}_{4}$ neutralized $\mathrm{NaOH}$ ? (2) Write the chemical reaction. (3) What was formed as the products of this reaction? (4) How can the salt product be obtained? (5) In writing the reaction, why do we use $2 \mathrm{NaOH}$ instead of $\mathrm{NaOH}$ ? (6) How does the product of Experiment ro differ from the product of Experiment II? (7) What other acids could be used for neutralizing $\mathrm{NaOH}$ and $\mathrm{NH}_{4} \mathrm{OH}$ ? (8) What other bases could be used for neutralizing $\mathrm{HCl}$ and $\mathrm{H}_{2} \mathrm{SO}_{4}$ ? (9) What is an acid? (IO) What is a base? (II) What is a salt? (I 2) Which do we find most abundantly in nature, acids, bases, or salts? Why?

Experiment 12. - Preparation of a salt. Put ro cc. dilute $\mathrm{HCl}$ and Io cc. water into an evaporator. Measure out io cc. of $\mathrm{NaOH}$ into a beaker and add $50 \mathrm{cc}$. water. Add this diluted $\mathrm{NaOH}$ to the 
evaporator a little at a time until the solution is neutral to litmus paper. Do not dip the paper into the solution, but transfer a drop by means of a glass rod from the evaporator to the paper. In case too much $\mathrm{NaOH}$ has been used, add a drop or two of the acid. Bases or alkalies turn red litmus paper bluc, while acids turn blue litmus paper red. When the solution is neutral, it has no perceptible action upon litmus paper. Place the evaporating dish upon the sand bath, and apply heat until the solution is evaporated to dryness. Carefully regulate the flame so as to avoid excessive heating. This will

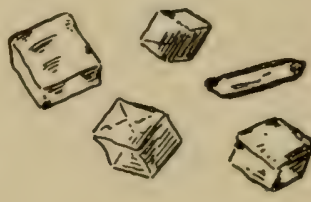

FIG. 39. - Sodium chlorid crystals (common salt). prevent spattering when the solution becomes concentrated.

Qucstions. - (I) What is left in the evaporator? (2) From what was it produced? (3) Write the chemical reaction. (4) Taste some of the material in the evaporating dish. How is it possible for this material to be formed from two such unlike compounds as $\mathrm{HCl}$ and $\mathrm{NaOH}$ ? (5) What is neutralization? (6) Are definite amounts by weight of $\mathrm{HCl}$ and $\mathrm{NaOH}$ required for neutralization? (7) How many molecules of $\mathrm{HCl}$ are required to neutralize one of $\mathrm{NaOH}$ ? (8) How much does a molecule of $\mathrm{HCl}$ weigh? (9) $\mathrm{Of} \mathrm{NaOH}$ ? (Io) How many parts by weight of each must be taken for neutralization? (II) How does this illustrate the law of definite proportion? 


\section{CHAPTER XI}

\section{Hydroclhloric Acid, Chlorin, and Chlorids}

85. Occurrence. - The element chlorin is never found in a free state in nature, but is always in combination with other elements, as with sodium, forming sodium chlorid. With hydrogen, chlorin forms hydrochloric acid.

86. Preparation. - Hydrochloric acid is produced by the action of $\mathrm{H}_{2} \mathrm{SO}$ on $\mathrm{NaCl}$, the reaction being $2 \mathrm{NaCl}+$ $\mathrm{H}_{2} \mathrm{SO}_{4}=\mathrm{Na}_{2} \mathrm{SO}_{4}+2 \mathrm{HCl}$. Heat is applied, and the hydrochloric acid gas is expelled and collected in water. In the preparation of hydrochloric acid, the $\mathrm{Cl}$ part of the compound is supplied by the $\mathrm{NaCl}$, while the sulfuric acid furnishes the hydrogen. Hydrochloric acid can also be made by direct union of the elements hydrogen and chlorin. It is prepared in the laboratory in the following way:

Experiment 13. - Preparation of hydrochloric acid. Arrange the apparatus as shown in Fig. 40. A sand bath, containing sand, is placed upon either the tripod or the large ring of the iron ring stand. Tube B connects flask A with Woulff bottle C, which contains $100 \mathrm{cc}$. of water. The tube is made from a piece of glass tubing 22 to 24 inches long, with one right-angled bend about 3 inches from the end, and another, parallel and about 6 inches from the first bend. This tube is connected with both flask $\mathrm{A}$ and the Woulff bottle by means of tight-fitting corks. Tube B passes into the bottle, but not below the surface of the liquid. Through a tightfitting cork in the middle neck of Woulf bottle $\mathrm{C}$ passes a safety tube so adjusted that it dips just below the surface of the water in 
C. This safety tube is a straight piece of glass tubing, 9 or to inches long. Woulff bottle $\mathrm{C}$ is connected with a second Woulff bottle by means of a bent tube which passes below the water in the second bottle, but is above the water in the first bottle. The apparatus, as constructed, allows the gas which is generated in flask $\mathrm{A}$ to pass through into $\mathrm{C}$ and saturate the water. Some of the acid passes over into the second Woulff bottle. Since the delivery tubes in $\mathrm{C}$ do not pass below the surface of the liquid, and the pressure is equalized, no liquid can be drawn back into flask A.

Place I5 grams sodium chlorid $(\mathrm{NaCl}$, common salt) and $30 \mathrm{cc}$. concentrated $\mathrm{H}_{2} \mathrm{SO}_{4}$ in flask A. Apply heat to the flask, and after ten minutes remove the

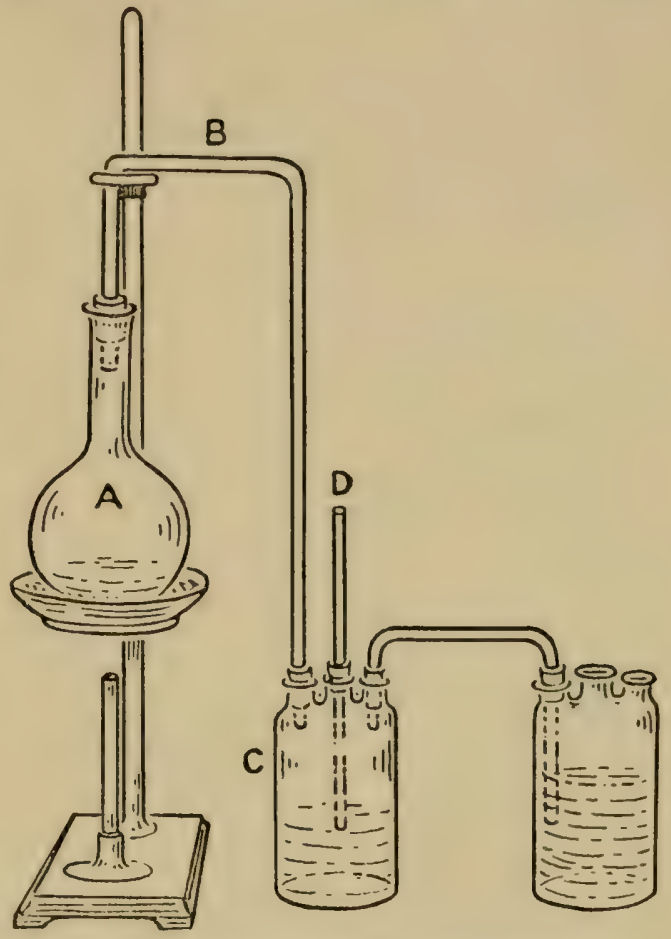

FIG. 40. - Preparation of hydrochloric acid. burner and test the liquid in both Woulff bottles with litmus paper. Then make the following tests:

(I) Disconnect the delivery tube and test the escaping gas with wet litmus paper. (2) Collect a little of the gas in a test tube, and test it with a burning splinter. (3) Put 2 or $3 \mathrm{cc}$. of silver nitrate $\left(\mathrm{AgNO}_{3}\right)$ into a test tube and then a like amount of $\mathrm{HCl}$ from the first Woulff bottle. Observe the result. (4) Leave the test tube and contents exposed to strong sunlight for a few minutes. (5) Put a small piece of zinc into a test tube and cover it with some of the acid from the first Woulff bottle. Observe the result.

Questions. - (I) What chemical reaction took place when $\mathrm{H}_{2} \mathrm{SO}_{4}$ and $\mathrm{NaCl}$ were brought together? (2) Is $\mathrm{HCl}$ a solid, liquid, or 
gas? Why? (3) Color? (4) Is it soluble in water? Why? (5) What was formed when the $\mathrm{HCl}$ was added to the test tube containing $\mathrm{AgNO}_{3}$ ? Give the reaction. (6) Is $\mathrm{HCl}$ combustible or a supporter of combustion? (7) What is a chlorid? (8) What effect would $\mathrm{HCl}$ gas have upon plants?

87. Properties. - Hydrochloric acid is a colorless gas, soluble in water. When exposed to the air, it combines with the moisture. The concentrated acid used in the laboratory is a solution of about 40 per cent $\mathrm{HCl}$. Chemically, $\mathrm{HCl}$ is an active acid, and is neither combustible nor a supporter of combustion. When it neutralizes bases, chlorids are always formed. Hydrochloric acid is distinguished from other acids by its reaction with silver nitrate, a white precipitate of silver chlorid being produced which is soluble in ammonia and is blackened in the sunlight. Hydrochloric acid is used extensively in the laboratory in the preparation of various compounds, and for the production of chlorin.

88. Preparation of Chlorin.-Chlorin is made by the action of an oxidizing agent, as manganese dioxid, upon hydrochloric acid, manganese chlorid, water, and chlorin gas being formed as products. The reaction is $\mathrm{MnO}_{2}+4 \mathrm{HCl}=\mathrm{MnCl}_{2}+2 \mathrm{H}_{2} \mathrm{O}+2 \mathrm{Cl}$. In this reaction the valence of manganese is changed from 4 to 2 , and as a result free chlorin gas is liberated. The method of preparation in the laboratory is as follows:

Experiment 14. - Preparation of chlorin. It is preferable to set up the apparatus for generating chlorin under one of the hoods. Arrange the apparatus as shown in Fig. 4I. Place ro grams of $\mathrm{MnO}_{2}$ and $\mathrm{I}_{5}$ or $20 \mathrm{cc}$. of $\mathrm{HCl}$ in flask $\mathrm{A}$. By means of delivery tube $\mathrm{B}$, and a tight-fitting cork, the $\mathrm{Cl}$ gas, when generated, passes into the large cylinder, in which has been placed a green leaf, a piece of colored cloth, and paper upon which is some writing. The 
delivery tube passes through the hole in the ground-glass plate, without any cork. To generate the chlorin, apply gentle heat to the flask, and as soon as the cylinder is nearly filled with the $\mathrm{Cl}$ gas, which can be observed by its color, remove the flame so as to prevent any of the gas from escaping into the room. Do not inhale any of the fumes, as they are irritating to the throat and lungs. Make the following tests:

(I) Observe the effect which the chlorin gas has upon the cloth, paper, and leaf. (2) To the cylinder, add 5 cc. water containing two or three drops of indigo solution. Observe the result.

Questions. - (I) Give the physical properties of $\mathrm{Cl}$ gas, odor, weight, and color. (2) What caused liberation of the $\mathrm{Cl}$ gas from the $\mathrm{HCl}$ ? (3) Write the reaction. (4) What are some of the chemical properties of chlorin as observed from the changes which have taken place in the materials in the cylinder? (5) What is a chlorid?

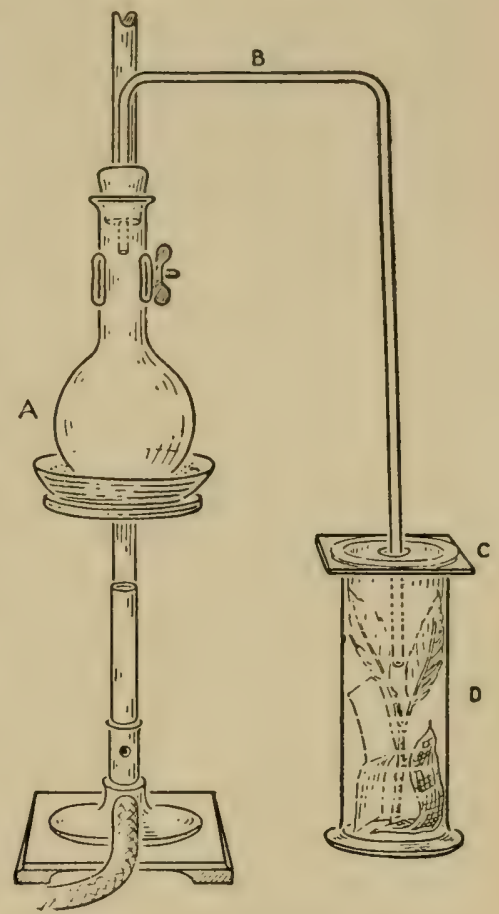

FIG. 4I. - Preparation of chlorin. (6) Name five compounds containing chlorin. (7) Why is $\mathrm{Cl}$ gas employed as a disinfectant? Explain its action as a disinfectant. (8) What is bleaching powder, and how is it used as a disinfectant? (9) $\mathrm{NaCl}$ is necessary for animal life; $\mathrm{Cl}$ is one of its elements and $\mathrm{Cl}$ is destructive to animal life; why can you not conclude that $\mathrm{NaCl}$ containing $\mathrm{Cl}$ is destructive to animal life?

89. Properties. - Physically considered, chlorin is a heavy, greenish yellow gas, with a penetrating, suffocating odor. Chlorin gas is poisonous. Chemically, it is an active element and has strong affinity for nearly all other elements. It readily combines with metals, form- 
ing chlorids, and light and heat are evolved during the reaction. Chlorin is an active bleaching reagent, as it changes the composition of vegetable dyes, thus destroying their color. Bleaching powder is a mixture of calcium hypochlorite and calcium chlorid, and when used, chlorin is liberated. Chlorin is also a disinfectant and a germicide, for it is destructive to life, particularly to the lower forms. It is used extensively for both bleaching and disinfecting purposes. Chlorin takes no part directly in life processes, although its compounds, particularly sodium chlorid, are necessary as mineral food for animals.

90. The Chlorin Group of Elements. - Fluorin, chlorin, bromin, and iodin constitute a natural group of elements, known as the chlorin family. These elements are all closely related. They form similar acids with $\mathrm{H}$, and similar salts with the metals. Some of the most important relationships and points of difference between members of the chlorin family will be observed in the following table:

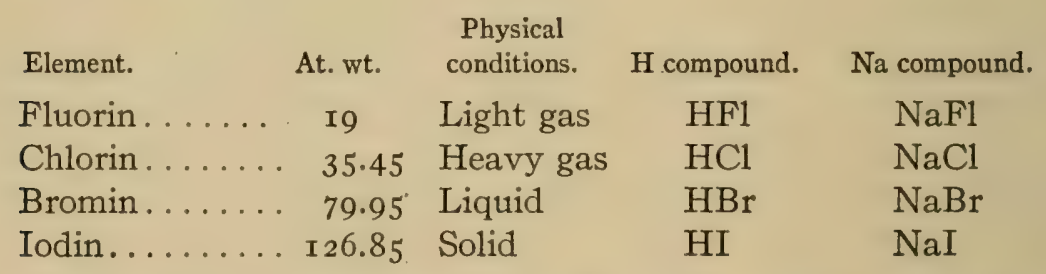

9I. Chlorids. - Combined with the metals, chlorin forms chlorids. As a class, the chlorids are quite stable compounds, inasmuch as chlorin has strong affinity for nearly all of the metals. The properties of the different chlorids vary with the metal with which the chlorin is combined. The chlorids do not take such a direct part in plant as in animal nutrition. When present in either soil or water in any appreciable amount, the soil is sterile 


\section{HYDROCHLORIC ACID, CHLORIN, AND CHLORIDS 8I}

and the water is not suitable for either drinking or irrigation purposes. Sodium chlorid is found in nature most abundantly of any of the chlorids.

Problem I. - How much $\mathrm{H}_{2} \mathrm{SO}_{4}$ is required to combine with 2000 pounds $\mathrm{NaCl}$ in making $\mathrm{HCl}$ ?

Problem 2. - How much $\mathrm{HCl}$ can be made from 2000 pounds of $\mathrm{NaCl}$ ?

Problem 3. - How much $\mathrm{Na}_{2} \mathrm{SO}_{4}$ is produced when 2000 pounds $\mathrm{NaCl}$ are used for making $\mathrm{HCl}$ ? 


\section{CHAPTER XII}

\section{Nitric Acid ANd Nitrogen Compounds}

92. Occurrence. - Nitric acid does not occur in nature in a free state, but as nitrates or salts of nitric acid. Since all normal nitrates are soluble in water, they are never present in great abundance in soils. In regions of scant rainfall, where climatic conditions have been favorable for the formation of nitrates, deposits of nitrate of soda are occasionally found. The nitrifying organisms of the soil, when supplied with food, moisture, suitable temperature, and other requisite conditions, produce nitrates which are utilized as food by plants. The process of nitrification which takes place in the soil results in changing the inert and unavailable nitrogen to a soluble and available condition.

93. Preparation. - The same principle is applied in the preparation of nitric acid as in the preparation of hydrochloric acid. Nitric acid is produced by the action of $\mathrm{H}_{2} \mathrm{SO}_{4}$ upon a salt; when a chlorid is used, hydrochloric acid results, and when a nitrate is used, nitric acid is the product. The reaction with sodium nitrate is : $2 \mathrm{NaNO}_{3}$ $+\mathrm{H}_{2} \mathrm{SO}_{4}=\mathrm{Na}_{2} \mathrm{SO}_{4}+2 \mathrm{HNO}_{3}$.

Experiment 15. - Preparation of nitric acid. Special care should be exercised by the student in the preparation of nitric acid, because if any is spilled on the hands, it causes painful burns and wounds that are difficult to heal. Provided the student is careful and follows the directions given, there is no danger. Arrange the apparatus as shown in Fig. 42. The delivery tube used in the preparation of $\mathrm{NH}_{3}$ may be used for this experiment. A cork stopper should be used. If necessary, a brick or block may be placed under 
the cylinder. The delivery tube should pass into and nearly to the bottom of a test tube which is immersed in cold water in the cylinder. Put $\mathrm{I}_{5} \mathrm{cc}$. concentrated sulfuric acid $\left(\mathrm{H}_{2} \mathrm{SO}_{4}\right)$ and Io grams of either sodium nitrate $\left(\mathrm{NaNO}_{3}\right)$ or potassium nitrate $\left(\mathrm{KNO}_{3}\right)$ into the flask and apply heat until about 4 or $5 \mathrm{cc}$. of $\mathrm{HNO}_{3}$ are distilled and collected in the test tube. Do not remove the flame unless the end of the delivery tube is above the liquid in the test tube, otherwise the liquid will be drawn back into the flask.

Make the following tests with $\mathrm{HNO}_{3}$. (I) Remove a drop of the acid by means of a glass tube, and apply it to a piece of either woolen cloth or silk. Observe the result. (2) Place a few drops of indigo solution in a test tube containing 5 cc. of water, then add about 2 cc. of $\mathrm{HNO}_{3}$. Observe the result. (3) Place a small piece of copper in the test tube containing the remainder of the acid. Observe the result. If no reaction takes place, add a little water. Do not pour the contents of the flask into the sink or waste jars until cool, otherwise the hot acid

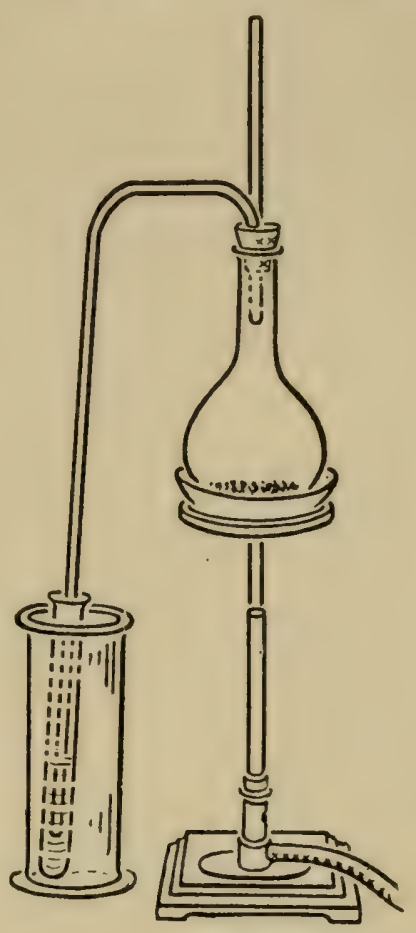

FIG. 42. - Preparation of nitric acid. coming in contact with cold water may cause spattering of the acid.

Questions. - (I) Why was $\mathrm{H}_{2} \mathrm{SO}_{4}$ used in the preparation of this compound? (2) What material supplied the $\mathrm{NO}_{3}$ radical ? (3) Write the reaction which took place in the flask after heat was applied. (4) Is $\mathrm{HNO}_{3}$ a solid, liquid, or gas? What is the proof? (5) What caused the red fumes to be given off when the copper was added to the test tube? (6) Does $\mathrm{HNO}_{3}$ give off $\mathrm{H}$ when a metal is added to it? Why? (7) Why did the $\mathrm{HNO}_{3}$ bleach the indigo solution? (8) Why is ordinary $\mathrm{HNO}_{3}$ colored yellow? (9) $\mathrm{Is}^{\mathrm{HNO}_{3}}$ an active or inert chemical? (го) What is a nitrate?

94. Properties. - When pure, nitric acid is a colorless liquid; the commercial acid has a yellow color because 
of the presence of oxids of nitrogen. Nitric acid is an active oxidizing reagent, and when metals, as copper and iron, are dissolved in it, brown fumes of $\mathrm{NO}_{2}$ are given off because the hydrogen, as soon as liberated, is oxidized by the excess of acid, and $\mathrm{NO}_{2}$ is formed. $\mathrm{H}+\mathrm{HNO}_{3}=$ $\mathrm{H}_{2} \mathrm{O}+\mathrm{NO}_{2}$. Nitric acid imparts a permanent yellow color to wool, silk, and all albuminous matter.

95. Importance. - In the laboratory nitric acid is used as an oxidizing agent. Commercially it is employed in the dyeing of cloth, although it has a tendency to weaken the wool fibers. Salts of nitric acid are important because they are of much value as plant food, and particularly in the manufacture of commercial fertilizer, where they supply nitrogen. Potassium nitrate is used in the manufacture of gunpowder. Nitrates are of great importance in agriculture.

\section{Ammonia}

96. Occurrence. - Ammonium compounds are present in small amounts in the air, in rain water, and in the soil, and are produced from decaying nitrogenous organic matter. The chief source of the ammonia which serves as the basis for the preparation of ammonium salts is the ammonia water obtained in the process of purifying illuminating gas made from soft coal. The nitrogen compounds of the coal form ammonia gas, $\mathrm{NH}_{3}$, during the destructive distillation process.

97. Preparation. - In the laboratory, ammonia is usually prepared from ammonium chlorid by treatment with a strong base, as $\mathrm{Ca}(\mathrm{OH})_{2}$. The reaction is :

$2 \mathrm{NH}_{4} \mathrm{Cl}+\mathrm{Ca}(\mathrm{OH})_{2}=\mathrm{CaCl}_{2}+{ }_{2} \mathrm{NH}_{4} \mathrm{OH}$.

Experiment I6. - Preparation of ammonia. Arrange apparatus as directed for the preparation of $\mathrm{HCl}$ (see Fig. 40). Into flask A, 
place Io grams each of dry ammonium chlorid, $\mathrm{NH}_{4} \mathrm{Cl}$, and porvdered calcium hydroxid, $\mathrm{Ca}(\mathrm{OH})_{2}$, and $25 \mathrm{cc}$. water. Barium hydroxid, $\mathrm{Ba}(\mathrm{OH})_{2}$, may be used in place of the $\mathrm{Ca}(\mathrm{OH})_{2}$. When properly connected, apply heat to the sand bath from eight to twelve minutes.

Tests for Ammonia. - (I) Test the gas with wet litmus paper. Note the result. (2) Test the water in both Woulff bottles with litmus paper, and note the result. (3) In an evaporator place $5 \mathrm{cc}$. $\mathrm{HCl}$ and ro cc. water. Disconnect the delivery tube from Woulff bottle $\mathrm{C}$, and pass some of the fumes of the escaping gas over the acid in the evaporator. Avoid inhaling any of the gas. (4) Collect some of the gas in a test tube and then place the test tube inverted in a cylinder about one third full of water. (5) Add $5 \mathrm{cc}$. of the $\mathrm{NH}_{3}$ solution from either of the Woulff bottles to $5 \mathrm{cc}$. of a solution of alum. Note the result.

Questions. - (I) What material supplied the $\mathrm{NH}_{4}$ part of the $\mathrm{NH}_{4} \mathrm{OH}$ ? (2) What caused the gas to be liberated from these materials? (3) What chemical reaction took place in flask A after the heat was applied? (4) Why was water used in the Woulff bottle? (5) What did the water and the $\mathrm{N}_{3} \mathrm{H}$ gas form? (6) What reaction did the $\mathrm{NH}_{3}$ gas and the $\mathrm{N}_{4} \mathrm{HOH}$ give with the litmus paper? (7) Why was not this gas given off into the room? (8) Why was not $\mathrm{N}_{3} \mathrm{H}$ collected over water, like $\mathrm{H}, \mathrm{N}$, and $\mathrm{O}$ ? (9) What caused the water to rise in the test tube? (Io) Why have you reason to believe that the $\mathrm{N}_{4} \mathrm{HOH}$ caused a chemical reaction when added to the solution of alum?

98. Properties and Uses. - Ammonia is a colorless, non-combustible, pungent gas, which unites with water to form ammonium hydroxid, $\mathrm{NH}_{4} \mathrm{OH}$, a basic compound. It is completely soluble in water, from which it is easily liberated by heat. The gas can be reduced to liquid form by cold and pressure. Liquefied ammonia reverts to a gas upon removal of the pressure, and in so doing, heat is absorbed from surrounding bodies. If this heat is absorbed from water, the temperature of the water is lowered sufficiently to produce ice. This property of liquefied ammonia is taken advantage of for the artificial 
production of ice, and for refrigerating purposes. The transportation of perishable food materials is rendered possible by this method of refrigeration.

In the laboratory, ammonium hydroxid is used extensively as a reagent for neutralizing acid solutions and precipitating insoluble hydroxids. Ammonium salts, except in very small amounts, are destructive to plants, $\left(\mathrm{NH}_{4}\right)_{2} \mathrm{SO}_{4}$ is less injurious than either $\mathrm{NH}_{4} \mathrm{Cl}$ or $\left(\mathrm{NH}_{4}\right)_{2} \mathrm{CO}_{3}$, and may be used as a fertilizer.

Dilute solutions of the ammonium compounds serve as food for plants, supplying them with nitrogen, which is used for producing, within the plant cells, complex nitrogenous compounds, as proteids. Ammonium compounds supply only one form of nitrogenous plant food. Because of its being a volatile alkali, ammonia is valuable as a reagent for softening water.

99. Oxids of Nitrogen. - Nitrogen forms five compounds with oxygen:

$\mathrm{N}_{2} \mathrm{O}$ nitrogen monoxid or nitrous oxid.

$\mathrm{N}_{2} \mathrm{O}_{2}$ nitrogen dioxid or nitric oxid.

$\mathrm{N}_{2} \mathrm{O}_{3}$ nitrogen trioxid or nitrous anhydrid.

$\mathrm{N}_{2} \mathrm{O}_{4}$ nitrogen tetroxid.

$\mathrm{N}_{2} \mathrm{O}_{5}$ nitrogen pentoxid or nitric anhydrid.

While the oxids of nitrogen do not serve either as plant or animal food, they are nevertheless important, and a study of them is necessary in order to understand the subject of nitrogen.

Ioo. Anhydrids. - An anhydrid is an oxid of an acid element, or the product which is left after the elements which form water are abstracted from an acid. $\mathrm{SO}_{3}$ is sulfuric anhydrid, and is formed by abstracting $\mathrm{H}_{2} \mathrm{O}$ from $\mathrm{H}_{2} \mathrm{SO}_{4}$. $\quad \mathrm{H}_{2} \mathrm{SO}_{4}=\mathrm{H}_{2} \mathrm{O}+\mathrm{SO}_{3}$. $\mathrm{N}_{2} \mathrm{O}_{5}$ is nitric anhydrid, derived from two molecules of $\mathrm{HNO}_{3} . \quad 2 \mathrm{HNO}_{3}=$ $\mathrm{H}_{2} \mathrm{O}+\mathrm{N}_{2} \mathrm{O}_{5}$. 
Derive and name the anhydrids of the following acids: $2 \mathrm{H}_{3} \mathrm{PO}_{4}, \mathrm{H}_{2} \mathrm{CO}_{3}, \mathrm{H}_{2} \mathrm{SiO}_{3}, 2 \mathrm{HNO}_{2}, \mathrm{H}_{2} \mathrm{SO}_{3}$.

I0I. Law of Multiple Proportion. - When nitrogen and oxygen combine, the number of parts of nitrogen in the various compounds is constant; namely, 28 parts by weight in each compound. The number of parts of $\mathrm{O}$ is always a multiple of the first combination, $\mathrm{N}_{2} \mathrm{O}$; that is, it is either $2,3,4$, or 5 times as much in the other compounds as in the first. This is an example of the law of multiple proportion where two elements combine in more than one way. It is to be noted that the amount by weight of one of the elements remains constant in all the combinations, while the amount of the other element is always a multiple of the first combination.

The law of definite proportion holds true for each individual compound, while the law of multiple proportion applies to the entire series, and is a broader application of the law of definite proportion.

I02. Utilization of Atmospheric Nitrogen. - When a current of nitrogen obtained from the air is passed through a mixture of lime and coal heated in an electric furnace, a chemical union of calcium, carbon, and nitrogen is effected, calcium cyanamid, $\mathrm{CaCN}_{2}$, being formed. This compound is used as a fertilizer, and supplies the element nitrogen to plants. By this process of manufacturing $\mathrm{CaCN}_{2}$, the inactive nitrogen of the air, is combined and made available for the production of crops.

103. Importance of the Nitrogen Compounds. - The compounds of nitrogen, particularly nitrates and ammonium compounds, are of importance in agriculture as they serve as food for plants. They are difficult to retain in soils because of their solubility and the volatility of ammonia. In human and animal foods, the nitrogenous 
compounds are of importance in many ways and hence, in economic agriculture, they receive special consideration.

Problem $I$. - How many pounds of $\mathrm{HNO}_{3}$ can be produced from roo pounds $\mathrm{NaNO}_{3}$ ?

Problem 2. - How much $\mathrm{H}_{2} \mathrm{SO}_{4}$ is required when 100 pounds $\mathrm{HNO}_{3}$ are made?

Problem 3. - How much $\mathrm{NH}_{4} \mathrm{OH}$ can be produced from Io pounds of $\mathrm{NH}_{4} \mathrm{Cl}$ ?

Problem 4. - What per cent of $\mathrm{NH}_{4} \mathrm{OH}$ is $\mathrm{NH}_{3}$ ? 


\section{CHAPTER XIII}

\section{Phosphorus and its Compounds}

104. Occurrence. - Phosphorus is found in nature in combination with oxygen and other elements, forming phosphates, as $\mathrm{Ca}_{3}\left(\mathrm{PO}_{4}\right)_{2}$. It is never found in a free or uncombined state. There is little in soils, but in many rocks and minerals, as apatite or phosphate rock, it is present in large amounts. It is also in the ash of plants, and in animal bodies, particularly as a constituent of bones.

105. Preparation. - It is prepared from bones, which are first freed from organic matter by burning. The bone ash is treated with sulfuric acid, producing acid phosphates, which, when roasted with charcoal, liberate free phosphorus.

I06. Properties. - There are two forms of phosphorus: the yellow and the red. Yellow phosphorus is a solid which ignites at a low temperature. Red phosphorus is an allotropic form of the element produced by heating the yellow variety in a sealed tube. Yellow phosphorus more readily combines with oxygen than does the red, and is kept under water to prevent contact with air.

107. Oxids of Phosphorus. - When phosphorus is burned in a current of oxygen or dry air, phosphorus pentoxid, $\mathrm{P}_{2} \mathrm{O}_{5}$, is obtained. This material is a white flocculent mass which readily dissolves in water, forming metaphosphoric acid. When phosphorus is burned in a limited amount of air, it yields phosphorus trioxid, $\mathrm{P}_{2} \mathrm{O}_{3}$, 
which after long standing dissolves in water, forming phosphorous acid. In fertilizer, soil, and food analysis, the amount of phosphorus is expressed in terms of $\mathrm{P}_{2} \mathrm{O}_{5}$.

I08. Phosphoric Acid and Phosphates.-Ordinary phosphoric acid is produced by the action of $\mathrm{H}_{2} \mathrm{SO}_{4}$ upon bone ash.

$$
3 \mathrm{H}_{2} \mathrm{SO}_{4}+\mathrm{Ca}_{3}\left(\mathrm{PO}_{4}\right)_{2}={ }_{2} \mathrm{H}_{3} \mathrm{PO}_{4}+{ }_{3} \mathrm{CaSO}_{4} \text {. }
$$

Salts of ortho or ordinary phosphoric acid are the most common forms of the acid derivatives. Since this acid contains three replaceable $\mathrm{H}$ atoms, three salts are formed, as: $\mathrm{Na}_{3} \mathrm{PO}_{4}$, normal sodium phosphate; $\mathrm{Na}_{2} \mathrm{HPO}_{4}$, disodium phosphate; ' and $\mathrm{NaH}_{2} \mathrm{PO}_{4}$, monosodium phosphate. The three calcium salts of phosphoric acid are:

$\mathrm{CaH}_{4}\left(\mathrm{PO}_{4}\right)_{2}$, monocalcium phosphate.

$\mathrm{Ca}_{2} \mathrm{H}_{2}\left(\mathrm{PO}_{4}\right)_{2}$, dicalcium phosphate.

$\mathrm{Ca}_{3}\left(\mathrm{PO}_{4}\right)_{2}$, tricalcium phosphate.

In addition to the ordinary phosphoric acid, there are other derivatives, as :

$\mathrm{H}_{3} \mathrm{PO}_{4}=\mathrm{H}_{2} \mathrm{O}+\mathrm{HPO}_{3}$ (metaphosphoric acid).

$2 \mathrm{H}_{3} \mathrm{PO}_{4}=\mathrm{H}_{2} \mathrm{O}+\mathrm{H}_{4} \mathrm{P}_{2} \mathrm{O}_{7}$ (pyrophosphoric acid).

ro9. Phosphate Fertilizers. - In deposits of phosphate rock, the phosphoric acid is mainly in combination with calcium as $\mathrm{Ca}_{3}\left(\mathrm{PO}_{4}\right)_{2}$, and is of little value as plant food until it is treated with $\mathrm{H}_{2} \mathrm{SO}_{4}$ and converted into monocalcium phosphate, which is soluble and available as plant food. $\mathrm{Ca}_{3}\left(\mathrm{PO}_{4}\right)_{2}+2 \mathrm{H}_{2} \mathrm{SO}_{4}=\mathrm{CaH}_{4}\left(\mathrm{PO}_{4}\right)_{2}+$ $2 \mathrm{CaSO}_{4}$. Large amounts of phosphates undergo this treatment in the manufacture of commercial fertilizers.

Experiment 17. - In a beaker on a sand bath, dissolve $\frac{1}{2}$ gram of bone ash in ro cc. dil. $\mathrm{HNO}_{3}+20 \mathrm{cc} . \mathrm{H}_{2} \mathrm{O}$; filter, and to the filtrate, while still warm, add $5 \mathrm{cc}$. ammonium molybdate, and then stir. Observe the precipitate, which is a compound of phosphoric acid, ammonium, and molybdenum. 
Questions. - (I) What was the solvent of the phosphoric acid? (2) Why was the solution boiled and filtered? (3) Describe the color and properties of the precipitate.

Experiment $I 8$. - Dissolve $\frac{1}{2}$ gram of sodium phosphate in ro $\mathrm{cc}$. distilled water, then add ro cc. of a solution containing $\frac{1}{2}$ gram $\mathrm{CaCl}_{2}$. Observe the result. Write the reaction. Repeat this experiment, using $\mathrm{AlCl}_{3}$ or alum in place of $\mathrm{CaCl}_{2}$.

IIo. Compounds of Phosphorus. - Phosphorus forms a large number of compounds, as phosphates, metaphosphates, and pyrophosphates. It also combines with $\mathrm{H}$, $\mathrm{Cl}$, and $\mathrm{I}$. With $\mathrm{H}$ it forms $\mathrm{PH}_{3}$, phosphine. Phosphorus also enters into combination with $\mathrm{C}, \mathrm{H}, \mathrm{N}, \mathrm{O}$, and $\mathrm{S}$, forming complex organic compounds, as nucleo proteids and lecithin. It is an element which has a wide range of combinations.

\section{Importance of Phosphorus and its Compounds.}

The compounds of phosphorus, particularly the phosphates, are important in plant development, being forms of mineral food essential for crop growth. Agriculturally considered, phosphorus is one of the most important of the elements. It is stored in the seeds of grains; and in combination with the elements which form the organic compounds of plants, it takes an important part in animal nutrition. Compounds of phosphorus are used in the manufacture of matches, and as poison for insects. Phosphorus forms a large number of compounds, both with the metals and with the elements which enter into the organic compounds of plant and animal bodies.

Problem I. - How much $\mathrm{P}_{2} \mathrm{O}_{5}$ in a ton of bones, 80 per cent $\mathrm{Ca}_{3}\left(\mathrm{PO}_{4}\right)_{2}$ ?

Problem 2. - How much would the $\mathrm{P}_{2} \mathrm{O}_{5}$ in a ton of $\mathrm{Ca}_{2} \mathrm{H}_{2}\left(\mathrm{PO}_{4}\right)_{2}$ be worth at 5 cents per pound for the $\mathrm{P}_{2} \mathrm{O}_{5}$ ?

$$
\mathrm{Ca}_{2} \mathrm{H}_{2}\left(\mathrm{PO}_{4}\right)_{2}=\mathrm{P}_{2} \mathrm{O}_{5}+{ }_{2} \mathrm{CaO}+\mathrm{H}_{2} \mathrm{O} \text {. }
$$




\section{CHAPTER XIV \\ Sulfur and its Compounds}

II2. Occurrence. - Sulfur is found free, and in combination with other elements; sulfids and sulfates are the compounds which occur most abundantly. Sulfur is also found in small amounts in combination with carbon, hydrogen, oxygen, and nitrogen, forming the organic compounds of plant and animal bodies.

II3. Preparation. - When taken from the mines, sulfur is mixed with impurities, as sand and clay, which are
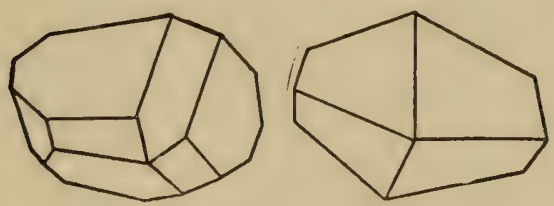

FIG. 43. - Crystals of sulfur. partially removed by heating the sulfur, out of contact with air, much in the same way that charcoal is produced. Crude sulfur is refined by vaporizing and condensing the volatile sulfur upon the surfaces of brick chambers, the product being known as flowers of sulfur. By drawing off the molten sulfur into wooden molds, roll sulfur, or brimstone, is made.

II4. Properties. - Like carbon and a few other elements, sulfur has a number of allotropic forms. It may assume either an amorphous or several crystalline forms. It melts at a low temperature, and when molten sulfur is poured into water, a rubber-like, amorphous mass is obtained. Sulfur combines with oxygen; and with the metals it forms sulfids. 
II5. Uses. - Sulfur is used in the preparation of sulfuric acid, in the production of vulcanized rubber, in the manufacture of matches and gunpowder, and for bleaching and disinfecting purposes. A small amount in the form of sulfates is necessary as plant food.

Experiment 19. - Properties of sulfur. Place I5 grams of sulfur in a test tube and heat slowly until it is a thin, amber-colored liquid. As the heat increases, notice that it becomes darker until black, and so thick and viscid that it cannot be poured from the test tube. Continue to apply heat until slightly lighter in color and again a liquid. Then pour the sulfur into an evaporating dish containing water, and, when cold, examine it and describe its properties. Examine the sulfur product or crystals left in the test tube, and compare with the original sulfur, using a lens for the purpose.

Questions. - ( I) Are the crystals of sulfur formed by fusion like those of the original powdered form? (2) How is it possible for sulfur to assume different physical forms? (3) Is sulfur soluble in water? (4) What is a sulfate? Give the formula for one. (5) What is a sulfite? Give the formula for one. (6) What is a sulfid?

II6. Sulfur Dioxid. - When sulfur is burned either in air or oxygen, $\mathrm{SO}_{2}$, a colorless, suffocating, non-combustible gas is produced. $\mathrm{SO}_{2}$ combines with water, forming $\mathrm{H}_{2} \mathrm{SO}_{3}$, sulfurous acid. Sulfur dioxid is used in bleaching and for disinfecting purposes, as it is alike destructive to organic coloring matter and to germ life.

Experiment 20. - Sulfur dioxid. Fill the deflagration spoon half full of sulfur; ignite, and then lower into a small cylinder containing a piece of wet colored cloth and a piece of wet blue litmus paper. As soon as the sulfur ceases to burn, remove the spoon and cover the cylinder with a glass plate.

Questions. - (I) What reaction does the $\mathrm{SO}_{2}$ give with the litmus paper? (2) What effect did it have upon the cloth? (3) What does the $\mathrm{SO}_{2}$ form with $\mathrm{H}_{2} \mathrm{O}$ ? (4) Is $\mathrm{SO}_{2}$ a heavy or a light gas? (5) Is it a chemically active substance? (6) Why does it act as a bleaching agent? (7) Why is it valuable as a disinfectant? 
II7. Sulfuric Acid. - Sulfuric acid cannot be produced from sulfates, as $\mathrm{HCl}$ and $\mathrm{HNO}_{3}$ are from their salts, because there is no acid or other material that can be used economically for the purpose. $\mathrm{H}_{2} \mathrm{SO}$ is made from its elements by the use of an oxidizing agent. The different steps in its production are:

(I) Burning of sulfur, or roasting of some ore, as pyrites, which contains sulfur. The $\mathrm{S}$ forms with $\mathrm{O}, \mathrm{SO}_{2}$.

(2) Union of $\mathrm{SO}_{2}$ and $\mathrm{H}_{2} \mathrm{O}$, forming sulfurous acid, $\mathrm{H}_{2} \mathrm{SO}_{3}$.

(3) Oxidation of $\mathrm{H}_{2} \mathrm{SO}_{3}$ to form $\mathrm{H}_{2} \mathrm{SO}_{4}$. This is accomplished by the use of $\mathrm{NO}_{2}$ reduced to $\mathrm{NO}$, which in turn is capable of uniting with the oxygen of the air, re-forming $\mathrm{NO}_{2}$. $\quad \mathrm{NO}$ is used as a carrier of $\mathrm{O}$; hence the oxygen of the air is used indirectly for the oxidation of $\mathrm{H}_{2} \mathrm{SO}_{3}$. The different reactions take place simultaneously in lead-lined chambers :

$$
\begin{aligned}
\mathrm{SO}_{2}+\mathrm{H}_{2} \mathrm{O}+\mathrm{NO}_{2} & =\mathrm{H}_{2} \mathrm{SO}_{4}+\mathrm{NO} \\
\mathrm{NO}+\mathrm{O} & =\mathrm{NO}_{2} .
\end{aligned}
$$

Other and more complicated reactions also take place. The crude acid is then concentrated and purified.

Sulfuric acid is extensively used in industrial operations. There is scarcely a chemical product in the preparation of which $\mathrm{H}_{2} \mathrm{SO}_{4}$ is not used either directly or indirectly. $\mathrm{H}_{2} \mathrm{SO}_{4}$ takes an important part in the manufacture of soda, which, in turn, is used for making glass, also in the preparation of commercial fertilizers, and of many food products. The amount of sulfuric acid which a country consumes is a fair index of the extent of its manufacturing industries.

I I8. Properties of $\mathrm{H}_{2} \mathrm{SO}_{4}$ - - When pure, it is a colorless, heavy, oily liquid. It has a strong affinity for water, 
with which it combines with evolution of heat. It will decompose organic materials containing $\mathrm{C}, \mathrm{H}$, and $\mathrm{O}$, liberating the $\mathrm{H}_{2} \mathrm{O}$ as water, with which it combines, while the carbon, which is partially oxidized, separates and blackens the acid. When sugar is acted upon by concentrated sulfuric acid, this change takes place. $\mathrm{H}_{2} \mathrm{SO}_{4}$ is used in the laboratory for drying gases, for drying the air in desiccators, and for oxidizing purposes, as in the determination of organic nitrogen in food materials. It is one of the most useful and most extensively used of any of the reagents in the laboratory.

Experiment 2I. - Make the following tests with some of the sulfuric acid from the reagent bottles: (I) Put 2 or 3 cc. concentrated $\mathrm{H}_{2} \mathrm{SO}_{4}$ into a test tube; thrust a splinter of wood into it and leave it there for a few minutes. Then remove the splinter from the test tube. Wash off the acid and examine the splinter. (2) Place in an evaporating dish $5 \mathrm{cc}$. water and $\mathrm{I}_{5} \mathrm{cc} . \mathrm{H}_{2} \mathrm{SO}_{4}$. Stir it with a small test tube containing I or $2 \mathrm{cc}$. $\mathrm{NH}_{4} \mathrm{OH}$. Observe that the heat generated by the action of the $\mathrm{H}_{2} \mathrm{SO}_{4}$ and water volatilizes some of the $\mathrm{NH}_{3}$. (3) Put Io cc. of water and I cc. dilute $\mathrm{H}_{2} \mathrm{SO}_{4}$ into a test tube. Then add 2 or $3 \mathrm{cc}$. of barium chlorid, $\mathrm{BaCl}_{2}$. Observe the result.

Questions. - (I) Why is not $\mathrm{H}_{2} \mathrm{SO}_{4}$ made from sulfates? (2) Why is heat produced when water and $\mathrm{H}_{2} \mathrm{SO}_{4}$ are mixed? (3) What use was made of this heat in test No. 2? (4) What caused the precipitate when $\mathrm{BaCl}_{2}$ was added? (5) Write the reaction. (6) What is the name of the product? (7) What are some of the uses of $\mathrm{H}_{2} \mathrm{SO}_{4}$ ? (8) How many kinds of salts does $\mathrm{H}_{2} \mathrm{SO}_{4}$ form? (9) Why is nitric oxid used in the manufacture of $\mathrm{H}_{2} \mathrm{SO}_{4}$ ? (Io) What are the physical properties of $\mathrm{H}_{2} \mathrm{SO}_{4}$ ? (II) Of what agricultural value is $\mathrm{H}_{2} \mathrm{SO}_{4}$ ? (I 2 ) Does $\mathrm{H}_{2} \mathrm{SO}_{4}$ dissolve lead? (I3) Why does commercial $\mathrm{H}_{2} \mathrm{SO}_{4}$ often appear dark-colored or deposit a fine, white sediment?

II9. Sulfates. - Sulfuric acid is a dibasic acid, and hence may form two series of salts, as $\mathrm{NaHSO}_{4}$, primary 
sodium sulfate (acid sodium sulfate), and $\mathrm{Na}_{2} \mathrm{SO}_{4}$, secondary sodium sulfate (normal sodium sulfate). The sulfates of the metalsform a large class of compounds which vary in chemical and physical properties according to the metal that is present. As a class they are fairly stable compounds. Some, as sodium and potassium sulfates, are soluble; others, as calcium sulfate, are sparingly so, while barium sulfate is one of the most insoluble substances in nature. Many of the sulfates contain water of crystallization. Calcium and potassium sulfates are valuable as fertilizers, and copper sulfate is used as a fungicide.

I20. Sulfids. - Sulfids are compounds of the metals with sulfur, as $\mathrm{K}_{2} \mathrm{~S}, \mathrm{FeS}$, and $\mathrm{CuS}$. When a sulfid, as $\mathrm{FeS}$, is treated with a dilute acid, $\mathrm{H}_{2} \mathrm{~S}$, hydrogen sulfid, is liberated. $\mathrm{FeS}+2 \mathrm{HCl}=\mathrm{FeCl}_{2}+\mathrm{H}_{2} \mathrm{~S}$.

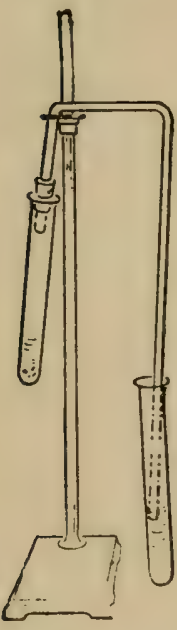

FIG. 44.- $-\mathrm{Hy}-$ drogen sulfid generator.

The differences in solubility and other properties of the sulfids are taken advantage of in the separation and identification of metals. $\mathrm{H}_{2} \mathrm{~S}$ is formed when albuminous matter, as the white of an egg, decays. It is also one of the gases given off from sewers. It is a poisonous, suffocating gas.

Experiment 22. - Hydrogen sulfid. (This experiment should be performed under the hood.) Arrange the apparatus as shown in Fig. 44. The delivery tube and cork should fit tightly, and the delivery tube should pass into a test tube containing ro cc. of $\mathrm{Pb}\left(\mathrm{NO}_{3}\right)_{2}$ solution. Test tubes containing ro cc. respectively of $\mathrm{NaCl}$ and $\mathrm{CuSO}_{4}$ solutions should be conveniently at hand. Place 5 grams of pulverized $\mathrm{FeS}$ in the generating test tube, add ro cc. dilute $\mathrm{HCl}$, and immediately connect with the delivery tube. After the gas has passed through the lead nitrate solution for two minutes, pass it through the sodium chlorid and copper sulfate solutions; 
then allow a little of the gas to escape into a cylinder containing water. Do not permit the free gas to escape into the room. With $\mathrm{NaCl}$ no insoluble sulfid is formed.

Qucstions. - (I) What is the odor of the gas? (2) Write the equation for its production. (3) What was formed when the gas was passed into $\mathrm{Pb}\left(\mathrm{NO}_{3}\right)_{2}$ ? Write the reaction. (4) What was formed when the gas was passed through $\mathrm{Cu}\left(\mathrm{NO}_{3}\right)_{2}$ ? Write the reaction. (5) $\mathrm{Is}_{2} \mathrm{~S}$ soluble in water? (6) When albumin decays, from what is the $\mathrm{H}_{2} \mathrm{~S}$ produced? (7) Why was no precipitate formed when the gas was passed through $\mathrm{NaCl}$ ?

Problem I. - How much $\mathrm{H}_{2} \mathrm{SO}_{4}$ can be made from one ton of sulfur?

Problem 2. - What per cent of $\mathrm{H}_{2} \mathrm{SO}_{4}$ is $\mathrm{SO}_{3}$ ?

Problem 3. - How much $\mathrm{H}_{2} \mathrm{SO}_{4}$ is required to neutralize 500 pounds $\mathrm{NaOH}$ ? 


\section{CHAPTER XV}

\section{Silicon AND ITS Compounds}

I2I. Occurrence. - Silicon is found in nature in combination with oxygen as silica, $\mathrm{SiO}_{2}$; and with oxygen and the metals as silicates. It is never free, but always in combination with other elements. Next to oxygen it is the most abundant element in nature. In the form of silicates it is the basis of the composition of nearly all rocks, and in the soil $\mathrm{SiO}_{2}$ is present to the extent of from 60 to 90 per cent. It is in the ash of plants, and, to a slight extent, in animal bodies.

I22. Preparation and Properties. - Silicon is separated from its compounds with difficulty. By treatment in an

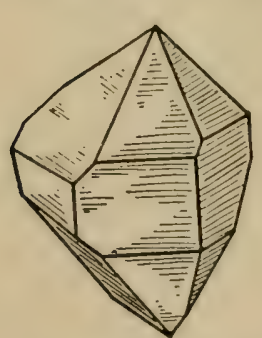

FIG. 45.- Quartz crystal. electric furnace, quartz, or $\mathrm{SiO}_{2}$, is reduced. Like carbon, silicon has crystalline and amorphous forms. Pure quartz, $\mathrm{SiO}_{2}$, and other forms of silicon, are insoluble in nitric, hydrochloric, and sulfuric acids. When acted upon by hydrofluoric acid, silicon tetrafluorid, a gas, is formed. $\mathrm{SiO}_{2}$ $+{ }_{4} \mathrm{HF}=\mathrm{SiF}_{4}+2 \mathrm{H}_{2} \mathrm{O}$. $\mathrm{HF}$ is used for the decomposition of silicates.

123. Silicic Acid. - When $\mathrm{SiO}_{2}$ is fused with hydroxids or carbonates of potassium or sodium, potassium or sodium silicate is obtained:

$$
\begin{aligned}
\mathrm{SiO}_{2}+\mathrm{K}_{2} \mathrm{CO}_{3} & =\mathrm{K}_{2} \mathrm{SiO}_{3}+\mathrm{CO}_{2} . \\
\mathrm{SiO}_{2}+4 \mathrm{KOH} & =\mathrm{K}_{4} \mathrm{SiO}_{4}+2 \mathrm{H}_{2} \mathrm{O} . \\
& 98
\end{aligned}
$$


The silicates of potassium and sodium are soluble in water, and are commonly called water-glass. Some of the silicates are soluble in acids, but most of them are insoluble complex compounds difficult to decompose.

When $\mathrm{K}_{4} \mathrm{SiO}_{4}$ is treated with $\mathrm{HCl}$, a gelatinous mass containing silicic acid is obtained: $\mathrm{K}_{4} \mathrm{SiO}_{4}+4 \mathrm{HCl}=$ $\mathrm{H}_{4} \mathrm{SiO}_{4}+4 \mathrm{KCl}$.

$\mathrm{H}_{4} \mathrm{SiO}_{4}$ is normal silicic acid. Upon exposure to the air it loses a molecule of water and forms ordinary silicic acid, $\mathrm{H}_{2} \mathrm{SiO}_{3}$, which is decomposed by heat and in the presence of acids forms $\mathrm{H}_{2} \mathrm{O}$ and $\mathrm{SiO}_{2}$.

In addition to the two silicic acids, $\mathrm{H}_{2} \mathrm{SiO}_{3}$ and $\mathrm{H}_{4} \mathrm{SiO}_{4}$, there are other forms known as polysilicic acids, as: $\mathrm{H}_{2} \mathrm{Si}_{3} \mathrm{O}_{7}, \mathrm{H}_{4} \mathrm{Si}_{3} \mathrm{O}_{8}$, and $\mathrm{H}_{2} \mathrm{Si}_{2} \mathrm{O}_{5}$, obtained by removing water from the normal and ordinary silicic acid.

$$
\begin{aligned}
& 2 \mathrm{H}_{2} \mathrm{SiO}_{3}=\mathrm{H}_{2} \mathrm{SiO}_{5}+\mathrm{H}_{2} \mathrm{O} . \\
& 3 \mathrm{H}_{4} \mathrm{SiO}_{4}=\mathrm{H}_{4} \mathrm{Si}_{3} \mathrm{O}_{8}+{ }_{4} \mathrm{H}_{2} \mathrm{O} .
\end{aligned}
$$

I24. Dialysis. - In the preparation of silicic acid, the process known as dialysis is employed for dissolving and removing the impurities. Some substances, as $\mathrm{NaCl}$ and $\mathrm{HCl}$, dissolve and readily pass through animal membrane; these are called crystalloids, while bodies like silicic acid, which do not penetrate animal membrane, or do so very slowly, are called colloids. The removal of the $\mathrm{HCl}$ from the solution containing the gelatinous silicic acid is

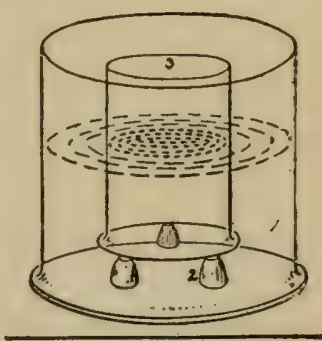

Fig. 46.-Dialyzer. accomplished by means of the dialyzer, Fig. 46. This property of materials, readily or slowly to diffuse through animal membrane, is a physical characteristic, and is occasionally made use of for washing and separating compounds. 
I25. Silicates. - Since silican forms such a variety of acids, the number of silicates found in nature is very large. The hydrogen atoms of silicic acid can be replaced with different metals, forming double salts, as $\mathrm{AlKSi}_{3} \mathrm{O}_{8}$, which is feldspar, or the double salt of trisilicic acid, $\mathrm{H}_{4} \mathrm{Si}_{3} \mathrm{O}_{8}$. This renders the composition of the silicates very complex. Many of the silicates contain also water of hydration as part of the molecule; as aluminum silicate, $\mathrm{Al}_{4}\left(\mathrm{SiO}_{4}\right)_{3} \cdot \mathrm{H}_{2} \mathrm{O}$. Since rocks are composed mainly of silicates, and soils are formed from the decay of rocks, it follows that soils are practically a mechanical mixture of silicates with small amounts of other compounds. Hence, the importance of silicic acid and the silicates in agriculture. Unfortunately the structure and composition of the silicates have not been determined as completely as of other salts and acids. Pure clay is aluminum silicate, formed from the disintegration of feldspar rock, a double silicate of potassium and aluminum. Mica, hornblende, and zeolites are all complex forms of silicates.

I26. Importance of Compounds of Silicon. - The compounds of silicon, as silicon dioxid, $\mathrm{SiO}_{2}$, and of the silicates, are used in the manufacture of glass, porcelain, and brick. The element itself takes no direct part in animal or plant life, but indirectly is important, for it is in combination with many elements which serve as plant food. Some of the simpler and more soluble silicates are capable of being acted upon by decaying animal and vegetable matter and undergoing chemical changes which prepare them for plant food. Since silicon forms the principal acid element which enters into the composition of rocks, soils, building stones, glass, brick, and porcelain, and is associated with the elements in the soil which serve 
as plant food, it follows that it is an important element in industrial operations and in agriculture.

Experiment 23. - To about $5 \mathrm{cc}$. of sodium silicate in a test tube add a few drops of $\mathrm{HCl}$ and observe the result. Then add $\mathrm{NaOH}$ and observe the result. Add more $\mathrm{HCl}$, and evaporate the material to dryness in the evaporating dish. When cool, test the solubility of the residue in water.

Questions. - (I) What was formed when $\mathrm{HCl}$ was added to sodium silicate? Write the reaction. (2) What was the appearance of the product? (3) What effect did the $\mathrm{NaOH}$ have, and what was formed? (4) What was formed when the material was evaporated to dryness? (5) What can you say as to the solubility of the product?

Problem $I_{\text {. }}$ - What per cent of $\mathrm{SiO}_{2}$ in clay, $\mathrm{Al}_{4}\left(\mathrm{SiO}_{4}\right)_{3} \cdot \mathrm{H}_{2} \mathrm{O}$ ?

Problem 2. - How much silicic acid is formed when 10 grams of $\mathrm{HCl}$ act upon $\mathrm{K}_{4} \mathrm{SiO}_{4}$ ? 


\section{CHAPTER XVI}

\section{Oxids of Carbon, Carbonates, and Carbon} Compounds

I27. Carbon Dioxid. - Carbon dioxid is obtained from the combustion of carbon and also from the treatment of a carbonate with an acid. A carbonate is a salt of carbonic acid, $\mathrm{M}_{2} \mathrm{CO}_{3}$, in which $\mathrm{M}$ represents any monovalent metal, as $\mathrm{K}$ or $\mathrm{Na}$. Calcium carbonate, $\mathrm{CaCO}_{3}$, is the most abundant carbonate found in nature. When a carbonate is treated with an acid, $\mathrm{CO}_{2}$ is liberated, and a salt is formed, as

$$
\mathrm{CaCO}_{3}+{ }_{2} \mathrm{HCl}=\mathrm{CaCl}_{2}+\mathrm{CO}_{2}+\mathrm{H}_{2} \mathrm{O} .
$$

Experiment 24. - Preparation of carbon dioxid. Arrange the apparatus as for the preparation of hydrogen. Put ro grams of marble, $\mathrm{CaCO}_{3}$, into the Woulff bottle, and sufficient water to cover the end of the thistle tube. Fill 2 or 3 cylinders with water for collecting the gas, which is only slightly soluble in water, then add slowly, through the thistle tube, about $20 \mathrm{cc}$. concentrated $\mathrm{HCl}$. Allow a little of the first gas generated to escape into the room and then collect 2 or 3 cylinders of $\mathrm{CO}_{2}$. Remove the cylinders from the pneumatic trough and place them on the desk, right side up. Now remove the delivery tube from the pneumatic trough and allow the gas to pass into a test tube containing about ro cc. of clear lime water, $\mathrm{Ca}(\mathrm{OH})_{2}$. If necessary, add through the thistle tube a little more acid to the generator. Observe the white precipitate formed in the test tube. Let the gas pass through the lime water for several minutes, until the solution becomes clear. Now boil the solution and observe the reappearance of the white precipitate. Test some of the escaping gas with a burning splinter. Pour a receiver of the gas over a candle or a low gas flame, and observe 
the result. Thrust a burning splinter into a cylinder of $\mathrm{CO}_{2}$. $\mathrm{Ob}$ serve the result. Add $5 \mathrm{cc}$. water to the cylinder in which the splinter was placed, and then a little lime water; shake, and observe the result.

Questions. - (I) Write the reaction for the preparation of $\mathrm{CO}_{2}$. (2) What is a carbonate? (3) Is $\mathrm{CaCO}_{3}$ soluble in pure water? (4) Is it soluble in water containing $\mathrm{CO}_{2}$ ? (5) What caused the precipitate to from when the $\mathrm{CO}_{2}$ gas was passed through the lime water? (6) What is this precipitate? Write the reaction. (7) What caused this precipitate to disappear when more gas was passed through the solution? (8) What caused it to reappear when the solution was boiled? (9) What caused the candle to be extinguished when a receiver of $\mathrm{CO}_{2}$ was poured over the flame? (Io) $\mathrm{O}$ is a supporter of combustion; $\mathrm{CO}_{2}$ contains $\mathrm{O}$; why does $\mathrm{CO}_{2}$ not support combustion? (II) Is $\mathrm{CO}_{2}$ a heavy or a light gas, and what tests indicate that it is heavy or light? (г 2) What other carbonate could be used for making $\mathrm{CO}_{2}$ ? (I3) What other acid could be used for making $\mathrm{CO}_{2}$ ?

I28. Carbon Monoxid. - Carbon monoxid is formed when carbon is only partially oxidized because of an insufficient supply of air. In a coal stove, for example, there is not a perfect supply of air in the interior of the burning mass ; carbon monoxid is formed there and passes to the surface, where it burns as a blue flame. If the draft is imperfect, a large amount of carbon monoxid is formed. When a coal stove gives off gas, the carbon monoxid is not oxidized, but is thrown into the room. Carbon monoxid is a light, colorless, combustible, poisonous gas, and can be produced by subjecting highly heated carbon to the action of steam. The reaction is $\mathrm{C}+$ $\mathrm{H}_{2} \mathrm{O}=\mathrm{CO}+2 \mathrm{H}$. Both $\mathrm{CO}$ and $\mathrm{H}$ are combustible, and when they are enriched by some of the hydrocarbons, thus introducing materials that give light when burned, they may be used for illuminating purposes, and the product is called water gas. Carbon monoxid is pro- 
duced in furnaces from the coke which is mixed with ore, and in the smelting and refining of ores, it is an important reducing agent; in fact, the main reducing agent of the blast furnace.

I29. Marsh Gas (Methane, $\mathrm{CH}_{4}$ ). - When vegetable matter decays under water, where the supply of air is incomplete, methane, $\mathrm{CH}_{4}$, is one of the products formed. It is given off in bubbles from the surface of stagnant pools. It often collects in coal mines, and is there called fire damp. $\mathrm{CH}_{4}$ can be prepared in the laboratory in a number of ways, and is a colorless, combustible gas, which with air forms an explosive mixture.

I30. Hydrocarbons. - A compound, as methane, composed of hydrogen and carbon is called a hydrocarbon. There are a large number of such compounds, forming series in which the members differ from one another in composition by a definite number of $\mathrm{C}$ and $\mathrm{H}$ atoms, as methane, $\mathrm{CH}_{4}$, and ethane, $\mathrm{C}_{2} \mathrm{H}_{6}$. The next member is propane, $\mathrm{C}_{3} \mathrm{H}_{8} ; \mathrm{CH}_{2}$ being the common difference between the members of this series. By oxidation, reduction, and substitution, in which a part of the $\mathrm{H}$ is replaced with equivalent radicals, a large number of derivatives, as alcohols, aldehydes, ethers, and organic acids, are formed.

I3I. Petroleum. - Petroleum is an oily liquid obtained in some parts of the world by boring wells into the rock strata, where it is found as a natural product. It is a mechanical mixture of various liquid and solid hydrocarbons, often accompanied with gaseous hydrocarbons. The hydrocarbons distilled at low temperature, ranging from $8^{\circ}$ to $68^{\circ} \mathrm{C}$., are the gasoline and benzene products, while those which distil between $175^{\circ}$ and $215^{\circ} \mathrm{C}$. are the various grades of kerosene. In the preparation of gaso- 
line, benzene, and kerosene, the separation of the various grades of hydrocarbons is not complete; kerosene, for example, may contain traces of gasoline or paraffin products. Kerosene should have a flashing point not below $44^{\circ} \mathrm{C}$. ( I I I $^{\circ} \mathrm{F}$.), in order to render it safe for illuminating purposes. The flashing point of kerosene may be approximately determined in the following way:

Experiment 25. - Testing kerosene. Pour into a small porcelain crucible some kerosene; place the crucible upon a water bath, and suspend a thermometer in the kerosene. Do not allow the water in the bath to come in contact with the crucible or the thermometer to touch the bottom. Cautiously heat the water until the thermometer registers $40^{\circ} \mathrm{C}$, then remove the lamp and draw a lighted match across the surface of the kerosene. If it flashes, note its temperature; do not let it burn; should this occur, remove the thermometer and cover the crucible. If the kerosene does not flash, repeat the test, and if necessary apply more heat until the

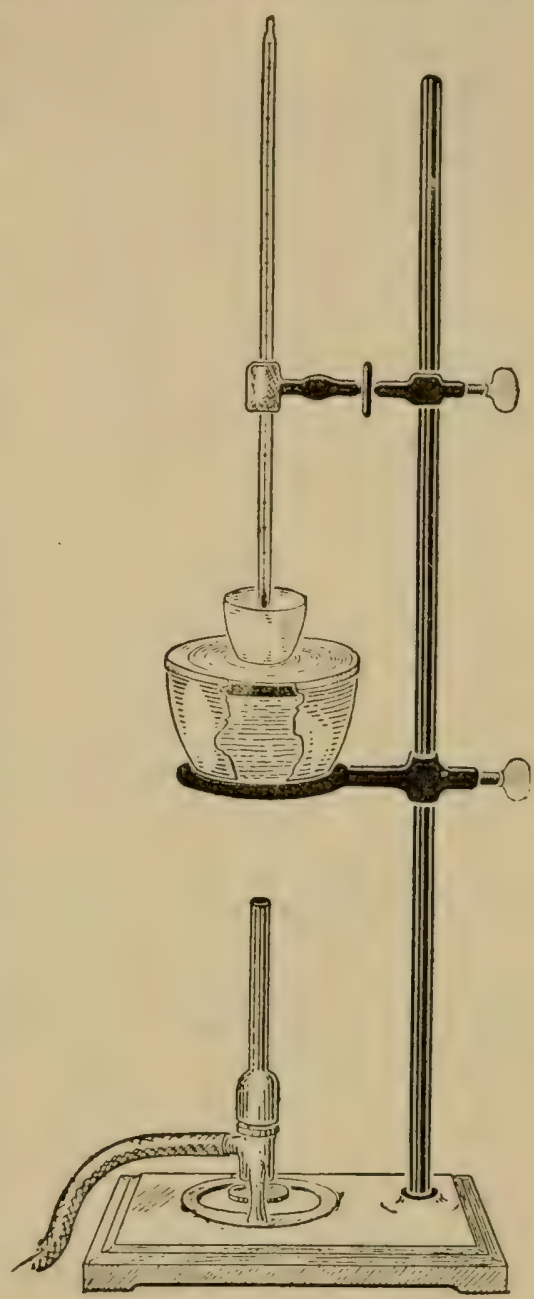

FIG. 47. - Testing kerosene. flashing point is reached. Calculate the corresponding temperature on the Fahrenheit scale.

I32. Use of Gasoline. - Gasoline is safe for use as a fuel, provided precautions are observed: (I) Never use 
a gasoline stove when there is but little gasoline in the tank, because the last gas generated is mixed with air, and is liable to form an explosive mixture. (2) All joints and connections about the stove should be tight to prevent escape of gasoline into the air. Lack of care in this respect is the most frequent cause of fires. (3) The gasoline can should be well corked and stored in a cool place. (4) The stove should be kept clean, and no deposit of carbon should be allowed to collect upon the burners. (5) Do not fill tank while stove is lighted.

I33. Illuminating Gas. - Illuminating gas is made from soft coal and petroleum by destructive distillation. The gases formed are washed and separated from ammonia

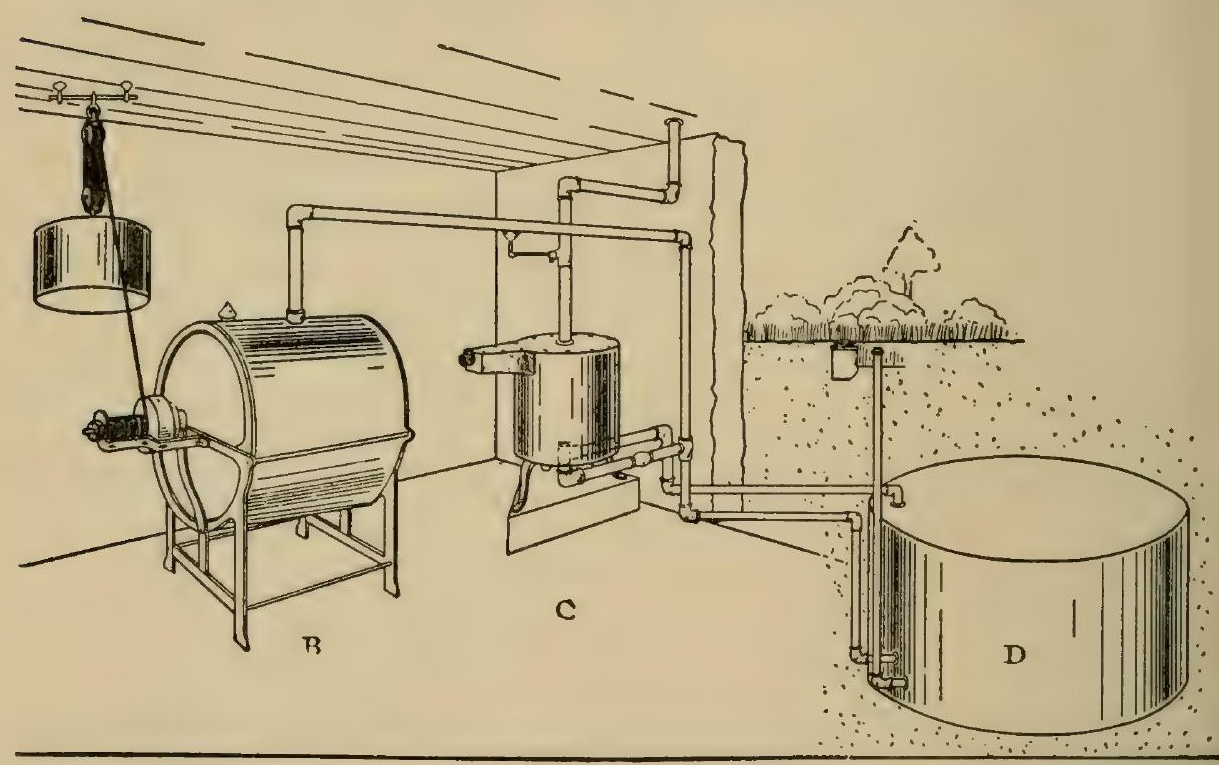

FIG. 48. - Illuminating gas plant for producing gas from gasoline. A, weight to ai pump, B. D, carburetor or generating tank into which air is forced.

and coal tar, and consist of various hydrocarbons which are used for illuminating purposes. The coal, after being deprived of its gaseous products, is converted into coke, 
which bears the same relation to coal which charcoal bears to wood. Ammonia and coal tar are recovered as byproducts. Various coloring matters are made from coal tar.

If air is forced through gasoline in an inclosed chamber, or if gasoline is vaporized, it will burn like ordinary coal gas. Gasoline can be vaporized on a small scale, and machines suitable for the purpose are made for illuminating dwellings. Five gallons of gasoline will produce about Iooo feet of gas or vapor. The illuminating power of gas, and of flames in general, is expressed in terms of candle power. A sixteen candle-power light is one that gives sixteen times as much light as a standard candle, composed of spermaceti, and burned at the rate of $\mathrm{r} 20$ grains per hour, the comparison being made by means of a photometer. In some localities, hydrocarbons, due to decomposition of organic matter, are given off from the earth as natural gas in amounts sufficient to be used for illuminating and fuel purposes.

I34. Mineral Oils. - The heavier products obtained in the distillation of petroleum, after removal of the gasoline, benzene, and kerosene, are used for lubricating purposes, and are called mineral oils. They have a boiling point from $250^{\circ}$ to $350^{\circ} \mathrm{C}$.

135. Oil of Turpentine $\left(\mathrm{C}_{10} \mathrm{H}_{16}\right)$. - O Oil of turpentine is obtained by distilling the resinous material which exudes from incisions in certain species of pines. Resin is obtained in the retorts. Oil of turpentine is inflammable, and dissolves readily in ether, alcohol, and naphtha. It is a valuable solvent, extensively used in the preparation of varnishes and paints, and as a solvent for caoutchouc. Turpentine belongs to the class of compounds known as essential oils. 
I36. Creosote. - When wood tar is distilled, various products are obtained which, after treatment with chemicals for purification, are called wood-tar creosote. This is a yellowish liquid with a smoky odor. It is a powerful antiseptic, and is the preservative employed in the preparation of "smoked meats," as hams and fish. It has no marked action on albuminous matter, and in small amounts is not poisonous. Because of its antiseptic powers, wood creosote is used for the preservation of wood, as it prevents decay. When some kinds of wood, as beech wood, are burned, the wood tar condenses in the chimney.

I37. Benzene or Benzol $\left(\mathrm{C}_{6} \mathrm{H}_{6}\right)$. - When coal tar, obtained in the manufacture of illuminating gas, is subjected to fractional distillation, commercial products are obtained known as coal tar, naphtha, middle oil, heavy oil, anthracene oil, and pitch or artificial asphaltum. The naphtha or light oil consists of a mixture of hydrocarbons, benzene being among the number. Benzene is used as a solvent for fatty bodies. It is very inflammable.

\section{I38. Aliphatic and Aromatic Series of Compounds. -} In organic chemistry benzene occupies an important position, as the direct treatment of benzene and its derivatives produces the aromatic series of compounds, which form one of the two main divisions of the subject. The other series is obtained from methane and its derivatives, and constitutes the aliphatic series. The alcohols, ethers, glycerides, fatty acids, organic acids, carbohydrates, and amids are members of the aliphatic series, while essential oils, coloring matters, and mixed nitrogenous compounds are members of the aromatic series. In organic chemistry a study is made of the formation, rela- 
tionship, structure, and properties of all these compounds. Hence the importance of this branch of chemistry.

I39. Carbon Disulfid. - With sulfur, carbon forms carbon disulfid, $\mathrm{CS}_{2}$, a clear liquid with a characteristic odor. It readily burns and is easily vaporized. It is a solvent for fats, resins, sulfur, and iodin, and is used for the destruction of insects, particularly those infesting grains, and for killing small burrowing animals, as gophers.

I40. Cyanids. - In the presence of metals carbon unites indirectly with nitrogen, forming cyanids, as $\mathrm{KCN}$. When mercuric cyanid is heated, cyanogen gas and metallic mercury are formed: $\mathrm{Hg}(\mathrm{CN})_{2}=\mathrm{Hg}+{ }_{2} \mathrm{CN}$. Cyanogen and the cyanids are very poisonous. With $\mathrm{H}$, cyanogen forms hydrocyanic acid (prussic acid), which is used for the destruction of scale insects and in the preparation of pigments. Traces of this compound are found in a few plants; some owe their poisonous properties to its presence in excessive amounts.

I4I. Carbids. - With some of the metals, notably calcium, carbon forms carbids, as $\mathrm{CaC}_{2}$ which is produced by the fusion of coke and limestone in electric furnaces. In the presence of water $\mathrm{CaC}_{2}$ is decomposed, forming acetylene gas, $\mathrm{C}_{2} \mathrm{H}_{2}$, and calcium hydroxid.

$$
\mathrm{CaC}_{2}+{ }_{2} \mathrm{H}_{2} \mathrm{O}=\mathrm{C}_{2} \mathrm{H}_{2}+\mathrm{Ca}(\mathrm{OH})_{2} \text {. }
$$

Acetylene generators are made for illuminating dwellings. Acetylene, like all gaseous hydrocarbons, as methane and benzene, forms an explosive mixture with oxygen. All illuminating gases should be dealt with as highly combustible and explosive materials.

I42. Fuels. - There are three forms of fuel: (I) gas, (2) liquid, and (3) solid. Natural gas, coal gas, and gas 
generated from gasoline and naphtha are the principal forms of gas fuel; kerosene, gasoline, and crude petroleum are liquid fuels; while coal, coke, lignite, peat, and wood are the chief forms of solid fuel. The composition of coal, coke, lignite, and peat is discussed in Chapter V. Wood is composed largely of cellulose, and contains, when dry, about 50 per cent carbon, 6 per cent hydrogen, and 43 to 44 per cent oxygen. Air-dried wood contains from Io to 15 per cent moisture. Different kinds of wood vary in density between wide limits; for example, a cord of dry pine weighs about 3000 pounds, while a cord of dry maple or other hard wood weighs from 4500 to 5000 pounds, or more. Hence the same volume (as a cord) of soft wood yields less total heat than a cord of hard wood, but a pound of the different kinds of wood of equal moisture content gives nearly the same amount of heat. The amount of heat which a material produces when burned is measured in the calorimeter, and is given in terms of calories or heat units. A calorie is the heat required to raise the temperature of I kilo of water I centigrade degree. The presence of water in fuels generally lowers the caloric value, because it requires heat to evaporate and expel as steam the moisture before combustion can take place. At a high temperature (above $1100^{\circ} \mathrm{C}$.) the water in fuel is converted into combustible gases by the action of heated carbon, as explained in Section $\mathrm{I} 28$, in which case the loss in fuel value is reduced to a minimum.

I43. Comparative Value of Fuels. - The heat-producing value of fuels is also expressed as British thermal units, B. T. U., the heat required to raise I pound of water $I^{\circ}$ F. B. T. U. per pound are changed to calories per kilo by dividing the number of B. T. U. by I.8. 
B. T.U.

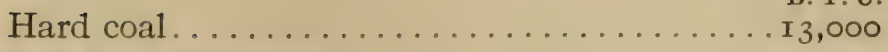

Soft coal, Hocking . . . . . . . . . . . . . I I,800

Soft coal, Pocahontas................ I3,000

Soft coal, Splint................. I 2,500

Lignite with 30 per cent water ......... 7,000

I44. Foods. - The materials used as human and animal foods are mechanical mixtures of various organic compounds, as starch, sugar, fat, albumin, etc., together with various mineral salts. The composition of the organic compounds of foods forms a part of the study of organic chemistry, while their economic value and the uses made of them by the body are studied in physiological chemistry. Knowledge in regard to the composition and uses of foods, particularly of human foods, is somewhat limited, although along this line many facts and laws of economic and sanitary importance have been discovered. The subject of foods is treated more fully in the chapters relating to the chemistry of foods.

Vegetable foods and fuels are alike in chemical composition, and serve somewhat the same functions, but in different ways. Food is used as fuel by the body, and also for the renewal of old and the production of new tissues. The heat produced from food is transformed into muscular and other forms of energy; the heat from the combustion of fuel is converted into chemical energy, which is utilized for mechanical purposes.

I45. Production of Organic Compounds in Plants. The carbon dioxid of the air is the source of the carbon used by plants for the production of the various organic compounds found in vegetable substances, and since about 50 per cent of the ash-free tissue of plants is carbon, it follows that the carbon dioxid of the air is an important factor in plant growth. Hydrogen and oxygen are 
obtained from the water of the soil which is received from the air. The production of the various organic compounds of plants takes place in the cells of the leaves and is the result of chemical changes induced by life

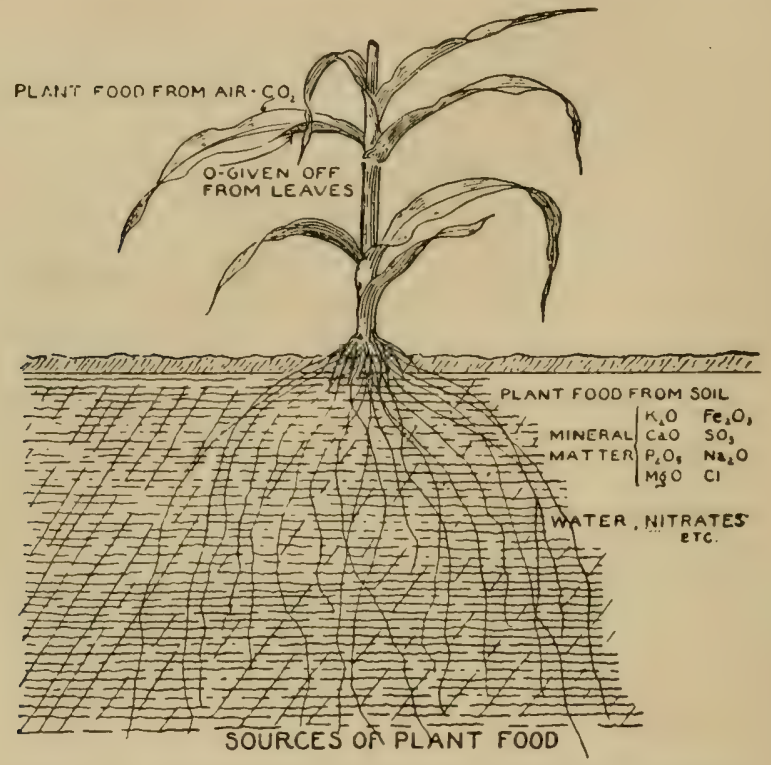

FIG. 49. - Production of organic compounds in plants, showing sources of plant food.

processes. In order to promote cell activity, sunlight and a suitable temperature are necessary. The sun's rays take an important part in promoting chemical changes in the leaves of plants. In addition to carbon dioxid, water, heat, and sunlight, various mineral elements in the form of compounds of potassium, calcium, phosphorus, nitrogen, iron, magnesia, sulfur, and possibly a few others are required as plant food. Without these essential elements and requisite conditions, the growth of crops cannot take place. It often happens that soils are unproductive because of the absence, in available 
form, of some of the elements essential for plant life. The production in the leaves of plants of the various organic compounds, as cellulose, starch, sugar, fat, albumin, etc., and a few of the complex chemical changes which take place, are discussed in the second part of this work.

146. Decay of Organic Compounds. - All organic compounds, particularly those found in the tissues of plants and used for food, are subject to the chemical change commonly called decay. Such change is nearly always produced as the result either of the action of organized ferments, or of the chemical products known as chemical or soluble ferments. Fermen-

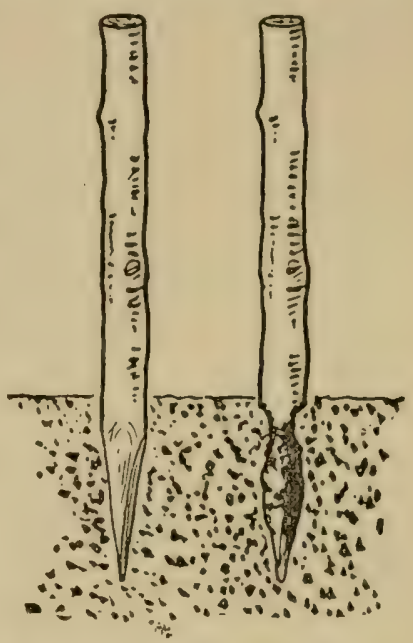

Fig. 50.-Decay of wood. Note that the decay is more rapid near the moist surface where the supply of air is greater. tation changes and decay take place whenever cell activity becomes feeble or ceases; then the material becomes food for microörganisms. Many chemical changes occur as the result of fermentation; some of these are necessary in plant and animal nutrition. If the chemical changes, coördinate with fermentation, are uninterrupted, the organic materials are decomposed until carbon dioxid, water, ammonia gas, and hydrogen sulfid are obtained as the final products, and the mineral matter combined and associated with the organic matter is left as non-volatile material. In economic agriculture, it is the aim to conserve and return to the soil the essential elements, as nitrogen, potassium, phosphorus, and calcium, which are frequently unavailable or present in soils in scant amounts, so that the 
fertility will not be impaired. The elements in plant and animal bodies pass through a cycle of chemical changes; they are never lost to nature, but appear in different chemical compounds, as exemplified by the law of inde-

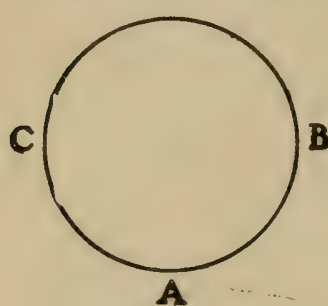

FIG. 51. structibility of matter.

A. Elements of plant growth in soil and air.

B. Elements from soil and air elaborated into plant tissue.

C. Elements in plant tissue elaborated into animal tissue.

The elements in either plant or animal bodies may pass back to $\mathrm{A}$, and then pass again through the same cycle of chemical changes. 


\section{CHAPTER XVII}

\section{Writing EqUations}

I47. Importance. - A chemical equation expresses concisely the changes which take place when two or more compounds are brought together so as to react, or when a material is acted upon by any agent which causes a chemical change. When chemical equations are understood by the student, they are of great assistance, as they necessitate a knowledge of the laws of valence, of the power of replacement, and of the properties of the elements and their compounds.

148. Common Errors in Writing Equations. - Some of the more common errors in writing equations are:

(I) Failure to use correct formulas.

(2) Failure to use the correct number of parts of compounds, radicals, or elements.

(3) Failure properly to balance the equation.

(4) Failure to form reasonable compounds or products. If the correct formula, or the right number of molecules, is not used, the equation is incorrect, it cannot be balanced, and the principle represented by the sign of equality is violated. There should be as many atoms of an element on one side of an equation as on the other. In order properly to balance an equation, as many molecules of the compounds on the left of the equation should be taken as are needed to satisfy the valences of the reacting elements and radicals. In the equation

$$
\mathrm{AgNO}_{3}+\mathrm{HCl}=\mathrm{AgCl}+\mathrm{HNO}_{3},
$$


only one molecule each of $\mathrm{AgNO}_{3}$ and $\mathrm{HCl}$ is necessary, because all of these elements and radicals are monovalent. A simple exchange takes place in which the $\mathrm{H}$ of the acid is replaced by the metal Ag. If the elements $\mathrm{H}$

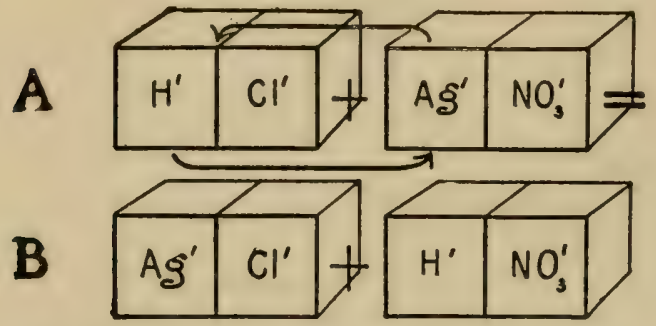

FIG. 52.- Graphic illustration of a chemical reaction. and $\mathrm{Ag}$ were to exchange places, they would occupy, after the exchange, the positions shown on the right-hand side of the equation. This exchange is represented graphically in Fig. $5^{2}$;

A represents the order before, and $\mathrm{B}$ after, the reaction. Blocks of wood marked to represent the elements and radicals can be used, the block marked $\mathrm{H}$ being replaced by the equivalent block marked Ag. When difficulty is experienced in writing chemical equations, this method of illustration will be found helpful.

In an equation as

$$
2 \mathrm{NaCl}+\mathrm{H}_{2} \mathrm{SO}_{4}=\mathrm{Na}_{2} \mathrm{SO}_{4}+2 \mathrm{HCl},
$$

where both monovalent and bivalent elements and radicals are present, it is necessary to take two molecules of $\mathrm{NaCl}$ because there are two $\mathrm{H}$ atoms to be replaced. $\mathrm{H}$ and $\mathrm{Na}$ have the same valence, viz., $\mathrm{I}$, and $\mathrm{SO}_{4}$ has a valence of 2. In order to obtain two atoms of $\mathrm{Na}$, it is necessary to take $2 \mathrm{NaCl}$; then two atoms of $\mathrm{Na}$ replace two of $\mathrm{H}$. The products are $\mathrm{Na}_{2} \mathrm{SO}_{4}$ and $2 \mathrm{HCl} . \mathrm{SO}_{4}$ is a radical with a valence of 2 and requires $2 \mathrm{Na}$ atoms in order to form a compound. A similar reaction is represented graphically by the use of blocks in Fig. 53. A represents the arrangement before, and $\mathrm{B}$ the arrange- 
ment after, the reaction. Observe that in this equation there is the same number of atoms of each element on each side of the equation. After writing an equation the student should always observe whether or not it is properly balanced, and that reasonable products are formed. The valences of the elements and radicals are given in Sections I5 and 77 .

There are always

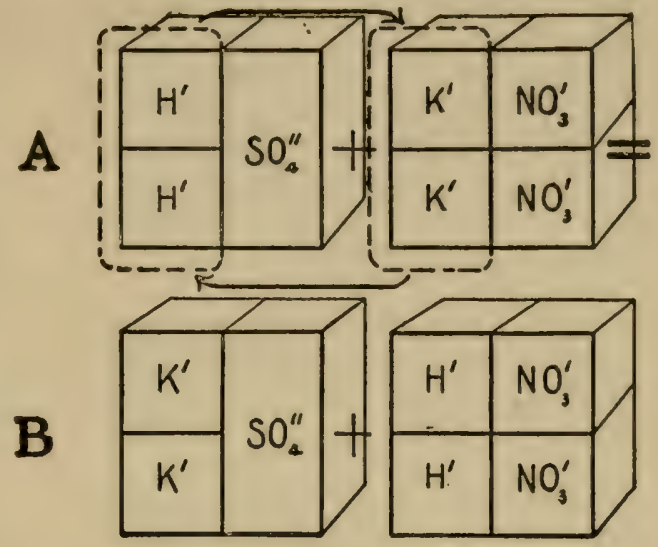

FIG. 53.- Graphic illustration of a chemical reaction.

as many parts by weight of the elements on one side of an equation as on the other. That is, the sum of the weights of the atoms and molecules on one side is equal to the sum of those on the other, as :
$2 \mathrm{NaCl}$
$+$
$\mathrm{H}_{2} \mathrm{SO}_{4}=2 \mathrm{HCl}$
$+$
2 $\mathrm{Na}={ }_{46}$
$2 \mathrm{H}=2$.
$2 \mathrm{H}=2$
$2 \mathrm{Cl}=7 \mathrm{I}$
$\mathrm{S}=32$
${ }_{2} \mathrm{Cl}=7 \mathrm{I}$
$2 \mathrm{Na}={ }_{4} 6$
$\mathrm{S}=32$
$4 \mathrm{O}=64$
II $17+98=2$ I 5 .
- 98
$4 \mathrm{O}=64$
73
142
$73+142=215$.

$\mathrm{Na}_{2} \mathrm{SO}_{4}$.

In the case of trivalent and bivalent elements and radicals, as in the reaction between $\mathrm{H}_{3} \mathrm{PO}_{4}$ and $\mathrm{Ca}(\mathrm{OH})_{2}$, it is necessary to take $2 \mathrm{H}_{3} \mathrm{PO}_{4}$ and $3 \mathrm{Ca}(\mathrm{OH})_{2}$, in order to make the equation balance. The $\mathrm{Ca}$ and $\mathrm{H}$ atoms exchange places; there are three $\mathrm{H}$ atoms to be replaced. $\mathrm{Ca}$ has a valence of 2 ; I Ca cannot replace $3 \mathrm{H}$, but 
$6 \mathrm{H}\left({ }_{2} \mathrm{H}_{3}\right)$ can be replaced by ${ }_{3} \mathrm{Ca}$, because $2 \mathrm{H}_{3}$ has a total valence of 6 and so has $3 \mathrm{Ca}$.

$$
2 \mathrm{H}_{3} \mathrm{PO}_{4}+{ }_{3} \mathrm{Ca}(\mathrm{OH})_{2}=\mathrm{Ca}_{3}\left(\mathrm{PO}_{4}\right)_{2}+6 \mathrm{H}_{2} \mathrm{O} \text {. }
$$

${ }_{3} \mathrm{Ca}$ atoms replace the $2 \mathrm{H}_{3}$ and form $\mathrm{Ca}_{3}\left(\mathrm{PO}_{4}\right)_{2}$, a balanced compound, because $\mathrm{PO}_{4}$ is a radical having a valence of 3 , and if taken twice, its total valence is 6 , with which $3 \mathrm{Ca}$ atoms can combine. The remaining $\mathrm{H}$ and $\mathrm{O}$ atoms form $6 \mathrm{H}_{2} \mathrm{O}$.

I49. Impossible Reactions. - Not all chemical compounds when brought together give a chemical reaction. Whether or not a reaction takes place can be determined only after a careful study of the elements and their properties; this often involves a more exhaustive knowledge of chemistry than can be obtained from an elementary study of the subject.

In the case of $\mathrm{BaSO}_{4}+2 \mathrm{HCl}$, no reaction can take place, although an apparently correct reaction can be written :

$$
\mathrm{BaSO}_{4}+{ }_{2} \mathrm{HCl}=\mathrm{BaCl}_{2}+\mathrm{H}_{2} \mathrm{SO}_{4} .
$$

This is because $\mathrm{BaSO}_{4}$ and $\mathrm{HCl}$ are the products of the reaction

$$
\mathrm{BaCl}_{2}+\mathrm{H}_{2} \mathrm{SO}_{4}=\mathrm{BaSO}_{4}+{ }_{2} \mathrm{HCl} \text {. }
$$

In the equations given at the end of this chapter a reaction takes place in each case.

I50. A Knowledge of Reacting Compounds and Products Necessary. - In order that the writing of chemical equations may become more than a mere mechanical operation, the student should study the character and properties of the compounds used and of the products formed. If one of the compounds is an acid and the other a base, the subject of neutralization is illustrated. If one of the 
compounds is an acid and the other a metal, the replacement of the $\mathrm{H}$ of the acid occurs. Should one of the compounds be an acid and the other a salt, an equivalent amount of the $\mathrm{H}$ is replaced by the metal or basic element of the salt. Other principles and laws should be observed by the student in writing equations. The character of the compounds, as acid, base, or salt, with their names, forms a part of equation work, which is an essential feature of elementary chemistry.

I5I. Equations for Classroom Work. - The student should write the following equations:

I. $\mathrm{CaCl}_{2}+\mathrm{Na}_{2} \mathrm{CO}_{3}=$

2. $\mathrm{CaCl}_{2}+\mathrm{Na}_{2} \mathrm{SO}_{4}=$

3. $\mathrm{Ca}(\mathrm{OH})_{2}+\mathrm{H}_{2} \mathrm{SO}_{4}=$

4. $\mathrm{CaCO}_{3}+\mathrm{HCl}=$

5. $\mathrm{MgCO}_{3}+\mathrm{HCl}=$

6. $\mathrm{KNO}_{3}+\mathrm{H}_{2} \mathrm{SO}_{4}=$

7. $\mathrm{CaCl}_{2}+\mathrm{Na}_{3}\left(\mathrm{PO}_{4}\right)=$

8. $\mathrm{Pb}\left(\mathrm{NO}_{3}\right)_{2}+2 \mathrm{HCl}=$

9. $\mathrm{AlCl}_{3}+\mathrm{NH}_{4} \mathrm{OH}=$

Io. $\mathrm{Ba}(\mathrm{OH})_{2}+\mathrm{H}_{2} \mathrm{SO}_{4}=$

II. $\mathrm{BaCl}_{2}+\mathrm{H}_{2} \mathrm{SO}_{4}=$

I2. $\mathrm{Pb}\left(\mathrm{NO}_{3}\right)_{2}+\mathrm{H}_{2} \mathrm{SO}_{4}=$

I3. $\mathrm{Na}_{2} \mathrm{CO}_{3}+\mathrm{H}_{2} \mathrm{SO}_{4}=$

I4. $\mathrm{Na}_{3} \mathrm{PO}_{4}+\mathrm{H}_{2} \mathrm{SO}_{4}=$

I5. $\mathrm{Ca}(\mathrm{OH})_{2}+\mathrm{Na}_{2} \mathrm{SO}_{4}=$

I6. $\mathrm{Fe}(\mathrm{OH})_{3}+\mathrm{H}_{2} \mathrm{SO}_{4}=$

I7. $\left(\mathrm{NH}_{4}\right)_{2} \mathrm{SO}_{4}+\mathrm{Ca}(\mathrm{OH})_{2}=$

I8. $\mathrm{NH}_{4} \mathrm{NO}_{3}+\mathrm{H}_{2} \mathrm{SO}_{4}=$

I9. $\left(\mathrm{NH}_{4}\right)_{2} \mathrm{CO}_{3}+\mathrm{HCl}=$

20. $\mathrm{NH}_{4} \mathrm{Cl}+\mathrm{H}_{2} \mathrm{SO}_{4}=$

2I. $\mathrm{NH}_{4} \mathrm{Cl}+\mathrm{Ca}(\mathrm{OH})_{2}=$ 
22. $\mathrm{NH}_{4} \mathrm{Cl}+\mathrm{NaOH}=$

23. $\mathrm{NH}_{4} \mathrm{Cl}+\mathrm{Ba}(\mathrm{OH})_{2}=$

24. $\mathrm{NH}_{4} \mathrm{NO}_{3}+\mathrm{Ca}(\mathrm{OH})_{2}=$

25. $\mathrm{NH}_{4} \mathrm{OH}+\mathrm{HCl}=$

26. $\mathrm{NH}_{4} \mathrm{NO}_{3}+\mathrm{KOH}=$

27. $\mathrm{FeCl}_{2}+\mathrm{NaOH}=$

28. $\mathrm{FeCl}_{2}+\mathrm{NH}_{4} \mathrm{OH}=$

29. $\mathrm{AgCl}+\mathrm{H}_{2} \mathrm{~S}=$

30. $\mathrm{Na}_{2} \mathrm{CO}_{3}+\mathrm{Ba}(\mathrm{OH})_{2}=$

3I. $\mathrm{Na}_{2} \mathrm{CO}_{3}+\mathrm{HCl}=$

32. $\mathrm{NaOH}+\mathrm{FeCl}_{2}=$

33. $\mathrm{AgNO}_{3}+\mathrm{NaCl}=$

34. $\mathrm{AgNO}_{3}+\mathrm{HCl}=$

35. $\mathrm{Ca}_{3}\left(\mathrm{PO}_{4}\right)_{2}+{ }_{3} \mathrm{H}_{2} \mathrm{SO}_{4}=$

36. $\mathrm{CaCO}_{3}+$ heat $=$

37. $\mathrm{CaO}+\mathrm{CO}_{2}=$

38. $\mathrm{Ca}(\mathrm{OH})_{2}+\mathrm{CO}_{2}=$

39. $\mathrm{K}+\mathrm{H}_{2} \mathrm{O}=$

40. $\mathrm{AlK}\left(\mathrm{SO}_{4}\right)_{2}+3 \mathrm{KOH}=$

41. $\mathrm{AlNH}_{4}\left(\mathrm{SO}_{4}\right)_{2}+\mathrm{NH}_{4} \mathrm{OH}=$

42. $\mathrm{CaCl}_{2}+\left(\mathrm{NH}_{4}\right)_{2} \mathrm{CO}_{3}=$

43. $\mathrm{CaCl}_{2}+\mathrm{H}_{2} \mathrm{SO}_{4}=$

44. $\mathrm{Na}_{2} \mathrm{SiO}_{3}+\mathrm{HCl}=$

45. $\mathrm{CaSiO}_{3}+\mathrm{Na}_{2} \mathrm{CO}_{3}=$

46. $\mathrm{C}+\mathrm{CuO}=$

47. $\mathrm{CuCl}_{2}+\mathrm{H}_{2} \mathrm{~S}=$

48. $\mathrm{C}_{6} \mathrm{H}_{10} \mathrm{O}_{5}+\mathrm{I}_{2} \mathrm{O}=$

49. $\mathrm{AlCl}_{3}+\mathrm{H}_{3} \mathrm{PO}_{4}=$

50. $\mathrm{AlCl}_{3}+\mathrm{NH}_{4} \mathrm{OH}=$ 


\section{CHAPTER XVIII}

\section{Potassium, Sodium, And their Compounds}

I52. Occurrence of Potassium. - Potassium is found in nature largely in combination with silicon and other elements forming silicates, which undergo slow disintegration with liberation of potassium salts which become food for plants. Potassium is in the ash of all plants and food materials and is one of the elements required by crops. In some "alkali" soils, small amounts are found in the form of potassium salts. Deposits of various double salts of potassium, supposed to have been formed by crystallization from sea water, are found at Stassfurt in Prussia, and are commonly known as Stassfurt salts. These are the chief sources of the potassium compounds, some of which are extensively used for fertilizer.

The element potassium is most typical of all the base elements as a class. It is never found in nature in a free state, but always in combination with other elements, from which it is separated with difficulty. It is a light substance with a metallic luster, and in the laboratory is kept from contact with air and water, with which it readily reacts.

153. Potassium Hydroxid. - This is a strong basic compound extensively used in the laboratory and in manufacturing operations. It is prepared by treating $\mathrm{K}_{2} \mathrm{CO}_{3}$ with $\mathrm{Ca}(\mathrm{OH})_{2}$, the reaction being $\mathrm{K}_{2} \mathrm{CO}_{3}+\mathrm{Ca}(\mathrm{OH})_{2}$ $=\mathrm{CaCO}_{3}+2 \mathrm{KOH} . \quad \mathrm{CaCO}_{3}$ is insoluble and can be separated by filtering from $\mathrm{KOH}$, which is soluble. 
$\mathrm{KOH}$, commonly called caustic potash, is a white, brittle substance which readily absorbs moisture and carbon dioxid from the air.

Experiment 26. - Preparation of $\mathrm{KOH}$. Dissolve 5 grams potassium carbonate, $\mathrm{K}_{2} \mathrm{CO}_{3}$, in an evaporating dish containing $\mathrm{I} 5 \mathrm{cc}$.

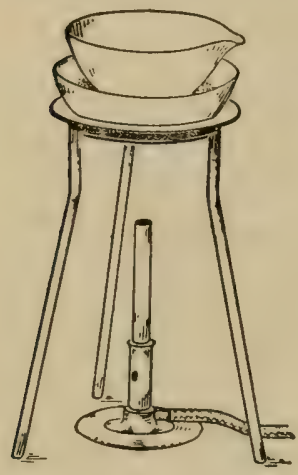

FIG. 54. - Preparation of $\mathrm{KOH}$. of water. Add a mixture of 3 grams $\mathrm{Ba}(\mathrm{OH})_{2}$ and ro cc. of water. Heat on the sand bath for five minutes. Filter off the solution. Observe the precipitate. Evaporate some of the solution to dryness in the evaporator.

Questions. - (I) Write the reaction which takes place between $\mathrm{K}_{2} \mathrm{CO}_{3}$ and $\mathrm{Ba}(\mathrm{OH})_{2}$. (2) What is the insoluble white material left on the filter paper? (3) Is the $\mathrm{KOH}$ soluble or insoluble? (4) What other material could be used in place of $\mathrm{Ba}(\mathrm{OH})_{2}$ ? (5) If $\mathrm{Na}_{2} \mathrm{CO}_{3}$ were used instead of $\mathrm{K}_{2} \mathrm{CO}_{3}$, what product would be formed? Write the reaction. (6) What reaction does $\mathrm{K}_{2} \mathrm{CO}_{3}$ give with litmus paper? (7) What reaction does $\mathrm{NaOH}$ give? (8) What are some of the uses made of $\mathrm{KOH}$ ? (9) What would result if the $\mathrm{KOH}$ in the evaporator were left exposed to the air for a day or more?

I54. Potassium Nitrate. - This salt is found in small amounts in fertile soils where conditions have been favorable for nitrification processes (see Section 92). It is extensively used in the arts, and is prepared from sodium nitrate deposits which occur as natural products known as Chile saltpeter. It is an oxidizing agent and is one of the ingredients of gunpowder, which is a mixture of sulfur, carbon, and potassium nitrate. Potassium nitrate, in small amounts, is occasionally used for the preservation of meats.

I55. Potassium Carbonate. - When wood ashes are leached, potassium carbonate is the chief alkaline salt extracted, and this product is called potash, which, by 
the removal of impurities, furnishes pure $\mathrm{K}_{2} \mathrm{CO}_{3}$. Potassium carbonate is prepared from the chlorid in the same way that sodium carbonate is prepared from its chlorid as explained in Section 162 .

156. Potassium Chlorate is prepared by the action of chlorin gas upon potassium hydrate. It is used in the laboratory as an oxidizing agent, and for the preparation of oxygen. It is one of the ingredients of safety matches.

I57. Potassium Sulfate is found in nature in the form of double salts, in the Stassfurt deposits and elsewhere. It is employed in the preparation of alum and other compounds. There are two sulfates of potassium: primary or acid potassium sulfate, $\mathrm{KHSO}_{4}$, and secondary or normal potassium sulfate, $\mathrm{K}_{2} \mathrm{SO}_{4}$.

I58. Miscellaneous Potassium Salts. - Potassium forms a large number of salts, as $\mathrm{KCl}, \mathrm{KBr}, \mathrm{KF}, \mathrm{K} 1$, $\mathrm{KCN}, \mathrm{K}_{2} \mathrm{~S}, \mathrm{KNO}_{2}$, many of which are very valuable in medicine, in the arts as photography, and in the laboratory for the preparation of other compounds. The salts of potassium vary in chemical and physical properties according to the acid elements or radicals with which the potassium is combined. All of the common salts of potassium, except the double silicates, are soluble in water.

I59. Occurrence of Sodium. - Sodium and potassium are very much alike in general properties, and form analogous salts and compounds. Sodium is not so strong a type of basic element as is potassium, and can be separated from its compounds more readily, although it is not easily replaced by other elements or by simple chemical forces. Sodium and its compounds are less expensive than potassium and its compounds. In industrial operations sodium salts are more extensively used, but to the agricultural student potassium is of greater importance 
because sodium takes little or no part in plant nutrition. In animal life, however, sodium chlorid plays an important rôle. Sodium is never found in nature in a free state, sodium chlorid being one of the most abundant of its salts. Sodium is also found as silicates and in small amounts in other forms.

I6o. Sodium Chlorid. - Extensive deposits of this salt are found in nature. In some places it is mined, the product being known as rock salt. It is in sea water in large amounts, from which it is occasionally obtained in an impure form along with a number of other salts. When pure, sodium chlorid forms colorless, transparent cubes. Much commercial salt is obtained by evaporation of water from salt springs. In some localities, water is forced into and through deposits of salt, which it dissolves, and it is then pumped out and evaporated to dryness. Sodium chlorid is extensively used for the preparation of sodium carbonate and other compounds, as hydrochloric acid. It is not found to any appreciable extent in ordinary agricultural plants, but in some alkali plants there are quite large amounts. When sodium chlorid contains impurities, as calcium chlorid and lime salts, the material readily absorbs moisture from the air, while other compounds cause it to form lumps and hard cakes. Hence a salt which readily absorbs moisture or forms hard lumps is not pure. Sodium chlorid takes little or no part in plant life, but is necessary for animal life.

I6r. Sodium Nitrate. - Extensive deposits of sodium nitrate are found in Peru, Chile, and other South American countries. It is commonly called Chile saltpeter. As stated in Section I54, it is used for the preparation of potassium nitrate and in the manufacture of nitric acid and commercial fertilizers. Sodium nitrate is commer- 
cially and agriculturally an important product. The value of nitrogen in fertilizers is usually based upon the selling price of sodium nitrate. Small amounts of this salt, formed by the process of nitrification, are found in soils of high fertility. Because of its solubility, however, it never accumulates in soils.

I62. Sodium Carbonate. - Commercially, this salt is known as soda, and is one of the most useful chemicals manufactured. It is used in the making of soap and glass, and in other commercial operations. It is prepared by two processes, one known as Le Blanc process, and the other as ammonia or Solvay process. By Le Blanc process, it is prepared from sodium chlorid treated with sulfuric acid, which produces $\mathrm{Na}_{2} \mathrm{SO}_{4}$.

$$
{ }_{2} \mathrm{NaCl}+\mathrm{H}_{2} \mathrm{SO}_{4}=\mathrm{Na}_{2} \mathrm{SO}_{4}+{ }_{2} \mathrm{HCl} \text {. }
$$

The sodium sulfate is heated with charcoal; which produces sodium sulfid.

$$
\mathrm{Na}_{2} \mathrm{SO}_{4}+{ }_{2} \mathrm{C}=\mathrm{Na}_{2} \mathrm{~S}+{ }_{2} \mathrm{CO}_{2} .
$$

When heated with calcium carbonate, sodium sulfid forms sodium carbonate and calcium sulfid, the latter product being insoluble in water, while sodium carbonate is soluble in water and hence is readily separated by filtration. The process of manufacture usually consists in mixing coal and calcium carbonate with sodium sulfate, the product being known as crude soda, which is refined, and from which calcined and crystallized soda are obtained.

In the Solvay process, $\left(\mathrm{NH}_{4}\right)_{2} \mathrm{CO}_{3}$ is employed, which forms, with sodium chlorid, $\mathrm{HNaCO}_{3}$, which when heated yields $\mathrm{Na}_{2} \mathrm{CO}_{3}, \mathrm{CO}_{2}$, and $\mathrm{H}_{2} \mathrm{O}$.

I63. Sodium Hydroxid. - This base is prepared in the same way as $\mathrm{KOH} ; \mathrm{Na}_{2} \mathrm{CO}_{3}$ being used in place of $\mathrm{K}_{2} \mathrm{CO}_{3}$. $\mathrm{NaOH}$ is extensively used in the manufacture of soaps. 
I64. Sodium Phosphates. - Sodium forms three phosphates: primary sodium phosphate, secondary sodium phosphate, $\mathrm{Na}_{2} \mathrm{HPO}_{4}$, and tertiary or normal sodium phosphate, $\mathrm{Na}_{3} \mathrm{PO}_{4}$. Phosphates of soda are not found to any appreciable extent in soils, because phosphoric acid forms, with iron, alumina, and calcium, which are always present, insoluble compounds.

165. Miscellaneous Sodium Salts. - Like potassium, sodium forms a large number of salts, as $\mathrm{Na}_{2} \mathrm{SO}_{4}, \mathrm{NaHSO}_{4}$, $\mathrm{NaBr}, \mathrm{NaCN}, \mathrm{Na}_{2} \mathrm{~S}$ and $\mathrm{Na}_{2} \mathrm{O}$. Sodium compounds are

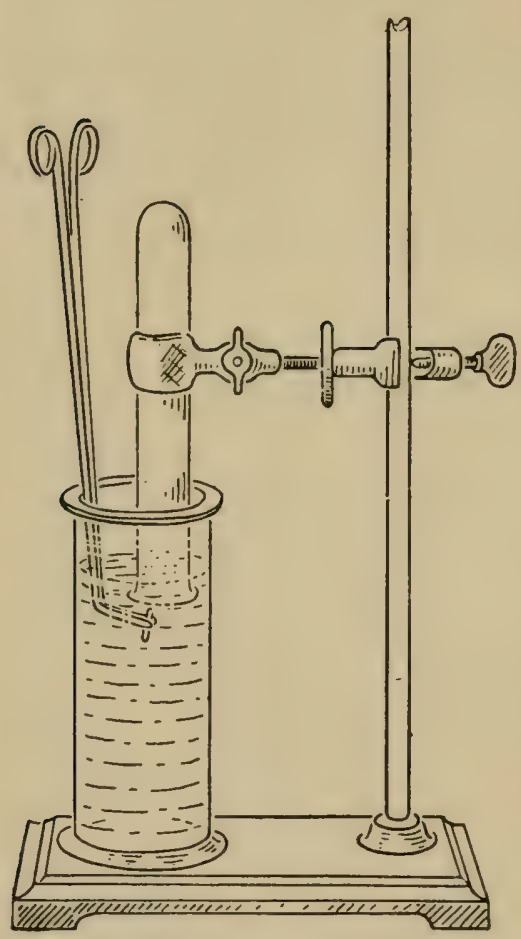

FIG. 55.-Decomposition of water by the use of sodium. all soluble except the silicates and a few of the more complex salts.

As previously stated, salts of sodium are similar to the corresponding salts of potassium. The sodium compounds are among the most useful and important compounds found in nature.

Experiment 27. - Fill a cylinder about two thirds full of water, and place upon the surface of the water a piece of $\mathrm{Na}$ about half as large as a pea, using forceps for the purpose. If there is no small piece of $\mathrm{Na}$ in the bottle, one may be cut by means of a knife without removing the $\mathrm{Na}$ from the naphtha which surrounds it. Observe the result when the $\mathrm{Na}$ is placed upon the water. The apparatus can be arranged and the escaping hydrogen collected as shown in Fig. 55. (The test tube should be filled with water and the Na wrapped in a piece of filter-paper.) 
Questions. - (I) Give the reaction which takes place between $\mathrm{Na}$ and $\mathrm{H}_{2} \mathrm{O}$. (2) What gas is liberated? (3) What becomes of $\mathrm{Na}$ in the experiment? (4) Is this product soluble or insoluble? (5) Test the liquid in the cylinder with litmus paper and observe the result. (6) Is $\mathrm{Na}$ a light or heavy metal? Why? (7) Is it active or inert? (8) Why is $\mathrm{Na}$ always kept in a bottle containing naphtha or kerosene? (9) Since $\mathrm{NaCl}$ is found in sea water, why does not $\mathrm{Na}$ of the $\mathrm{NaCl}$ decompose sea water as the element $\mathrm{Na}$ did the water in this experiment? 


\section{CHAPTER XIX}

Calcium, Magnesium, and their Compounds

I66. Occurrence of Calcium. - This element is found widely distributed in nature in the form of calcium carbonate, $\mathrm{CaCO}_{3}$, calcium phosphate, $\mathrm{Ca}_{3}\left(\mathrm{PO}_{4}\right)_{2}$, and calcium sulfate, $\mathrm{CaSO}_{4}$, and is a yellowish metal which readily oxidizes and decomposes water. It enters into the composition of both plant and animal bodies and takes an important part in life processes. Its compounds are useful in the industries, lime, cement, and mortar being

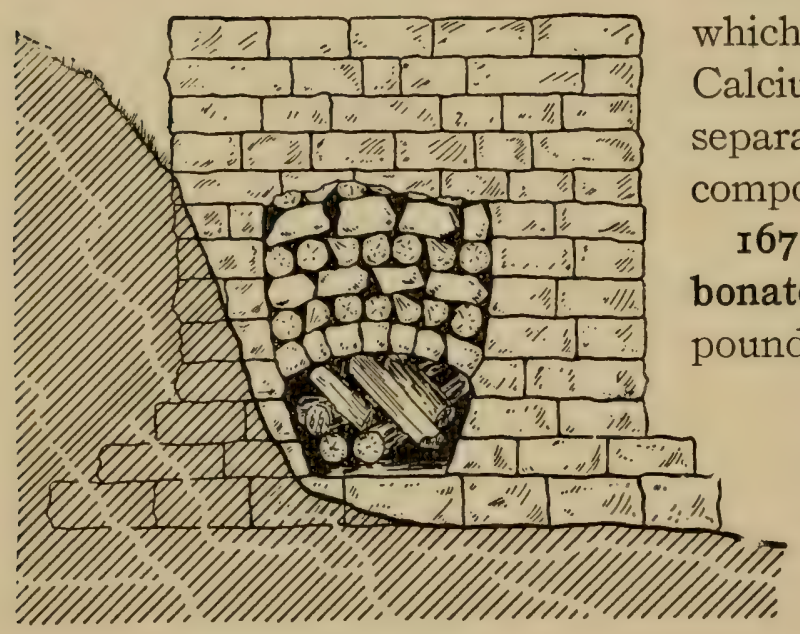

Fig. 56.-Sec'ion of lime kiln. some of the forms in which it is employed. Calcium is not easily separated from its compounds.

I67. Calcium Carbonate. - This compound, in the form of limestone and marble, is found extensively. It is somewhat soluble in water charged with carbon dioxid, and hence many waters, as stated in Section 65 , owe their hardness to its presence. Calcium carbonate is used principally for the preparation of quicklime, 
in the manufacture of glass, and in the refining of some metals, where it is employed as a flux.

I68. Calcium Oxid. - When calcium carbonate is subjected to heat, as in lime kilns or specially constructed furnaces, the carbon dioxid is separated and the oxid obtained. Layers of limestone and wood are placed alternately in the lime kiln, as shown in Fig. 56. The combustion of the wood furnishes the necessary heat for the decomposition of the carbonate. Calcium oxid or quicklime readily combines with both the carbon dioxid and the moisture of the air,. forming air-slaked lime. During this process of slaking, there is a material increase in volume, often resulting in the bursting of the barrels in which the lime is stored. Calcium oxid is used for the preparation of calcium hydroxid and mortar.

I69. Calcium Hydroxid. - When water is added to calcium oxid or quicklime, the material undergoes the slaking process, and calcium hydroxid, $\mathrm{Ca}(\mathrm{OH})_{2}$, is produced.

$$
\mathrm{CaO}+\mathrm{H}_{2} \mathrm{O}=\mathrm{Ca}(\mathrm{OH})_{2} .
$$

Calcium hydroxid or slaked lime readily absorbs carbon dioxid from the air and forms calcium carbonate. $\mathrm{Ca}(\mathrm{OH})_{2}$ is somewhat soluble in water, forming what is commonly called lime water. When carbon dioxid is passed into lime water, the solution becomes turbid, due to the formation of $\mathrm{CaCO}_{3}$. This reaction furnishes a means of testing for carbon dioxid. If a small amount of

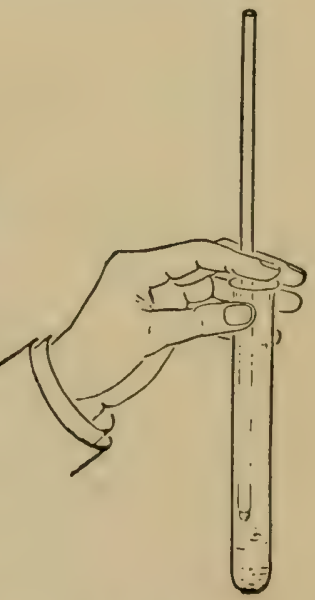

FIG. 57. any material supposed to contain carbonates is placed in a test tube with a little water, and then a small glass 
tube or loop tube containing a few drops of lime water is inserted in the test tube, after the gas is liberated by hydrochloric acid, the drop of lime water becomes turbid, due to the formation of $\mathrm{CaCO}_{3}$ (see Fig. 57).

I70. Calcium Sulfate. - Deposits of this salt known as gypsum, $\mathrm{CaSO}_{4} .2 \mathrm{H}_{2} \mathrm{O}$, are found abundantly in some localities. Gypsum or land plaster is used as a fertilizer and also for the preparation of plaster of Paris. The "setting" of plaster of Paris is due to the fact that when the water of crystallization has been expelled, the substance is again capable of taking up water, expanding, and forming a hard mass.

I7I. Calcium Chlorid. - This salt is not found in nature to any appreciable extent. It is employed in the laboratory in desiccators and for the drying of gases.

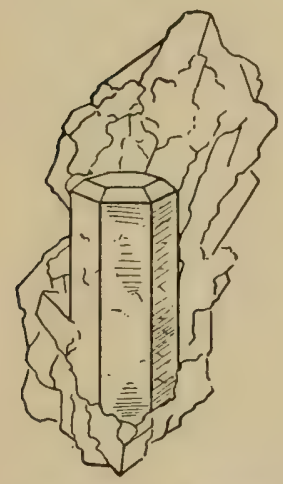

FIG. 58. - Apatite rock.

I72. Bleaching-powder is made by passing chlorin into a solution of lime water. The chlorin is held in chemical combination, forming calcium hypochlorite, $\mathrm{Ca}(\mathrm{ClO})_{2}$, which readily gives up its chlorin and is extensively used for bleaching and disinfecting purposes, as explained in Section 89.

I73. Calcium Phosphate. - Deposits of this material are found in nature in various physical forms as soft phosphate, and in crystalline form, as apatite rock, see Fig. 58. Calcium phosphate is extensively used for the preparation of commercial fertilizers, as explained in Section Iog.

I74. Mortar. - When quicklime is slaked and mixed with sand, it forms at first a mechanical mixture. When it is placed upon the walls of buildings, a chemical change, 
known as the hardening or setting process, takes place. When this change occurs, the moisture is expelled and the carbon dioxid of the air changes the calcium hydroxid to calcium carbonate. In the slaking of lime and the setting of mortar, the following reactions take place:

$$
\begin{aligned}
& \text { (I) } \mathrm{CaO}+\mathrm{H}_{2} \mathrm{O}=\mathrm{Ca}(\mathrm{OH})_{2} \text {. } \\
& \text { (2) } \mathrm{Ca}(\mathrm{OH})_{2}+\mathrm{CO}_{2}=\mathrm{CaCO}_{3} \text {. }
\end{aligned}
$$

When magnesium carbonate and aluminum silicate are present, forming part of the composition of the original lime rock, hydraulic cement is produced, which has the property of setting under water.

Experiment 28. - Testing quality of lime. Place about 40 grams of lime, $\mathrm{CaO}$, in an evaporating dish and moisten with water warmed to about $350^{\circ} \mathrm{C}$. Note the reaction. Good lime readily undergoes the slaking process. Place some of the slaked lime in a bottle, add about roo cc. of distilled water, shake vigorously and leave the lime in contact with the water for four hours or longer, then filter some of the solution of lime water, and test it by forcing respired air through it as explained in Experiment 24.

Place about one half gram of the slaked lime in a test tube, add ro cc. of water and then a few drops of $\mathrm{HCl}$. When action ceases, add more $\mathrm{HCl}$, a little at a time, and heat. The material which fails to dissolve usually consists of insoluble silica and clay. Lime of a high degree of purity contains less than ro per cent of acidinsoluble impurities.

Questinns. - (I) Was any heat evolved when the lime was slaked ? Why? (2) Did any noticeable change take place in volume during slaking? (3) What is lime water? (4) What is shown by forcing respired air through the lime water of the test tube? (5) Write the reaction which took place. (6) Write the reaction when $\mathrm{HCl}$ was added to $\mathrm{Ca}(\mathrm{OH})_{2}$.

I75. Glass. - Glass is a double silicate of calcium and sodium, produced by fusing pure sand, sodium carbonate, and lime. To make Bohemian or hard glass potassium 
carbonate is substituted for the sodium salt. Other kinds and varieties of glass are made by introducing other substances and giving different mechanical treatment to the material during its preparation.

I76. Occurrence of Magnesia. - This element does not occur as extensively in nature as calcium, which it resembles in many respects. It is found mainly associated with calcium in the mineral dolomite, which is a double carbonate of calcium and magnesium. Magnesium is found in both plant and animal substances, as is calcium, but is separated from its compounds more readily than calcium. In some plants, and in some parts of the plant, as in the seeds of grains, it is found more abundantly than calcium. It is generally considered an essential element of plant food. The compounds of magnesium resemble those of calcium in many respects, but differ materially from the calcium salts in both chemical and physical properties.

I77. Magnesium Salts. - Magnesium carbonate and magnesium sulfate (Epsom's salt) are among the most common of the magnesium compounds. Magnesium chlorid, $\mathrm{MgCl}_{2}$, and $\mathrm{MgSO}_{4}$ are found as double salts in the Stassfurt deposits. Magnesium oxid is obtained by combustion of magnesium. Magnesium forms also other compounds, as nitrates, phosphates, silicates, etc.

Experiment 29. - Hold a piece of magnesium ribbon about an inch long in the forceps and apply a lighted match to the ribbon. Examine the product.

Questions. - (I) What are some of the chemical properties of the element as observed from this experiment? (2) What product was formed? Write the reaction. (3) Which would weigh more, the original magnesium ribbon or the white powder obtained from its combustion? Why? (4) Why does magnesium produce such an intense light? 


\section{CHAPTER XX}

Iron, Aluminum, and their Compounds

178. Occurrence of Iron. - Iron is found in nature mainly in the form of its oxids, hematite, $\mathrm{Fe}_{2} \mathrm{O}_{3}$, and magnetite, $\mathrm{Fe}_{3} \mathrm{O}_{4}$. It also occurs as carbonate, $\mathrm{FeCO}_{3}$, pyrite, $\mathrm{FeS}_{2}$, and brown iron ore or basic hydroxid. In the soil it is in combination with silicon and other elements, forming double silicates. It enters into the composition of all plant and animal bodies and has an essential part in plant growth and animal life. Some waters contain carbonate of iron which, like calcium carbonate, is soluble in the presence of carbon dioxid. Upon exposure to the air, the iron is precipitated as hydroxid, forming a brown deposit. Iron takes an important part in industrial operations, and its chemistry has been more extensively studied than that of any other element.

I79. Reduction of Iron Ores. - Only iron ores of high degree of purity are in condition, as mined, for the blast furnace. Magnetic iron ore is concentrated and separated from its impurities by magnetic concentrators. The blast furnace used for the production of cast iron is constructed of brick; a type of it is shown in Fig. 59. Ore, coke, and flux, usually limestone, are mixed in the right proportions and introduced into the top of the furnace. The flux is used to separate the impurities, forming a fusible slag which is largely calcium silicate. Hot air is forced into the furnace by means of blowing engines, through tuyeres. The carbon dioxid produced is first 


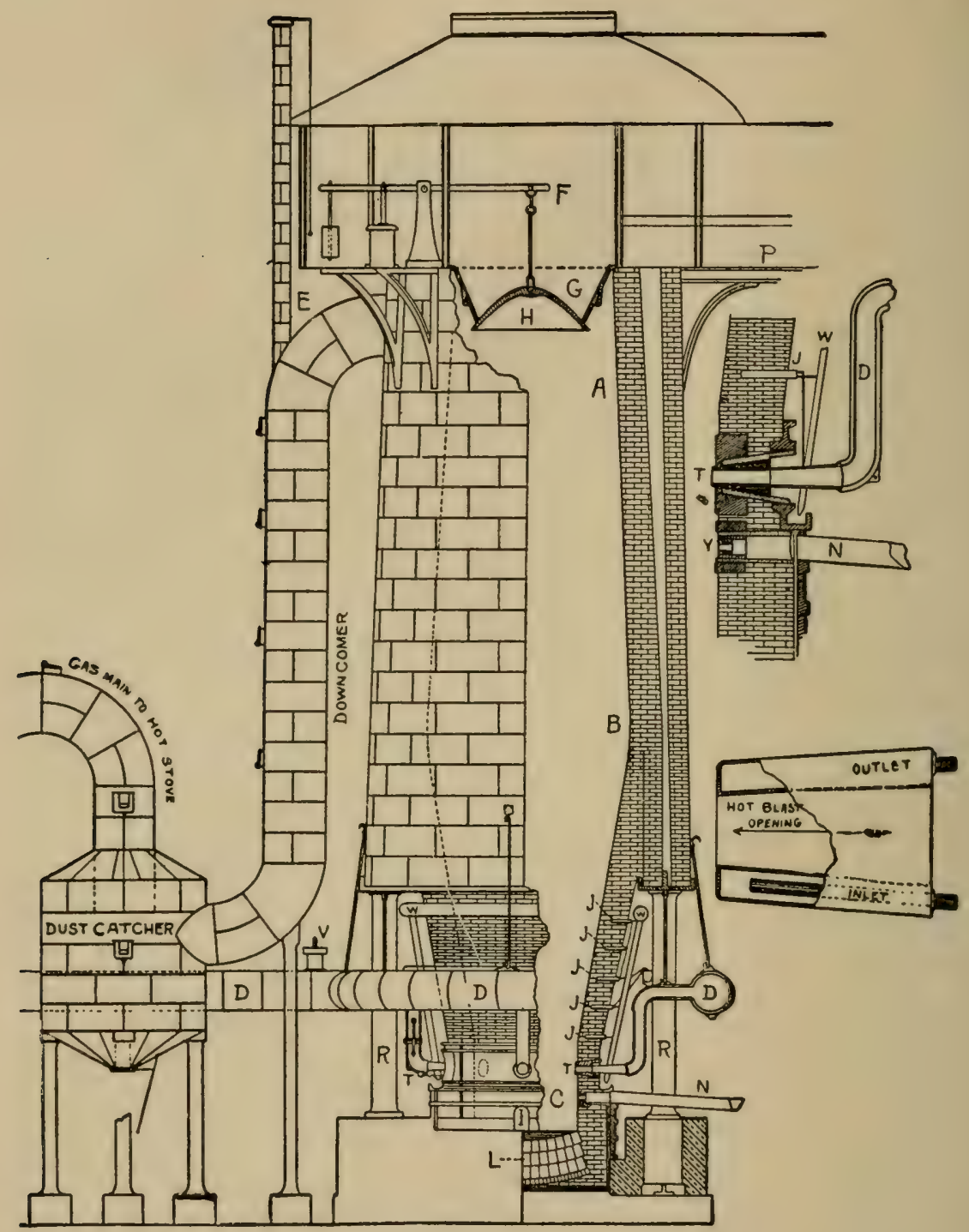

FIG. 59. - Blast-furnace (after Hart). 
reduced to carbon monoxid, which passes over the heated ore in the upper part of the furnace, and is the main reducing agent of the blast furnace. The carbon monoxid given off at the top of the furnace is collected and used for heating the blast. The furnace is constructed to utilize the heat to the best advantage so the blast can act efficiently. The slag which carries a large portion of the impurities of the ore, being lighter than the molten iron, collects on the surface and is removed from time to time. The molten iron is run off from the bottom of the furnace into molds; iron that is produced in this way is known as pig iron. It contains a number of impurities, as phosphorus, carbon, silicon, and sulfur.

I80. Wrought Iron. - Wrought iron is produced from cast iron by two processes: (I) puddling, which consists of oxidizing the impurities by means of a blast of hot air passed over or blown through the iron, and known as the Bessemer process; and (2) cementation, by which the cast iron is mixed with iron ores reasonably pure and heated to a high temperature so that the oxygen of the ores may oxidize the carbon, phosphorus, and sulfur of the cast iron. Wrought iron is the purest commercial form of iron. It usually contains about 0.5 per cent of carbon, and melts at about $2000^{\circ} \mathrm{C}$. The nature of the impurities determines the character of both wrought iron and steel, as any increase in the amount of carbon decreases its malleability and other desirable properties.

I8I. Steel. - This form of iron contains less carbon than cast iron, but more than wrought iron. It is prepared by oxidizing the impurities of iron with a blast of hot air. The cast iron is heated in converters and then there is forced through it a blast of hot air which oxidizes most of the impurities. By adding cast iron, steel con- 


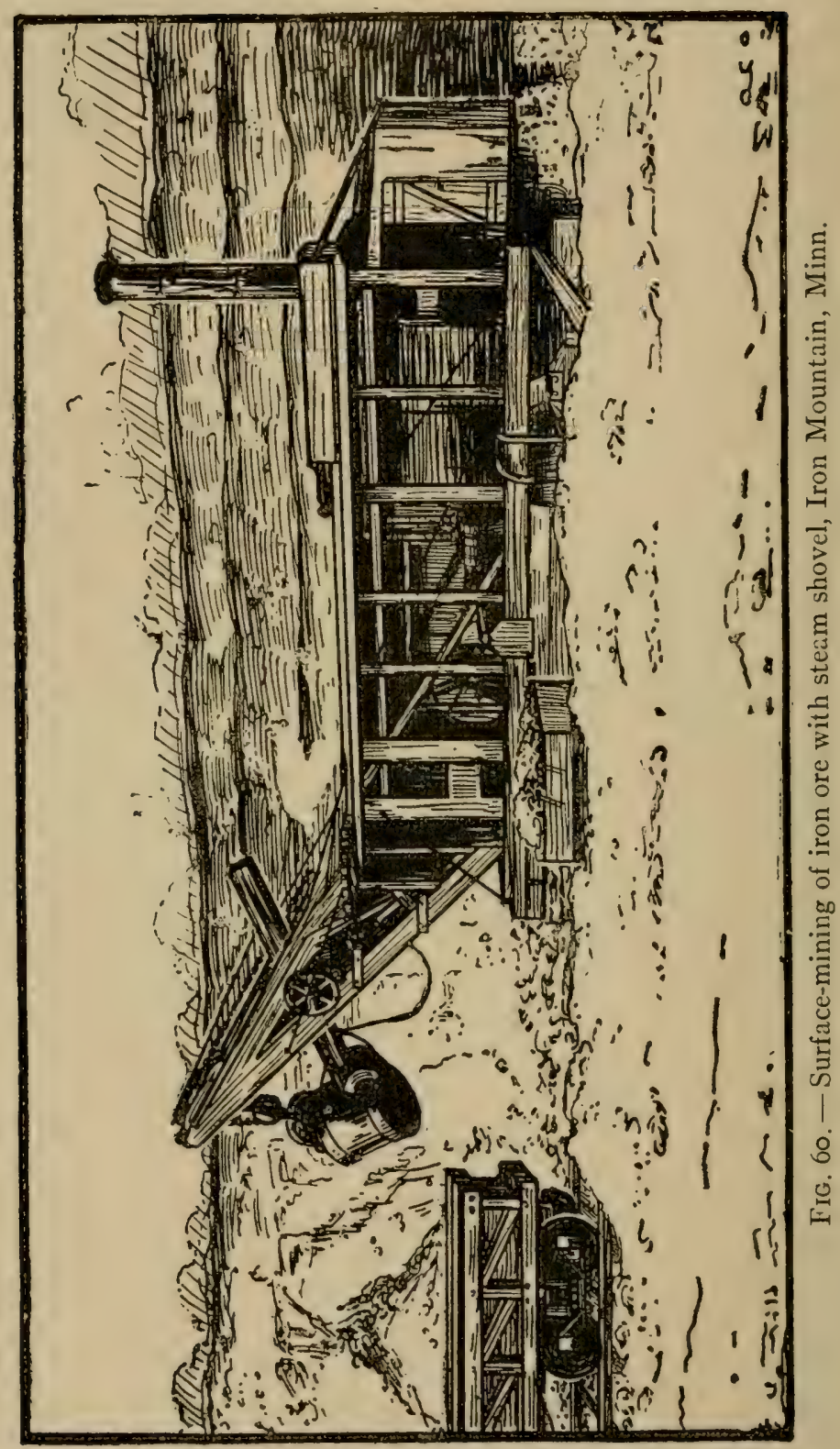


taining almost any desired amount of carbon can be obtained. Iron and steel wire are made by drawing rods through hardened steel plates, the material being properly tempered during the operation. The thin coat of oxid formed on the surface is removed by dipping the wire into a bath of dilute sulfuric acid.

I82. Rusting of Iron. - Iron in all of its forms readily undergoes oxidation and rusting, due to the joint action of oxygen and water, and results in the production of a basic oxid of iron. When the surface of iron is protected, as by painting, oxidation and rusting are prevented. When iron is heated to its kindling temperature, it readily oxidizes, as in Experiment I. In welding iron, oxidation is prevented as far as possible by manipulation and occasionally by the use of some material, as borax, to remove the thin coating of oxid. Iron is readily acted upon by all acids, forming a large number of salts.

183. Iron Compounds. - Iron forms two series of salts : ferrous and ferric. Ferrous sulfate, $\mathrm{FeSO}_{4}$, commonly called copperas, is used most extensively of any of the iron salts, especially in the dyeing of cloth, and to some extent as a disinfectant.

Experiment 30. - Dissolve 0.5 gram of ferrous sulfate in $20 \mathrm{cc}$. of water. Filter if the solution is not clear, and divide the filtrate into two portions. To the first portion, add a few drops of ammonium hydroxid until a precipitate is obtained. To the second portion, add about 5 drops of strong nitric acid. Heat to boiling; when cool, add ammonia to neutralize the acid and precipitate the iron. Nitric acid oxidizes iron and changes it from the ferrous to the ferric state. Compare the two precipitates.

Questions. (I) What was formed when $\mathrm{NH}_{4} \mathrm{OH}$ was added to $\mathrm{FeSO}_{4}$ ? Write the reaction. (2) Give the color and other physical properties. (3) What change did the $\mathrm{HNO}_{3}$ produce? (4) What change did you observe in the color of the solution during the boil- 
ing ? (5) What was produced when $\mathrm{NH}_{4} \mathrm{OH}$ was added to $\mathrm{Fe}_{2}\left(\mathrm{SO}_{4}\right)_{3}$ ? Write the reaction. (6) Give the color and some of the physical properties. (7) How does this last precipitate differ from the first one obtained?

Experiment 3 I. - Dissolve I gram tannic acid in $25 \mathrm{cc}$. of hot water. Dip a piece of cotton cloth into this solution. Dry the cloth and then dip it into a solution of ferrous sulfate (I gram per 25 cc. of water). After the cloth has dried, see if the color can be removed by washing. Add $5 \mathrm{cc}$. of ferrous sulfate solution to $5 \mathrm{cc}$. of tannic acid solution. Observe the result. The $\mathrm{FeSO}_{4}$ forms, with the tannic acid, iron tannate.

Questions. - (I) Would the $\mathrm{FeSO}_{4}$ alone give the same color to the cloth? Why? (2) Was the color a permanent one? (3) Tea contains tannic acid; why does tea prepared in an iron kettle give a black infusion? (4) What was produced when the solution of $\mathrm{FeSO}_{4}$ was added to the tannic acid?

I84. Occurrence of Aluminum. - Aluminum is a grayish white metal much lighter than iron and of greater tensile strength, and is found mainly as one of the constituents of clay $\left(\mathrm{Al}_{4}\left(\mathrm{SiO}_{4}\right)_{3}+{ }_{4} \mathrm{H}_{2} \mathrm{O}\right)$ that is formed from the disintegration of feldspar, $\mathrm{AlKSi}_{3} \mathrm{O}_{8}$, a double silicate of potassium and aluminum. It is also found in other combinations, as in mica and cryolite $\left(\mathrm{Na}_{3} \mathrm{AlF}_{6}\right)$, and is present in nearly all soils and in small amounts in plant substances, although it takes no part as plant food. Aluminum is not easily isolated from its compounds. It can be produced by treatment of its chlorid with sodium, but is now extensively prepared by electrolysis. When pure, it is not so readily oxidized or acted upon by acids as is iron. Aluminum forms a large number of compounds and also alloys with many of the metals.

185. Alums. - In industrial operations, alum is used most extensively of any of the compounds of aluminum. An alum is a double sulfate of aluminum. It has the general composition of $\mathrm{MAl}(\mathrm{SO})_{2} \mathrm{I}_{2} \mathrm{H}_{2} \mathrm{O}$, in which $\mathrm{M}$ represents 
any monovalent metal, as potassium. The Al can also be replaced by a trivalent element. Alum is used in the tanning of leather, in the manufacture of paper, and in the coloring of cloth as the basis of the mordant or material for making the dye permanent. Alum is also used occasionally in the preparation of baking powders.

Experiment 32. - Add a few drops of alum solution to a test tube containing $5 \mathrm{cc}$. of water, and then add a few drops of tincture of logwood and 2 cc. $\left(\mathrm{NH}_{4}\right)_{2} \mathrm{CO}_{3}$. Observe the result. Mix about 2 grams of flour in a dish with water containing a few drops of alum. Add a few drops of logwood and the same amount of ammonium carbonate solution; mix well, and observe the result. Repeat the test, using a baking powder, and test for the presence or absence of alum. In the presence of alum, a blue color is always obtained with tincture of logwood and ammonium carbonate solution.

Experiment 33. - To a solution of egg albumin, add a few drops of alum solution and observe the result.

Questions. - (I) Does the alum cause a precipitate? (2) Of what is the precipitate composed? (3) How would alum act in the digestive tract in the presence of soluble albuminous compounds? (4) Why is alum an undesirable ingredient in baking powders and foods?

I86. Pottery. - Pure clay or kaolin is used for the manufacture of the best grades of porcelain and pottery. The plastic clay is modeled into the desired form and then dipped into a bath containing feldspar and other materials which, when fused, form the glaze. Ordinary earthenware is made from impure clay which contains compounds of iron and other elements. Brick and tile are also made from clay, the physical properties, as color, hardness, wearing qualities, etc., depending upon the amounts of iron, lime, magnesia, and alkalies present. As ordinarily found in the soil, clay is mechanically associated 
with a large number of other substances, many of which contain the elements essential to plant life, as potassium and calcium. Pure clay itself contains no plant food, but clay soils are usually among the most fertile because, along with the disintegration of feldspar and other rocks, various minerals that impart fertility are made available and are associated with the clay. 


\section{CHAPTER XXI}

Copper, Zinc, Lead, Tin, Arsenic, Mercury, and their Compounds aNd Alloys

187. Commercial Importance. - The compounds of copper, zinc, lead, tin, and arsenic, while they do not enter into the composition of either plant or animal bodies, are of value in agriculture because of their presence in many useful materials.

\section{I88. Occurrence of Copper and its Metallurgy. -} Copper is found in the free state and also in combination with oxygen as $\mathrm{CuO}$ and $\mathrm{Cu}_{2} \mathrm{O}$, with sulfur as $\mathrm{Cu}_{2} \mathrm{~S}$, and with iron and sulfur as copper pyrite, $\mathrm{Cu}_{2} \mathrm{~S} \cdot \mathrm{Fe}_{2} \mathrm{~S}_{3}$. The ores of copper are first roasted, and if iron is present in large amounts, it is removed as a silicate. The " matte," as it is called, thus produced is subjected to further refining. Copper is also separated by electrolysis.

I89. Copper Sulfate. - This salt is used the most extensively of any of the copper compounds, and is produced by the action of sulfuric acid upon either metallic copper or its sulfid. It crystallizes with 5 molecules of water of crystallization. It is commonly called blue vitriol, and is extensively used in the preparation of pigments, for the preservation of wood, for copper-plating, and for the treatment of fungous diseases of plants, as in the Bordeaux mixture, where it is the principal ingredient.

Experiment 34.-Dissolve 6.2 grams of copper sulfate, 3.50 grams of sodium potassium tartrate, and $2 \frac{1}{2}$ grams $\mathrm{KOH}$ in $100 \mathrm{cc}$. of water. This is Fehling's solution. Dissolve o.I gram of glucose 
in $5 \mathrm{cc}$. of water, add $5 \mathrm{cc}$. of alkaline copper sulfate solution and heat to boiling. Observe the brown precipitate of $\mathrm{Cu}_{2} \mathrm{O}$. The amount of $\mathrm{Cu}_{2} \mathrm{O}$ produced is proportional to the amount of glucose present, and when the work is carefully done and the copper weighed or determined by other means, the per cent of glucose in a material can be determined. A hot alkaline solution of copper sulfate (Fehling's solution) is reduced to $\mathrm{Cu}_{2} \mathrm{O}$ in the presence of glucose and a few other organic compounds.

I90. Bordeaux Mixture. - In this preparation, the copper is present as an insoluble hydroxid. To prepare the Bordeaux mixture I2.5 pounds of copper sulfate are dissolved in about 2 gallons of hot water; 3.5 pounds of lime are slaked in 2 gallons of water, and strained into a barrel through a coarse cloth to remove any large pieces. The solution of copper sulfate is then poured into the barrel and well stirred. The reaction which takes place is

$$
\mathrm{Ca}(\mathrm{OH})_{2}+\mathrm{CuSO}_{4}=\mathrm{Cu}(\mathrm{OH})_{2}+\mathrm{CaSO}_{4} \text {. }
$$

In preparing the Bordeaux mixture, just sufficient lime should be used to combine with all of the copper.

I9I. Occurrence of Zinc. - This metal is found in nature mainly as zinc carbonate, $\mathrm{ZnCO}_{3}$, and to a less extent as the sulfid. Small amounts are in other forms. Zinc is separated from its ores by roasting with charcoal, which volatilizes. It is then collected as zinc dust, purified, and prepared for various purposes.

I92. Compounds of Zinc. - Zinc forms a large number of compounds, as $\mathrm{ZnCl}_{2}, \mathrm{Zn}(\mathrm{OH})_{2}, \mathrm{ZnS}$, and $\mathrm{ZnSO}_{4}$. Some of the zinc salts are used in the preparation of paints, while the metal itself is employed in many ways, as in making alloys, solder, and galvanized iron.

I93. Galvanized Iron. - Iron is galvanized by being covered with a layer of zinc. Galvanized iron is exten- 
sively used for water pipes because it does not rust so readily as ordinary iron. When heated, however, the zinc coating is removed.

194. Occurrence of Tin. - Tin is found in nature largely in the form of the oxid, $\mathrm{SnO}_{2}$, and, to a less extent, in combination with other metals. The oxid is heated in a furnace with charcoal, and the molten tin cast into bars.

195. Tin Salts. - Tin forms two series of salts, stannous and stannic. In the former, the element is bivalent, and in the latter, it is tetravalent. Stannous and stannic chlorid, the sulfid, oxid, and hydroxid are among the more common tin salts. They are used in the arts in various ways as pigments and as mordants in the coloring of cloth. Tin forms a number of alloys and is extensively used for roofing and for other purposes. Ordinary tinware is simply iron coated with a layer of tin.

I96. Occurrence of Lead. - Lead occurs principally in the form of sulfid (galena). It is also found in combination with silver and other metals, and, in the process of refining silver, is separated as a by-product.

I97. Oxids of Lead. - There are four oxids of lead; namely, lead monoxid, $\mathrm{PbO}$, lead peroxid, $\mathrm{PbO}_{2}$, lead suboxid, $\mathrm{Pb}_{2} \mathrm{O}$, and lead sesquioxid, $\mathrm{Pb}_{2} \mathrm{O}_{3}$. The suboxid, $\mathrm{Pb}_{2} \mathrm{O}$, is produced when lead is exposed to the air. In a pure condition, it is a black powder. Lead oxid, $\mathrm{PbO}$, is a yellow powder which, if heated, produces litharge, a yellowish red material obtained largely in the separation of lead from silver. Lead peroxid, $\mathrm{PbO}_{2}$, is an oxidizing agent, and in some respects resembles manganese dioxid. Red lead or minium, $\mathrm{Pb}_{3} \mathrm{O}_{4}$, is made by heating lead oxid, and is used as a pigment.

198. Lead Carbonates. - The normal carbonate, $\mathrm{PbCO}_{3}$, is occasionally found in nature. The basic car- 
bonate, $\mathrm{Pb}(\mathrm{OH})_{3} \cdot{ }_{3} \mathrm{PbCO}_{3}$, is common white lead so extensively used as a pigment. It is produced by different methods from litharge and other compounds of lead, as well as by treatment of the metal itself.

I99. Lead Salts. - Lead nitrate, $\mathrm{Pb}\left(\mathrm{NO}_{3}\right)_{2}$, is produced by the action of nitric acid on lead; and lead sulfate, by the action of a sulfate upon a soluble lead salt. Lead chlorid, $\mathrm{PbCl}_{2}$, is precipitated whenever hydrochloric acid or a chlorid is added to a solution containing a lead salt. The salts of lead are more insoluble than those of many other metals.

200. Uses of Lead. - Lead is used for making water pipes, in the preparation of solder and many alloys, and for lining tanks, particularly those in which sulfuric acid is stored. Lead is insoluble in most waters, although the salts and organic matter in some waters may cause enough to dissolve to render the use of lead pipes objectionable from a sanitary point of view.

201. Occurrence of Arsenic. - This element occurs in the free state to a limited extent, but is usually in combination with other elements, as oxygen, iron, and sulfur. In some of its properties, arsenic resembles phosphorus, and forms similar compounds, although arsenic has weaker acid properties than phosphorus. It forms a large number of compounds, among which are the arsenates and arsenites, which are salts of arsenic and arsenious acids. In the presence of a strong base element, arsenic deports itself as an acid, while with a strong acid element, it exhibits basic properties. Other elements, particularly antimony and bismuth, and to a less extent aluminum, have this same property of acting both as acid- and base-forming elements. Some of the compounds of arsenic are extensively used as pigments and insecticides. 
202. Paris Green. - Pure Paris green is an acetoarsenite of copper and has the following composition: Copper oxid, 31.29 per cent, arsenious oxid, 58.65 per cent, acetic acid, ro. 06 per cent. Some of the commercial grades of Paris green contain an excess of soluble forms of arsenic, while others are adulterated with lime and insoluble silicates. The arsenic should be practically insoluble and have no injurious effect upon vegetation. In case much soluble arsenic is present, the foliage is destroyed. Pure Paris green should completely dissolve in hydrochloric acid. If silica is a constituent, an insoluble residue appears when the material is treated with hydrochloric acid. London purple and various arsenates and arsenites are occasionally used for insecticides. London purple contains soluble arsenic. In case of accidental poisoning with Paris green, hydroxid of iron is usually employed as an antidote.

203. Occurrence of Mercury. - Mercury is found in nature mainly in the form of the sulfid, $\mathrm{HgS}$, commonly called vermilion, which, when roasted, yields $\mathrm{SO}_{2}$ and $\mathrm{Hg}$. Mercury is extensively used in the preparation of alloys and amalgams.

204. Compounds of Mercury. - Like copper, tin, and many other elements, mercury forms two series of salts, the mercurous and mercuric compounds. Mercurous and mercuric oxids, $\mathrm{Hg}_{2} \mathrm{O}$ and $\mathrm{HgO}$, mercurous and mercuric chlorids, $\mathrm{HgCl}$ and $\mathrm{HgCl}_{2}$, and the nitrates and sulfids are among the more important compounds of mercury. Mercuric chlorid is employed as an insecticide and also as a germicide. It is very poisonous and very destructive to all forms of animal and plant life, and is frequently used for the treatment of fungus diseases of plants. 
Experiment 35. - Replacement of metals. Place, in separate test tubes, (I) $5 \mathrm{cc}$. of silver nitrate, (2) $5 \mathrm{cc}$. copper nitrate, and (3) 5 cc. of lead nitrate. To the first test tube, add a piece of cop-

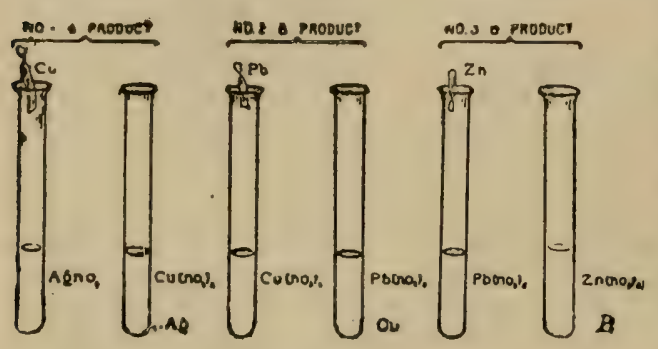

Fig. 61. per foil, to the second, a small piece of lead, and to the third, a piece of zinc. After a few minutes, examine the contents of the various test tubes and observe the results. Copper has the power of replacing silver in solution, lead has the power of replacing copper, and zinc has the power of replacing lead.

The more electropositive elements replace those which are less electropositive. Observe in these experiments that the copper is coated with silver, the lead with copper, and the zinc with lead. Write the following reactions which have taken place:

(I) $\mathrm{AgNO}_{3}+\mathrm{Cu}=$

(2) $\mathrm{Cu}\left(\mathrm{NO}_{3}\right)_{2}+\mathrm{Pb}=$

(3) $\mathrm{Pb}\left(\mathrm{NO}_{3}\right)_{2}+\mathrm{Zn}=$

Questions. - (I) Which element is the most positive? (2) What elements can zinc replace? (3) Why does copper replace silver? (4) Why does lead replace copper? (5) What does this experiment show as to the relative properties of the three elements, copper, silver, and lead? 
PART II 



\section{CHAPTER XXII \\ Water Content and Ash of Plants}

205. Water. - There is water in all food materials, and in many cases it makes up a large portion of the weight of a substance. In vegetables, in milk, and in the juices of meat, water is present to such an extent as to be per-

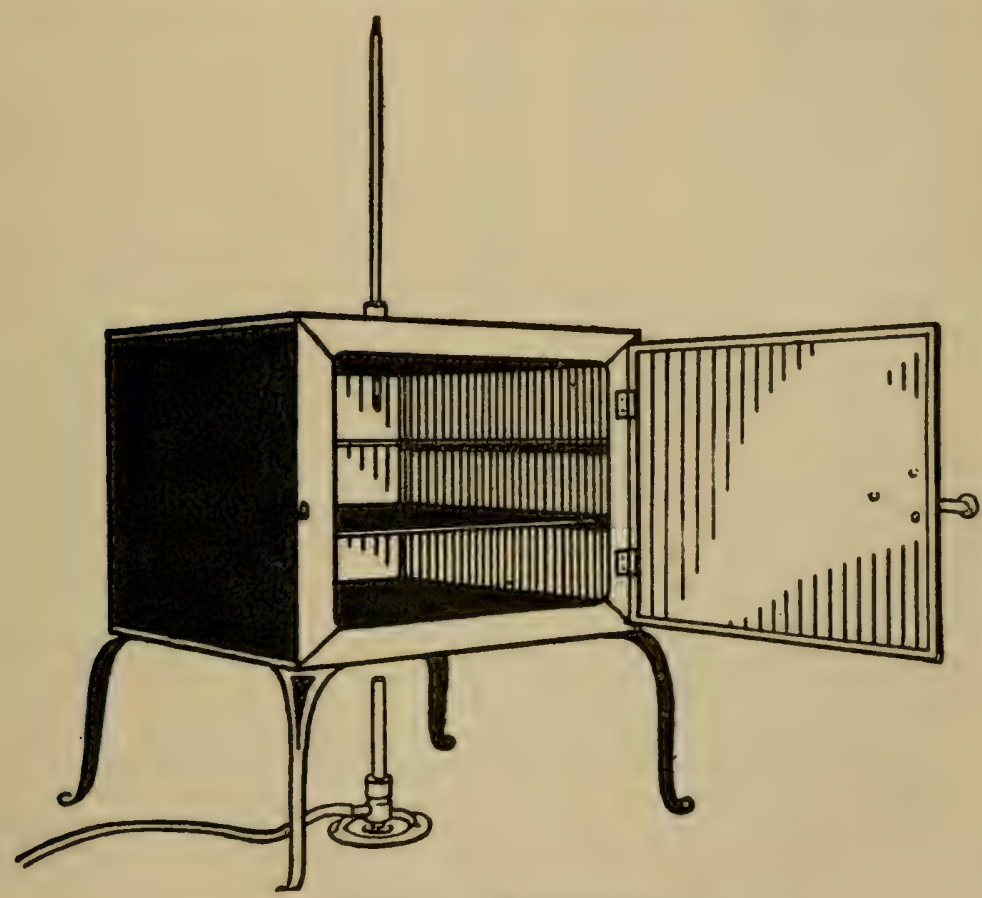

FIG. 62.- Water oven.

ceptible to the senses. Substances like flour, meal, and starch, which appear to be perfectly dry, are not free from water, but contain from 9 to I 2 per cent. This 
hydroscopic water, as it is called, is held mechanically by the particles of which the material is composed, and the amount thus held depends upon the extent of the previous drying of the material and the hydroscopic condi-

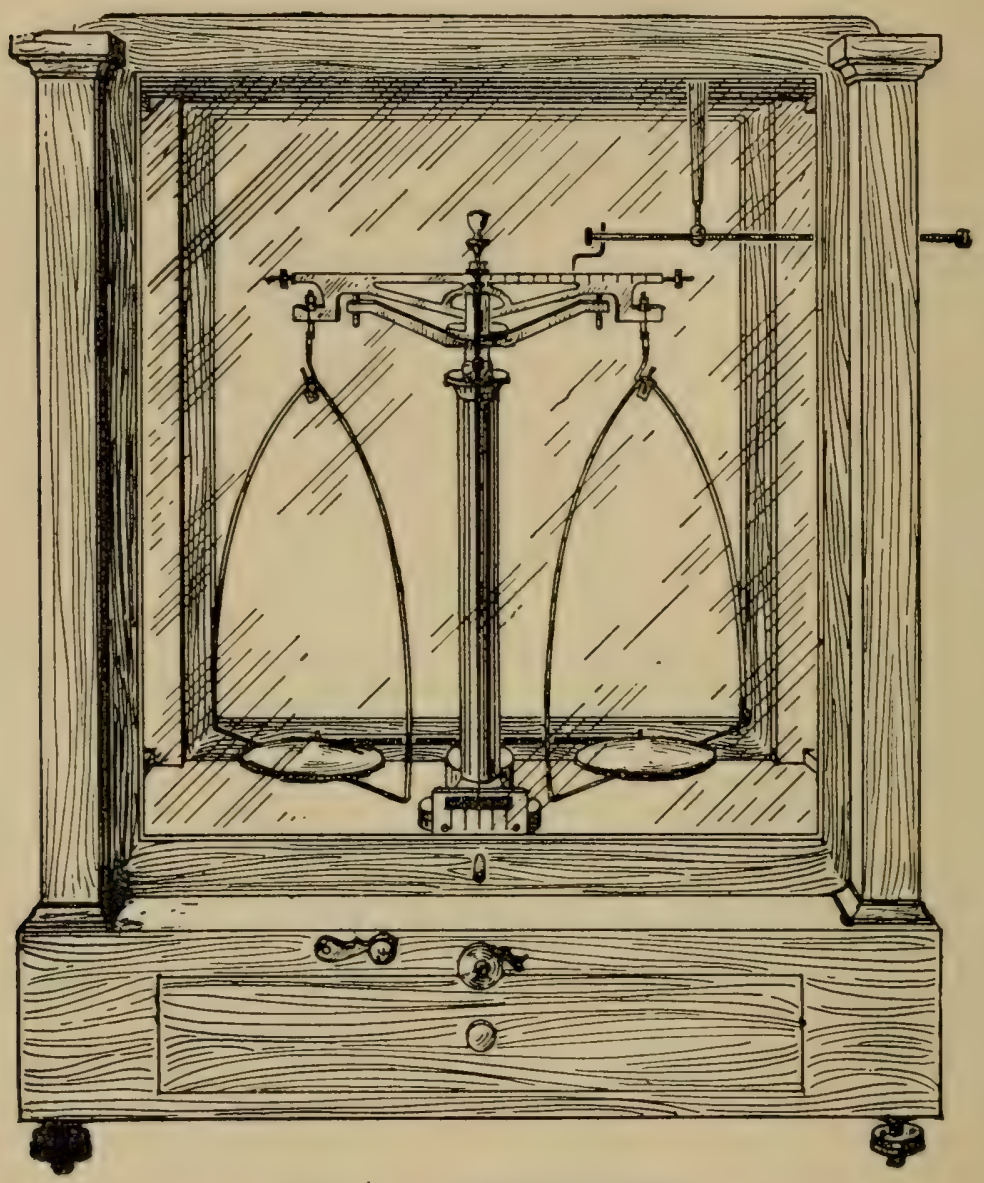

FIG. $\dot{6}_{3}$ - Analytical balance.

tion of the air. Inasmuch as there is always some water in the air, it necessarily follows that all substances exposed to the air must likewise contain some water.

In order to remove the last traces of water from a 
substance, it is dried either in a water or a hot-air oven at a temperature of $100^{\circ} \mathrm{C} .,-$ the boiling point of water. This converts all of the water in the material into steam, which is then expelled. A water oven (see Fig. 62) has double walls, the space between the walls being partially filled with water, which is kept boiling by means of a gas burner placed below the oven. The substance to be dried is weighed in a suitable dish and then dried in the water oven until the weight is reasonably constant, the loss of weight being considered water.

The determination of water in foods, although apparently simple, is a difficult and troublesome chemical process, because many foods, when heated to $100^{\circ} \mathrm{C}$., suffer changes, and give off volatile organic compounds along with the water; or the organic matter may undergo change in composition, as oxidation. For determining the absolute moisture content of foods, the chemist employs a drying bath of different pattern from that shown, and the material is dried in a current of some neutral gas, as hydrogen, to prevent oxidation of the substance. All dishes in which substances are placed, during analysis, are dried and cooled in desiccators out of contact with air, so as to remove all traces of hydroscopic moisture. The weighings are made on ana-

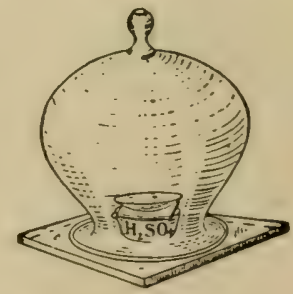

FIG. 64.-Desiccator. lytical balances which are scales of extreme accuracy (see Fig. $6_{3}$ ). Determination of the water is one of the most difficult parts of the analysis of plant or animal substances. 206. Dry Matter. - The dry matter of a material is the portion which is left after all of the water has been removed. Dry matter, as the term implies, is the dry material free from all traces of hydroscopic moisture, and 
the amount is determined by subtracting the per cent of water from roo. For example, if flour contains I 2 per cent water, there will be 88 per cent of dry matter. The amount of dry matter in substances ranges between wide limits, as 7 per cent or less in some fruits to 99 per cent in granulated sugar.

Experiment 36. - Determination of water in potato. Carefully weigh an aluminum dish (Fig. 65). Cut thin slices from different parts of a potato and reduce them to $\frac{1}{8}$-inch cubes. Weigh in the dish some of these pieces, forming a layer not more than two deep. Record the

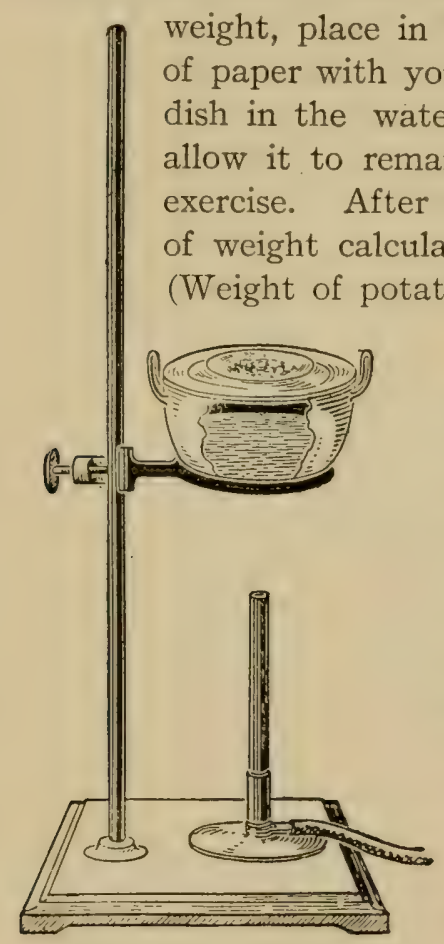

H. G. 66 .

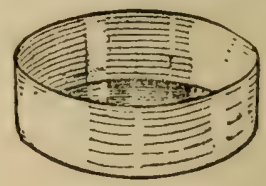

FIG. 65. allow it to remain twenty-four hours, or until the next exercise. After drying, weigh again, and from the loss of weight calculate the per cent of water in the potato. (Weight of potato and dish before drying, minus weight of potato and dish after drying, equals weight of water lost. Weight of water divided by weight of potato taken, multiplied by гоo, equals the per cent of water in the potato.)

Experiment 37. - Water in flour. In the same manner, determine the per cent of water in flour, using about ro grams of flour, and noting the exact weight before and after drying.

Experiment 38. - Water in milk. Weigh a watch glass and place it on the water bath (see Fig. 66). Measure with a pipette $3 \mathrm{cc}$. of milk into the watch glass. Evaporate to dryness on the water bath, completing the process in the water oven. When dry, weigh, and from the loss of weight, calculate the per cent of solids. Sp. gr. of milk, I.032. I cc. $\mathrm{H}_{2} \mathrm{O}$ $=\mathrm{I}$ gram. $\mathrm{x}$ cc. milk $=\mathrm{I} .032$ grams. If skim milk is used, the sp. gr. is 1.035 . 
Experiment 39. - Water in clover. Weigh an aluminum dish. Take three or four large clover plants and cut tinely with shears or knife. Weigh a portion in the dish; dry, and weigh again as in Experiment 36. Determine the per cent of water in clover.

Questions. - (I) How did the potato, after drying, compare in appearance and volume with the material before drying? (2) How does the percentage amount of water which you have obtained compare with the figures given in the tables of analyses? (3) In the determination of water in milk, what was the appearance of the milk solids? (4) What classes of compounds are present in milk solids? (5) How does the amount of water obtained in Experiment 37 compare with the amount given in the tables of analyses? (6) What would be the shrinkage in weight of a barrel of flour if 2 per cent of moisture were removed, and what would be the increase in weight if 2 per cent of moisture were absorbed from the air? (7) How does the amount of water obtained in Experiment 39 compare with that obtained from the other materials? (8) How much water is present in a ton of green clover?

207. Plant Ash. - The ash of a plant, or of any material, is that portion which remains after the substance is burned at the lowest temperature necessary for complete combustion. It is sometimes spoken of as the mineral or inorganic part, also as the non-volatile part, and includes all of the materials, with the exception of water and nitrogen, which the plant takes from the soil during growth. The term ash as used in chemistry differs from the term as ordinarily used in that the chemical ash is pure ash, free from particles of carbon, and also contains elements, as sodium, chlorin, sulfur, and phosphorus, traces of which are volatile at a high temperature. Crude ash is obtained by burning a substance until all of the carbon is oxidized.

Experiment 40. - Determination of ash. Weigh to the second decimal place in grams a dish given out for this experiment. Then weigh into the dish about 2 grams of dry clover or other hay, 
place in the muffle furnace, and let it remain until there is no charred material left. Cool on an asbestos mat. Weigh again and deter-

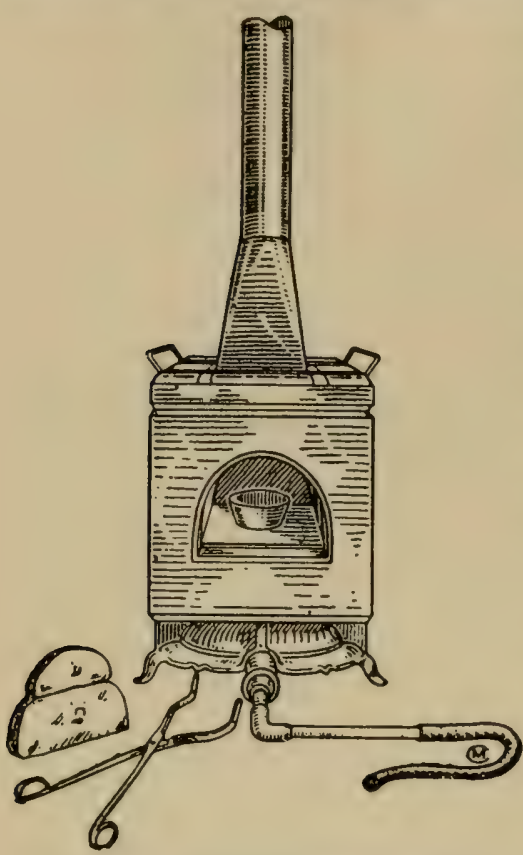

FIG. 67. - Muffle furnace used for determination of ash. mine the per cent of ash from the material taken and the weight of the ash obtained. Calculate the per cent of organic matter. Save the ash for future experiments.

[The 500, 200, and 100 $\mathrm{mg}$. weights are to be recorded as 0.5 , 0.2 , and o.I gram; the 50,20 , and Io $\mathrm{mg}$. weights as $0.05,0.02$, and 0.01 gram. If one used a ro-gram weight, a 500-mg. weight, and a 20-mg. weight, the weight would be written 10.52 grams.]

\section{Form of the Ash Ele-} ments. - None of the elements in the ash of plants ever exist there in the elementary or free state, as free sodium or free silicon, but they are always in chemical combination, forming salts, or are combined with the elements which constitute the organic part of the plant. The ash elements are never present in the form of free acids or free bases, although, in chemical analyses, they are expressed as acid or basic oxides. Phosphorus, for example, never ex-

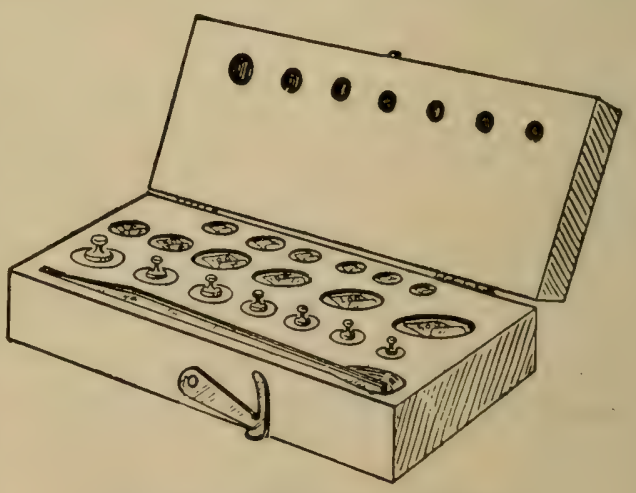

FIG. 68. - Weights for balance. ists in the plant as free phosphorus or as phosphoric acid, 
but either as a phosphate or combined with some of the elements which constitute the organic part.

209. Amount of Ash in Plants. - While the amount of ash in plants is fairly constant, it varies with the stage of growth, climatic conditions, and nature of the soil. In mature agricultural plants, the ash rarely exceeds Io per cent of the dry weight of the material. Clover grown in different localities is found to contain from 6 to 8.5 per cent ash; other crops also show limited variations. The ash is not evenly distributed throughout all parts of a plant; the leaves, for example, contain more than the seed. In the case of corn, the amount of ash in different parts is as follows:

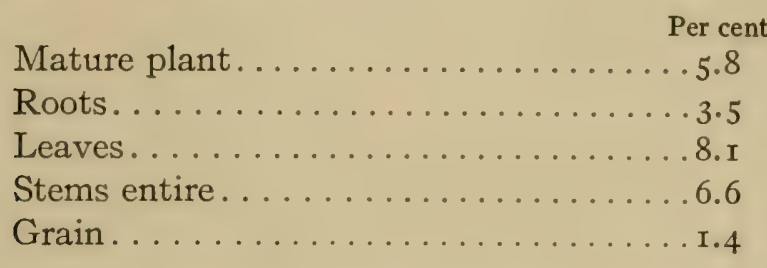

As previously stated, the ash elements of a plant, together with the nitrogen and water, represent all of the material which is taken from the soil. In roo parts of the dry matter of any crop, from 5 to ro parts are derived from the soil, while 90 to 95 parts are supplied either directly or indirectly from atmospheric sources.

210. Importance of Ash Elements. - Plant ash is composed of potassium, sodium, calcium, magnesium, iron, phosphorus, sulfur, silicon, and chlorin compounds. These, with a few others in small amounts, as aluminum and occasionally manganese, boron, etc., are the elements which make up the mineral matter of plants. Some of the ash elements, as potassium and phosphorus, are absolutely necessary for the life of the plant, while others, 
as aluminum and silicon, are, so far as known, unnecessary. The essential ash elements are potassium, calcium, magnesium, iron, phosphorus, and sulfur. The nonessential elements are sodium, silicon, chlorin, and aluminum. Although in some alkali and sea plants, sodium, chlorin, and other elements usually considered nonessential are needed for growth.

Chemically considered, the elements found in the ash of plants are divided into two classes:

(I) Metals or base-forming elements.

Potassium............. K

Sodium.............. Na

Calcium............. Ca

Magnesium ............Mg

Iron ............... Fe

Aluminum............Al
(2) Non-metals or acid-forming elements.

Phosphorus............P

Sulfur...............S

Silicon................. Si

Chlorin

To the above list must be added other elements in small amounts occasionally found in the ash of plants, and also oxygen, which is in chemical combination with all of the above elements.

The essential ash elements are absolutely necessary for the normal growth and development of plants. They take a direct part in the production of plant tissue. The function of each ash element in plant growth has been known only for a comparatively short time. At one time it was believed that the ash elements were largely accidental, that plants in taking up water from the soil could not well keep out soluble earthy substances, but sand and water culture experiments have demonstrated the necessity and the functions of the various ash elements.

2II. Water Culture. - In water culture experiments the seed is germinated, and then the roots are suspended in water containing small amounts of the different ash 
elements. The roots are protected from the light, and the solution is frequently changed. In case it is desired to learn what effect the absence of an element has upon the growth and development of the plant, all of the elements are supplied in known amounts except the one in question, which is withheld altogether. The development of the plant is observed, and if it reaches maturity and produces fertile seeds, it is concluded that the element withheld is not necessary to plant growth, while on the other hand, if the plant does not develop normally, the element withheld is considered necessary. By eliminating the ash elements in order, conclusions may be drawn as to the part which each element takes in plant nutrition. After repeated experiments with various modifications, aided by chemical

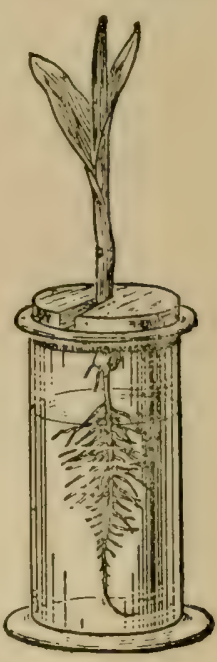

FIG. 69. - Water culture. and microscopical examinations of the plant, the functions of an element are determined. When a plant develops under normal conditions, there is a definite part which every essential element performs during growth. In fact, a plant may be fed, and the effects of the food be observed as accurately as in the case of the feeding of men or animals.

2I2. Sand Culture is essentially the same in principle as water culture. Pure sand is treated with strong acids, washed with distilled water and ignited, and when thus properly prepared, furnishes a perfectly sterile medium to which is added, as desired, known amonuts of the various ash elements in the form of neutral salts. The sand serves physically as soil, and the salts supply the plant food. 


\section{Occurrence and Function of Ash Elements}

213. Potassium. - Potassium is one of the most important and least variable of all the elements found in the ash of plants. It is quite evenly distributed throughout the growing plant and generally occurs in the entire plant in the largest proportion of any of the essential ash elements. It is taken from the soil in the early stages of plant growth and is always present to the greatest

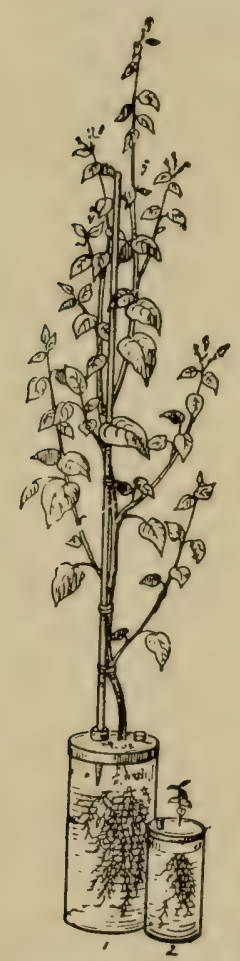

Fig. 70.-Plants grown with and without potash.

extent in the active and growing parts, as in the leaves, where the production of plant tissue occurs. Potassium is one of the elements most essential for the plant's development.

The function of potassium is apparently to aid in the production and transportation of the carbohydrate compounds, as starch and sugar, and thus indirectly in the formation of all organic matter. In sugar- and starch-producing crops, as sugar beets and potatoes, potassium takes an important part in the growth and development. It doubtless has much to do in the way of regulating the acidity of the sap by forming organic salts, such as potassium bitartrate in grapes. At the time of seed formation there is a slight retrograde movement of the potash, in some cases a small part being returned to the soil. The supply of available potash in the soil has great influence upon the vigor of plant growth. Weak and sickly plants are often deficient in potash. Some crops require more for growth than do others, and some experience difficulty in obtain- 
ing it. Some plants contain such large amounts of potash that they are called "potash plants."

Experiment 4 I. - Alkalinity of ashes. Weigh 2 grams unleached hard wood ashes into a beaker containing roo cc. $\mathrm{H}_{2} \mathrm{O}$. Heat over a sand bath until it boils; filter. To one half of filtrate, add ro drops of cochineal solution; from the burette (see Fig. 38), add dilute $\mathrm{HCl}$ ( $\mathrm{I}$ cc. acid, $40 \mathrm{cc} . \mathrm{H}_{2} \mathrm{O}$ ) until the solution is neutral. The alkali in wood ashes is mainly $\mathrm{K}_{2} \mathrm{CO}_{3}$, which is neutralized with $\mathrm{HCl}$. Write the reaction. Repeat the experiment, using leached ashes. Note number of cubic centimeters $\mathrm{HCl}$ used in each case. What do the results indicate?

214. Sodium. - This element, which resembles potassium in its chemical deportment, is not absolutely necessary for agricultural plants and does not occur in the plant ash in such large amounts as potassium. Nearly all agricultural plants are brought to maturity without its aid, except for the small amount in the seed. Plants require so little, if any, that it is not sufficient to take into consideration. It is supposed to be an accidental ingredient, because sodium chlorid is universally present in the soil, in water, and occasionally traces of it are in the air; hence plants could not very well exclude it. Some alkali plants require and store up large amounts of sodium compounds. Unlike potassium, sodium is not so evenly distributed through the plant. It has no special movement, but is found mostly in the lower parts of the plant. Seeds contain but little of it, more being in the straw and stems.

215. Calcium. - This element is always present in the ash of plants. None of the higher plants can reach maturity without a normal supply. Some, like clover, beans, peas, and lucern, require so much for their development that they are called "lime plants." Accumula- 
tions of lime are found in many leafy plants, particularly clover, where crystals of calcium oxalate may be observed. In leaves, it appears to have the special function of aiding in the construction of the cell walls. No new plant cells can be produced without the aid of calcium.

From the culture experiments of various investigators, calcium appears to take a prominent part in the production of new tissue. Whenever it is withheld, the growth of the plant is restricted. Some plants, after their growth has been checked by withholding calcium, will show increased vigor within a few hours after it is supplied. Calcium is assimilated in the early stages of plant development. In wheat, for example, 8 o per cent is assimilated before the plant heads out. Calcium assists in imparting hardiness to crops. It does not accumulate in the seeds to such an extent as do other elements. Only about one tenth of the total amount removed in grain crops is in the seeds, the remaining nine tenths being present in the straw. Crops grown on lime soils are usually well nourished, and are more capable of withstanding unfavorable climatic conditions, as drought and early frosts, than are crops not so liberally supplied with lime.

Experiment 42. - Lime, $\mathrm{CaO}$, in plant ash. Transfer the ash from Experiment 40 to a beaker containing $5 \mathrm{cc} . \mathrm{HCl}$ and $50 \mathrm{cc}$. $\mathrm{H}_{2} \mathrm{O}$; heat ten minutes, filter, and divide into two portions. Save portion for Experiment 44. Make one portion neutral with ammonia, $\mathrm{NH}_{4} \mathrm{OH}$. Add 5 cc. $\mathrm{NH}_{4} \mathrm{Cl}$ solution. To the solution, add 5 cc. ammonium oxalate, $\left(\mathrm{NH}_{4}\right)_{2} \mathrm{C}_{2} \mathrm{O}_{4}$; note the precipitate which is calcium oxalate, $\mathrm{CaC}_{2} \mathrm{O}_{4}$.

Into a separate test tube put o.I gram $\mathrm{CaCl}_{2}$, add 5 cc. $\mathrm{H}_{2} \mathrm{O}$ and a little $\mathrm{HCl}$ until acid; then nearly neutralize with $\mathrm{NH}_{4} \mathrm{OH}$ and add $\mathrm{NH}_{4} \mathrm{Cl}$ and $\left(\mathrm{NH}_{4}\right)_{2} \mathrm{C}_{2} \mathrm{O}_{4}$. Compare this precipitate with that from the clover ash. Observe, in this second test, that you have taken a pure calcium salt, and that the same precipitate was given 
as by the plant ash. Write the following reactions which have taken place: $\mathrm{CaC}_{2} \mathrm{O}_{4}+\mathrm{Heat}=$ ? $\mathrm{CaCO}_{3}+\mathrm{HCl}=$ ? $\mathrm{CaCl}_{2}+$ $\left(\mathrm{NH}_{4}\right)_{2} \mathrm{C}_{2} \mathrm{O}_{4}=$ ?

2r6. Magnesium is also an essential element. It occurs in all plants and farm crops in somewhat smaller amounts than calcium, but in the seeds of grains it is stored up three times more liberally. Magnesium is assimilated more slowly than calcium; in fact, it is assimilated, as a rule, more slowly than any other ash element. The plant does not require magnesium until the approach of seed formation, although a small amount is necessary for perfect leaf action as it enters into the chemical composition of the chlorophyll. When plants are grown with an incomplete supply of magnesium, the seeds are frequently sterile. In culture experiments, the absence of magnesium is not observed so much in the first stages of growth as near the time of seed formation, when its absence is followed by restricted development.

2I7. Aluminum is found in the ash of many plants, as wheat, peas, beans, and rice, although it occurs in very small amounts and, so far as known, is not essential for plant growth. Most soils contain traces of soluble silicates of aluminum, and hence plants cannot well be free from this element.

218. Iron is necessary for plant growth. It occurs in about the smallest amount of any of the ash elements, but is always present in plants. When plants are unable to obtain their requisite supply of iron, the production of chlorophyll does not take place and they fail to develop a normal green color.

The function of the iron is to assist in the formation of chlorophyll, the coloring matter of plants. It is not known whether iron enters into the chemical composition of 
the chlorophyll, or is simply organically associated with it.

219. Phosphorus, in the form of phosphates, is found in all parts of plants. It is one of the essential elements for plant growth. Its function is to aid in the produc-

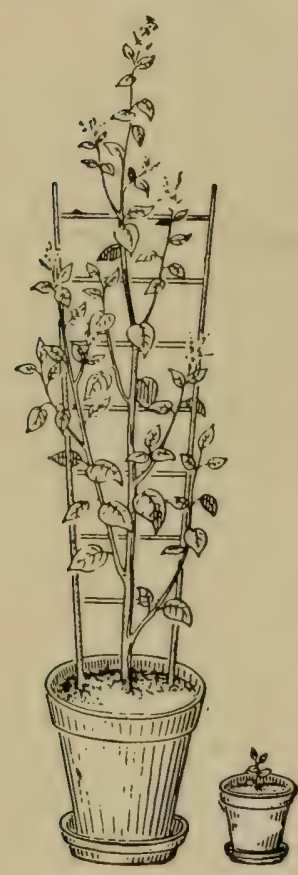

Fig. 7I.-Plants grown with and without phosphoric acid. tion and transportation of the proteid bodies. The phosphorus and nitrogen compounds are closely associated in the work of producing proteids, which can take place only in the plant cells. The proteid compounds produced in the leaves of plants are finally transported to the seed. Many proteids which are insoluble in water are soluble in the presence of phosphate compounds. The phosphates are essential in the early stages of the plant's development. In the case of wheat, 80 per cent is assimilated in the first fifty days, and in other crops, the assimilation is equally rapid. The phosphates accumulate to a greater extent in the seeds of grains than in the leaves and stems. From 60 to 75 per cent of the total phosphates are removed in the seeds. The loss of phosphates from the farm is one of the reasons why soils decline in fertility.

Experiment 43. - Phosphoric acid in seeds. Crush 25 kernels of wheat in a mortar. Place the crushed wheat in a small Hessian crucible and ignite; when cool, transfer the charred mass to a small beaker. Add Io cc. concentrated $\mathrm{HNO}_{3}$ and 50 cc. $\mathrm{H}_{2} \mathrm{O}$, and boil ten minutes. Break the charred particles with a stirring rod during the boiling. If the beaker shows signs of becoming dry, add 
a little hot water. Filter. To half the filtrate add $3 \mathrm{cc}$ ammonium molybdate. The yellow precipitate is ammonium phosphomolybdate. See Experiments I 7 and 18.

220. Sulfur also is an essential element of plant and animal bodies, but occurs in plant tissue in comparatively small amount. It enters into the composition of albumin and other proteids. Sulfur is used by plants only in the form of sulfates. It takes a part in plant life, as there must be a supply of sulfur for the proteid compounds which always contain this element in chemical combination. Culture experiments show that in its absence no growth results. As sulfur forms a part of the volatile products when a plant is burned, that present in the ash represents only a portion of the sulfur taken by the plant from the soil.

Experiment 44. - Sulfur as sulfates in plant ash. To the second portion of the filtrate from Experiment 42 add $2 \mathrm{cc}$. barium chlorid, $\left(\mathrm{BaCl}_{2}\right)$, observe the result, and write the reaction, assuming $\mathrm{SO}_{3}$ to be in the form of $\mathrm{K}_{2} \mathrm{SO}_{4}$. In a second test tube, add a few crystals of $\mathrm{Na}_{2} \mathrm{SO}_{4}$ or $\mathrm{K}_{2} \mathrm{SO}_{4}$ to ro cc. $\mathrm{H}_{2} \mathrm{O}$ containing a few drops $\mathrm{HCl}$. When dissolved add $\mathrm{BaCl}_{2}$ and compare with precipitate obtained in first part of experiment.

22I. Chlorin is not an essential ash element. It accumulates mainly in the lower part of the plant, and its presence appears to be accidental, it having no decided functions to perform. The statements made about sodium, its occurrence, distribution, and importance apply also to chlorin, with which it is combined, forming sodium chlorid.

222. Silicon occurs in all plants. It is found in largest amounts in the dense and older parts, as the stalk and straw, where there is less activity. In some of the lower plants, as diatoms, there is so much silica that when the 
organic matter is removed by burning, a skeleton of silica is left. It was formerly supposed that silica gave the stems of grains and grasses their stiffness. Perfect wheat, however, with normal strength of straw has been grown in the absence of silica, except for the small amount originally present in the seed. Lawes and Gilbert have shown that the lack of silica is not the cause of grain lodging. Some authorities claim that silica takes a part in plant economy and is necessary in seed formation. Whatever its function, it is not an important element as plant food, and there is always an abundance in the soil for crop purposes.

In the living plant, the mineral elements are not in the same form or combination as in the plant ash. During growth, many of the ash elements are combined with the organic compounds, for example phosphorus, which forms phosphorized proteids and fats. The ash forms a part of the plant tissue. When the plant is burned, the organic compounds are volatilized, while the ash elements, which are non-volatile, are left. The essential ash elements are absolutely necessary as food for the growth and development of all crops, and plant growth is frequently arrested because of the lack of a sufficient supply for purposes of nutrition. The food requirements of individual farm crops are discussed in "Soils and Fertilizers." 


\section{Summary Table.}

Plant ash elements.

Metals.

Occurrence.

Function.

Potassium $\mathrm{K}_{2} \mathrm{O}+$ Mainly in the active growing parts of plant leaves and stems

Sodium $\quad \mathrm{Na}_{2} \mathrm{O}-$ Stems and roots

Calcium

$$
\mathrm{CaO}+\text { Leaves and stems }
$$

Assists in formation of starch, carbohydrates, and in plant growth in general, and makes plants vigorous

No function

Assists in formation of plant cells, and makes plants hardy

Magnesium $\mathrm{MgO}+$ Seeds and leaves Aids in seed formation Iron $\mathrm{Fe}_{2} \mathrm{O}_{3}+$ Leaves and stems Aids in chlorophyll formation

Aluminum $\mathrm{Al}_{2} \mathrm{O}_{3}$ - Lower parts of No function plants

Manganese $\mathrm{Mn}_{2} \mathrm{O}_{3}$ - Lower parts of No function plants

Non-metals.

Phosphorus $\mathrm{P}_{2} \mathrm{O}_{5}+$ Seeds

Leaf action and formation and movement of proteids

Sulfur $\quad \mathrm{SO}_{3} \quad+$

Silicon $\quad \mathrm{SiO}_{2} \quad-$ Stems and leaves Production of proteids Chlorin ... - Lower parts No apparent function No apparent function

Problem I. - How many pounds of potash are removed from an acre of soil yielding $1_{5} \circ$ bushels of potatoes?

The potatoes weigh 60 pounds per bushel. $150 \times 60=9000$ pounds, total yield of potatoes. The potatoes contain 24 per cent dry matter (see Table). This dry matter contains 3.8 per cent ash. Hence $2 \mathrm{I} 60$ pounds dry matter contain $(2 \mathrm{I} 6 \times 0.038=82.08)$ 82.08 pounds ash. 60 per cent of this ash is potash; or $(82.08 \times$ 
0.60) 49.25 pounds are potash. Therefore, 150 bushels of potatoes remove from the soil 49.25 pounds of potash. In the same way, the amount of each separate element removed from the soil may be calculated.

Problem 2. - Calculate the pounds of total ash, $\mathrm{K}_{2} \mathrm{O}, \mathrm{CaO}, \mathrm{MgO}$, and $\mathrm{P}_{2} \mathrm{O}_{5}$, removed in 25 bushels of wheat.

Problem 3. - Calculate the same ingredients removed in 1500 pounds of wheat straw. Compare these with the corresponding elements removed in the grain (Problem 2).

Problem 4. - Calculate the $\mathrm{CaO}, \mathrm{MgO}, \mathrm{K}_{2} \mathrm{O}$, and $\mathrm{P}_{2} \mathrm{O}_{5}$ removed in 50 bushels of oats weighing 32 pounds per bushel.

Problem 5. - Calculate the same for 40 bushels of barley weighing 48 pounds per bushel. In what respects does the mineral food of barley differ from the mineral food of wheat?

Problem 6. - How much $\mathrm{P}_{2} \mathrm{O}_{5}$ is removed in $\mathrm{I}_{5}$ bushels of flax? 

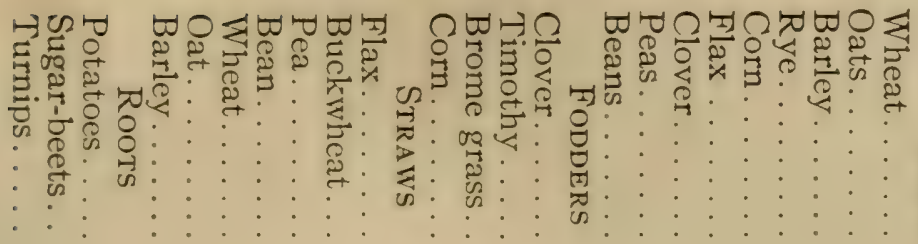

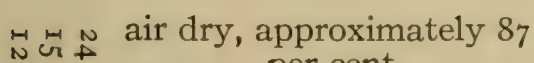
per cent

approximately 90 per cent

范

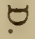

莺

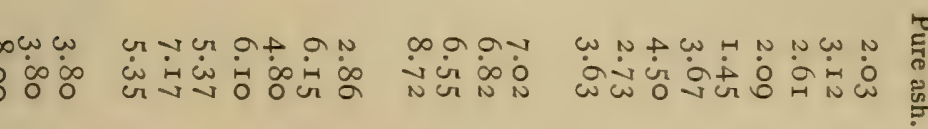

$\rightarrow \tilde{C}$

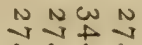

HW W

tr

- Dn w w m ment

O O HO

HOOONHHNHO

z

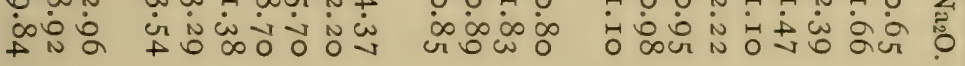

Han $\operatorname{tancun} \infty \operatorname{con}^{n}$ in

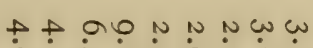
คํㅇ in

w. g̊o

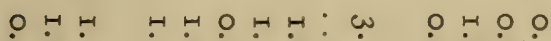

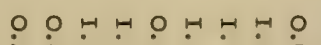

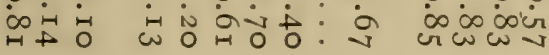
âे

N

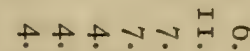

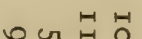

$\omega \omega \omega \rightarrow A+\omega N A$

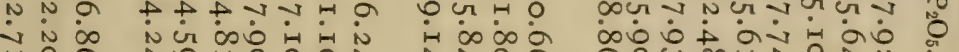

Hô

$+\infty \%$

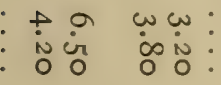

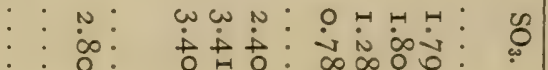

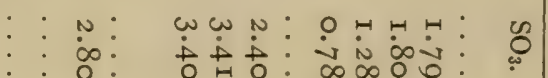




\section{CHAPTER XXIII}

The Non-nitrogenous Organic Compounds of Plants

223. Organic Matter. - The organic matter of a plant or material of any kind is that portion which can be converted into volatile or gaseous products; it is the combustible part, and is simply a mechanical mixture of the various organic compounds, as starch, sugar, and fat, of which the material is composed. The term organic compounds was originally applied to those bodies which it was believed could be produced only as the result of life processes, but it is no longer used in that sense because many of the organic compounds are now produced in the laboratory by synthetic methods. The organic matter of a substance is obtained by subtracting the ash from the dry matter. The dry matter of wheat, for example, contains 2.io per cent ash and 97.90 per cent organic matter. The organic matter of plant and animal bodies includes a number of classes and types of compounds.

224. Non-nitrogenous and Nitrogenous Organic Compounds. - For purposes of study, the organic compounds of animal and plant bodies are divided into two large classes: (I) nitrogenous, and (2) non-nitrogenous. This division is made on the presence or absence of the element nitrogen. The nitrogenous or nitrogen-containing compounds are those in which the element nitrogen is in combination with carbon, hydrogen, oxygen, and small I68 
amounts of other elements, while the non-nitrogenous compounds are those which contain no nitrogen, but are composed of carbon, hydrogen, and oxygen. Starch, sugar, and fat are types of non-nitrogenous compounds, while albumin, casein, and fibrin are types of the nitrogenous.

225. Classification of Non-nitrogenous Compounds. There are six large divisions of the non-nitrogenous compounds: (I) carbohydrates, (2) pectose substances, (3) fats, (4) organic acids, (5) volatile or essential oils, and (6) mixed compounds. Each division is, in turn, divided into various subdivisions and groups:

Organic non-nitrogenous compounds
I. Carbohydrates, Cellulose, Starch, Sugar, Pentosans, Gums.

2. Pectose substances (jellies).

3. Fats $\left\{\begin{array}{l}\text { I. Olein, } \\ \text { 2. Stearin, } \\ \text { 3. Palmitin, etc. }\end{array}\right.$

4. Organic acids $\left\{\begin{array}{l}\text { I. Tartaric, } \\ \text { 2. Oxalic, } \\ \text { 3. Malic, etc. }\end{array}\right.$

5. Volatile or essential oils.

6. Mixed compounds.

\section{Carbohydrates}

226. General Characteristics. - Carbohydrates, the first subdivision of the non-nitrogenous compounds, include the starches, sugars, gums, cellulose and pentosan bodies. They form the largest group of the organic compounds in plants, and in many plants and food materials are present largely as starch. The carbohydrates occur in 
plants in three physical forms: (I) as the framework of the plant cells, as cellulose, (2) in solution in the plant sap, as sugar, and (3) deposited as solid substances within the plant cells, like starch. In coarse fodders, as hay, they are largely in the form of cellulose and pentosan bodies. While the various carbohydrates differ chemically and physically, they all possess a few common characteristics : (I) they are all neutral bodies, and (2) they all contain twice as many hydrogen as oxygen atoms in their molecules. The $\mathrm{H}$ and $\mathrm{O}$ are present in the same proportion as found in water, viz., 2 atoms of $\mathrm{H}$ and $\mathrm{I}$ of $\mathrm{O}$. In starch, $\mathrm{C}_{6} \mathrm{H}_{10} \mathrm{O}_{5}$, the $\mathrm{H}$ and $\mathrm{O}$ would form $5 \mathrm{H}_{2} \mathrm{O}$.

\section{Cellulose}

227. Occurrence. - Cellulose is found most abundantly in the stems, roots and leaves of plants, particularly at

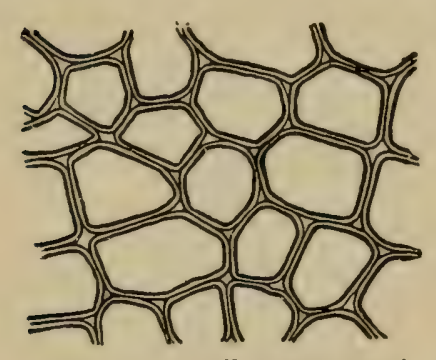

FIG. 72.-Cell structure of plant tissue. maturity. It is the structural basis of the vegetable world, and forms the framework of every plant cell. In some plants it is the most abundant material present; in hay and coarse fodders it makes up from 30 to 40 per cent of the dry matter. Crops like cotton, flax, and hemp contain large amounts, and are cultivated mainly for the cellulose which they yield.

228. Physical Properties. - Pure cellulose is a colorless insoluble material, differing in texture according to its source. In hemp, it is flexible and tenacious, while in wood it is hard and compact; in the pith of the elder, it is elastic, in the potato, porous, and in germinating seeds, loose and spongy. Cotton and filter paper are examples 
of nearly pure cellulose. The proportion and properties of cellulose in a food influence its digestibility. Some foods are less valuable because of the tenacious character of the cellulose, which prevents the cells from undergoing disintegration and digestion.

\section{Chemical Properties. -} Cellulose is composed of carbon, hydrogen, and oxygen. Its formula is $\mathrm{C}_{6} \mathrm{H}_{10} \mathrm{O}_{5}$. Cellulose from one source may have a different multiple of $\mathrm{C}_{6} \mathrm{H}_{10} \mathrm{O}_{5}$ than that from another source. In young and growing plants, the cellulose is
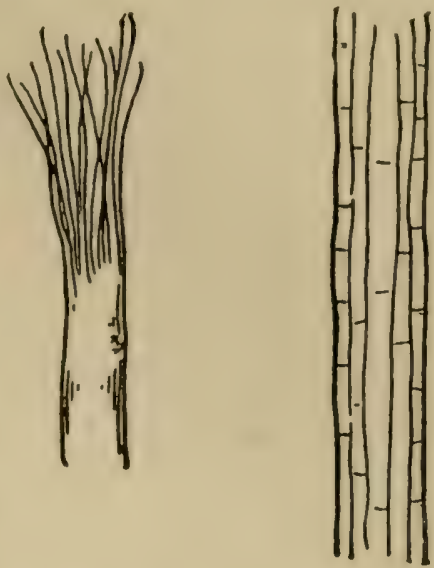

FIG. 73. - Flax fiber. in a hydrated condition; that is, water is chemically united with the cellulose molecule, as $\left(\mathrm{C}_{6} \mathrm{H}_{10} \mathrm{O}_{5} \cdot \mathrm{H}_{2} \mathrm{O}\right)_{n}$. Hydrated cellulose is more readily acted upon by chemicals than are other forms. As the plant develops, the cellulose is gradually dehydrated, and this is one reason why cellulose, at different stages of growth, has different food value. Lignocellulose is found in wood and many mature plants. It contains a larger per cent of carbon than does cellulose.

230. Function and Value. - In the plant, the function of cellulose is to form the structural part of the cell walls. It constitutes the main portion of the walls of every plant cell. In seeds, it is a reserve food material for the young plant. Commercially, cellulose is employed for making paper, cloth, guncotton, and other explosives, and is extensively used in the arts.

23r. Food Value. - The food value of cellulose depends upon its degree of hydration. Hydrated cellulose, when 
digested, has practically the same food value as starch. Lignocellulose is indigestible, and has no food value. Indirectly, a minimum amount of cellulose imparts mechanical value to a food by acting as an absorbent for concentrated waste products. When crops are cut and cured while some of the cellulose is in a hydrated condition and but little has passed into the ligno form, the cellulose is valuable as food.

232. Amount of Cellulose in Plants. - Cellulose is found more abundantly in the stems and leaves of plants than in the seeds. In the straw of wheat, oats, rye, and barley, it makes up from 35 to 45 per cent of the dry material. It also constitutes a large portion of the roots of plants. In seeds, the amount of cellulose is small, and usually ranges from 2 to 5 per cent, while in wood, the range is from 50 to 80 per cent. In tables of analyses, the cellulose is usually included with other bodies under the head of crude fiber.

233. Crude Fiber. - Crude fiber includes the cellulose, lignin, and other materials which make up the framework of vegetable substances. In vegetable foods, as flour and the cereal products, the amount of crude fiber is small compared with that in many other plant bodies. Crude fiber and cellulose are not identical terms. In the chemical analysis of plants, the crude fiber is determined by first digesting the material in dilute sulfuric acid to dissolve all that is soluble, as sugar, hydrolyzed starch, some of the proteids and related bodies. The substance is then digested with dilute sodium hydroxid to remove all compounds which have failed to dissolve in the acid. Crude fiber and insoluble mineral matter are about the only substances which are insoluble in the dilute acid and alkali, hence the fiber is obtained by dissolving all other 
compounds and deducting the insoluble mineral matter left. For the determination of cellulose more exact methods have been devised. The crude fiber determination, however, is valuable because it shows the amount of fibrous material contained in plants.

Experiment 45. - Preparation of cellulose. Place in a beaker about $\mathrm{r}$ gram of ground straw or hay; add $200 \mathrm{cc}$. of water, and 20 drops of $\mathrm{H}_{2} \mathrm{SO}_{4}$. Boil on the sand bath twenty minutes, and after the material settles, pour off the liquid, then add roo cc. water, and wash thoroughly by decantation. Add $200 \mathrm{cc}$. water and $4 \mathrm{cc}$. $\mathrm{NaOH}$ solution, boil twenty minutes, and wash the fibrous material as before. Place some of the crude fiber in a test tube, add $5 \mathrm{cc}$. $\mathrm{HCl}$, го cc. $\mathrm{H}_{2} \mathrm{O}$, and a crystal of $\mathrm{KClO}_{3}$; heat, and then wash the cellulose product.

Questions. - ( I) What element was liberated by the action of $\mathrm{HCl}$ upon the $\mathrm{KClO}_{3}$ ? (2) What effect did this element have in the bleaching and purification of the crude fiber? (3) In what other experiment has this element been used as a bleaching reagent? (4) When examined with a lens, how did the cellulose appear? (5) Is cellulose soluble in dilute acids? (6) Why were the dilute acid and alkali solutions used in this experiment? (7) What becomes of the ash or mineral matter in the material used in this experiment? (8) What does this experiment show in regard to the properties of cellulose?

\section{STARCH}

234. Occurrence. - Starch is found most abundantly in the seeds, roots, and tubers of plants, being stored up in those parts which are concerned with new growth. During growth, starch is produced in the leaves of all green plants; at maturity, it is stored in the seed or tuber. It is present in the plant cells as granules which have regular organized forms.

235. Physical Properties. - The starch granules from a given cereal are always constant in form and physical 
properties. Each grain is composed of overlapping layers which can be observed under the microscope. The walls of the layers are composed of a material called "starch cellulose "; between the walls is the pure starch known as granulose. All starch grains have a somewhat similar general structure. Starch is insoluble in cold water because the walls of starch cellulose prevent the water from dissolving the pure starch. In hot water some of the granulose is dissolved and a paste is formed. Pure dry starch is tasteless and odorless. Starch is exceedingly hydroscopic, and commercial starch always contains from Io to I2 per cent, or more, of water. A food which contains a large amount of starch will vary in moisture content and weight according to the hydroscopicity of the air. The starch grains obtained from different cereals and food products vary in form according to the source

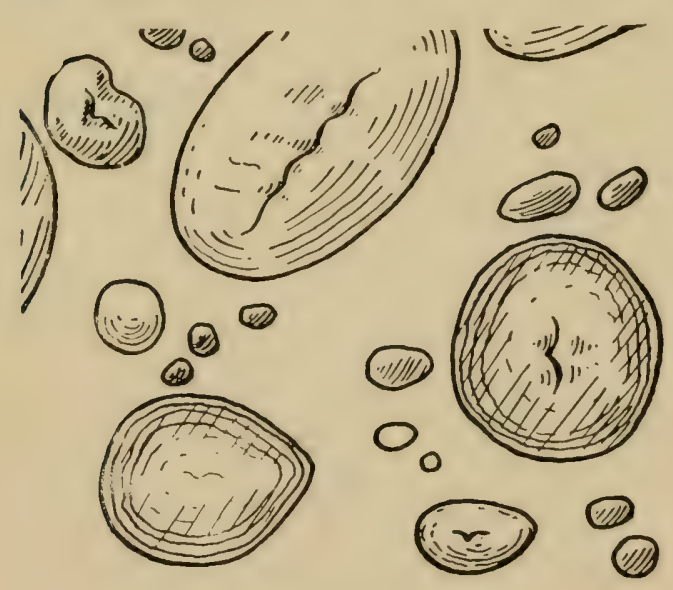

Fig. 74.-Wheat starch. from which they are obtained. Wheat starch is circular in outline, and has a slightly concave center. There are but few markings or rings (see Fig. 74). The granules vary in size from 0.05 to 0.01 millimeter in diameter. Cornstarch is somewhat smaller ( 0.02 to 0.03 millimeter), more angular than wheat starch, and has a star-shaped center or helum (see Fig. 75). Oat starch is composed of a number of small segments forming a compound grain, or mass, each segment in itself a com- 
plete structure. Barley and rye starch grains are somewhat similar to wheat. In some vegetables, as the parsnip, the starch grains are minute.

236. Chemical Properties. - Starch is composed of carbon, 44.44 per cent; hydrogen, 6.I7 per cent; and oxygen, 49.39 per cent. Its formula is $\left(\mathrm{C}_{6} \mathrm{H}_{10} \mathrm{O}_{5}\right)_{n}$. The value of $n$ has been variously estimated from 2 to 200. The different starch grains, as of wheat, corn, and oats, are all composed of the same elements, $\mathrm{C}, \mathrm{H}$, and $\mathrm{O}$, and differ in form because these elements are put to-

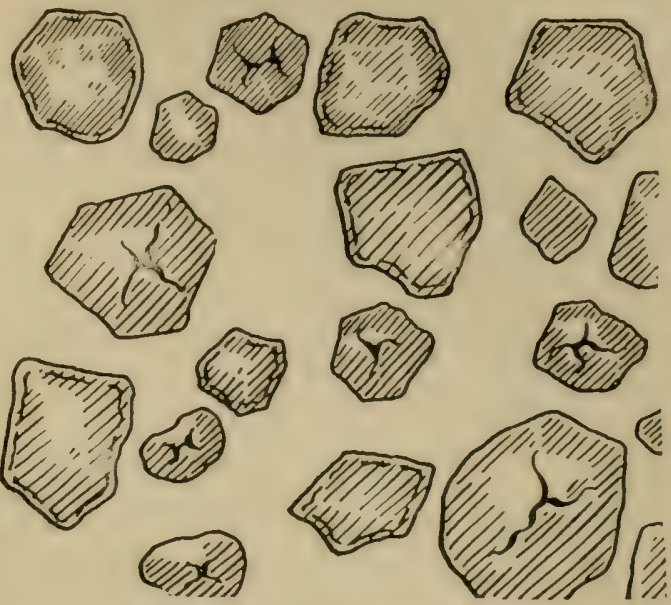

FIG. 75.-Cornstarch. gether in a different way in each. When acted upon by heat, as in the popping of corn, the starch grains are ruptured. At a temperature above $\mathrm{r} 20^{\circ} \mathrm{C}$., starch gradually is changed to dextrin. In the presence of water and dilute acids, starch gradually undergoes hydration; that is, water is chemically added to the molecule. By the joint action of heat, ferments, and various chemicals, starch is converted into a number of products, as soluble starch and dextrose. In the presence of iodin, starch is colored blue, different kinds of starch giving different shades and tints. The nature and mechanical form of the starch granules in a food determine, to a slight extent, its rapidity and ease of digestion. Some starches are more easily digested than others, and all undergo important chemical 
and physical changes in their cooking and preparation as food. Since starch makes up such a large portion of many human and animal foods, its composition, properties, and food value are of prime importance.

237. Function and Value. - In the seed, starch is a reserve form of food for the use of the young plant before it is able to obtain its own food; in roots and tubers also, it is stored up for that purpose. Many crops, as potatoes, corn, and sago, contain so much starch that they are often cultivated for starch-making purposes. Starch is obtained mechanically from potatoes by first pulping to break the cells, and then washing the pulped mass with water from which the starch slowly settles. In the arts, starch is used in many ways. As a food, it is used mainly in its original form associated with the other organic compounds with which it is found in plants.

238. Food Value of Starch. - Starch is a valuable nutrient, and when digested, produces heat and energy. When burned in the bomb calorimeter I pound of digestible starch produces I860 calories. A calorie is the unit employed for measuring heat, and is the amount of heat required to raise $\mathrm{I}$ kilo of water $\mathrm{I}^{\circ} \mathrm{C}$., or approximately I pound of water $4^{\circ} \mathrm{F}$. One gram of starch yields 4.2 calories. Pure starch alone is incapable of sustaining life, because it contains no combined nitrogen, and does not supply any material for repairing the tissues of the body or for the construction of new nitrogenous tissue. When associated with nitrogenous compounds, starch can be used by the body for the production of fat as well as for the production of heat and energy.

239. Amount of Starch in Plants. - In grains, the amount of pure starch ranges from 50 to 75 per cent of the dry weight of the material; in hay and forage crops, 
it is small, usually less than 2 per cent. The amount of pure starch in some of the cereals and farm crops is approximately as follows:

Wheat........................ 68

Pure starch.

Per cent.

Wheat flour....................... 72

Oats.......................... 55

Corn............................ 75

Rice.......................... 78

Potatoes....................... . 80

Wheat bran...................... 8

Straw............................. than

Hay.......................... I to 3

Experiment 46. - Preparation of potato starch. Reduce one or two clean potatoes to pulp on the grater. Tie the pulp in a clean cloth and squeeze into a large cylinder filled with water, occasionally dipping the bag into the water. Allow the cylinder to stand

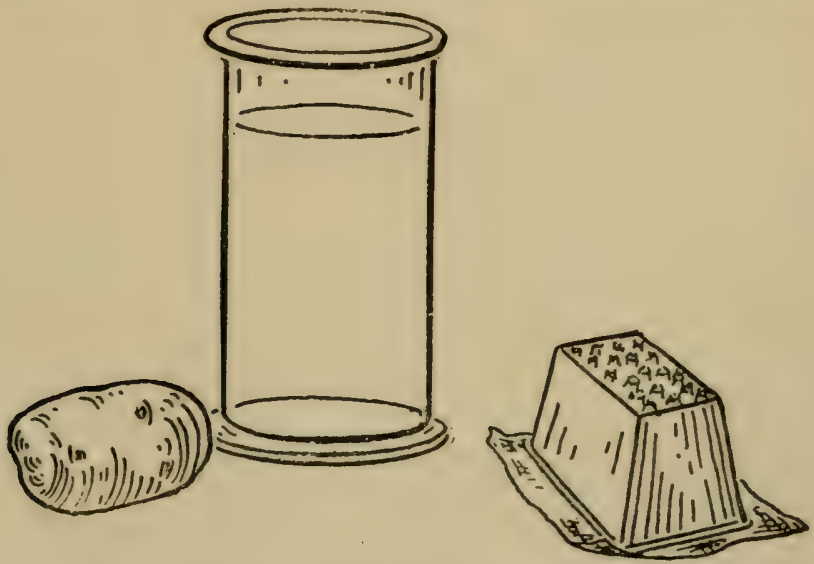

FIG. 76. - Obtaining starch from potato.

for twenty minutes, or until the starch has all settled; pour off the water. If the starch is not clean, wash by adding more water, and allow it to settle again; then pour off the water. Leave the cylinder in the desk until the starch is dry. Save this starch for the following tests: Tests for starch. Place $0.5 \mathrm{gram}$ of starch in a 
test tube, about one half full of water. Shake the test tube, boil, and filter; then to this filtrate add a few drops of iodin. Treat a second portion of starch with cold water and then add iodin.

Questions. - (I) What was the difference in the action of hot and cold water upon starch? (2) How did this difference show itself in the tests? (3) Why in the one test tube were there a blue mass and a clear liquid, and in the other opposite results?

240. Dextrin is a carbohydrate which has the same general formula as starch, from which it differs in structural composition. Dextrin is produced from starch by the action of heat. When this change takes place, nothing is added to or taken from the starch molecule. The three elements, $\mathrm{C}, \mathrm{H}$, and $\mathrm{O}$, are simply rearranged in the new molecule. Dextrin is not found naturally in food products to any appreciable extent, but is present in starch-containing foods which have been subjected to the action of heat. The brown crust of bread is composed mainly of dextrin. Dextrin is soluble in water, and is more readily digested than starch, but it has the same general fuel and energy-producing value.

Experiment 47. - Preparation of dextrin. Place about 2 grams of flour in a porcelain dish; heat cautiously on a sand bath for five minutes, constantly stirring, so that it will not burn. When cool, add three times its bulk of water and heat nearly to boiling; observe the appearance of the solution; then filter. The filtrate contains dextrin. To a portion, add twice its bulk of alcohol; the dextrin is precipitated. To another portion, add a few drops of iodin solution; blue color indicates soluble but unaltered starch.

Questions. - (I) What agent was employed to change the starch to dextrin? (2) How does dextrin differ from starch in solubility? (3) Is dextrin soluble in alcohol? (4) In what ways does dextrin differ from starch?

24I. Structural Formulas. - Cellulose, starch, dextrin, and inulin have the same general formula $\left(\mathrm{C}_{6} \mathrm{H}_{10} \mathrm{O}_{5}\right)_{n}$, but all differ both in physical and chemical properties. This 
is because the elements, $\mathrm{C}, \mathrm{H}$, and $\mathrm{O}$, are put together in different ways in the three compounds. For example, a pile of bricks may be put together to form one structure, and again in different ways to form other structures, while in each structure there are the same number and kinds of bricks. So in the molecules of starch, dextrin, inulin, and cellulose, there are the same number and kinds of atoms, but in each they are combined in a different way. In the study of the composition of plants, organic compounds are frequently met with which have the same general composition, but different chemical and physical properties. Whenever two compounds have the same general formula and percentage composition, but different chemical and physical properties, the difference is said to be one of structural composition.

\section{SUGAR}

242. Classification of Sugars. - As commonly used, the term sugar is applied to the product obtained from sugar-cane or sugar-beets. As used in chemistry, it includes a large class of compounds of which maple-, cane-, and beet-sugar are examples of only one division. The two main classes of sugars present in plant bodies are sucrose and dextrose ; occasionally, other sugars are found.

The sucrose group includes cane-, beet-, maple-, milk-, and malt-sugar. These sugars have the general formula $\mathrm{C}_{12} \mathrm{H}_{22} \mathrm{O}_{11}$, and are characterized by the molecule containing $\mathrm{I} 2$ atoms of carbon. The dextrose group includes glucose, levulose, galactose, and all sugars having the general formula $\mathrm{C}_{6} \mathrm{H}_{12} \mathrm{O}_{6}$. This group is characterized by the molecule containing 6 atoms of carbon. The term monosaccharide is applied to the dextrose group, and disaccharide to the sucrose group. 
243. Occurrence of Sucrose. - Sucrose is found in plants in largest amounts of any of the sugars. Juices from the sugar-cane and sugar-beet contain from I 2 to $I 8$ per cent. It is also, in small amounts, in seeds and cereal products. From 1.5 to 2 per cent is found in sweet corn and about $0.5^{\circ}$ per cent in wheat flour. In some fruits, as apples, sucrose is present to the extent of 5 per cent or more.

\section{Physical and Chemical Properties of Sucrose. -} The chemical and physical properties of sucrose obtained from sugar-cane or sugar-beets are alike in all respects. When the two sugars have been subjected to the same degree of refining, they are identical. When examined under the microscope, sucrose is in the form

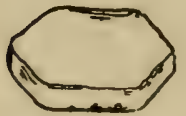
of regular crystals, as shown in the illustration (see Fig. 77). Above $160^{\circ} \mathrm{C}$. sucrose crystals Fig. 77. - Su- melt, and when cool form a colorless, glassy crose crystal. mass. A concentrated solution boils at a little above $100^{\circ} \mathrm{C}$. At $160^{\circ} \mathrm{C}$. a brown product known as barley sugar is formed. At $200^{\circ} \mathrm{C}$. sucrose is decomposed, and gases, as carbon monoxid, carbon dioxid, and methane, are given off. In concentrated solutions, a temperature of $100^{\circ} \mathrm{C}$. causes an inversion; that is, the sucrose molecule is split up and two new sugars are formed; namely, dextrose and levulose. Hence, in the refining of sugar, the concentration must be carried on in vacuum pans. In the presence of all acids, even dilute organic acids, hydrolysis or inversion of sucrose takes place.

245. Milk Sugar (lactose) is found in cow's milk to the extent of 4.5 to 5 per cent, and is present in the milk of all mammals. It has the same general composition as sucrose, but a different structural composition.

246. Maltose is a sugar produced in the malting of 
barley and other grains by the action of ferments upon starch, the reaction being

$$
2 \mathrm{C}_{6} \mathrm{H}_{10} \mathrm{O}_{5}+\mathrm{H}_{2} \mathrm{O}=\mathrm{C}_{12} \mathrm{H}_{22} \mathrm{O}_{11} \text {. }
$$

Maltose is not found to any extent in plant bodies, but is present in prepared foods which have undergone the malting process.

247. Inversion of Sucrose. - When sucrose is acted upon by heat and dilute acids, as well as other chemicals, inversion takes place. One molecule of water is chemically united to one molecule of sucrose which splits up and forms the two sugars, levulose and dextrose.

$$
\begin{aligned}
& \text { Sucrose. } \\
& \mathrm{C}_{12} \mathrm{H}_{22} \mathrm{O}_{11}
\end{aligned}+\mathrm{H}_{2} \mathrm{O}=\stackrel{\text { Levulose. }}{\mathrm{C}_{6} \mathrm{H}_{12} \mathrm{O}_{6}}+\stackrel{\text { Dextrose. }}{\mathrm{C}_{6} \mathrm{H}_{12} \mathrm{O}_{6}} \text {. }
$$

This process takes place in the ripening of fruits and in the curing of many fodders, as well as in the cooking and preparation of human foods.

Experiment 48. - Inversion of cane-sugar. Place 2 grams sugar, $30 \mathrm{cc} . \mathrm{H}_{2} \mathrm{O}$, and 2 cc. $\mathrm{H}_{2} \mathrm{SO}_{4}$ in an evaporator. Heat fifteen minutes on a sand bath, replacing the water lost by evaporation. Neutralize with $\mathrm{CaCO}_{3}$ and filter, adding more water if necessary for filtration. Test $5 \mathrm{cc}$. of the filtrate with an alkaline solution of copper sulfate (Fehling's solution) as directed in Experiment 34. Take o.I gram of sugar, dissolve in ro cc. cold water, add 2 cc. alkaline copper sulfate solution, and heat cautiously for about a minute. Cane-sugar, unless inverted, gives no reaction with copper sulfate solution. Compare this result with the first test. Observe that in the first test the same precipitate is obtained as in Experiment 34 . Questions. - ( $\mathrm{r}$ ) What is meant by inversion of cane-sugar? (2) Why was hot sulfuric acid used? Write the reaction. (3) Why was $\mathrm{CaCO}_{3}$ used? (4) What becomes of the calcium salt when the solution is filtered? (5) What was the result when the filtrate was heated with alkaline copper sulfate solution (Fehling's solution)? (6) Did the sucrose, when tested, give any reaction with this reagent? (7) Under what condition in nature does this process of inversion take place? (8) What are invert sugars? 
248. Refining Sugar. - At the present time, the larger portion of commercial sugar is obtained from sugarbeets. In the diffusion process of manufacture, the beets, after cleaning and slicing, are passed into large tanks, where they are subjected to water under pressure which removes the sugar by liquid diffusion. The impurities associated with the sucrose are precipitated with lime water, $\mathrm{Ca}(\mathrm{OH})_{2}$, the excess of lime being removed by carbon dioxid gas which converts the calcium hydroxid into insoluble calcium carbonate. For the purpose of producing the pure lime and the carbon dioxid gas, limestone is burned in specially constructed kilns at the sugar factory. After removal of the impurities and the lime, the solution containing the sugar is concentrated in a large vacuum pan and allowed to crystallize; the crystals are then washed in centrifugal washing machines and granulated. Commercial sugar is ordinarily about 99 per cent pure sucrose.

249. Occurrence of Dextrose. - Dextrose occurs widely distributed in nature. It is found in small amounts in the sap of saccharine plants, in seeds, ripe fruit, honey, animal tissues, and in all food products in which the sucrose has undergone inversion.

250. Chemical and Physical Properties. - Dextrose is a solid, white substance which gives off water from its molecule when heated to $170^{\circ} \mathrm{C}$. At $200^{\circ} \mathrm{C}$., volatile gases and acid products are formed. Acids and alkalies act upon dextrose and produce a large number of compounds. Dextrose can undergo a number of different kinds of fermentation, alcohol, succinic acid, lactic acid, and glycerol being some of the products formed. Whenever foods which contain dextrose are exposed to favorable conditions, fermentation takes place. Dextrose is pro- 
duced commercially by the action of dilute acids upon starch. The acid causes a molecule of water to unite chemically with a molecule of starch.

$$
\mathrm{C}_{6} \mathrm{H}_{10} \mathrm{O}_{5}+\mathrm{H}_{2} \mathrm{O}=\mathrm{C}_{6} \mathrm{H}_{12} \mathrm{O}_{6} \text {. }
$$

The thick syrup formed after the acid is neutralized is called glucose syrup. If a solid mass is produced, it is called grape sugar.

Experiment 49. - Preparation of glucose. Add 20 drops $\mathrm{H}_{2} \mathrm{SO}_{4}$ to about $70 \mathrm{cc}$. water in an evaporator. Heat on the sand bath until the boiling point is reached. Then add 2 grams of pulverized starch. Observe the appearance of the starch immediately after adding. Heat twenty-five minutes, stirring occasionally, and replacing the water should too much evaporate. Add $\mathrm{CaCO}_{3}$ to neutralize the $\mathrm{H}_{2} \mathrm{SO}_{4}$; when neutral to test paper, filter, washing the contents of the filter with $25 \mathrm{cc}$. of water. Take a few drops of the filtrate and test with iodin for starch. Then evaporate the rest of the filtrate to about $20 \mathrm{cc}$. and observe its appearance.

Tests for glucose. Place about $3 \mathrm{cc}$. of glucose solution in a test tube, add 3 cc. alkaline solution of copper sulfate (Fehling's solution; see Experiment 34), and heat. Dissolve .r gram glucose in $5 \mathrm{cc}$. water; add $3 \mathrm{cc}$. Fehling's solution. Heat, and compare with the first test.

Questions. - (I) Why was sulfuric acid used in this experiment? (2) What chemical change did the starch undergo? Write the reaction. (3) Why was $\mathrm{CaCO}_{3}$ used? Write the reaction. (4) Was any reaction obtained with iodin for starch? (5) What was the result when the glucose solution was added to the hot alkaline solution of copper sulfate? (6) How did this precipitate compare with that obtained when glucose from the shelf bottle was used?

25I. Levulose, commonly called fruit sugar, is formed along with dextrose whenever sucrose undergoes inversion. It has the same formula as dextrose, $\mathrm{C}_{6} \mathrm{H}_{12} \mathrm{O}_{6}$, but different chemical and physical properties, due to a different structural composition. Levulose is very sweet, and is found in many ripe fruits and vegetables. Its properties 
are somewhat similar to those of dextrose, but it is more susceptible to the action of heat, acids, and alkalies, and less to the action of ferments.

Experiment 50. - Levulose and reducing sugars from carrots. Reduce a small clean carrot to a pulp. Place the pulp in a beaker and add $200 \mathrm{cc}$. water. After half an hour, filter, heat the filtrate for fifteen minutes, and then filter a second time. Evaporate $50 \mathrm{cc}$. of the filtrate nearly to dryness. Test a portion with Fehling's solution as in Experiment 49.

Questions. - (I) How was sugar separated from the carrots? (2) What was the result when the filtrate was heated, and what compounds were precipitated? (3) Describe the appearance of the concentrated filtrate. (4) What reaction was obtained with Fehling's solution? (5) How does levulose differ in composition and properties from dextrose?

252. Miscellaneous Sugars. - A number of sugars that do not belong either to the dextrose or sucrose group are found in plants. Raffinose, for example, is a sugar present in beets and other vegetables in small amounts. It can be converted into dextrose sugars by treatment with dilute acids.

253. Optical Properties of Sugar. - Sugars are characterized as optically active or inactive. Those which have the power of turning a ray of polarized light to the right are called dextrorotatory, while those which turn the ray to the left are called levorotatory. Polarized light has no action upon the inactive sugars. This principle is taken advantage of in the commercial testing of sugar by means of the polariscope, which is a piece of apparatus so constructed that the number of degrees which a ray of polarized light is diverted in passing through a solution of sugar can be accurately measured, and the purity of the sugar determined. A given weight of pure sucrose dissolved in a definite amount of water always turns a ray 
of polarized light a definite number of degrees which are accurately measured by the polariscope. Any decrease in purity influences proportionally the angle of divergence of the polarized light. Hence, if the angle of

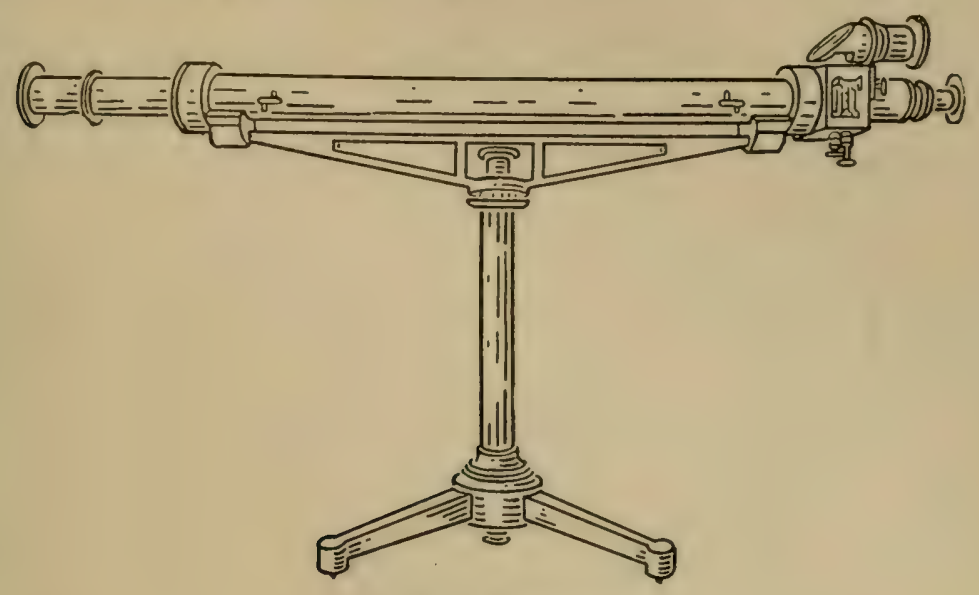

Fig. 78. - Polariscope

divergence of a commercial sugar is determined, its purity is likewise determined.

254. Sugar-beets are usually paid for on the basis of their content of sugar and purity of juice. For sugarmaking purposes, the higher the content of sugar and the purer the juice, the more valuable the beets. Ordinarily, sugar-beets contain from I 2 to I 6 per cent sugar; occasionally as low as 8 and as high as 20 per cent. In addition to sugar, the beet juice has other solids, as small amounts of organic acids, albumin, and pectin. When the content of solid matter is 20 per cent and 16 of the 20 parts are sugar, the juice has a purity coefficient of $80\left(\frac{16}{20} \times 100\right)$.

255. Food Value of Sugar. - When properly combined with other foods, sugar is a valuable nutrient for the production of heat and energy. Like starch, it is incapable of sustaining life unless associated with nitrogenous 
compounds. One pound of sugar, when burned, yields I. 5 pounds of carbon dioxid and $0.5^{8}$ pound of water.

$$
\mathrm{C}_{12} \mathrm{H}_{22} \mathrm{O}_{11}+{ }_{24} \mathrm{O}=\mathrm{I}_{2} \mathrm{CO}_{2}+\text { II } \mathrm{H}_{2} \mathrm{O} \text {. }
$$

In a ration, sugar is considered as having the same caloric value as starch, viz., I pound yields I 860 calories.

256. Gums. - Closely related to the sugars are the gums, like gum arabic, and those which exude from peach and cherry trees. In the seeds also of many grains there are gum-like bodies. When treated with dilute acids, the gums are converted into dextrose sugars and acid products. Bassorin, or mucilage, as flaxseed mucilage, is found in a few seeds and fruits. The formula for some of the gums is the same as for sucrose sugars and dextrose.

257. Pentosans. - The pentosans are a class of carbohydrates present in liberal amounts in many plants. They are insoluble, and aid the cellulose in giving form and structure to plant tissues. When acted upon by dilute acids, the pentosans are rendered soluble, while true cellulose is insoluble. They are called pentosans because they yield a sugar which contains five atoms of carbon in the molecule. When acted upon by the digestive fluids they are rendered soluble and available as nutrients. In some fodders they form a large part of the nitrogenfree extract. The digestible pentosans are considered as having the same food value as other digestible carbohydrates. The percentage amounts of pentosans in some common foods are approximately as follows:

Per cent.

Hay, timothy . . . . . . . . . . . . . 20

Linseed meal. ................. I 2 to $\mathrm{r}_{5}$

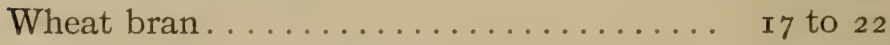

Wheat....................... 4 to 6 
Per cent.

Oats..................... I 2

Corn....................... 5

Barley...................... 5 to 7

Flour........................ trace

258. Pectin Bodies are found in many ripe fruits and vegetables. They are jelly-like substances, which are soluble in hot water, and are commonly known as fruit jellies. When treated with dilute acids, digestive fluids, and other reagents, the pectin bodies are converted into dextrose sugars and other products. Potatoes, turnips, beets, and all fruits contain pectin. In unripe fruits, and in some uncooked vegetables, the pectin is in acid forms which are insoluble and indigestible. In the last stages of ripening, the pectin of fruits and vegetables undergoes a change to soluble forms. Soluble pectin is considered to have the same food value as soluble carbohydrates.

Experiment 5I. - Soluble pectin from potatoes. Reduce a small clean potato to a pulp. Squeeze the pulp through a clean cloth into a beaker, add ro cc. $\mathrm{H}_{2} \mathrm{O}$, and heat on a sand bath to coagulate the albumin. Filter; add a little hot water if necessary. To the filtrate add a little alcohol. The precipitate is soluble pectin.

Questions. - (I) Is the pectose from the potato soluble? (2) Is pectose coagulated by heat? (3) Is it soluble in alcohol? (4) In what ways does pectin differ from sugar? (5) In what ways does it resemble sugar?

259. Nitrogen-free Extract. - In the analysis of plants and foods, the chemist determines the percentage of water, ash, crude protein, ether extract, and crude fiber, and then classes the remainder in one group or division called nitrogen-free extract. Wheat, for example, contains: 
Per cent.

Water. . . . . . . . . . . . . . . . . 9.25

Ash......................... $\quad 2.95$

Crude protein................. $\mathbf{1 3 . 2 5}$

Ether extract.................. 2.20

Crude fiber............... 2.25

Total................ $\overline{29.90}$

I00 $-29.90=70$. Io per cent nitrogen-free extract.

The nitrogen-free extract compounds contain no nitrogen; they are nitrogen-free or non-nitrogenous, and are soluble in dilute acids and alkalies. The nitrogenfree extract of wheat is principally starch; in some foods, as carrots, it is largely sugar. In human foods, it is mainly carbohydrates as starch and sugar, while in animal foods, it consists of pentoses and a large number of compounds, dissimilar in character and food value. In plant bodies, the nitrogen-free extract usually constitutes the largest of any of the groups of compounds. Meats and animal products, except milk, contain very small amounts.

\section{FATS}

260. Presence in Plants. - Fats and oils form one of the subdivisions of the non-nitrogenous compounds of plants. Fat is in nearly all plants, but in smaller amounts than the carbohydrates. The fat in plants is produced from starch. For example, in flax, there is more starch than fat when the plant is growing, but in the mature plant there is more fat than starch, due to the starch being converted into fat. This change of starch to fat can take place only in plant cells; fat, as yet, cannot be made synthetically. During germination, the fat of seeds reverts to starch. While fat is present in nearly 
all parts of plants, it is most abundant in the seeds, as flax, rape, and cotton, which are often called oil seeds. Fat occurs in the form of minute oil globules within the plant cell; and is removed mechanically by aid of heat and pressure, as in the manufacture of linseed, rape, cottonseed, and other oils. It is also extracted by means of solvents, as benzine and carbon disulfid. In roots and stems, fat is found only in traces. It is often in the form of a waxy coating on leaves, while in nuts it is stored in large amounts in the kernel.

261. Physical Properties. - Fats are all characterized physically by being insoluble and of a lower specific gravity than water. There are many separate fats with individual characteristics, and each having its own specific gravity and melting point. As commonly found, they are not simple bodies, but mechanical mixtures of various fats, as stearin, palmitin, and olein. The fats are all soluble in ether, chloroform, and turpentine, and differ in physical properties according to the proportion and kinds of fats. When examined under the microscope, some have optical properties and definite crystalline forms.

262. Chemical Composition. - Fats are all characterized by having a high per cent of carbon and a low per cent of oxygen. For example, in stearin, $\mathrm{C}_{57} \mathrm{H}_{110} \mathrm{O}_{6}$, there are in the molecule 57 atoms of carbon and 6 atoms of oxygen. In starch and carbohydrates in general, the per cent of oxygen is greater, and of carbon less, than in fats.

Ultimate Composition of Fats.

$\begin{array}{ccccc} & \begin{array}{c}\text { Stearin. } \\ \text { Per cent. }\end{array} & \begin{array}{c}\text { Palmitin. } \\ \text { Per cent. }\end{array} & \begin{array}{c}\text { Olein. } \\ \text { Per cent. }\end{array} & \begin{array}{c}\text { Starch. } \\ \text { Per cent. }\end{array} \\ \text { Carbon........ } & 77.6 & 75.9 & 77.4 & 44.44 \\ \text { Hydrogen ...... } & \text { I } 2.4 & \text { I } 2.2 & \text { Ir.8 } & 6.17 \\ \text { Oxygen......... } & \text { I0.0 } & \text { II.9 } & \text { I0.8 } & 49.39\end{array}$


Fats are organic salts, the basic part consisting of the glycerol radical $\mathrm{C}_{3} \mathrm{H}_{5}$, which is combined with a fatty acid. Glycerin is the basic constituent common to all fats. One fat, as stearin, differs from another, as olein, by containing a different fatty acid in combination with the glycerol radical. When the simple fats are separated into their component parts, the acids formed are: stearic, palmitic, oleic, and butyric.

Some of the fatty acids, as stearic and palmitic, are solids, while others, as butyric, are volatile. Those fatty acids which distil with boiling water are called volatile fatty acids. Butter, for example, contains nearly 5 per cent of volatile fatty acids, present mainly as butyric acid combined with the glycerol radical. Some of the fats undergo fermentation and become rancid, as butyrin in butter, while others slowly take up oxygen from the air and undergo oxidation. The chemical and physical properties of the fats in plants and foods are determined by the kinds and amounts of the separate fats. Olein, stearin, and palmitin are always present in larger amounts than are other fats.

263. Stearin $\left(\mathrm{C}_{57} \mathrm{H}_{110} \mathrm{O}_{6}\right)$ is a solid fat with a high melting point, $69.4^{\circ} \mathrm{C}$. Beef and mutton tallow and animal fats in general are composed mainly of stearin. When pure, it is a white and tasteless body, and has a definite crystalline structure. Stearin predominates in all hard fats.

264. Palmitin $\left(\mathrm{C}_{51} \mathrm{H}_{98} \mathrm{O}_{6}\right)$ is a white, solid fat obtained from butter, palm oil, and human fat. When chemically pure, it is tasteless, and crystallizes in the form of tufts and needles. It has a melting point of $63^{\circ} \mathrm{C}$. Its general properties are somewhat similar to those of stearin. 
265. Olein $\left(\mathrm{C}_{57} \mathrm{H}_{104} \mathrm{O}_{6}\right)$ at moderate temperatures is a liquid. It solidifies at $4^{\circ} \mathrm{C}$. Olein predominates in the oil of fish, as sperm oil and cod-liver oil. It is also found to a great extent in many vegetable oils, as olive oil. Whenever olein predominates, the fat is a liquid.

266. Miscellaneous Fats. - In addition to the three fats mentioned, there are others, as butyrin, the characteristic fat of butter, and linolein, the characteristic fat of flaxseed.

267. Saponification is a chemical change brought about by the action of an alkali, as potash or soda, upon a fat. An exchange takes place between the glycerol of the fat and the metal of the alkali. Glycerin is a base, but potash is a stronger base; hence the potash replaces the glycerol and forms salts, as potassium stearate or palmitate, according to the fat used.

Experiment 52. - Saponification. Weigh about 20 grams of lard into an evaporator. Melt the lard, but do not heat above $50^{\circ} \mathrm{C}$. Dissolve Io grams $\mathrm{NaOH}$ in about $40 \mathrm{cc}$. water in a beaker. (Do not let the $\mathrm{NaOH}$ come in contact with the scale pan.) Add this solution to the evaporator, stirring constantly, and leave the evaporator on the warm sand bath, with a low flame underneath, for 40 to 50 minutes. Then place on the sand bath in the desk until the following day, when a good soap should have formed. Dissolve a little of the soap thus produced in a test tube with $20 \mathrm{cc}$. water. Divide the solution into two parts; to one add a little salt, and to the other a few drops of $\mathrm{HCl}$.

Questions. - (I) Why was $\mathrm{NaOH}$ used in this experiment, and what portion of the fat did it replace? (2) What other materials could be used in place of $\mathrm{NaOH}$ ? (3) What influence did the salt have upon the soap solution? (4) What was the result when $\mathrm{HCl}$ was added to the soap solution? (5) Why is it necessary to weigh both the lard and the $\mathrm{NaOH}$ ? (6) What would be the result if the fat and alkali were taken in different proportions from those used in this experiment? (7) Why does soap form an insoluble mass with hard waters? 
268. Fatty Acids. - Formic acid, found in pine needles and in red ants, has the formula $\mathrm{H}_{2} \mathrm{CO}_{2}$, which is also written $\mathrm{HCO}_{2} \mathrm{H}$. Acetic acid has the formula $\mathrm{H} . \mathrm{CH}_{2}$. $\mathrm{CO}_{2} \mathrm{H}$, and differs from formic acid simply in containing $\mathrm{CH}_{2}$ more than found in formic acid. If $\mathrm{CH}_{2}$ were added to acetic acid, $\mathrm{H} . \mathrm{C}_{2} \mathrm{H}_{4} \cdot \mathrm{CO}_{2} \mathrm{H}$, propionic acid would be produced. This is present in some plants. In like manner, butyric acid can be obtained from propionic acid. By the addition of $\mathrm{CH}_{2}$, about twenty acids can be formed in the way described. This list includes palmitic, stearic, and other acids found in fatty bodies and named fatty acids; various of these are present in nearly all foods. When a series of compounds, like the fatty acids, shows a uniform difference between two adjacent members the term homologous series is employed.

269. Waxes. - Wax is similar in composition to fat, but contains an ethyl radical in place of the glycerol radical. Beeswax, for example, is composed of palmitic acid and ethyl radicals. Waxes, like fats, undergo saponification and are considered as having the same food value.

270. Food Value of Fat. - Fat is the most concentrated non-nitrogenous nutrient of foods. On account of containing such a large amount of carbon and so little oxygen, fat, when either burned or oxidized as food, produces 2.25 times more heat than the same weight of starch or sugar. One gram of fat yields 9.2 calories, and I pound, 4225 calories. The fact that so much more heat is produced from the oxidation of fat is apparent when the products of oxidation of starch and fat are compared.

Stearin.

$$
\begin{gathered}
\mathrm{C}_{57} \mathrm{H}_{110} \mathrm{O}_{6} \\
890
\end{gathered} \text { I6 }_{3} \mathrm{O}=\underset{2508}{57 \mathrm{CO}_{2}}+\underset{55 \mathrm{H}_{2} \mathrm{O} .}{990}
$$

I pound of fat produces 2.8 pounds $\mathrm{CO}_{2}+$ I.I pounds of water. 


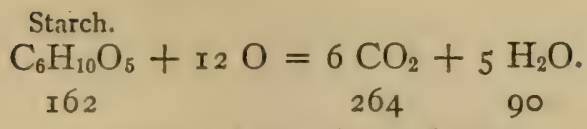

I pound of starch produces

I. 6 pounds $\mathrm{CO}_{2}+0.56$ pound $\mathrm{H}_{2} \mathrm{O}$.

890 parts, by weight, of fat produce, when burned, 2508 parts, by weight, of carbon dioxid and 990 parts of water. I62 parts, by weight, of starch produce 264 parts, by weight, of carbon dioxid and 90 parts of water. One pound of fat yields 2.8 pounds of carbon dioxid and I.I pounds of water, while one of starch yields I.6 of carbon dioxid and 0.56 of water. Fat produces approximately 2.25 times more heat than starch.

\section{Amount of Fat in Plants and Foods. - The} amount of fat in various plant substances ranges from a few hundredths of I per cent in tubers to 35 per cent and more in flaxseed. Of ordinary grains, oats and corn are the richest in fat and contain from 3.5 to 5 per cent, while wheat and rye have about 2 per cent each. In hay the amount of pure fat is less than 2 per cent, and in straw it is less than I per cent. In nearly all food products the per cent of pure fat is included with the ether extract.

Experiment 53. - Fat from wheat germ. Place 2 grams wheat germ in a test tube, and add gasoline until the test tube is about one third full. Cork and shake at intervals of three or four minutes. Do not let the gasoline come near the gas flame. Filter into a clean porcelain dish, and place the dish in an open window until the gasoline is evaporated. Observe the residue of fat.

Experiment 54. - Fat from yolk of egg. Repeat the preceding experiment, using one fourth of the yolk of a hard-boiled egg, and 5 cc. ether instead of gasoline.

Questions. - (I) What was the solvent used for separating the fat from the wheat germ? (2) From the yolk of the egg ? (3) Describe the fat obtained from the wheat germ. (4) From the yolk 
of the egg. (5) How were the solvents removed in these experiments? (6) Are fats volatile bodies? (7) Why do fats obtained from different sources vary in appearance and properties?

272. Ether Extract. - The term ether extract is applied to that class of compounds which is soluble in ether. In the case of human foods, the ether extract consists largely

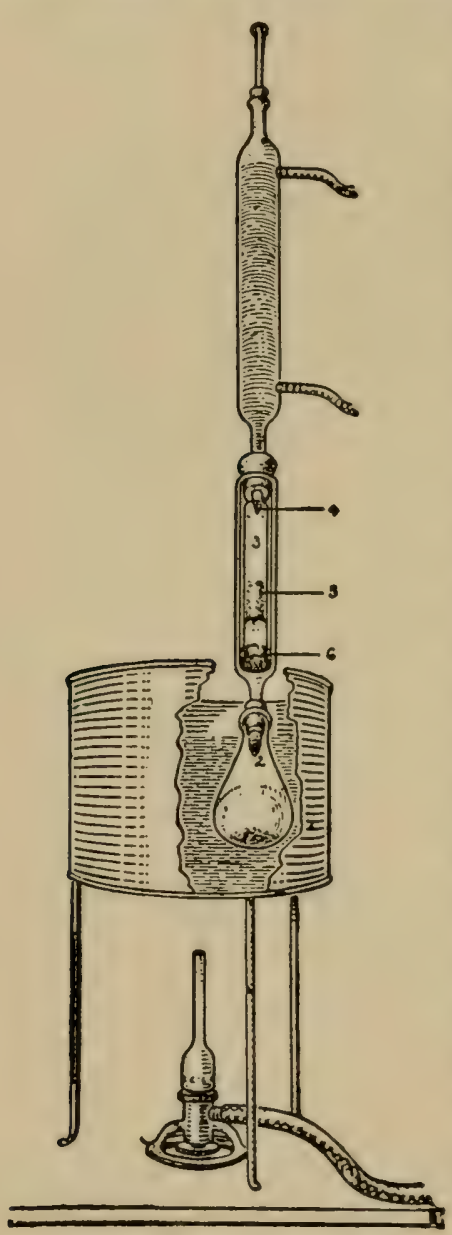

FIG. 79. - Ether extractor. of fats and oils with variable amounts of waxes, resins, chlorophyll, vegetable coloring matters, and nitrogenous and phosphorized bodies, as lecithin. The value of the ether extract depends entirely upon its source; in milk, meats, and cereals and their products, the ether extract is nearly pure fat, while in many vegetables it is less than half fat. Methods of chemical analysis have not, as yet, been sufficiently perfected to allow the separation and determination of the pure fat of all materials. The ether extract is obtained by weighing a small amount of the dry material in tube 3 (Fig. 79), which is then placed in a glass extractor connected with a small weighed flask containing ether. The flask is immersed in a water bath heated by a gas burner, the ether is volatilized, and the vapor passes through openings 2 and 4 into the condenser, where it is cooled and falls back in drops from point 4 on the substance at 5 . The ether 
percolates through the substance and returns to the flask. The fats and ether soluble bodies are not volatilized, but remain in the flask while the ether is vaporized and condensed again and again. After the extraction is completed, the ether is distilled from the flask, the ether extract dried and weighed, and the percentage amount calculated. While the process appears to be simple, it is difficult to control, because even after many days' extraction, certain materials will continue to give up ether extract, and unless unusual care is taken some of the fats are oxidized. Then, too, the ether extract is liable to be contaminated with impurities if ether of a high degree of purity is not used. When the determinations are made under uniform conditions, the results are comparable and are of value when properly interpreted.

\section{Organic ACIDS}

273. Occurrence in Plants. - In all plants and vegetable foods, there are bodies known as organic acids. An organic acid, like all acids, contains hydrogen which can be replaced by a metal (see Section 75). The negative radical of the acid contains carbon, hydrogen, and oxygen. For example, in tartaric acid, $\mathrm{H}_{2} \mathrm{C}_{4} \mathrm{H}_{4} \mathrm{O}_{6}$, the $\mathrm{H}_{2}$ can be replaced by a metal; $\mathrm{C}_{4} \mathrm{H}_{4} \mathrm{O}_{6}$ is the tartaric acid radical. Organic acids, like mineral acids, are neutralized by bases.

$$
\begin{array}{cc}
\substack{\text { Tartaric } \\
\text { acid. }} & \begin{array}{c}
\text { Potassium } \\
\text { tartrate. }
\end{array} \\
2 \mathrm{KOH}+\mathrm{H}_{2} \mathrm{C}_{4} \mathrm{H}_{4} \mathrm{O}_{6}=\mathrm{K}_{2} \mathrm{C}_{4} \mathrm{H}_{4} \mathrm{O}_{6}+2 \mathrm{H}_{2} \mathrm{O} .
\end{array}
$$

As a rule, the organic acids are not present in a free state, but are combined with base-forming elements, as potassium and calcium, forming organic and acid salts. 
In plants the organic acids are mainly in solution, as in the sap. When the plant matures, they are used either for the construction of other organic compounds, or are neutralized by bases to form insoluble salts, as calcium oxalate, and deposited as crystals in the leaves. A small amount of acid is found in all mature seeds, and during germination, some of the carbohydrates are converted into acids. In green vegetables and small fruits the organic acids are found more liberally than in the seeds of grains; in the leaves and stems of matured plants there is but little acid. Some of the organic acids from fruits are of commercial value, as crude tartaric acid or argol in grapes, from which cream of tartar is prepared. There are a large number of organic acids found in plants and food materials, and in the study of organic chemistry these acids constitute an important part. In this work, only a few of the more common organic acids are considered.

274. Tartaric Acid is the characteristic acid of grapes. It is also found in small amounts in pineapples, cucumbers, and potatoes. It can be produced in the laboratory by oxidation of milk sugar and other carbohydrates. Crude tartar or argol, from which commercial cream of tartar is made, is deposited when grape juice ferments. When tartaric acid is neutralized with bases, tartrates are formed. Sodium potassium tartrate (Rochelle salt) is one of the most important salts of tartaric acid.

275. Malic Acid occurs in many vegetables and small fruits, as tomatoes, currants, and strawberries. It is the organic acid found most abundantly in small fruits. Malic acid can be produced from tartaric acid by the action of hydrochloric acid.

276. Succinic Acid is found in many plants, and also 
in animal tissues. Small amounts of this acid are formed when dextrose undergoes alcoholic fermentation. Succinic acid occurs also in soils, particularly those of a peaty character. It can be produced from malic acid by the action of hydrochloric acid. Chemically, the three acids, tartaric, malic, and succinic, are closely related.

277. Oxalic Acid is found in small amounts in nearly all plants, particularly those of the oxalis variety. In some plants, it is present in sufficient amounts to be poisonous. Oxalic acid can be produced, in the laboratory, by the action of nitric acid upon sugar and other carbohydrates.

278. Citric Acid is in lemons and many small fruits, also in small amounts in peas, beans, vetches, and lupines, and with malic acid in cherries, strawberries, and currants.

Experiment 55. - Citric acid from lemons. Measure with the pipette ro cc. of the prepared lemon juice solution. Dilute with about $25 \mathrm{cc}$. distilled water, and add 5 to 7 drops phenolphthalein indicator. Then add dilute $\mathrm{KOH}$ from the burette until a faint pink tinge remains permanent. The $\mathrm{KOH}$ is made by dissolving $5 \mathrm{gm}$. in $100 \mathrm{cc}$. distilled water and the phenolphthalein indication by dissolving a little of the powder in dilute alcohol. The lemon juice solution is prepared by diluting clear lemon juice with ten times its bulk of distilled water and filtering.

Questions. - (I) Why was $\mathrm{KOH}$ used in this experiment? (2) What chemical change took place when $\mathrm{KOH}$ was added to the diluted lemon juice? (3) What change in color was observed? (4) What was the final product in this experiment? (5) How does this experiment compare in principle with Experiment Io?

279. Tannic Acid. - In many seeds and leaves of plants there are bitter astringent compounds, as tannin and tannic acid. They may lessen the value of a food because they retard the natural process of digestion. 
Tannic acid is not found in food plants in any appreciable amount. Commercially, the tannins are valuable for the tanning of leather and for other purposes. Tanninyielding plants are occasionally grown as marketable crops.

\section{Function and Food Value of the Organic Acids.}

The organic acids of plants are valuable mainly because they impart palatability to foods and exert a favorable influence upon digestion by stimulating the secretion and flow of the digestive fluids. Many of the organic acids have medicinal properties, and some, as oxalic acid, are poisonous. The organic acids cannot be considered heator flesh-producing nutrients, but simply food adjuncts. In plants, they take an important part in the assimilation of the mineral elements of plant food, and the production of new tissue. The acid sap comes in contact with the soil particles, dissolving the plant food, which is then absorbed by osmosis.

\section{Essential Oils}

28I. General Properties. - The essential or volatile oils are the compounds which impart characteristic taste and odor to plants. They differ from the fixed oils or fats by completely volatilizing when heated, and leaving no permanent residue on cloth or paper. They also have entirely different chemical composition from the fats.

282. Occurrence. - Volatile or essential oils are found, in some form, in nearly all plants, particularly during growth. In some fruits and seeds they impart characteristic flavor and give individuality to the material. Oil of lemon, oil of cedar, and oil of nutmeg are examples of essential oils. In nearly every plant, one or more of the essential oils is present at some period of growth. 
283. Chemical Composition and Properties. - The essential oils are mixed bodies, many of them belonging to the aromatic series of compounds (see Section I38). According to chemical composition, they may be divided into four groups, and each group in turn into a number of subdivisions.

Groups.

Examples.

I. Terpenes, $\mathrm{C}_{10} \mathrm{H}_{16} \ldots \ldots$. . . il of lemon, oil of turpentine.

2. Cedrenes, $\mathrm{C}_{15} \mathrm{H}_{24} \ldots \ldots$. Oil of cedar, oil of cubeb.

3. Aromatic aldehydes..... Oil of cinnamon, oil of almond.

4. Etherical salts........ Pineapple and fruit flavors.

The essential oils are separated from plants by distillation. At moderate temperatures, most of them are liquids, insoluble in water, but soluble in alcohol. When the terpenes and cedrenes oxidize, they produce resinous deposits from which turpentine is obtained (see Section I35). The aromatic aldehydes form a homologous series, beginning with benzoic aldehyde, $\mathrm{C}_{6} \mathrm{H}_{5}$. CHO, and are present in many plants and fruits, imparting flavor. Ethyl formate, $\mathrm{C}_{2} \mathrm{H}_{5} \cdot \mathrm{HCO}_{2}$, peach flavor, ethyl butyrate, $\mathrm{C}_{2} \mathrm{H}_{5} \cdot \mathrm{C}_{4} \mathrm{H}_{7} \mathrm{O}_{2}$, pineapple flavor, and amyl valerate found in apples are some of the common etherical salts.

284. Essential Oils of Agricultural Crops. - When hay is cut, the odor produced is due to a volatile oil. This is lost when hay is overcured or exposed to leaching rains. The characteristic odor of clover, particularly pronounced in sweet clover, is that of an aromatic body. The odors of all fodder crops are imparted by characteristic essential oils. In the preparation of hay and fodder crops, it should be the aim to prevent, as far as possible, any loss of essential oils. This can be accomplished by cutting the fodder before it is overripe, and then avoiding 
bleaching and leaching. Rape, turnips, cabbage, parsley, and onions contain essential oils.

285. Synthetic Production of Essential Oils. - Nearly all the essential oils found in fruits, as pineapple flavor, peach flavor, and vanilla, may be produced synthetically in the laboratory. They are definite chemical compounds, and it is only necessary to bring together, under right conditions, their radicals or component parts for them to unite and form these compounds. Pineapple flavor is ethyl butyrate. The acid constituent of this salt, butyric acid, is found in stale butter, while the basic part of the radical is in ether and alcohol. The chemical union of butyric acid and the ethyl radical gives ethyl butyrate or pineapple flavor. In fact, nearly all of the commercial fruit flavors are laboratory products. When properly made, they are identical with the same flavors as found in fruits, but frequently they contain traces of acid or alkaline products used in their preparation.

286. Amount of Essential Oils in Plants. - The amount of essential oils in plants and foods is small, less than I per cent, and usually only a fraction of a per cent. This, however, is sufficient to give characteristic taste.

287. Food Value. - Some of the essential oils of fodders, like the organic acids, exert a favorable influence upon digestion by imparting palatability and stimulating the secretion and flow of the digestive fluids. They are not heat- or muscle-forming nutrients, but simply food adjuncts. Some of the essential oils have medicinal properties, while others, as oil of bitter almonds, are poisonous.

Experiment 56. - Essential oil from tea. Place 0.5 gram tea in a small flask, and add $50 \mathrm{cc}$. water. Connect the flask with a delivery tube, one end of which leads into a test tube containing 
water. Arrange apparatus as shown in Fig. 8o. Apply heat and distil 3 to $5 \mathrm{cc}$. Observe odor of distillate, which is that of the volatile oil of tea. Repeat this experiment, using sweet or red clover.

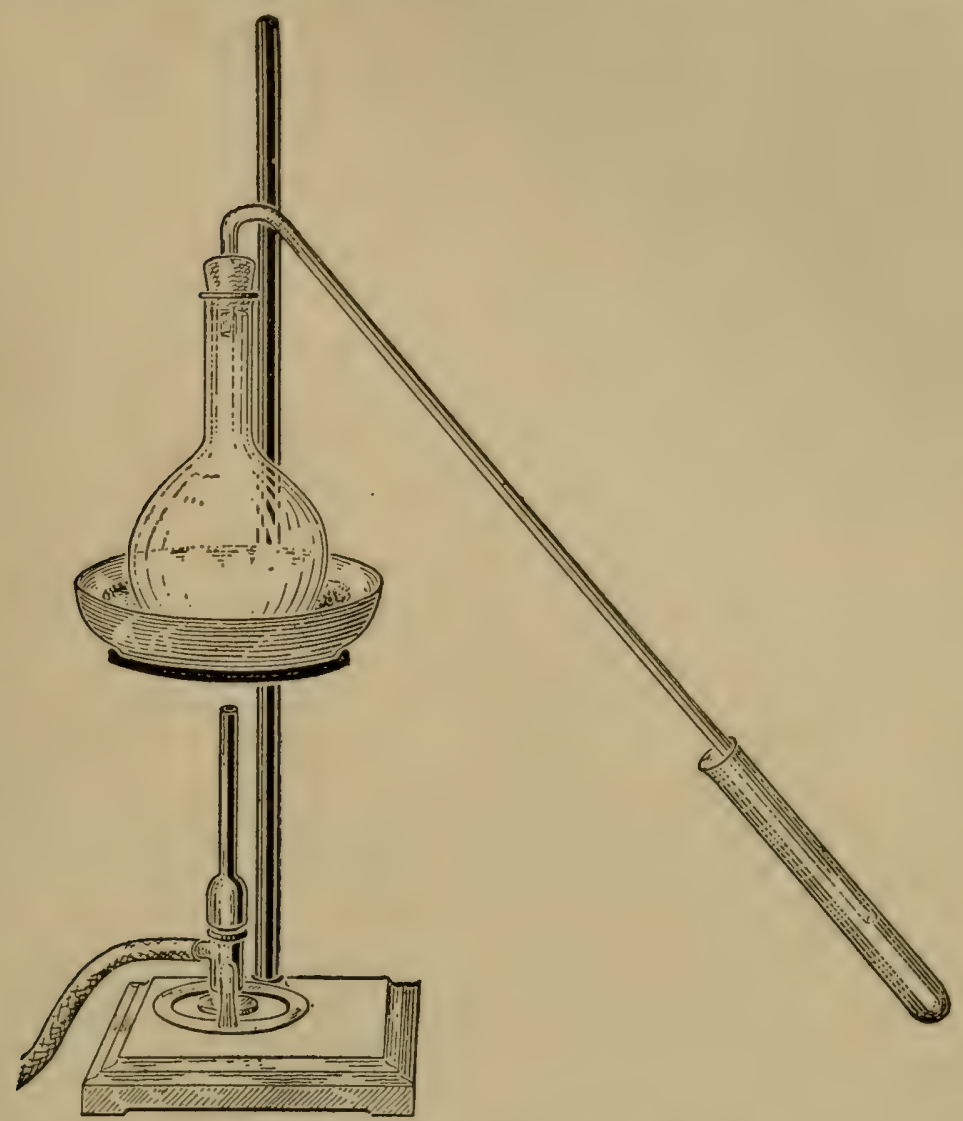

Fig. 80. - Preparation of essential oils.

288. Miscellaneous Compounds of Plants. - Not all of the non-nitrogenous compounds in plants are included in the subdivisions: carbohydrates, fats, organic acids and essential oils. The most important and common ones, however, are included in the above list. There are many others which, for convenience of classification, are called miscellaneous or mixed compounds. 
289. Relationship of Non-nitrogenous Compounds of Plants. - A marked general relationship exists between many of the non-nitrogenous compounds. For example, the various carbohydrates may undergo chemical changes in which one form is converted into another. Starch can be changed to cellulose, sucrose, maltose, or any other carbohydrate, and conversely cellulose can be converted into starch or other similar compounds. These changes take place in plant growth, particularly during germination of the seed, and are brought about by the action of ferment bodies, which cause either addition or elimination of water from the molecule, as

$$
{ }_{2} \mathrm{C}_{6} \mathrm{H}_{10} \mathrm{O}_{5}+\mathrm{H}_{2} \mathrm{O}=\mathrm{C}_{12} \mathrm{H}_{22} \mathrm{O}_{11} \text {. }
$$

Not all of these reactions can take place in the laboratory. Starch may be changed to glucose or maltose, and sucrose may undergo inversion and form invert sugars, but sucrose cannot be made in the laboratory; neither can starch or cellulose be made from glucose. During germination, some of the carbohydrates are converted into organic acids.

The fatty acids are the characteristic constituents of fats. In germinating seeds, fat is formed from starch by the addition of oxygen. The pectose substances are capable of being separated in the laboratory into glucose and acid products. Likewise the glucosides may be split up into glucose and acid bodies. In fact, the various non-nitrogenous compounds of plants, considered as a whole, are more or less related in chemical composition.

290. Food Value of the Non-nitrogenous Compounds. - As a class, the non-nitrogenous compounds are valuable as heat- and energy-producing nutrients. They do not all have the same caloric or fuel value; for 
example, a gram of starch yields 4.2 calories, while a gram of fat yields 9.2. As a rule, the more concentrated the compound in carbon, the greater its fuel value. When properly associated and combined with the nitrogenous compounds, the non-nitrogenous nutrients of plants may produce fat in the animal body. A few of the nonnitrogenous compounds, as the essential oils, have but little direct value as nutrients. Others, as some bitter principles and tannic compounds, may lessen the value of foods or impart a negative value. The carbohydrates, fats, and related non-nitrogenous compounds take an important part in the nutrition of man and animals, and many foods owe their value entirely to the fats and carbohydrates which they contain. 


\section{CHAPTER XXIV}

\section{Nitrogenous Organic Compounds of Plants}

29r. Amount of Nitrogenous Matter in Plants. - As a rule, less than I 5 per cent of the dry matter of plants is nitrogenous material. In the seeds of legumes, as beans and peas, it amounts to about 22 per cent. In nearly all plants, the non-nitrogenous compounds are from six to ten times more abundant than the nitrogenous.

292. Different Terms Applied to Nitrogenous Compounds. - Unfortunately, the various terms used to designate the nitrogenous compounds have not been uniformly applied. Nitrogenous compounds, proteids, crude protein, and albuminoids all have been used synonymously, but each applies to a different class. Organic nitrogenous compounds and crude protein are the most satisfactory appellations for the entire group; proteids and albuminoids are subdivisions of the nitrogenous compounds.

293. Complexity of Composition. - The nitrogenous compounds are more complex in composition than the non-nitrogenous. The percentage composition and formulas of nearly all the non-nitrogenous compounds of plants have been determined, and while the percentage composition and the physical and chemical properties of many of the proteids are known, no definite formulas have, as yet, been applied because of the complexity of their molecular structure. The nitrogenous compounds are composed of carbon, hydrogen, nitrogen, and oxygen, 
and many contain, in addition to these, phosphorus, sulfur, and other elements.

294. Classification of Nitrogenous Compounds. - For food purposes, the nitrogenous compounds of plant and animal bodies may be divided into four groups: (I) proteids, (2) albuminoids, (3) amides, and (4) alkaloids. There are a few nitrogenous compounds in plants that do not find a place in any of the above subdivisions.

\section{PROTEIDS}

295. General Composition. - Proteids are complex nitrogenous compounds that contain about i 6 per cent of nitrogen and less than 2 per cent of sulfur. The per cent of the different elements in protein compounds from various sources ranges as follows:

\begin{tabular}{|c|c|}
\hline Carbon. & $\begin{array}{l}\text { Per cent. } \\
5 \text { I.2-54.7 }\end{array}$ \\
\hline Hydrogen & $6.7-7.6$ \\
\hline Nitrogen. & I $5.2-18.0$ \\
\hline Oxygen. . & $20.2-23.5$ \\
\hline Sulfur. & $0.3^{-2.0}$ \\
\hline
\end{tabular}

It was believed, at one time, that all the various compounds called proteids had, in common, a nitrogenous radical in their molecule to which the name protein was given, but this hypothesis has not been found correct. The term protein has been retained, but not with its original meaning.

296. Occurrence. - Proteids are found more abundant in the seeds of plants than in the leaves or other parts, and are always present in the active living cells of both plants and animals. The proteids take an important part in life processes, protoplasm being largely of a proteid nature. In the growing plant, the proteids are 
found most abundant in the leaves; at maturity, they are stored up in the seed for future use of the embryo. The proteids occur either in a soluble form in the liquids of plant and animal tissues or in a semi-solid, insoluble condition as a part of the tissues. The proteids from animal and plant sources are closely related, but are not in every respect identical. For food purposes, however, they may be jointly considered.

297. Physical Properties. - While the members of the proteid group differ materially, they all have certain physical properties in common. All are optically active and turn polarized light to the left. The soluble proteids, with the exception of peptones and proteoses, are coagulated by heat. The proteids show a wide range in solubility, but all are soluble in either acid or alkaline solutions. As a class, they do not crystallize, and are not diffusible, with the exception of the peptones and proteoses.

298. Chemical Properties. - In structure the proteid molecule is a complex and unstable body. It is readily acted upon by ferments and chemicals. Nitrogen seems to form a weak link in the chain of elements. Proteids unite with acids and alkalies to form acid and alkali proteids. In plants, the proteids are generally united with small amounts of organic acids and mineral compounds, particularly phosphorus and potassium. They all respond to certain reactions: (I) nitric acid gives a permanent yellow color; (2) a solution of mercury and nitric acid, known as Millon's reagent, gives a brick-red color with the acid if heated; (3) a solution of copper sulfate and potassium hydrate gives a violet-colored solution. The proteids, found in living cells, have different properties from those in dead tissue. Proteids 
readily undergo oxidation, and are chemically altered in the preparation of many foods. When the protein molecule is acted upon by heat, a large number of products are formed, as fatty acids, amides, aromatic bodies, ammonia, and carbohydrate-like bodies. The most common change which the proteids undergo is rearrangement of the atoms and radicals in the molecule. Coagulation of albumin by heat is a chemical reaction in which the atoms and radicals in the albumin molecule are simply rearranged structurally. The fact that it is possible for such a large class of compounds as the proteids to be composed of only a few common elements, and for the various members to have different properties, is accounted for by differences in structural composition.

Experiment 57. - Testing for nitrogenous organic compounds. Mix 0.5 gram dry clover with enough soda lime to half fill a test tube. Connect the test tube with a delivery tube, one end of which leads into another test tube containing water. Apply heat for from five to seven minutes. Test the distillate with test paper. (Soda lime has the power to decompose proteid material and liberate the $\mathrm{N}$ as $\mathrm{NH}_{3}$. The $\mathrm{C}$ and $\mathrm{O}$ of the proteid unite and form $\mathrm{CO}_{2}$ and $\mathrm{H}_{2} \mathrm{O}$.)

Questions.-(I) What reaction was obtained when the distillate was tested with litmus? (2) What compound was produced which gave this reaction? (3) What does this indicate that clover contains? (4) Why was this compound liberated?

299. Classification of Proteids. - For purpose of study, the proteids may be divided into five classes: (I) albumins, (2) globulins, (3) albuminates (casein), (4) peptones and proteoses, and (5) insoluble proteids.

There are some proteids that do not belong to any of the above divisions. Albumin, albuminate (casein), and insoluble proteids are the proteids found most abundantly in plant and animal bodies. 
300. Albumins. - The albumins are proteids soluble in water and easily coagulated by heat. Egg albumin, serum albumin, and lactalbumin are examples of animal albumins. Wheat, oats, rye, and nearly all vegetables, when extracted with water, yield some albumin which can be coagulated by heat or precipitated with chemicals. From many vegetables, the albumin is lost when the material is soaked in water for any length of time. Potatoes, for example, lose a large amount of their albumin if soaked in cold water before boiling.

Experiment 58. - Tests for albumin. In each of four test tubes, place a $3 \mathrm{cc}$. portion of a solution of egg albumin. To No. I, add 3 cc. strong alcohol. To No. 2, add 2 cc. $\mathrm{HNO}_{3}$ and heat; when cool, add $\mathrm{NH}_{4} \mathrm{OH}$. To No. 3, apply heat. To No. 4, add a few drops of lead acetate.

Questions. - (1) What change occurred when the solution was heated? (2) When alcohol was added? (3) When $\mathrm{HNO}_{3}$ was used and heat applied? (4) What did the $\mathrm{Pb}\left(\mathrm{C}_{2} \mathrm{H}_{3} \mathrm{O}_{2}\right)_{2}$ do ? (5) What do these tests show in regard to the properties of albumin?

Experiment 59. - Albumin and allied proteids from oats. Place in a flask ro grams of ground oats and $50 \mathrm{cc}$. of water. Cork and shake vigorously; let stand for half an hour or until the next day. Filter (if not clear, refilter) and make the following tests with separate portions of the filtrate: (I) To 5 cc., add a few drops of tannic acid. (2) To 5 cc., add a few drops of lead acetate.

Questions. - (I) What were the results when tannic acid and lead acetate were added? (2) Do the tests indicate any large amount of albumin? (3) How do these tests compare with those of the preceding experiment?

301. Globulins form a group of proteids insoluble in water, but soluble in dilute salt solution. When animal or vegetable substances, as meat, eggs, wheat, rye, or oats, are treated with a dilute salt solution $(\mathrm{NaCl})$, after removal of the albumins, soluble proteid substances called globulins are obtained which are coagulated by heat. 
There are a large number of vegetable globulins. The chief globulin of meat is myosin. When meat is soaked in a dilute salt solution, and then cooked as food, the myosin is extracted and lost. In strong salt solution, myosin and other globulins are insoluble; hence the use of strong brine in the curing of meats. There are globulins in the blood; and in the yolk of an egg, a globulin-like body, vitellin, is found. As a rule, globulins do not make up a very large proportion of the proteids of foods.

Experiment 60. - Obtaining globulin from oats. To the residue left in the flask from Experiment 59, add 2 grams of salt and $50 \mathrm{cc}$. water. Shake vigorously and, after one hour, filter and make the same tests as in Experiment 59. Save the residue in the flask for Experiment 65.

Questions. - (I) What results were obtained when the solution was tested with lead acetate and tannic acid? (2) What do these results indicate? (3) What are globulins?

Experiment 6r. - Separation of meat globulin or myosin. Test as follows four $3 \mathrm{cc}$. portions of myosin solution, prepared by soaking fresh meat in a 5 per cent salt solution. To the first, add a few drops of alum solution. To the second, add a few drops of lead acetate. To the third, add salt until the solution is saturated. To the fourth, apply heat.

Questions. - ( I) What result was obtained with the alum solution and what does this indicate? (2) What did the lead acetate and the salt solutions do? (3) What was used as the solvent for the myosin? (4) What is myosin? (5) What are the properties of myosin?

302. Albuminates. - The albuminates are a group of proteids widely distributed in both animals and plants. They may be produced by the action of either dilute acids or alkalies upon albumins or globulins. Albuminates are insoluble in water, and when an acid albumin is neutralized with an alkali, the albuminate is precipitated. In like manner, an acid precipitates an alkali albumin. 
Casein is an albuminate present in milk, in a semi-soluble form combined with some of the mineral matter. Casein is soluble in dilute alkalies, but is precipitated by acids. In plants the albuminates are sometimes called vegetable casein. From peas, a casein-like body can be extracted.

Experiment 62. - Separation of meat albuminate or syntonin. To three portions of prepared syntonin solution, add: to the first, $\mathrm{Na}_{2} \mathrm{CO}_{3}$ until neutral, avoiding an excess, as it dissolves the precipitate; to the second, add $\mathrm{NaOH}$, a drop at a time until neutral; to the third, add a few drops of lead acetate. Syntonin solution is prepared by cutting fresh meat into small pieces, and extracting it for four hours, in water containing a few drops of $\mathrm{HCl}$.

Questions. - (I) What result was obtained when each reagent was added to the syntonin solution? (2) What was used in the preparation and what as the solvent for syntonin? (3) What is syntonin? (4) What are the properties of syntonin?

Experiment 63.- Preparation of vegetable casein from peas. Place in an evaporator I gram of pea meal, roo cc. $\mathrm{H}_{2} \mathrm{O}$, and 3 cc. $\mathrm{NaOH}$. Heat on the sand bath, occasionally stirring. Filter. If the filtration is slow, pour off and use some of the clear solution. Neutralize with $\mathrm{HCl}$ and observe.

Questions. - (I) To what class of proteids does vegetable casein belong? (2) What was used as the solvent for extracting the vegetable casein? (3) What effect had $\mathrm{HCl}$ ? (4) How does vegetable casein resemble the casein from milk in solubility and other properties?

303. Peptones and Proteoses are closely related groups of proteids found in animal and vegetable bodies. When any proteid material is acted upon by the peptic and tryptic ferments, peptones are formed. These are soluble in water, and are not coagulated by heat or precipitated by acids or alkalies. They are derived from other proteids by ferment action, and are the first products formed when the proteids of the food undergo digestion. In prepared or peptonized foods, the peptonizing process 
is carried on artificially. When meat undergoes curing or ripening, a small amount of peptones is produced. Peptones are present naturally in milk and also in traces in nearly all cereal products. When seeds germinate, proteoses are formed. These are never present in ordinary foods in any appreciable amount.

Experiment 64. - Tests with peptones. Measure into separate test tubes three $5 \mathrm{cc}$. portions of peptone solution. To the first, apply heat and, when cool, add a few drops of tannic acid. To the second, add a few drops of alum solution. To the third, add 5 cc. alcohol. The peptone solution is prepared by treating coagulated egg albumin with pepsin. Five grams of commercial pepsin are dissolved in I liter of water containing 5 drops $\mathrm{HCl}$. This artificial pepsin solution represents the solvent power of gastric juice upon proteid substances. The white of a hard-boiled egg is put into a flask, and $250 \mathrm{cc}$. pepsin solution added; the flask is then placed in a water bath which is kept at a temperature of $38^{\circ} \mathrm{C}$. for four or five hours.

Questions. - (I) What action did the pepsin have on the egg albumin and what was produced? (2) What was the result when heat was applied in test No. I, and how does this compare with the result when egg albumin was similarly treated? (3) What effect did tannic acid and alum have upon the pepsin solution and what did they produce? (4) What was the result when alcohol was added? (5) What are peptones? (6) What does this experiment show in regard to some of the properties of peptones?

304. Insoluble Proteids. - The insoluble proteids are present in plant and animal bodies in larger amounts than are any of the other proteids, and include a large number of similar though chemically distinct substances. Muscular tissue is composed largely of insoluble proteids. The term gluten is applied to this class of compounds in seeds and is a mixture of two or more insoluble proteids. For example, wheat gluten is composed of gliadin and glutenin. Gliadin is a glue-like body which binds together 
the flour particles, and in bread-making, enables the gas to be retained in the dough. Glutenin is a fine, gray material which unites mechanically with gliadin to form gluten. An excess of gliadin produces a soft gluten.

As a class, the insoluble proteids are not soluble in water or dilute salt solution, but are soluble in dilute acids and alkalies. They all undergo the peptonizing process and yield proteoses and peptones. Insoluble proteids are the most common form of proteids in foods.

Experiment 65.- Obtaining insoluble proteids from oats. To the residue left in the flask from Experiment 6o, add 2 cc. $\mathrm{NaOH}$ and $50 \mathrm{cc}$. water. After shaking and allowing half an hour (or until the next day) for extraction of the proteids, filter off the solution and make the following tests: (I) Neutralize 5 cc. with $\mathrm{HCl}$, and if no precipitate appears, add a few drops of lead acetate; (2) neutralize $5 \mathrm{cc}$. with $\mathrm{HCl}$ and evaporate to dryness on the water bath.

Questions.-(I) Why was $\mathrm{NaOH}$ used? (2) What effect did the $\mathrm{HCl}$ and lead acetate have when added to the solution, and what was formed? (3) How did this precipitate of insoluble proteids from oats compare in amount with the globulin and albumin precipitation in Experiments 59 and 6o? (4) What is an insoluble proteid?

305. Food Value of Proteids. - The proteid compounds of plant and animal bodies serve three purposes as nutrients: (I) to produce new muscular tissue and vital fluids in the body, and supply material for repairing broken-down tissue; (2) to produce heat and energy; (3) to assist in the production of fat.

The main function of the proteids is to produce new proteid tissue in the body, and to furnish material for the repair of old or worn-out proteid tissue. The vital fluids of the body, as blood, chyme, milk, and the diges- 
tive fluids, all contain proteids, and the animal body is incapable of producing any of these from either nonnitrogenous or amide compounds. When the food fails to supply sufficient protein, the body uses its reserve supply as long as it lasts, and then starvation results. When there is an excess of proteids in the food, it is used for producing heat or is stored in the body as fat. Either an excessive or a scant amount of proteids in a human or animal ration is not desirable or economical. As stated under chemical properties of proteids, Section 298 , the proteid molecule, when broken up, forms a large number of simpler bodies, as fatty acids and carbohydrate radicals; and it is poor economy to feed proteids in excess and have part perform the functions of fats and carbohydrates. Protein is deficient in many foods, and when such foods are used, they should be combined with those rich in proteids. There are a few proteids which are poisonous. Some of the toxins produced during disease are proteids.

306. The Amount of Proteids in Plants varies according to the kind of plant, stage of growth, and part of the plant. Seeds always contain most, and roots and stalks least. In wheat, oats, barley, and rye, the amount ranges from Io to I 5 per cent; in corn, from 9 to I 2 per cent. Beans and peas contain about 25 per cent, clover hay, from II to I4 per cent, timothy hay and corn fodder, 6 to 9 per cent; while in straw there is usually less than 4 per cent. During the early stages of growth, the dry matter in all plants is relatively richer in proteids than at maturity. This is because the proteids are formed mainly in the early stages, while the carbohydrates are produced more abundantly in the later stages of growth.

307. Crude Protein. - This term is applied to the 
nitrogenous compounds of foods, considered collectively. The word crude is used to distinguish this group because it contains various nitrogenous bodies, not proteids. Pure protein is a simple chemical compound, while crude

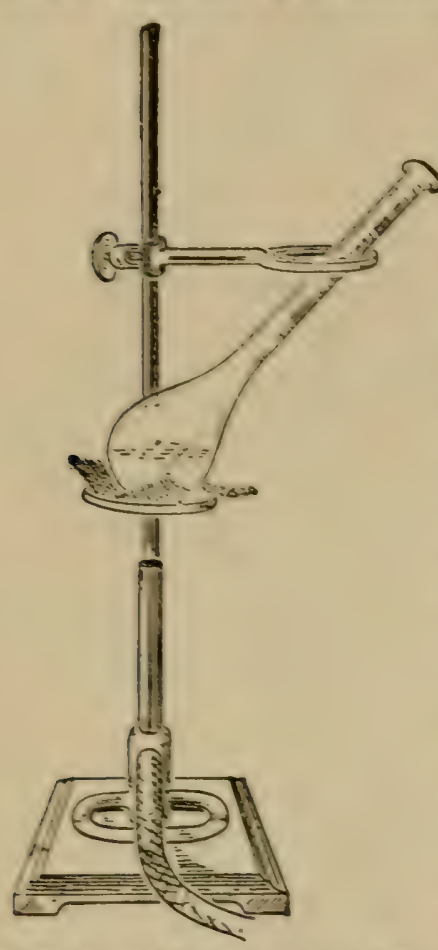

Fig. Si. - Digestion apparatus used in the determination of nitrogen.

protein consists of a group of compounds of which pure protein is one. The albumin of eggs and milk and the gluten of grains are types of pure proteids. In many foods, as potatoes, roots, and fruits, less than half of the crude protein is pure protein. Crude protein, from different sources, is unlike in character, composition, and, to a certain extent, in food value. Less is known of its composition and food value than of any other class of nutrients in foods.

In the analysis of plant and animal substances, the chemist first determines the per cent of total organic nitrogen and then multiplies this by 6.25 to obtain the equivalent amount of crude protein. This is because the proteids contain, on the average, about I6 per cent nitrogen, or there is about one part of nitrogen to every 6.25 of protein ( $100 \div$ I $6=6.25$ ). The nitrogen can be detemined with accuracy; in fact, the method for its determination is one of the most accurate in chemistry. In brief, the method consists in first digesting a small weighed amount of material in a flask with sulfuric acid to oxidize the organic matter and con- 
vert the nitrogen into ammonium sulfate (see Fig. 8r). The nitrogen, in the form of ammonium sulfate, is then

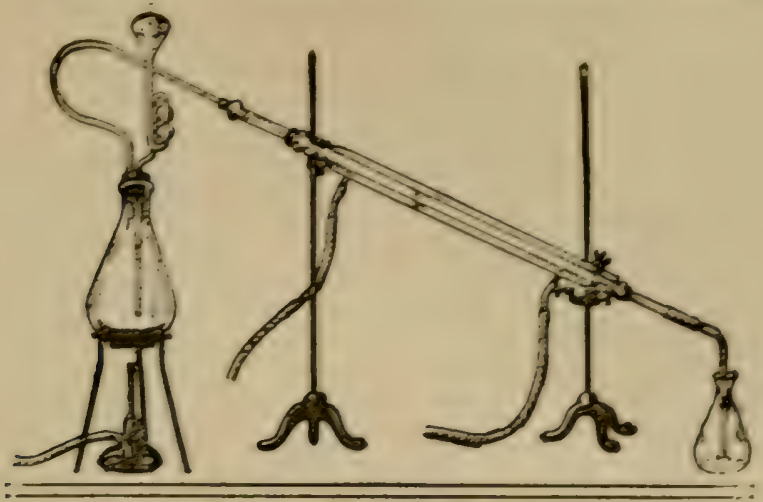

F1G. 82,-Distillation apparatus used in the determination of nitrogen.

liberated as free ammonia, distilled, and its amount determined (see Fig. 82).

\section{Albuminoms}

308. Composition of Albuminoids. - This term is applied to a class of bodies resembling proteids, but differing from them in composition and food value. Albuminoids are found in both animals and plants, but more abundant in animal tissue. Some albuminoids are composed of carbon, hydrogen, nitrogen, and oxygen, while others contain, in addition, phosphorus, sulfur, and other elements.

309. Nuclein is an albuminoid found in both plant and animal bodies; it is the material of which the nuclei of cells are composed, and has been separated from milk, the yolk of egg, and white blood corpuscles, as well as from plant tissue. This albuminoid contains phosphorus, and has been assigned the formula $\mathrm{C}_{59} \mathrm{H}_{49} \mathrm{~N}_{9} \mathrm{P}_{3} \mathrm{O}_{22}$. Nuclein takes an important part in the growth and life 
processes of both plant and animal cells. From different sources it has slightly different chemical properties. It is probably a mixture of several bodies, and not a distinct chemical compound.

310. Gelatin is an albuminoid obtained from connective tissue and bones by the action of either boiling water or dilute acids upon an albuminoid called collagen. Commercial gelatin or glue is the crude product obtained from animal refuse. The formula $\mathrm{C}_{102} \mathrm{H}_{151} \mathrm{~N}_{32} \mathrm{O}_{39}$ has been assigned to gelatin. Gelatin contains no sulfur, and has a different proportion of nitrogen from proteid bodies.

3II. Mucin is an albuminoid found in connective tissue. It is the chief constituent of mucus, and imparts sliminess to the secretions of the mucous membrane. Mucin is present in the saliva from the submaxillary glands, and in the bile and other fluids of the body, particularly those of an alkaline nature.

312. Elastin is an insoluble albuminoid found in connective tissue. Keratin is the hard, horny material in the nails, hoofs, and horns of animals, while chondrin is obtained from cartilage. A number of other albuminoids also are present in both animal and plant bodies.

313. Food Value of Albuminoids. - Gelatin and most of the animal albuminoids undergo digestion, but cannot take the place of protein in a ration. An animal would soon die if its nitrogenous food were entirely in the form of gelatin. Gelatin, when combined with other nutrients, may, however, prevent the rapid conversion of the tissue proteids into circulatory proteids, and thus it aids in establishing a proteid equilibrium in the body. Nuclein and some of the nucleated albuminoids have a higher food value than gelatin, and are considered as having 
the same value as the true proteids. The gelatin albuminoids conserve the proteids of the body, but do not take the place of proteids in the repair of worn-out tissues.

\section{Amides And Amines}

314. Composition and Properties. - The amides and amines are heterogeneous compounds found in both animal and plant bodies. They are less complex in composition than either proteids or albuminoids, and are produced by replacing one or more of the hydrogen atoms of ammonia with an organic radical. If the radical is acid in character, an amide is formed; if alcoholic or basic, the resultant product is an amine. Amides and amines are related to ammonia, as will be observed from the following formulas:

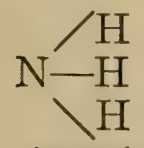

Ammonia.

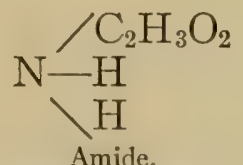

(Amidoacetic acid.)

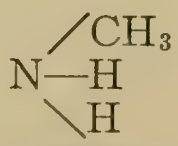

Amine. (Methylamine.)

When the methyl group or radical replaces one of the hydrogen atoms of $\mathrm{NH}_{3}$, the product is methylamine. When the acetic acid radical replaces one of the hydrogen atoms of $\mathrm{NH}_{3}$, the product is amidoacetic acid. The amides and amines are sometimes called compound ammonias, and are produced in plants from ammonia during growth, and in animals during the digestion of proteids.

315. Formation and Occurrence in Plants. - The amide and amine compounds in plants are found mainly in the early stages of growth. The young plant takes up from the soil simple nitrogenous compounds, as ammonia, then a chemical change occurs in the tissues of 
the plant, and as a result, a part or all of the hydrogen of the ammonia is replaced, and an amide is formed. In the study of the composition of proteids (see Section 295) it was stated that the proteid molecule when decomposed yields amide and amine products; consequently it would appear that these compounds are intermediate products in the production of proteids. In the early stages of plant growth, amides are present in greatest abundance, but as the plant approaches maturity, they are used for the production of proteids. In clover, for example, 35 per cent of the total nitrogen is in the form of amides before bloom, while only $\mathrm{I} 2$ per cent is in the same form after bloom.

316. Formation and Occurrence of Amides in Animals. - In the animal body, amides and amines are not formed from ammonium compounds, as in plants, but from proteids. When the proteid molecule is broken up, as in digestion, amides and amines are produced. Urea, an amide, is one of the final products in the metabolism of protein, and is excreted from the body in the liquid excrements, while amidoacetic acid is excreted with the solid excrements. The animal body cannot produce proteids from amides, or amides from ammonia. This elaboration or construction process can take place only in plants. The animal body can simply make over into other forms the proteids supplied in the food, or decompose them and form amides and other products.

In animal tissues, many amides are produced during fermentation and decay, as methylamine, the base which gives the characteristic odor to fish. Methylamine is also found in rye fodder when the plant is at the headingout stage, and imparts a fishy taste to the milk of cows fed upon such fodder. In meats, these compounds are 
associated with other bodies, as ptomaines, which are of poisonous nature. Amides are also produced during the digestion of food, and if the intermediate products between proteids and amides are not completely oxidized, poisonous substances are formed.

317. Food Value of Amides. - Amides do not have high food value compared with proteids, and cannot replace proteids in a ration. Amides possess only a secondary food value, and, like the gelatin albuminoids, they may to a limited extent prevent rapid waste of body tissue. Some give taste and character to foods, as asparagin in asparagus, and in meats they are the materials which give flavor. Some of the amides have medicinal properties, while others are poisonous.

318. Amount of Amides in Foods. - In matured grains, less than 5 per cent of the total nitrogenous matter is in the form of amides, and in meats there is less than I per cent. In some foods, notably roots and tubers, the amides constitute a third or more of the nitrogenous matter. In fodders, the amount depends upon the stage of growth at which the crop is cut. When mature, from ro to $\mathrm{I} 5$ per cent of the nitrogenous matter is in the form of amides, while in the early stages, there are two or three times as much. Amides and amines form a part of crude protein (see Section 307), and in comparing the crude protein content of foods the amount of amide nitrogen should be considered, because the amides are of less food value than the proteids.

319. Protein Production and Disintegration. - The following cycle of changes takes place in the production of proteids in plants :

(I) Ammonia is taken from the soil.

(2) An amide is produced from ammonia. 
(3) A proteid is finally formed from the amide.

When plants are used as food, the reverse order of changes takes place in the animal body:

(I) The proteid of the food undergoes digestion, and is made over into proteid tissue in the body. This proteid tissue is finally broken up into amides.

(2) The amide is expelled from the body as waste matter.

(3) In the soil, the amides are changed to ammonia, and are then ready to begin anew this cycle of changes.

\section{Alkaloids}

320. General Composition. - Alkaloids are nitrogenous organic compounds present in many animals and plants, but not found in any appreciable amount in food plants. They are basic in character and unite with acids to form salts, just as ammonia unites with acids to form salts. Quinine, for example, is an alkaloid, and with sulfuric acid yields quinine sulfate. Animal alkaloids are sometimes called ptomaines and leucomaines. Vegetable alkaloids are generally named from the species of plant or source from which they are obtained, as Peruvian bark alkaloids, lupine alkaloids, and opium alkaloids.

32I. Plant Alkaloids. - No alkaloids are found in cereals or ordinary food plants, though at one time it was supposed that oats contained such a stimulating material to which the name avenin was given; later investigations show that there is no avenin or other alkaloid in oats. The alkaloids are closely related chemically to the amines, and are produced by the action of amido compounds upon other bodies. They are also 
produced by the action of fungi, as ergotin, the alkaloid from ergot or grain smut. While found most abundantly in the leaves and seeds, they occur in all parts of plants. Some plants are cultivated for these compounds which possess medicinal properties. Many poisonous weeds contain alkaloids, as the water hemlock and monk's hood. Large numbers of alkaloids are known, and since they possess medicinal rather than food value, they are of more importance to the medical and pharmaceutical than to the agricultural student. A few of the more common alkaloids and their sources are:

Piperine, from seeds of black pepper.

Sinapore, from seeds of mustard.

Vicine, from seeds of vetch.

Nicotin, from leaves of tobacco.

Quinine, from Peruvian bark.

Strychnine, from strychnos bean.

Brucine, from strychnos bean.

Morphine, from opium (seeds of poppy).

Lupinin, from lupin seeds.

322. Animal Alkaloids. - In the animal body, alkaloids are produced by ferment action. During disease, and when the proteids of the food fail to undergo the natural chemical changes of digestion, alkaloids, or ptomaines, are produced which are active poisons or toxic bodies. When animal tissue undergoes decay, ptomaines are produced as the result of ferment action. In stale meat, fish, and cheese, there may be a number of such bodies.

323. Food Value and Production. - The alkaloids cannot be regarded as nutrients, as they possess no direct food value. Medicinally, many are valuable because of their action upon certain nerve centers. Some lessen 
the value of foods because they prevent the normal process of digestion. A few alkaloids have been made in the laboratory by synthetic methods, and it is believed that in a short time all of the more important ones will be produced in this way.

324. Mixed Nitrogenous Compounds. - There are a few nitrogenous organic compounds in foods which do not belong to any of the four divisions : proteids, albuminoids, amides, and alkaloids. Such are called mixed nitrogenous compounds, and are closely related to both the nitrogenous and the non-nitrogenous groups.

325. Lecithin is a nitrogenous fat. It is soluble in ether, and has many of the characteristics of fats. It contains fatty acids in combination with nitrogenous bases and other bodies. It is present in milk, egg-yolk, and in small amounts in all of the cereals.

326. Nitrogenous Glucosides. - There are a number of glucosides which contain nitrogenous radicals. When treated with acids, they yield glucose and nitrogenous acid products. The nitrogenous glucosides and lecithin may be regarded as compounds intermediate in the classification of the organic compounds into nitrogenous and non-nitrogenous groups.

\section{General Relationship of the Nitrogenous Organic} Compounds. - A general relationship exists among the nitrogenous compounds similar to that among the nonnitrogenous (see Section 289). Amides and amines are the simplest in chemical structure of the nitrogenous compounds, while the proteids are the most complex. In plants, the amides are intermediate products in the formation of proteids. The proteid molecule contains, with other bodies, amide and fatty acid radicals. Amides are likewise obtained from the albuminoids. Thus it 
appears that the amides and amines form the basal structure of the nitrogenous part of the molecules of proteids, albuminoids, and alkaloids, and these compounds differ from each other chemically, according to the nature and kind of radicals in combination with the different amide and amine compounds. 


\section{CHAPTER XXV}

\section{Chemistry of Plant Growth}

328. Seeds. - A seed is an embryo plant surrounded by reserve food materials in the form of mineral matter and nitrogenous and non-nitrogenous compounds.

329. Ash of Seeds. - The proportion of ash in seeds is small compared with that in other parts of plants. For example, the wheat kernel has 2 per cent and the straw 7 per cent; corn has I.75 per cent and the stalks 7 per cent. While seeds contain comparatively little ash, this ash is more concentrated in the essential elements than that of the other parts of plants. In the seeds are stored large amounts of phosphorus pentoxid, magnesia and potassium compounds, ash elements which are of greatest importance for the nutrition of the young plant; while in the straw are found most of the non-essential mineral elements, as silicon, sodium, and chlorin. The per cent of the various ash elements in cereals and other seeds is given in Section 209. The amount of ash in seeds is quite constant, more so than in the stems, leaves, or other parts of plants. In mature wheat, there is rarely more than 2.I0 per cent or less than I.80 per cent, while in the straw the ash may range from 5 to 9 per cent. Constancy of composition is a characteristic of the ash of seeds.

330. Non-nitrogenous Compounds of Seeds. - Starch, cellulose, and usually fat, are the most abundant nonnitrogenous compounds in seeds; and sugar, gums, pen- 
tosans, and organic acids are present in small amounts. There is no regular law as to the way in which the reserve food is stored in seeds. Even in the same family of plants, the nature of this reserve food may vary between wide limits. Starch forms the largest proportion of the reserve food of cereals. In oil sceds, as flax, rape, and mustard, fat is the main form of non-nitrogenous food. Since fat is about 2.25 times more concentrated in fuel value than starch, it follows that in oil seeds a large amount of reserve material is stored in a small space. Oil seeds are, as a rule, small in size, but concentrated in both non-nitrogenous and nitrogenous food. The cellular tissue of seeds is composed of cellulose and pentosan materials. The amount of pure cellulose is generally small.

33I. Nitrogenous Compounds of Seeds. - The nitrogenous compounds of seeds are mainly in the form of insoluble proteids, as the glutens of the cereals. Some other proteids, as albumin, globulin, and proteose, are also prescnt, as well as some of the albuminoids, as nuclein, and a small amount of amide compounds. In studying the carbohydrates, it was found that starch was present in regularly organized forms called starch granules. In many seeds, particularly cereals, the proteids also are in organized forms called aleurone grains. Under the microscope, the aleurone grains look like crystals. They are not true crystals because they are not built on a definite plan. An aleurone grain consists mostly of proteid matter, inclosed in a nitrogenous envelope. The nitrogenous compounds of seeds are stored liberally in the germ or portion adjacent to the embryo. The amount of nitrogenous material in seeds is, like the ash, quite constant in form and amount.

332. Chemical Changes during Germination. - All of 
the food materials in seeds undergo chemical changes during the process of germination. The chief agents in bringing about these changes are the various kinds of soluble ferments which are always present in seeds. The more important changes may be summarized as follows: cellulose to soluble carbohydrates; starch to soluble forms and then to dextrose bodies; fat to starch ; insoluble proteids to proteoses and a small amount to amides. Organic acids are produced during germination from both nitrogenous and non-nitrogenous compounds.

333. Change of Starch to Soluble Forms. - When seeds germinate, the starch is changed to soluble forms before it is utilized by the plantlet. During conversion of starch into soluble forms, the diastase ferment becomes

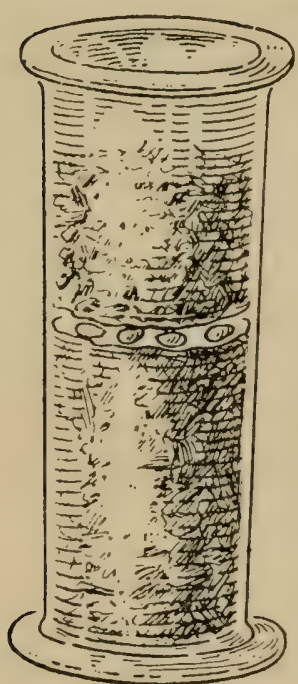

Fig. 83. active, rendering the granulose soluble, and finally leaving nothing but a pitted cellulose skeleton which is also rendered soluble. The change of starch into soluble forms and dextrose bodies is brought about by the action of ferments, particularly diastase, which is found in all seeds. During the process of germination, some of the starch is oxidized, and heat is produced. Not only starch, but other carbohydrates, as pentose and cellulose, undergo similar change during germination.

Experiment 66. - Reaction of germinating seeds. Fill a cylinder with moist sawdust; then place upon the sawdust between two blue litmus papers a few wheat seeds. Cover with a little of the moist sawdust. After germination, examine the litmus paper.

Questions. - (I) What was the reaction of the rootlets upon the 
litmus paper? (2) How was the material which caused the reaction produced? (3) What does this suggest as to the solvent action of plant roots? (4) How would the dry matter of the germinated seeds compare with that of the original seeds?

334. Change of Fats to Starch. - In germination, the fats are first broken up into fatty acids and then converted into starch, soluble carbohydrates, as dextrin and invert sugars. It is estimated that 887 parts of fat will produce I 700 parts of starch simply by the addition of oxygen from the air. Ferment action causes this change to take place. In the oil seeds, about twice the amount of reserve food is stored in the same space in the form of fat as in other seeds in the form of starch.

\section{Change of Insoluble Proteids to Soluble Forms.} - The proteid compounds of seeds, present mainly in insoluble forms, are converted by ferment action into soluble forms as proteoses. Some of the soluble proteids are broken down into amides which are then in condition to be transported through the plant tissues and used as building material. After passing through the cell walls, these compounds are reconstructed into proteids. There is always a slight loss of nitrogen in the germination of seeds.

336. Germination of Seeds and Digestion of Food Compared. - The chemical changes which take place in the germination of seeds are similar to those which occur in the digestion of food. In the germination process, starch, fat, and proteids are changed by ferment action to soluble forms. The diastase and peptonizing ferments are among the most active in producing the chemical changes in both germination and digestion processes. Seed germination is, in part, a digestion process.

337. The Necessary Conditions for Germination are: 
(I) moisture, (2) heat, and (3) oxygen. The same conditions which produce decay are necessary for germination. The temperature required for germination ranges between comparatively narrow limits:

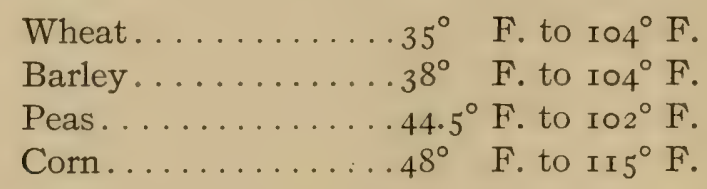

The necessity of oxygen for germination is shown by the following experiment: When seeds are put into water those that float are generally the only ones that germinate. A few of those that sink may germinate, getting their oxygen from that dissolved in water. If a current of air is passed through the water all the seeds will germinate. Oxygen is necessary during germination in order to oxidize some of the reserve material and produce heat. Seeds, in germinating, always lose weight. Malted or germinated seeds weigh less than the original seeds.

338. Heavy- and Light-weight Seeds. - While seeds are quite constant in chemical composition, there is a slightly greater amount of total plant food in heavythan in light-weight seeds. In case of wheat, experiments show that the additional reserve food in heavy-weight seeds favorably influences the growth of the crop, particularly when the soil is slightly deficient in available plant food. The additional reserve food in heavy-weight seeds enables the young plant to reach a more advanced stage of growth before being compelled to collect and assimilate food from the soil. When the soil is in a high state of fertility the difference in results between lightand heavy-weight seeds is less noticeable. 
Experiment 67. - Calculation of plant food in seeds. Weigh roo plump, well-formed wheat kernels. Then from this weight and the following data compute the grams of nitrogen, phosphoric acid, and potash per rooo wheat kernels. Wheat contains about 2 per cent nitrogen and 90 per cent dry matter. The dry matter contains about 2 per cent ash, approximately 50 per cent of the ash being $\mathrm{P}_{2} \mathrm{O}_{5}$, and 33 per cent $\mathrm{K}_{2} \mathrm{O}$. Repeat the experiment, using Ioo shrunken wheat kernels. Tabulate and compare the results.

Question.-How much more reserve plant food is there as $\mathrm{N}, \mathrm{P}_{2} \mathrm{O}_{5}$, and $\mathrm{K}_{2} \mathrm{O}$ in heavy- than in light-weight seeds?

\section{Movement of Plant Juices}

\section{Joint Action of Chemical and Physical Agents.}

- The compounds produced in the leaves of plants are transported and stored in other parts, as the seeds or roots. This is brought about by the joint action of physical and chemical agents. This action can best be understood by first considering some of the properties of plant tissucs, as porosity, capillarity, and osmosis.

340. Porosity of Tissues is a property common to all forms of matter, and one possessed particularly by vegetable substances. The living plant not only permits the passage of water through its tissues, but absorbs it until the pores are filled. Animal and vegetable tissues have powver to take up and tenaciously hold water within their fibers. This is, in part, due to capillary action. Capillarity, assisted by evaporation, explains only in part, however, the movement of the plant juices. Compounds formed within the leaf must be transported in an opposite direction to that of sap in moving from the roots to the leaves. This movement is effected by osmosis and chemical reaction within the cells.

34r. Osmosis. - When a bottle filled with a solution of salt colored with litmus is placed in a large vessel of water, the bottle will discharge its contents into the 
larger body of water and the movement of the solutions can be followed with the eye. With sugar and salt solutions separated by a membrane, there is a gradual interchange of the two solutions; some of the sugar finds its way into the salt solution, and some of the salt into the sugar solution. There is a tendency for an equilibrium to be established. This action or interchange is still further increased when the solutions are of different densities and when chemical action is taking place on both sides of the membrane. Such action occurs in plant tissues, which are composed of a large number of small cells, the walls of which serve in part as membranes, and offer but little resistance to diffusion. The cells are filled with sap, which is acid in nature and contains numerous solid substances in solution. Between the cells are intercellular spaces filled with sap of different density from that within the cells and charged with other kinds of matter. Here, then, are nearly the same conditions as those of the salt and sugar solutions, and the result, osmosis, is the same in each case. Within the cell walls active chemical changes are taking place which aid in this interchange. It cannot be said that there is a constant flow of sap in any one direction, as blood flows in the animal body. The movement of the plant juices is considered as due to (I) capillary action, aided by evaporation, which disturbs the equilibrium of the plant juices, together with (2) osmosis, aided by chemical action within the cells. These factors are, to a certain extent, mutually dependent upon each other. By their joint action, and the chemical changes within the plant, the water from the soil is taken into the plant through the roots with the mineral matter in solution, which serves as food, and finds its way all through the plant, 
finally returning to the roots charged with the material that can be made only in the leaf and by the aid of light and sunshine.

\section{Chlorophyll and Protoplasm}

342. Chemical Action in Leaves of Plants. - All of the organic compounds of plants are produced within the cells of the leaves. The mineral food and nitrogen taken from the soil and the carbon dioxid from the air are chemically united in the cells of the leaves to form the various non-nitrogenous and nitrogenous compounds of plants. Chlorophyll and protoplasm are the two substances which take the most active part in the production of the organic compounds.

343. Chlorophyll is the name applied to the material that imparts the green color to plants. It is not a simple compound, but is composed of a number of closely related organic bodies. Chlorophyll contains both organic and mineral matter. Chlorophyllan is one of the compounds obtained from chlorophyll. Iron, phosphorus, and magnesium are among the more important mineral elements necessary for the functional activity of chlorophyll. This mineral matter is in combination with the organic compounds which form a part of the chlorophyll grain. Chlorophyll is contained in the active living cells of plants, but makes up only a small part of the contents of the cell.

344. Protoplasm. - The chlorophyll body is suspended in a gelatinous, colorless liquid called protoplasm, which is composed mostly of proteids and albuminoids. It is the living substance of the plant organism, and is the part which gives life and activity. In chemical composition, it is exceedingly complex, and is composed of a number of proteids, albuminoids, and other organic compounds. 
Protoplasm, aided by chlorophyll, has the power of combining the food elements and producing all of the organic compounds of the plant. Protoplasm is the living part of both plant and animal cells.

345. Production of Chlorophyll. - When the plant cell is formed, the protoplasm contains no green grains. Small, colorless grains first appear, and then the greening of these grains takes place. The chlorophyll body may make its appearance in the absence of light, but the last stage of its development can take place only under the influence of light and at a higher temperature than is required for the first stage of the process. In cool spring weather there is plant growth, but the vegetation looks yellow because there is not sufficient heat to complete the second part of the process of chlorophyll development. Chlorophyll is destroyed by intense light as well as by absence of light. It is soluble in ether and alcohol and is one of the constituents of ether extract. The green color is easily destroyed, but the chlorophyll body is quite stable and resists the action of dilute acids and alkalies. Chlorophyll loses its activity and undergoes a decided change in composition as the plant matures. Some of the elements of which it is composed, as nitrogen and phosphorus, are used for seed formation. At the time of the most color in plants, there is the greatest cell activity and the largest amount of plant tissue is being produced. When a plant ripens, the decline of activity of the cells may be observed by the change in the color of the plant. With corn, for example, the lower joints of the stalk turn yellow first, indicating that growth and activity have ceased in those parts. Then the upper leaves become yellow, and finally the husk becomes yellow and inactive. Chlorophyll is one of the principal agents which takes 
an active part in plant growth, and whenever chlorophyll is destroyed, plant growth is checked.

Expcriment 68. - Extracting chlorophyll from leaves. Place in a test tube 0.5 gram of dry, green leaves. Add ro cc. alcohol, shake vigorously and, after the alcohol is colored green, filter off the solution, and evaporate to dryness at a low temperature on the water bath.

Questions. - (I) Describe the appearance of the chlorophyll residue. (2) What is chlorophyll? (3) Of what is it composed? (4) What other solvents could be used in place of alcohol?

346. Function of Chlorophyll. - The chief function of chlorophyll, aided by protoplasm, is the production of starch and other organic compounds in the cells of plant leaves. Chlorophyll alone cannot perform this function, but must be associated with, and aided by, protoplasm. Minute starch grains are sometimes found within the chlorophyll grains. The growth of starch within the chlorophyll body can be observed with the microscope. No other compound has been found so organically connected with the chlorophyll grains as starch. If a plant is placed in darkness, both the starch and the coloring matter in the plant cells disappear. The plant cell is the chemical laboratory in which the various organic compounds, as starch, sugar, and proteids, are elaborated. From the cells in the leaves, they are transported to other parts of the plant, as the seeds, roots, or tubers, where they are stored up and serve as reserve food.

347. Production of Organic Matter. - By the joint action of the protoplasm and chlorophyll within the plant cells, starch and all other organic compounds are produced from the carbon dioxid of the air and from the water, mineral matter, and nitrogen of the soil. All of the carbohydrates can be produced from starch, as was 
stated in Section 289 , which discusses the general relationship existing between the various non-nitrogenous compounds. Fat, as well as other non-nitrogenous compounds, is produced from starch. Proteids are produced from amides. By a succession of chemical changes, the amide molecule takes on fatty acid and carbohydrate radicals, and complex proteids are the result. All of these chemical changes take place within the plant cell; and for the production of the various compounds which constitute the dry matter of plants there are required the essential mineral elements, nitrogen in combination, carbon dioxid, and water. 


\section{CHAPTER XXVI}

Composition of Plants at Different Stages of GrowtH

348. Composition and Stage of Growth. - Plants do not have the same chemical composition at different stages of growth. Chlorophyll and protoplasm are most active in the early stages and produce the nitrogenous compounds more rapidly than the non-nitrogenous. The later stages of plant growth are utilized mainly for the production of carbohydrates and for the various chemical and physical changes incident to ripening and the transfer of the organic compounds from the leaves to the seeds. Plants have a different food value at their various stages of growth as well as a different chemical composition.

349. Assimilation of Mineral Food by the Wheat Plant. - The elements of plant food utilized by spring wheat are assimilated quite rapidly in the early stages of growth. The mineral matter essential for the production of the organic compounds is taken from the soil in advance of their formation. Before the crop has completed the first half of its growth, over 75 per cent of the total mineral matter needed for the ripened grain has been absorbed. Of the mineral elements, phosphorus, potassium, and calcium are assimilated most rapidly.

350. Assimilation of Nitrogen by the Wheat Plant. - The nitrogen utilized by a spring wheat crop is taken from the soil in advance of the mineral matter. Nitrogen is assimilated more rapidly than any other of the elements 
which form a part of the organic compounds of plants. Under normal conditions about $\delta_{5}$ per cent of the total nitrogen required has been taken from the soil when the wheat plant has completed half its growth. This is one reason why nitrogen and the essential ash elements should be present in the soil in available and liberal amounts for a wheat crop. With the maximum of any element or compound considered as Ioo, the corresponding amounts present during the different stages of growth of the wheat plant are as follows :

$\begin{array}{cccc}\begin{array}{c}\text { Wheat, } 50 \\ \text { days, before } \\ \text { heading out. }\end{array} & \begin{array}{c}\text { Wheat, } 65 \\ \text { days, headed } \\ \text { out. }\end{array} & \begin{array}{c}\text { Wheat, 80 } \\ \text { days, milk } \\ \text { state. }\end{array} & \begin{array}{c}\text { Wheat, } \\ \text { harvest } \\ \text { time. }\end{array} \\ 46 & 59 & 95 & \text { I00 } \\ 44 & 57 & 90 & \text { 100 } \\ 86 & 89 & 96 & \text { I00 } \\ 45 & 88 & 100 & 94 \\ 67 & 91 & 100 & 96 \\ 57 & 68 & 99 & \text { I00 } \\ 80 & 83 & 98 & \text { I00 }\end{array}$

Total dry matter.......

Organic matter..........

Total nitrogen........

Potassium oxid........

Calcium oxid.........

Magnesium oxid.......

Phosphoric anhydrid....

35I. Clover; Rapidity of Growth. - The same general order of changes occurs at the different stages of the growth of clover as of wheat, but the two plants are so unlike, clover being a biennial and a legume, and wheat an annual and a grain, that the rapidity of growth and formation of organic compounds in the two plants are naturally dissimilar. The largest portion of the dry matter in clover is produced between early and full bloom. During this period, too, about 60 per cent of the organic compounds are formed. As in the case of wheat, the nitrogenous compounds developed more rapidly and in advance of the non-nitrogenous. At the time of early bloom, about 37 per cent of the total nitrogenous compounds have been formed, but the crop at this stage has 
only 3 I per cent of the total organic compounds. When clover is very young, before the flower head is visible, it has only about Io per cent of the total organic compounds, but this organic matter is rich in nitrogen as it contains about I 5 per cent of the total amount assimilated by the crop; however, a large share of this nitrogen is in the form of amide compounds. Analyses of the leaves and stems, at different stages of growth, show that the leaves of young clover contain about 2.5 times as much nitrogenous matter as the stems, while at maturity there is less than twice as much. At full bloom, the largest amount of nitrogenous matter is present, and it is then in the form of proteids to the extent of about 88 per cent. In the last stages of growth there is a noticeable increase in the content of crude fiber. The differences in composition and feeding value between clover, cut and cured in full bloom, and at maturity, are as follows:

\section{Clover at Full Bloom.}

I. The crop contains less fiber than when mature.

2. The crop contains its maximum amount of proteids.

3. A smaller yield per acre is secured than at maturity, but the crop is more concentrated in protein.
4. The nutrients are more evenly distributed.

5. The crop contains its maximum amount of essential oils, which impart palatability.

6. The nutrients are more digestible.

Clover when Ripe.

I. The crop contains a larger amount of fiber.

2. The crop contains a smaller per cent of protein than when in full bloom.

3. A larger yield per acre is secured, and the crop is more concentrated in carbohydrates.
4. Some of the nutrients are transferred to the seeds, leaving less in the stems.

5. At maturity, there are less of the essential oils than at any other period.

6. At maturity, the crop is less digestible than at full bloom. 
Composition of Clover at Different Stages of Growth.

\begin{tabular}{|c|c|c|c|c|}
\hline $\begin{array}{l}\text { Flower head } \\
\text { invisible. } \\
\text { Per cent. }\end{array}$ & $\begin{array}{c}\text { Early } \\
\text { bloom. } \\
\text { Per cent. }\end{array}$ & $\begin{array}{c}\text { Full } \\
\text { bloom. } \\
\text { Per cent. }\end{array}$ & $\begin{array}{l}\text { End of } \\
\text { flowering. } \\
\text { Per cent. }\end{array}$ & $\begin{array}{c}\text { Ripe. } \\
\text { Per cent. }\end{array}$ \\
\hline 86.00 & 85.59 & 74.96 & 71.65 & 33.47 \\
\hline I 4.00 & $14.4 \mathrm{I}$ & 25.04 & 28.35 & 66.53 \\
\hline
\end{tabular}

Composition of the Dry Matter.

\begin{tabular}{|c|c|c|c|c|}
\hline Ash ........... & 10.57 & 10.22 & 6.85 & 7.02 \\
\hline Ether extract.... & $5 \cdot 35$ & 4.70 & $5 \cdot 73$ & $4 \cdot 26$ \\
\hline Crude protein.... & $23.6 I$ & I7.19 & $I 4.8 I$ & $I 4.40$ \\
\hline Crude fiber........ & $13 \cdot 37$ & 20.08 & 24.62 & 25.28 \\
\hline Nitrogen-free ex- & & $478 \mathrm{~T}$ & & 40.0 \\
\hline
\end{tabular}

Composition of the Dry Matter of the Leaves and Stems. Flower head invisible. Early bloom. Third period. Leaves. Stems. Leaves. Stems. Leaves. Stems. Per cent. Per cent. Per cent. Per cent. Per cent. Per cent.

$\begin{array}{lllllll}\text { Ash ........... I0.02 } & \text { II.02 } & \text { I0.07 } & \text { II.30 } & 9.19 & 4.87\end{array}$ $\begin{array}{lllllll}\text { Crude protein... } & 30.68 & \text { I } 3.44 & 27.38 & \text { II.25 } & \text { I9.37 } & \text { II. } 26\end{array}$ $\begin{array}{lllllll}\text { Crude fiber.... } & \text { I0.48 } & \text { I } 8.46 & \text { I0.5 I } & 26.32 & \text { I } 5.36 & 35.27\end{array}$

When the largest amount of any compound in the crop is considered as Ioo, the percentage amounts at the different periods of growth are as follows:

\section{Flower head Early Full End of invisible. bloom. bloom. flowering. Ripe. Per cent. Per cent. Per cent. Per cent. Per cent.}

\begin{tabular}{|c|c|c|c|c|}
\hline Dry matter............. & 9 & $3 \mathrm{I}$ & 97 & 100 \\
\hline Total ash............. & I4 & 46 & 98 & roo \\
\hline Total nitrogen ......... & $\mathbf{I} 5$ & 37 & IOO & 96 \\
\hline Proteid nitrogen. . . . . . . & 67 & 70 & 88 & 85 \\
\hline Fiber............... & 5 & 24 & 92 & 96 \\
\hline Potassium oxid........ & $I_{5}$ & 50 & 100 & 94 \\
\hline Calcium oxid......... & I 5 & 37 & 97 & 100 \\
\hline Magnesium oxid........ & 8 & 35 & 100 & 92 \\
\hline Phosphoric anhydrid.... . & I 4 & 34 & 98 & 100 \\
\hline
\end{tabular}

(These tables are from Minn. Expt. Sta. Bull. 34.) 
352. Flax; Rapidity of Growth. - The flax plant has a short growing period, about seventy days, and the plant food is assimilated at a rapid rate. Before the time of bloom, the nitrogen and mineral matters have been absorbed in quite large amounts. When 40 per cent of the organic matter has been produced, the flax plant contains 55 and 60 per cent, respectively, of its total nitrogen and mineral matter. When the flax is in full bloom, 75 per cent of the organic compounds have been formed. After seed formation begins, there is no nitrogen or mineral matter taken from the soil. Flax is very rich in nitrogen, containing even more than clover. This is one of the few crops in which the ash in the seed exceeds that in the straw; the seed contains about 3.75 per cent ash, while the straw contains less than 3 per cent. The oil in the seed is derived mainly from starch in the later stages of growth. Between full bloom and maturity, less than 25 per cent organic matter is produced. The rate of formation of the organic matter and assimilation of the elements from the soil are given in the following table:

Before In full Seeds well bloom. bloom. formed. Ripe.

Total organic matter Per cent. Per cent. Per cent. Per cent.

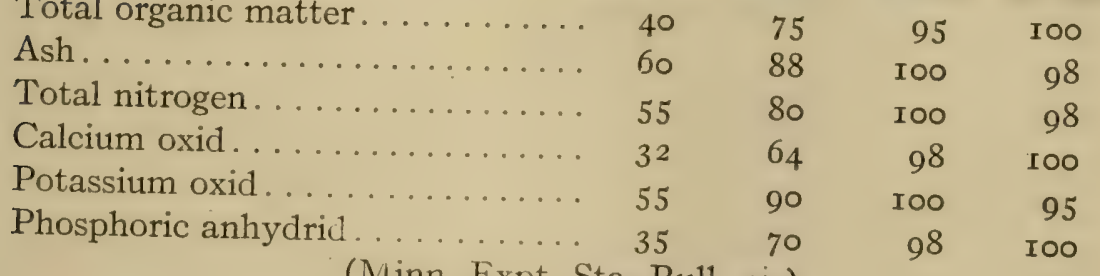

\section{Maize (Corn)}

353. Importance. - Indian corn or maize is grown over a wide range of territory, and is used alike for animal 
and human food, and since as an animal food it may serve either as grain or forage, a knowledge of the chemical changes which takes place during its growth, and the composition of the plant at maturity, will enable the student to utilize this crop more economically in the feeding of farm animals. The facts relating to the composition of corn at different stages of growth and the analyses given in this chapter, are taken largely from Bulletin No. 9, Mo. Agr. Expt. Station.

354. Roots. - The function of the roots is to collect, assimilate, and transport to other parts of the corn plant the nitrogen and mineral food from the soil. In mature corn, a small amount of the essential elements of plant food is in the roots, only sufficient for the structure of the root tissues. During growth, there is always some being transported to the parts above ground. At maturity, the dry matter in the roots constitutes about 5 per cent of the dry matter of the plant. The roots contain the most fiber and least fat of any part of the plant. Of the ash elements, soda is present in greater amounts than in the parts above the ground. In the early stages of growth, the roots are very rich in iron, which decreases as the plant matures, because of its being given over to other parts. The nitrogen in the roots never, at any stage of growth, exceeds $\mathrm{r} .25$ per cent of the dry matter; it is transported to the parts above ground more rapidly than any other element. During the last fifteen days of growth, there is but little mineral food, except magnesia, taken up, and there is a loss of about I 2 per cent of potash from the roots, which indicates that the retrograde movement of potash at maturity may extend from the roots back to the soil. In the later stages of growth, there is a great influx of mag- 
nesia. Silica and the non-essential ash elements make up the larger portion of the ash elements in the mature plant.

355. Stalk. - The stalk undergoes during growth a decided change in composition; there is a gradual increase in the content of fiber and a decrease in proteids. The outside of the stalk is different in chemical composition from the pith. The highest per cent of dry matter is found in the stalks from two to three weeks before maturity. As the plant matures, the proteid and circulatory carbohydrates are transferred to the seed. When mature, both pith and stalk have a low content of protein, fat, and digestible carbohydrate, and hence a low feeding value. The pith is somewhat richer in nitrogenous matter than the stalk. The ash of the stalk is characteristically rich in silica.

356. Leaves. - Since all the chemical compounds of the plant are first produced in the leaves, and then transported to other parts, it follows that the leaves at different stages of growth have a variable composition. The cells of the young leaves contain more protoplasm than mature leaves, the largest amount of nitrogenous matter being present there in the early stages of growth. As the plant matures, this nitrogenous matter is given up for the formation of other parts, and there is then a decline in the nitrogen of the leaves. The largest amount of dry matter in the leaves is about six weeks before maturity. The plant as a whole, however, increases rapidly in dry matter after this time, although no additional organic matter accumulates in the leaves, but it is used for seed formation. As the plant matures, the ash in the stems declines, while that in the leaves steadily increases, due to silica, which is deposited there as inert material. Also the phos- 
phorus content of the leaves declines, at this time, the phosphorus, like the nitrogen, being stored in the seeds. The largest amount of potash in the leaves is at the time of the most dry matter, about six weeks before maturity. Next to the seed, the leaves contain the most protein, fat, and digestible carbohydrates of any part of the plant. When green, the leaves have a higher nitrogen content than when yellow. The feeding value of corn fodder depends to a great extent upon the condition of the leaves.

357. Tassel. - The tassel has some of the chemical characteristics of the seed; it is concentrated in nitrogen, has less fiber, and an ash rich in phosphates. The flower stalks and anthers yield an ash in composition like that of the stems, while the ash of the pollen is nearly identical with that of the matured grain. The pollen is particularly rich in nitrogen. One of the claims made for detasseling corn is to prevent loss of nitrogen and phosphoric acid through the pollen. It is estimated that the nitrogen removed in the pollen amounts to from 5 to Io pounds per acre. Both the fresh and the dried silk (stigmas) show a decline in nitrogen and phosphoric acid after fertilization.

358. Husk. - The husk when first formed has all of the materials for the development of the seed, and its composition at different stages of growth shows a gradual transfer of its constituents to the ripening grain. When fully mature, the husks are much poorer in ash and nitrogen than the leaves or stems, but not so poor as the cob. The cob remains functionally active longer than any other part of the plant, and is composed largely of cellulose and pentose compounds, with but little protein or fat.

359. Ripening Period. - The corn plant, at first, absorbs its mineral food and nitrogen at a very rapid 
rate. In fact, there is little mineral matter or nitrogen assimilated during the last few weeks of growth. The last stage of development is a period of rearrangement and transportation of the compounds from the leaves to the seed. The composition of the different parts of the corn plant when mature and of the ash is given in the following table : 


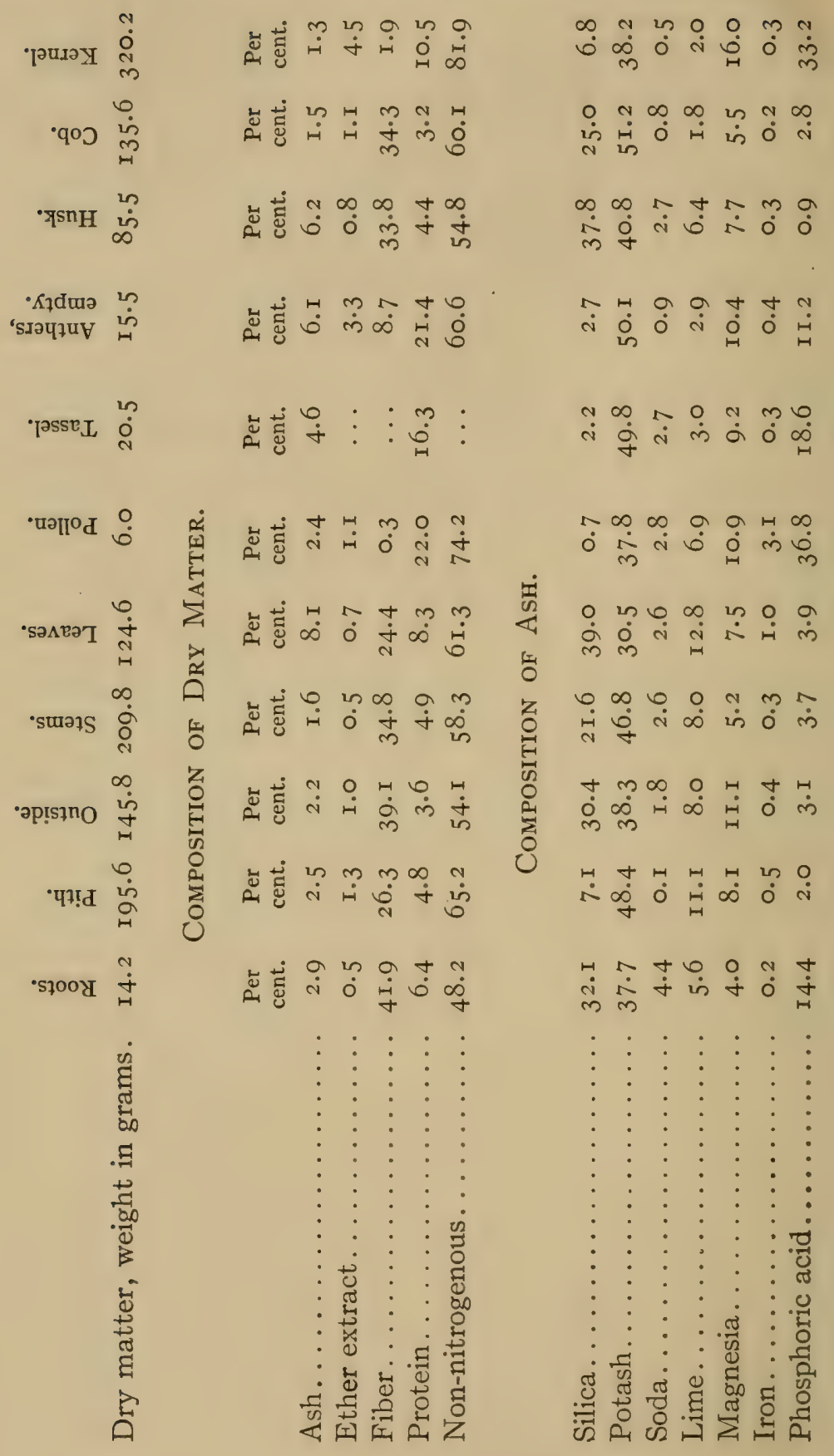




\section{CHAPTER XXVII}

\section{Factors which influence the Composition and Feeding Value of Crops}

THE main factors which influence the composition and feeding value of crops are: (I) seed, (2) soil, (3) climate, (4) stage of maturity, (5) method of preparation as food, and (6) combination with other foods.

360. Seed. - The composition and individuality of the seed influence the composition and feeding value of the forage crop. Heavy-weight seeds are usually more mature and contain a larger amount of reserve plant food than those of light weight (see Section 338). Experiments by Hellreigel show that the heavier the seed, the more vigorous the young plant. When there was not an overabundance of plant food in the soil, the difference in vigor of plants was discernible even up to the time of harvest. Experiments show that by careful selection of seed corn, the percentage amount of nitrogenous matter in the grain may be increased from 0.5 to I. 25 per cent. Not all of the cereals respond as does corn to the influence of seed selection to produce variations in chemical composition.

The care and storage which the seed receives prior to planting also influence its vitality. When seed corn is stored in a damp or poorly ventilated place, the excessive amount of moisture results in injuring the vigor of the germ. Seed wheat is often injured by being stored in elevators where bin-burning caused by fermentation takes place. Sound, heavy seeds of full maturity always give the best crop returns. Forage crops are more susceptible to seed influ- 
ences than are grain crops, because the leaves and stems of plants are less constant in composition than is the seed.

36r. Soil. - The condition of the soil as to available plant food has a material influence upon composition, and in promoting a balanced crop growth. Experiments conducted at the Connecticut Experiment Station (Storr's Annual Reports, I898, I899) show that fodder crops grown with a liberal supply of nitrogen have a tendency to contain more of the nitrogenous compounds than similar crops grown with a scant supply. The nitrogen and available mineral matter increase the activity of the protoplasm and chlorophyll in the production of all of the organic compounds. With a larger amount of available plant food, particularly nitrogen, a larger amount of foliage is produced. All foliage crops grown upon rich soils have larger leaves and a higher nitrogen content than those grown on poor soils.

The condition of the soil influences the composition of leaves and stems to a greater extent than it does the composition and character of the seeds because they are more constant in composition. The selection of seed corn has a greater influence upon the composition and feeding value of corn fodder than it has upon the grain. Fodder crops, produced upon fertile soils and under favorable climatic conditions, have the highest feeding value. The condition of the soil, as to acidity or alkalinity, also influences the character and composition of crops. Crops produced upon acid soils have a different appearance from those grown upon mildly alkaline soils. An unbalanced condition of plant food in the soil produces an unbalanced crop growth. It is not possible, however, by the use of manures or the selection of seeds, to entirely change the composition of crops. In the extensive experiments by 
Lawes and Gilbert (Rothamsted Memoirs, Vol. III), the continued use of nitrogen and mineral manures for a period of twenty years showed no material increase in the amount of nitrogenous matter in the wheat. In similar experiments with potatoes, in which nitrogenous manures alone were used, there was an increase of 0.05 per cent of nitrogenous matter. The sugar-beet has been greatly changed in composition by cultivation. The content of sugar has been increased from 8 to 16 per cent. Wheat and other grains show material differences in weight and composition when grown upon different types of soil. Experiments have been made where wheat grown from one lot of seed under different climatic and soil conditions showed a difference of 18 bushels per acre in yield, and 8 pounds per bushel in weight (Minn. Expt. Sta. Bull. No. 23). Forage crops produced upon soils of high fertility have a higher feeding value than crops grown upon poor soils. At the Minnesota Experiment Station, timothy and corn fodder grown on land that had been manured and rotated, and similar crops grown on unmanured land, showed the following amounts of protein :

$\begin{array}{cc}\text { Timothy hay grown on } \\ \text { manured } & \text { unmanured } \\ \text { land. } & \text { land. } \\ \text { Per cent. } & \text { Per cent. }\end{array}$

$\begin{array}{cc}\text { Corn fodder } & \text { grown on } \\ \text { manured } & \text { unmanured } \\ \text { land. } & \text { land. } \\ \text { Per cent. } & \text { Per cent. }\end{array}$

Crude protein (dry matter basis)...

8.75

6.45

8.85

6.32

362. Climate. - In the early stages of plant growth, the nitrogenous compounds are produced more abundantly than are the non-nitrogenous (Section 35I). If the growing season is in any way cut short, the crop has a slightly larger amount of nitrogenous matter than if normal conditions prevail. Any shortening of the growing period or forcing of the crop to maturity lessens the 
per cent of dry matter, increases the nitrogenous compounds, and decreases the carbohydrates. The composition of grains is influenced by climatic conditions, particularly at the time of seed formation, when growth is often checked before all of the compounds have been transferred from the leaves to the seeds; shrunken or immature grain is the result. Such grain contains less starch and more nitrogenous compounds than that which has fully matured. Experiments with potatoes by Lawes and Gilbert show that they too are, to a slight extent, influenced in composition and starch content by climatic conditions; the longer the growing period, the larger the amount of starch. A short and favorable growing season, together with a fertile soil, has the tendency to produce crops of high nitrogen content.

363. Stage of Maturity. - Since all crops at first produce nitrogenous compounds in larger amounts than at later stages, it follows that early cut crops contain proportionally more nitrogen than those cut later. This increase in nitrogenous matter is, however, at the expense of the total dry matter in the crop. If crops are cut too early, that is, before early bloom, too much of the nitrogen is in the form of amides, some of which are changed to proteids at a later stage. Early cutting results in securing a smaller yield per acre of dry matter, more concentrated in nitrogenous compounds. When fodder crops are cut at early or full bloom, the nutrients are more evenly distributed than at maturity, when some of the proteids and carbohydrates have been transferred from the leaves to the seeds, leaving stems and leaves with a larger amount of fiber and less protein. The composition and comparative feeding value of clover cut at different stages of growth are given in Section $35 \mathrm{I}$. 
364. Method of Preparation as Food. - The method of curing and preparing fodder affects its food value. Overdrying causes mechanical loss of leaves, which gives the fodder different composition and feeding value than when the leaves are all secured. Bleaching results in partial destruction of the chlorophyll and a loss of the essential oils that impart palatability. Other chemical changes which have a tendency to make the fodder less digestible also take place. Mechanical loss of leaves and exposure to leaching rains result in a loss of nutritive value. The materials extracted are the most soluble and digestible. A heavy, leaching rain may extract Io per cent or more of the nutrients, making the leached fodder less digestible and less palatable.

The method of storing and the mechanical condition of a fodder also influence, to a limited extent, the availability of the nutrients. The influence which the combination of fodders has upon digestibility and food value is discussed in Chapter XXXV.

\section{Improving the Feeding Value of Forage Crops. -} The main factors, as seed, fertility of soil, stage of maturity, and care which the fodder receives, are all under the control of the farmer, climate being the only factor that is not directly controllable. Lack of moisture in dry seasons can, however, in part, be overcome by shallow cultivation. By careful selection of seed, conserving the fertility of the soil, and suitable methods of cultivation and storage, it is possible not only to increase the yield but also to change the chemical composition and feeding value of forage crops. As yet, experiments have not demonstrated the extent to which all crops are susceptible to these influences. 


\section{CHAPTER XXVIII}

\section{Composition of CoArse Fodders}

366. The Term Coarse Fodders is applied to animal foods which usually contain large amounts of crude fiber, and, while bulky in nature, are essential foods, many of them having high nutritive value. A coarse fodder may be either green or field-cured; pasture grass, timothy hay, and corn fodder are all examples of coarse fodders. The proteid content ranges from 4 per cent and less, in straw, to I 2 per cent and more, in clover and legumes. Coarse fodders may be classed as :

Low protein content 2 to 5 per cent.

Medium protein content 5 to 9 per cent.

High protein content 9 per cent and upwards.

367. Straw. - The straw from wheat, oats, barley, and rye contains from 36 to 38 per cent of crude fiber, and

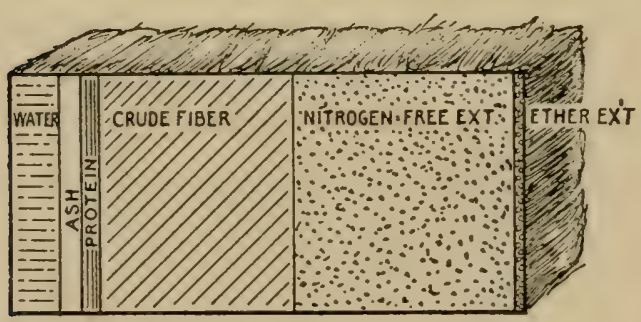

WHEAT STRAW

FIG. 84. - Composition of a bale of wheat straw. less than 4 per cent of crude protein, oat straw being the richest in protein. The amount of fat in straw is small, rarely exceeding $\mathrm{I} .5$ per cent. The water content is usually from 6 to 9 per cent. The pentose compounds make up a large portion of the nitrogen-free extract. Straw is a food poor in protein, fat, and digestible carbohydrates, and contains a high per 
cent of ligno-cellulose, pentose, and ash materials. Straw may produce some heat in a ration, but for the production of muscle or the repair of proteid matter, it occupies about the lowest place in the list of animal foods. The various factors which influence the composition of plants (see Chapter XXVII) affect the composition of the straw. That from immature grain has higher feeding value than from grain fully ripened, because in the unripe state less of the nutrients has been removed for seed formation. The greener the straw, the higher its food value.

368. Timothy Hay. - Timothy hay has more protein, but in other respects the same general characteristics as straw. The per cent of fiber usually ranges from 28 to $3^{2}$ per cent or more, which is from 6 to ro per cent less than in straw. The crude protein ranges from $5 \cdot 5$ to 9 per cent according to the conditions under which the crop was grown. Average timothy hay contains 7.5 per cent, which is about twice as much as found in straw. The

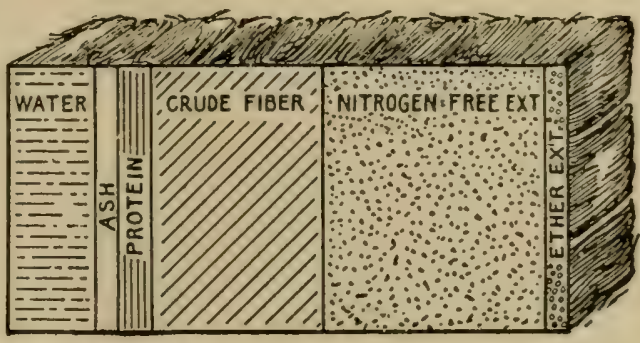

TIMOTHY HAY

FIG. 85. - Composition of a bale of timothy hay.

amount of ether extract is about 2.25 per cent, of which a large portion is non-fatty material. As in the case of straw, the nitrogen-free extract of timothy consists largely of pentose bodies; there is also a small amount of soluble carbohydrates. While timothy hay is not rich in protein, it is a valuable fodder, particularly when one of fair energy-producing power is desired, as for feeding work horses. Mixed timothy and clover hay have more protein than timothy alone. 
369. Hay Similar to Timothy. - Millet, blue grass hay, and the numerous varieties of native prairie hay have about the same general composition and feeding value as timothy hay. Each, however, differs from timothy to a slight extent, both in chemical composition and structure of parts, some being preferable to others for feeding certain kinds of animals. These hays are classed as coarse fodders containing low to medium amounts of crude protein, and they vary in protein content from 6 to 9 per cent according to the conditions under which they are grown and other factors which affect their composition.

370. Oat Hay. - When oats are cut at the heading-out stage and cured as hay, they make a valuable fodder which compares favorably with the best grades of timothy hay, and usually contains slightly more protein than timothy, or hays of similar character. Oat hay should be cured for fodder while the nutrients are evenly distributed, and before they are transported and stored up in the grain.

371. Hay Similar to Oat Hay. - Wheat and other cereals, cut at the right stage, have a similar composition and feeding value to oat hay. In localities where the climatic conditions do not admit of the growth of perennial grasses, these forage crops are grown.

372. Bromus Inermis varies in composition and feeding value according to the stage when cut. When overripe, its protein content is between that of straw and timothy hay. If cut or pastured while young, it has a high feeding value. In this crop, the non-nitrogenous compounds, particularly fiber, are formed at a rapid rate in the last stages of growth.

373. Clover Hay is characteristically rich in crude protein, containing nearly twice as much as poor grades of timothy. There is less crude fiber and more ether extract. 
The large amount of crude protein and other nutrients makes it one of the most valuable fodders that can be produced for growing, fattening, or milk-giving animals. There is no coarse fodder, except alfalfa, that has so high a protein content as clover when grown and cured under the best conditions. Clover ash is of different composition from timothy ash. It contains a small amount of silica and a large amount of lime, while timothy ash contains more silica and less

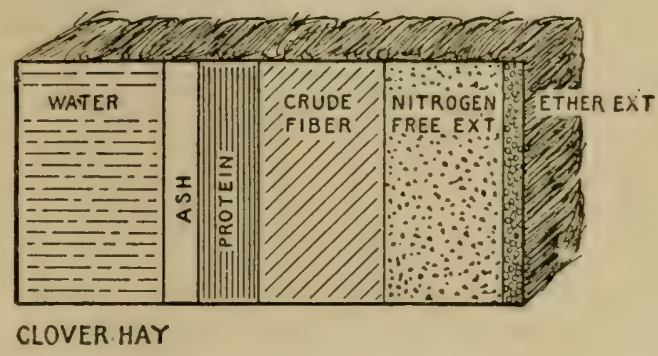

FIG. 86. - Composition of a bale of clover hay.

lime. The nitrogen-free extract of clover is largely pentose materials. The composition and comparative feeding value of early- and late-cut clover are given in Section $35 \mathrm{I}$. In curing clover hay, it should be the aim to prevent mechanical loss of leaves during handling of the crop. When clover hay is fed to stock, less grain and milled products are required than when hays of lower crude protein content are used. There are a number of varieties of clover; alsike, crimson, scarlet, and white clovers, all having about the same general composition. Each, however, has characteristic habits of growth which make it peculiarly adapted to certain soil and climatic conditions.

374. Alfalfa and Fodders Similar to Clover. - Alfalfa has somewhat the general composition and feeding value of clover, but its physical composition, as density of tissue and proportion of leaves to stems, is different, and it can be grown under more adverse climatic conditions. All members of the leguminous or pulse family, to which clover, alfalfa, peas, cowpeas, and vetch belong, are 
characteristically rich in protein, and are among the most valuable forage crops. The discovery, by Hellreigel, of the unique value of clover and other legumes in assimilating the free nitrogen of the air by means of the action of microörganisms associated with the roots of these plants, and of the use of leguminous crops in increasing the supply of nitrogen in the soil, is one of the greatest achievements of agricultural chemistry. In Plate III, the arrow indicates one of the nodules containing the nitrogen-assimilating organisms.

375. Rape. - The rape plant contains nearly as much crude protein as clover hay. Because of the presence of certain volatile oils, it cannot be fed to milk cows without imparting an unpleasant taste to the milk. Rape, however, is valuable for the feeding of all growing and fattening animals.

376. Pasture Grass. - In studying the composition of plants at different stages of growth, it was stated that the nitrogenous compounds are produced more rapidly than the non-nitrogenous (Section 35I). The dry matter of pasture grass is more nitrogenous in character than that of the matured crop. The dry matter of all kinds of pasture grass is rich in crude protein; the various nutrients, however, range between wide limits, according to the species of grass, and the conditions affecting its growth. When a piece of land is grazed, a smaller amount of total nutrients is secured than if a forage crop were harvested and fed. Pasturing is similar in results to a series of early cuttings, before bloom, rather than one later cutting, as in harvesting a crop.

377. Corn Fodder and Stover. - By corn fodder is meant the entire corn plant with or without ears, according to the conditions under which it has been grown, 


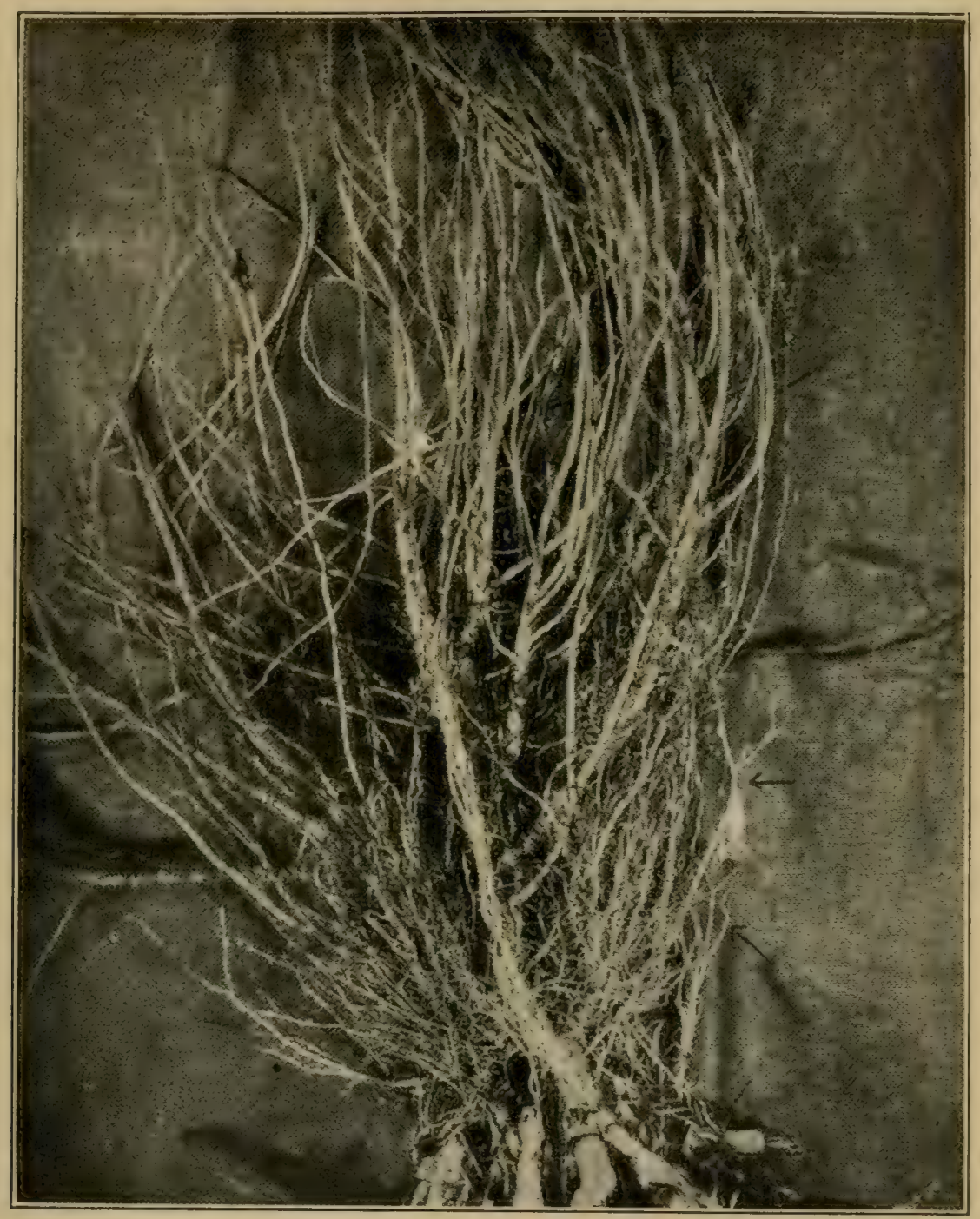

Plate III. - Clover Roots. 

while corn stover is the plant after the grain has been removed. Corn fodder is one of the most valuable, palatable, and largest yiclding crops that can be produced. When sown so that no ears, or very small ones, are developed, the leaves and stalks contain all of the nutrients which would otherwise be stored in the seed. When grown under favorable conditions, corn fodder contains about the same per cent of crude protein as timothy hay, and is equal in value to the best quality. When field-cured, it contains from 15 to 30 per cent of water, from $I 2$ to 25 per cent of crude fiber, and from 2.5 to 4 per cent of ash. In the study of the composition of the corn plant (Chapter XXVI), the content of crude protein and other nutrients in the various parts of the plant was

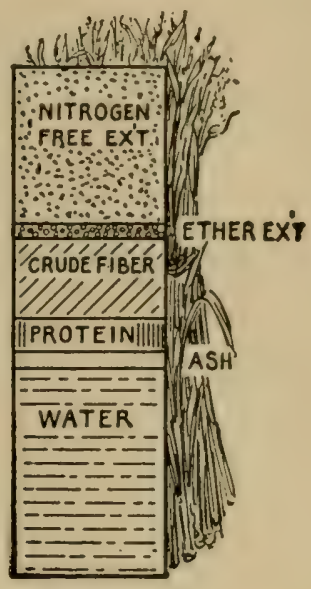

CORN FODDER

FIG. 87.-Composition of a shock of corn fodder. considered. In growing corn fodder, it should be the aim to produce a large number of medium-sized plants with large leaves, small or no ears, and small stalks. Thus the largest amount of nutrients most evenly distributed, palatable, and digestible are secured. Corn stover has more of the characteristics of a straw crop, and is not so valuable as corn fodder. When ears are produced, the protein is stored in them, and hence less is found in stalks and leaves. The physical condition and chemical form of the cellulose, as hydrated or lignose, also influence the feeding value of corn fodder and corn stover. Corn fodder can be fed to all kinds of farm animals, and is one of the cheapest forage crops. It is valuable alike for horses, sheep, and dairy and beef cattle. 
378. Silage. - In preparing silage the green material is placed in a nearly air-tight compartment. Corn, clover, or any green crop may be cured as silage. Corn, however, is the crop most generally given this treatment, and unless otherwise designated, silage usually has reference to corn fodder prepared in this way.

The chemical changes that take place in the silo are caused mainly by ferments. Carbon dioxid, hydrocarbons, and ammonia in small amounts are among the volatile products formed. There is always a loss of dry matter in curing silage. This is greatest in the top layer and least in the bottom. The losses in the different sections of a silo may range from 5 to 25 per cent. In a large silo the losses are less than in a small one, and they need not exceed 5 per cent of the dry matter.

The average of a number of trials shows that when corn fodder is prepared as silage, there is a loss of from 5 to 25 per cent of dry matter, of which a proportional amount is protein. Including mechanical losses, there is nearly the same in field curing of corn fodder as in its preparation as silage.

The temperature of the silage, when undergoing fermentation, ranges from $35^{\circ}$ to $75^{\circ} \mathrm{C}$. The lower temperatures generally produce poor silage, while the higher yield a better quality. In order to make sweet silage, the conditions should be such that the temperature during fermentation is kept above $43^{\circ} \mathrm{C}$., so as to render the acid spore that produces the sour silage less active and allow other ferments to act. No appreciable amount of alcoholic fermentation takes place in the silo. The corn for silage should be cut green rather than overripe, and should be evenly packed in the silo so that all parts will ferment alike. Comparatively short fermentation at a high temperature is preferable to slow fermentation at a low temperature. 
Average Composition of American Fodders.

(Jenkins and Winton.)

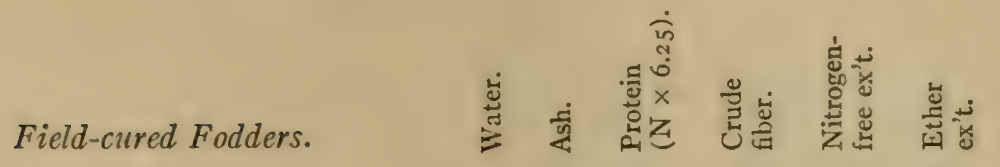

Pct. Pct. Pct. Pct. Pct. Pct.

$\begin{array}{llllllll}\text { Corn fodder, average } \ldots \ldots \ldots & 42.2 & 2.7 & 4.5 & \text { I } 4.3 & 34.7 & \text { I.6 }\end{array}$

$\begin{array}{lllllllll}\text { " " } & \text { " minimum........ } & 22.9 & \text { I.5 } & 2.7 & 7.5 & 20.6 & 0.6\end{array}$

$\begin{array}{lllllllll}\text { " “ maximum. . . . 6 } 60.2 & 5.5 & 6.8 & 24.7 & 47.8 & 2.5\end{array}$

$\begin{array}{llllllll}\text { Corn leaves, average........ } & 30.0 & 5.5 & 6.0 & 2 \mathrm{I} .4 & 35.7 & \text { I.4 }\end{array}$

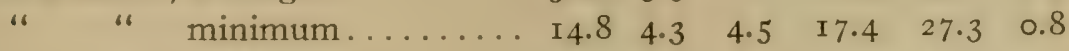

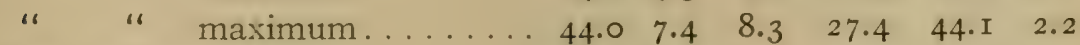

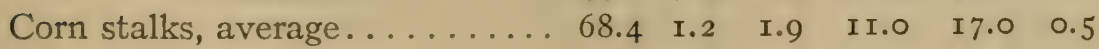

$\begin{array}{llllllllll}\text { " " } & \text { "minimum........ } & 5 \mathrm{I} .3 & 0.6 & \text { I.2 } & 6.9 & \text { II.2 } & 0.3\end{array}$

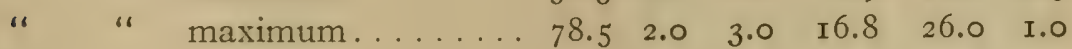

$\begin{array}{llllllll}\text { Corn stover, average. . . . . . } & 40 . \text { I } & 3.4 & 3.8 & \text { I9.7 } & 3 \text { I.9 } & \text { I.I }\end{array}$

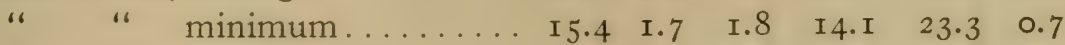

$\begin{array}{lllllllll}\text { " " } \quad \text { maximum....... } & 57.4 & 7.0 & 8.3 & 32.2 & 53.3 & 2.2\end{array}$

$\begin{array}{lllllllll}\text { Redtop.................. } & 8.9 & 5.2 & 7.9 & 28.6 & 47.4 & \text { I.9 }\end{array}$

Timothy:

$\begin{array}{llllllll}\text { All analyses............... I } 3.2 & 4.4 & 5.9 & 29.0 & 45.0 & 2.5\end{array}$

$\begin{array}{llllllll}\text { Cut in full bloom.......... I5.0 } & 4.5 & 6.0 & 29.6 & 4 \mathrm{I} .9 & 3.0\end{array}$

$\begin{array}{llllllll}\text { Cut soon after bloom........ } & \text { I } 4.2 & 4.4 & 5.7 & 28 . I & 44.6 & 3.0\end{array}$

$\begin{array}{lllllllll}\text { Cut when nearly ripe........ I } 4 . \text { I } & 3.9 & 5.0 & 3 \text { I.I } & 43.7 & 2.2\end{array}$

Red clover............... I $5.3 \quad 6.2$ I $2.3 \quad 24.8 \quad 38.1 \quad 3.3$

$\begin{array}{llllllll}\text { Alsike clover............... } & 9.7 & 8.3 & \text { I } 2.8 & 25.6 & 40.7 & 2.9\end{array}$

$\begin{array}{llllllll}\text { White clover. . . . . . . . . . . } & 9.7 & 8.3 & \text { I5.7 } & 24 . \text { I } & 39.3 & 2.9\end{array}$

$\begin{array}{llllllll}\text { Alfalfa.................. } & 8.4 & 7.4 & 14.3 & 25.0 & 42.7 & 2.2\end{array}$

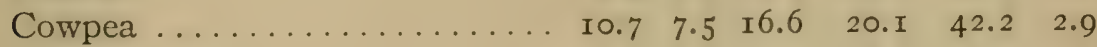

$\begin{array}{llllllll}\text { Wheat straw . . . . . . . . . . . . } & 9.6 & 4.2 & 3.4 & 38.1 & 43.4 & \text { I.3 }\end{array}$

$\begin{array}{lllllllll}\text { Oat straw............... } & 9.2 & 5.1 & 4.0 & 37.0 & 42.4 & 2.3\end{array}$

\section{Green Fodders.}

$\begin{array}{llllllll}\text { Corn fodder (Flint) average.... } & 79.8 & \text { I.I } & 2.0 & 4.3 & \text { I 2.I } & 0.7\end{array}$

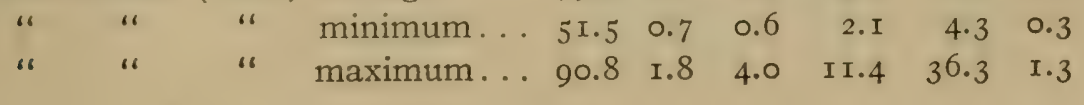


Green Fodders (continued).

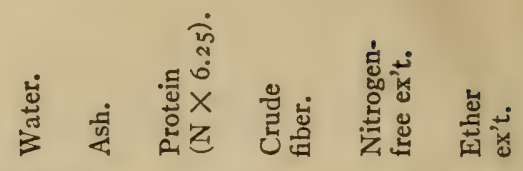

Pct. Pct. Pct. Pct. Pct. Pct.

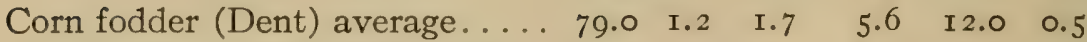

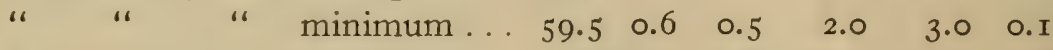

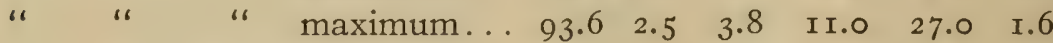

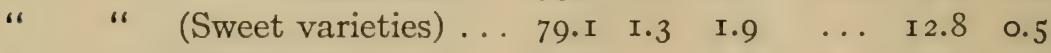

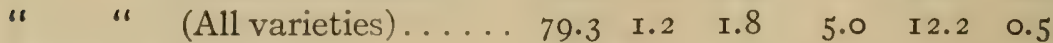

Redtop in bloom . . . . . . . 64.8 64.8 $2.3 \quad 3.3 \quad 9.4 \quad$ I9.I $\quad$ I.2

Timothy......... . . . 6 6I.6 2.I 3. I $\quad$ II.8 20.2 I.2

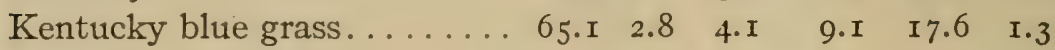

Legumes:

Red clover........... 70.8 2.I $4.4 \quad 8$. I $\quad$ I3.5 $\quad$ I.I

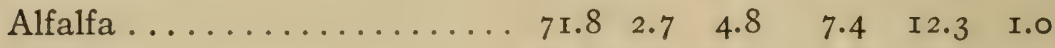

$\begin{array}{lllllllll}\text { Cowpea............... } & 83.6 & \text { I.7 } & 2.4 & 4.8 & 7.1 & 0.4\end{array}$

Soja bean............ Silage:

Corn.............. 79.I I.4 I.7 6.0 II.I 0.8 


\section{CHAPTER XXIX}

\section{WHEAT}

379. Structure of Kernel. - The wheat kernel has three distinct coverings (see Fig. 88): (I) The outer cuticle or pericarp, which is a hard, tough coat, composed largely of ligno-cellulose; this is the seed pod inclosing the seed, and constitutes the main part of the bran. (2) An inner double cuticle of cellular tissue called the episperm, consisting of two hard coats called respectively the inner and

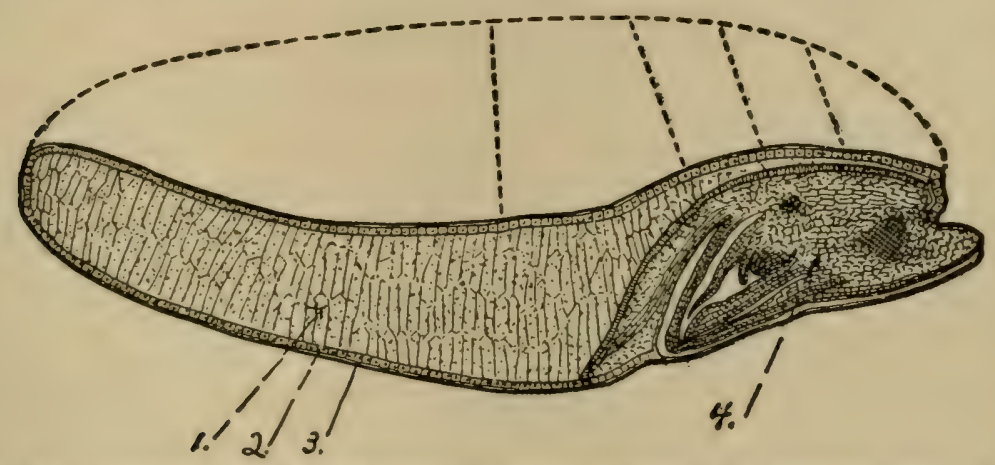

FIG. 88. - Structure of wheat kernel : I, floury portion; 2, aleurone layer ; 3 , the bran composed of three layers; 4, germ (adapted from Bull. 32, Neb. Exp. Station).

outer integument; this double skin or layer may be considered one coat and forms part of the bran. (3) A hard, thin skin or layer called the perisperm. The three bran coats constitute about 5 per cent of the weight of the grain. Within these three bran layers is a single layer of large cells, the aleurone layer. This is sometimes erroneously termed the gluten layer. The germ or 
embryo plant is in the lower part of the kernel opposite the rounded end. The main part of the seed is the endosperm, which is the floury portion, sometimes incorrectly spoken of as the starch cells, in reality composed of starch, gluten, mineral matter, and other compounds in small amounts.

380. Proteids of Wheat. - Wheat contains the largest amount of proteids of any of the cereals, and proteids of an entirely different character from those of other grains. There are five distinct proteids in wheat: (I) an albumin (leucosin), (2) a globulin (edestin), (3) a proteose, and two insoluble proteids called (4) gliadin, and (5) glutenin, which together constitute the gluten. Wheat gluten may be obtained by washing a sample of dough from wheat meal or flour with water to remove the starch and other non-gluten compounds. The gluten mass from hard wheat is usually elastic and tenacious, varying in quality according to the nature of the wheat from which it was obtained. The milling qualities of wheat and the baking qualities of flour are determined largely by the composition of the gluten.

Wheat gluten is composed of two proteids, gliadin and glutenin; these-form about 85 per cent of the proteids of wheat. Gliadin may be extracted from either gluten or flour with a 70 per cent solution of alcohol, and appears after evaporation of the alcohol in the form of thin, transparent flakes which resemble gelatin. In fact, gliadin was called by earlier investigators plant gelatin. When moistened, gliadin expands and forms a mucilagenous mass. When more water is added, a small amount is dissolved. Gliadin is soluble in dilute acid and alkali solutions; in some wheats, particularly those that have undergone slight fermentation, there is sufficient acid 
developed to combine with and render soluble appreciable amounts. Gliadin, like all the wheat proteids, is characterized by a high per cent of nitrogen. Gliadin takes a very important part in bread making, and is the material which binds the flour together to form dough and enables the mass to expand, retaining the gas generated by the yeast. Wheat gluten contains from 40 to 75 per cent of gliadin and from 25 to 60 per cent of glutenin.

Glutenin is the proteid which remains after extracting gliadin from gluten. When dry and pure, it forms a light gray mass which may be reduced to a fine powder. Glutenin is insoluble in dilute alcohol and salt solutions and is only sparingly soluble in water, but is readily soluble in dilute acid and alkali solutions. This proteid also takes an important part in bread making. It combines mechanically with the gliadin and, "serving as a nucleus to which the gliadin adheres," prevents the dough from becoming too soft and sticky. Two samples of wheat may contain the same amount of gluten, and the flour from one produce good bread, while that from the other be of very poor quality. The most valuable wheats for bread-making purposes are those which have I2 per cent or more of protein. A wheat may produce a good quality of bread and contain only a medium per cent of protein, while, on the other hand, poor bread-making qualities may be associated with a high per cent of protein. Glutens considered the most valuable for bread-making purposes are hard, elastic, and of a light yellowish tinge. Poor gluten is dark in color, has an uneven surface, possesses but little power to recoil, and may be very sticky.

Gliadin and glutenin contain about I 7 per cent nitrogen, one part of nitrogen to 5.70 of protein (I00 $\div$ I7.50). 
Average proteids have approximately i 6 per cent nitrogen and a protein conversion factor of 6.25 (see Section 307). In scientific work the protein of wheat is sometimes calculated as $\mathrm{N} \times 5.70$, which means that the special factor 5.70 instead of the general factor 6.25 is used. For general nutritive purposes, however, the 6.25 factor should be employed, inasmuch as special factors are not used for other foods. In the case of wheat with a proteid more concentrated in nitrogen, if 5.70 and not 6.25 were used, too low a food value would be assigned compared with other foods having a proteid less concentrated in nitrogen, for it is the nitrogenous part of the molecule which gives the unique food value to the proteids, and if the special conversion factor is used for calculating protein in wheat or other food, then the individual value of wheat protein must be considered in making comparisons and assigning food values. It is believed that the general factor 6.25 represents for comparative nutritive purposes the value of the proteids, as it expresses the protein content on a uniform basis of concentration of the molecule in nitrogen, and dispenses with giving separate value to each protein.

Experiment 69. - Gluten from wheat flour. To about 30 grams of flour made from hard spring wheat, add sufficient water to form a stiff dough and allow it to stand for half an hour, in order that the physical properties of the gluten may develop. Place the dough in a cloth and work it gently with the fingers, while a stream of water is allowed to flow over it. Continue the washing until the water that runs away is clear, which indicates that all starch has been washed from the dough. The washing may be completed with the mass in the hand. Leave this gluten in water until the gluten from flour made from soft winter wheat has been prepared. Compare the two samples of gluten.

Questions. - (I) What is wheat gluten? (2) Describe hard wheat gluten. (3) How does it differ from soft wheat gluten? (4) How 
do the two moist glutens compare as to weight? (5) Which gluten contains the larger amount of gliadin? (6) Which is the better quality of gluten for bread-making purposes?

Experiment 70. - Gliadin from flour. Place in a flask ro grams of flour, $30 \mathrm{cc}$. of alcohol, and $20 \mathrm{cc}$. of water. Cork the flask and shake, and after a few minutes shake again. Allow the alcohol to act on the flour for an hour, or until the next day. Then filter off the alcohol solution and evaporate the filtrate to dryness over the water bath. Examine the residue. To a portion add a little water. Burn a little. Treat a little in a test tube with water containing a few drops of $\mathrm{HCl}$.

Questions. - (I) Describe the appearance of the gliadin. (2) What was the result when water was added? (3) When burned, what was the odor of the gliadin, and what does this indicate? (4) What effect did the dilute $\mathrm{HCl}$ have upon the gliadin? (5) What is gliadin?

\section{I. Relation of Nitrogen in Wheat to Nitrogen Con- tent of Flour. - Medium-sized, amber-colored, hard,} well-formed wheat kernels usually contain more nitrogen and gluten than large, rotund kernels. The size of the germ, the proportion of aleurone to endosperm, and the nitrogen content of the endosperm or floury portion are the three factors which determine the relation of the nitrogen in wheat to the nitrogen in flour. Ordinarily, the bran and offal make up about 25 per cent of the weight of the kernel, and the endosperm from 75 to 80 per cent. When the amount of endosperm is increased, there is proportionally less offal and more flour. The size of the wheat kernel, together with the size of the indentation marking the germ area, indicate approximately the amount of germ in the kernel. The larger the per cent of germ and aleurone, the smaller the amount of flour recovered when the wheat is milled. As a general rule, wheats which contain the most nitrogen produce the most nitrogenous flours, but the total nitrogen in the wheat cannot always 
be taken as an index of that in the flour. Two wheats may contain about the same total nitrogen and the nitrogen be distributed differently in each, - in one a larger portion being present in the offal, and in the other more in the endosperm and hence recovered as flour. In the following table are given the percentages of protein in the grain and in the patent flour by the modern roller process of milling. These tests were made under the supervision of the author in large flour mills of Minneapolis, Minn. The percentage amount of the wheat recovered as patent flour was about the same in all of the tests.

Per Cent of Protein.

Mill $B$.

\begin{tabular}{|c|c|c|}
\hline Wheat. & & Flour. \\
\hline I5. I9 & & I 4.60 \\
\hline I 5.44 & & I $4 . I_{3}$ \\
\hline I 5.75 & & I 4.00 \\
\hline \multicolumn{3}{|c|}{ Mill C. } \\
\hline I 5.50 & & I3.90 \\
\hline I 5.38 & & 14.65 \\
\hline I 4.33 & & I3.88 \\
\hline I 5.51 & & I 4.44 \\
\hline I 5.00 & & I3.94 \\
\hline I 5.15 & & I4.06 \\
\hline I5.19 & & I 4.19 \\
\hline
\end{tabular}

382. Influence of Fertilizers upon Composition of Wheat. - Experiments by Lawes and Gilbert (Rothamsted Memoirs, Vol. III) show that the different kinds of manure, as nitrogenous, mixed, and mineral, influence the yield but not materially the composition of the grain. During the time of the experiment, covering a period of twenty years, the nitrogen, phosphoric acid, and potash in the dry matter of the grain were fairly constant, and when different manures were used, there were no greater 
variations in the composition of the grain than between crops upon the same plots similarly manured during different seasons. Climatic conditions influenced the composition of the kernel to a greater extent than did fertilizers. Fertilizers, however, exert an influence upon commercial grade and bread-making value of wheat to a greater extent than is reflected by chemical analysis of the wheat.

383. Variations in Composition of Wheat. - In Jenkins and Winton's "Average Composition of American Feeding Stuffs," spring wheat is given as containing $\mathrm{I} 2.5$ per cent protein and winter wheat II. 8 per cent. In both spring and winter wheat there are variations in protein content from 8 to $\mathrm{I} 6$ per cent. While average wheat is given as containing $\mathrm{I} 2.5$ per cent, later analyses show some to contain as high as I9 per cent.

The greatest differences in composition are noticeable between wheats grown in different seasons. Five samples of the I89I crop of wheat analyzed by the author at the Minnesota Experiment Station contained I2.0I per cent of protein. The wheat was of high milling and baking value. In 1892 , six samples from the same localities showed $\mathrm{I}_{3.22}$ per cent of protein, and in I90I, I4 samples contained I 5.2I per cent.

Some of the effects of climate and soil upon the physical and chemical properties of wheat are noted in Bulletin No. I8, Part 9, Division of Chemistry, United States Department of Agriculture, from which the following paragraphs are taken:

"The inherent tendency to change which is found in all grains is most prominent in wheat; it may be fostered by selection and by modifying such of the conditions of environment as it is in the power of man to effect. The 
most powerful element to contend with is the character of the season or unfavorable climatic conditions. The injury done in this way is well illustrated in Colorado, and it would seem advisable in such cases to seek seed from a source where everything has been favorable, and begin selection again. It must be borne in mind that selection must be kept up continuously, and that reversion takes place more easily than improvement. Hallett, in England, was able to make his celebrated pedigree wheat by selection, carried on through many years, but the same wheat grown by the ordinary farmer under unfavorable conditions for a few years without care has reverted to an ordinary sort of grain.

"The effect of climate is well illustrated by four specimens of wheat which are to be seen in the collection of the Chemical Division. Two of these were from Oregon and Dakota some years ago, and present the most extreme contrast which can be found in this variable grain. One is light yellow, plump and starchy, and shows on analysis a very small per cent of albuminoids; the other is one of the small, hard, and dark-colored spring wheats of Dakota, which are rich in albuminoids. Between these stand two specimens from Colorado, which have been raised from seed similar to the Oregon and Dakota wheat. They are scarcely distinguishable except by a slight difference in color. The Colorado climate is such as to have modified these two seed wheats, until after a few years' growth they are hardly distinguishable in the kernel. All localities having widely different climates, soils, or other conditions produce their peculiar varieties and modify those brought to them. The result of these tendencies to change and reversion from lack of care in seed selection or other cause has led to the practice of 
change of seed among farmers. A source is sought where either through greater care or more favorable conditions the desired variety has been able to hold its own. Sometimes this change is rendered necessary by conditions which are beyond the power of man to modify. As an example, No. Io of Professor Blount's wheats, known as 'Oregon Club,' a white variety from Oregon, has been deteriorating every year since it has been grown in Colorado, whereas if the seed had been supplied every season directly from Oregon, the quality would probably have remained the same. In extension of this illustration the fact may be mentioned that the annual renewal of the seed from a desirable and favorable source often makes it possible to raise cereals where otherwise climatic conditions would render their cultivation impossible through rapid reversion. This is particularly the case with extremes in latitude, the effect of which is not founded so much upon the composition of the crop as on the yield and size of the grain."

The water supply of a crop during growth greatly influences its composition. Irrigated wheats, grown with excess of water, have large, starchy kernels. With a limited amount of water the kernels are smaller, darkercolored, and harder. Wheats raised by "dry farming" methods of cultivation are richer in protein than the same class of wheats grown by irrigation.

384. Storage of Wheat in Elevators. - New wheat is subjected to a fermentation change known as "sweating." This affects, to a slight extent, the chemical composition and improves the milling qualities of the grain. When wheat is damp, the fermentation may cause the temperature to rise high enough to cause spontaneous combustion. Thoroughly sound wheat undergoes but 
little change in temperature even when stored in large elevators where $\mathrm{I} 20,000$ bushels are placed in one tank. The changes during storage are brought about by the enzymes or soluble ferments in the grain and the organized ferments and molds that are present on the surface of the grain. When wheat has been thoroughly cleaned, it does not readily undergo fermentation, while uncleaned, damp, and unsound wheats deteriorate.

385. Manufacture of Wheat into Flour. - The manufacture of wheat flour is a mechanical process. The cleaned wheat is broken into pieces at the first breakrolls, and is separated by means of sieves (bolters) into a number of grades of stock of varying size, as bran flakes, pieces of flattened and cracked wheat, coarse and fine middlings, masses of flour particles about the size of granulated sugar, and a little flour and flour dust. The residue of cracked wheat is reduced to finer particles at the second break, and separated into products similar to the first break bolting. The process of reducing the residue is repeated until the flour is removed from the bran. The various middlings stocks pass in thin layers over long stretches of silk bolting cloth, where carefully regulated air currents lift out the fine fibrous material and dust while the heavier flour granules are bolted or passed through the cloth. These purified middlings are then reduced to flour by means of smooth rolls and form the basis of the patent grades of flour. When all the merchantable flour is recovered as one product, it is called straight grade or standard patent flour. If it is separated into two or more parts, it is designated as patent and clear, or first and second patent and first and second clear. (See Section 4II for wheat by-products.)

386. Composition of Unsound Wheat. - When wheat 
fails to fully mature or is affected by frost, fungus disease, as rust or smut, or excessive heat, causing bleaching, the composition of the kernel is affected. Such wheats may contain a larger percentage of soluble carbohydrates, organic acids, and soluble proteids than fully matured wheat. Wheats damaged by bleaching, frost, or fungus disease give lower yield of flour with poorer keeping and bread-making qualities. Frost and excessive heat affect the physical qualities of the gluten.

\section{Composition of Different Varieties of Wheat. -} The different varieties of wheat, as spelt and durum, are similar in general composition to ordinary wheat with variations in quality of gluten. In durum, as in other wheats, the percentage of protein varies with the conditions under which the grain is grown. In the table given at the close of this chapter, it will be seen that durum has about the same content of proteid matter and other nutrients as hard spring wheat grown under similar conditions. Winter wheats generally contain less protein than spring wheats. Large, light-colored kernels contain less protein than darker-colored amber, denser, and more corneous kernels of the same variety.

Experiment 7I. - Grading wheat. Make the following test with three samples of wheat. (I) Obtain the weight per quart (dry measure), and then calculate the weight per bushel of each. (2) Weigh roo kernels of each sample. (3) Place ten representative kernels (of each) end to end and measure the length in millimeters and inches. (4) Note the color and appearance of each sample. (5) Observe if the kernels are "well filled"; (6) free from weed seeds, and if there are any indications of smut, frosting, or bleaching. (7) Assign a grade to each sample (see Section 409).

388. American and Foreign Wheats. - A compilation of analyses of wheats and of other cereals grown in different countries has been made by König. Absolute 
comparisons as to composition cannot be made because of numerous local factors which affect the wheat, as climate and soil. As great a difference is found in the composition of wheats raised in various parts of the United States as between those of different countries where there exist similar varieties of climate and soil. In the case of American wheats, the tables given were compiled before any large number of northwestern wheats were analyzed, hence the protein content is low because so small a number of wheats of highest protein content are included in the averages. In general, the tables of analyses show that wheat grown in tropical climates is less nitrogenous than that grown in more northern latitudes on equally fertile soils. In making use of the figures given in the following tables, it should be remembered that the comparisons are only relative, as some of the samples contain a much larger amount of moisture than others; and samples proportional to the wheat-growing regions are not included in the averages.

389. Wheat as Animal Food. - Wheat is not generally used for fattening farm animals, because of its high market value. Occasionally, however, it is more economical to use it in preference to other grains for the feeding of stock. Experiments show that it has a high feeding value. As a food for growing pigs, it is somewhat preferable to corn; for fattening pigs, there is but little difference between wheat and corn. The best results are obtained when wheat is ground and fed with other grains. A mixture of equal parts of ground wheat and corn gives better results than either wheat or corn fed alone. When the price of wheat is low and it can be purchased for the same or less per pound than corn, it will pay to use it for feeding farm animals. As a food for dairy animals, 
ground wheat is fully equal to either corn or a mixture of corn and barley. When fed to fattening steers, ground wheat produces about the same results as ground corn.

390. Wheat as Human Food. - Wheat is used as human food more extensively than any other cereal. This is due largely to its production over wider ranges of latitude and its containing proteids specially adapted to bread making. With the exception of rye, wheat is the only grain that contains gliadin, the proteid which forms the dough and with the gas causes expansion of the mass during the bread-making process.

"Among all civilized nations bread, in its broad sense, is the basis of human nutrition, all dietary standards cluster about it as the center and support of the system of nutrition. Not only is it the most important, but at the same time it is the cheapest of nutrients. Measured by actual nutritive power there is no other complete ration which in economy can compare with bread." 1

\section{Composition of Wheat}

(Jenkins and Winton, and König's works)

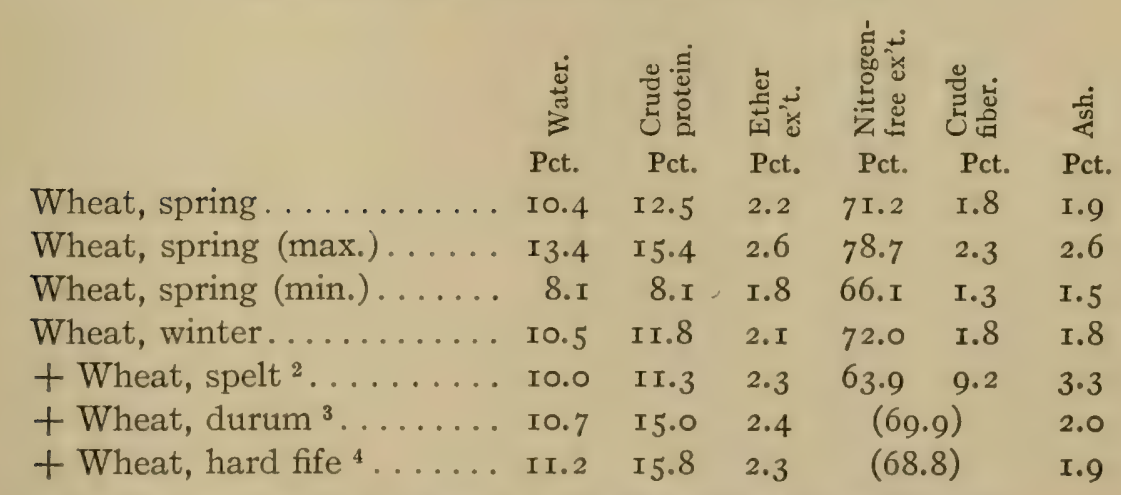

${ }^{1}$ H. W. Wiley, Bul. I3, Part IX, U. S. Dept. Agr. Div. Chem.

${ }^{2}$ Minn. analyses. $\quad{ }^{3}$ Average of thirteen northern grown samples.

${ }^{4}$ Spring wheat grown under similar conditions as durum. 
通苛

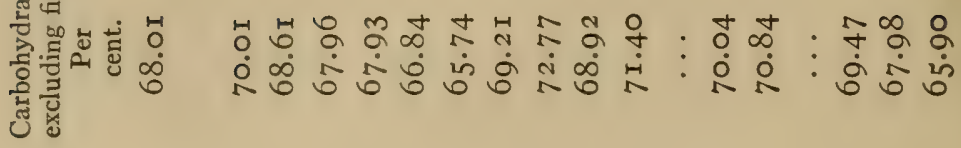

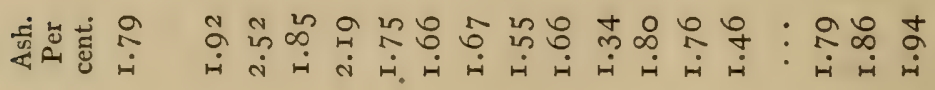

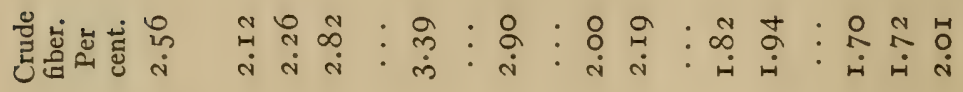

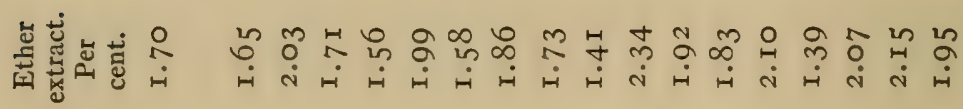

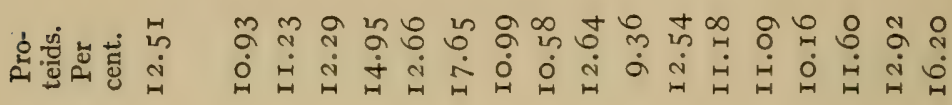

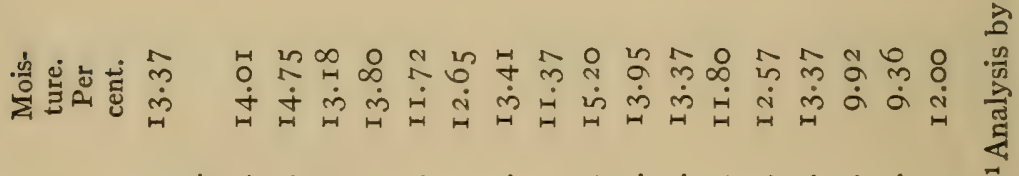

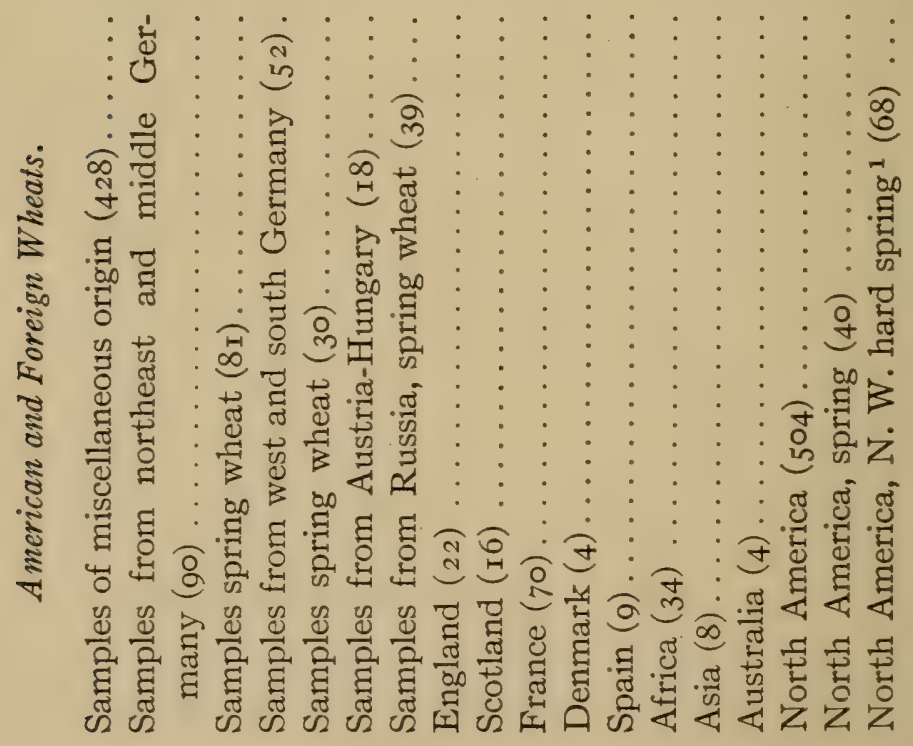




\section{CHAPTER XXX}

\section{MAIZe (INDian CoRN)}

39I. Structure of the Kernel. - Corn has somewhat the same general structure as wheat. The seed coat, however, is composed of two instead of three layers (see Fig. 89 ). Within the seed coat or hull (I) there is a hard aleurone layer (2) which is thicker at the sides than at the crown. The floury portion (4), which . is usually hard and flinty, is the larger part of the kernel, while the germ (3) constitutes about Io per cent of the weight. The proportional amounts of germ, floury portion, and aleurone layer differ with individual samples. The hulls make up about 5.5 to 6 per cent of the kernel, while about 85 per cent is floury portion and aleurone layer. In the milling of corn, as in the milling of

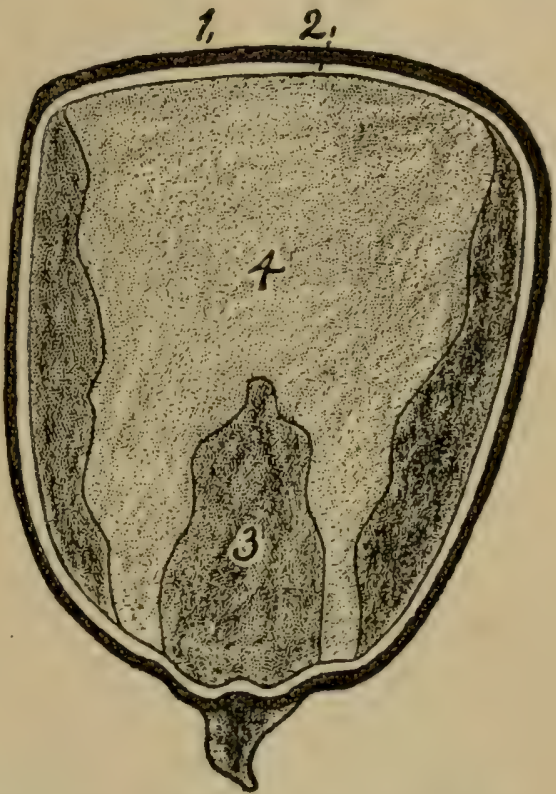

FIG. 89. - Structure of corn kernel : I, seed coat; 2, aleurone layer; 3 , germ ; 4, floury portion (adapted from N. J. Expt. Station Bull.). wheat, a mechanical separation of the different parts is effected.

392. Composition of Corn. - Corn is fairly constant in 
composition. As the result of a large number of analyses made by the Department of Agriculture, the following conclusion is drawn: "A study of all the analyses which have been made reveals the fact that maize is one of the most unvariable of the cereals, maintaining under the most different climatic conditions a most remarkable uniformity of composition, varying chiefly in the size, color, and general physical characteristics of its kernels rather than in their composition."

From the figures given at the close of the next chapter it will be observed that corn contains a much larger amount of fat than wheat, also somewhat less protein; the nitrogen-free extract, which is mainly starch, is about the same in amount in both. Investigations at the Illinois Experiment Station show that all the kernels upon the same ear are fairly constant in composition, although the kernels on the tip of the ear have a tendency to contain slightly less protein than those either in the middle or at the base; the difference in both protein and carbohydrates in a few extreme cases was about I per cent. The composition of the kernel is slightly influenced also by the stage of maturity. If, for any reason, corn fails to reach full maturity, there is usually more protein and less carbohydrates in the dry matter.

393. Proteids of Corn. - The proteids of corn are quite different in character from those of wheat. Small amounts of albumin and globulin are present, but the larger portion of the corn proteids is in insoluble forms called zeins, one of which is soluble and the other insoluble in alcohol. The zeins differ both in physical and chemical composition from wheat gliadin. The corn proteids contain about I part nitrogen to every 6.23 parts proteid material, while in wheat there is about I part nitrogen to 5.7 proteids. 
394. Glutenins and Starchy Corn. - The germ and aleurone layers are more nitrogenous in character than the interior or floury portion of the kernel. Since the proportion or germ and aleurone in corn, as in wheat, varies with individual samples, the nitrogenous matter, being greater in these parts, also varies. Taking advantage of this knowledge, it is possible, by mechanical means, to distinguish corn samples of high from those of low proteid content. The Illinois Experiment Station directs attention to this fact in Bulletin 55 .

"By making cross sections and longitudinal sections of several kernels from an ear of corn, one can judge, with a very satisfactory degree of accuracy, whether the corn is rich or poor in protcin. The illustration (Fig. 90) here shown was made from a photograph
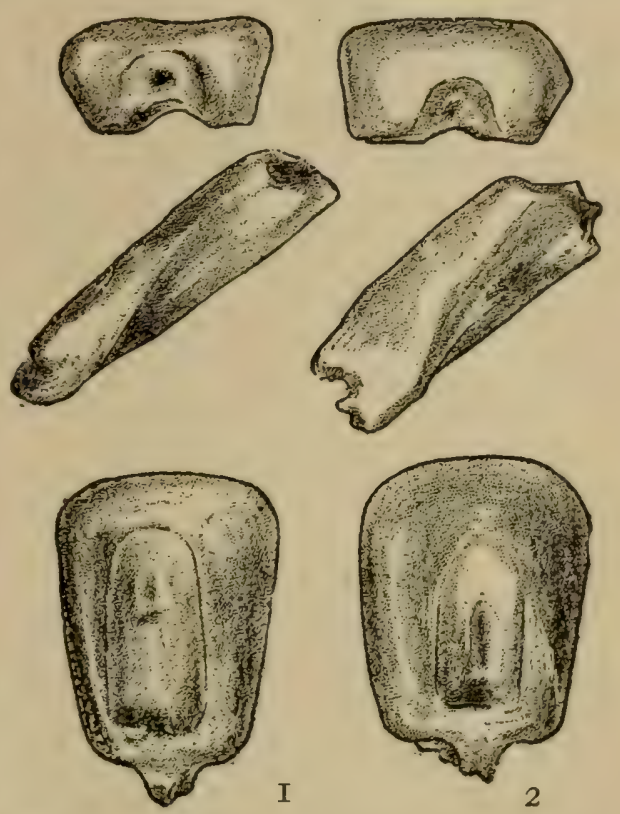

FIG. 90. - Nitrogenous and non-nitrogenous corn: I, corn with 14.92 per cent protein; 2 , corn with 7.76 per cent protein.

taken of the corn kernels and sections with a magnification of three diameters. At the left are two sections and a whole kernel from corn containing $\mathrm{I} 4.92$ per cent of protein. The sections and kernel at the right are from corn containing 7.76 per cent of protein. About one fourth of the kernel was cut off from the tip end in making the cross sections. In the longitudinal sections the tip end of the kernel points upward to the right. It will be seen that in the 
cross sections the white starchy layer nearly disappears in the high-protein corn, but becomes very prominent in the low-protein corn. In the longitudinal sections this difference is also apparent, the white starch in the highprotein corn being confined almost entirely to the crown end of the kernel, while in the low-protein corn it extends into the tip end in considerable amount. The germ in the high-protein corn is somewhat larger. This is also indicated by the depressions in the whole kernels."

There are occasionally exceptions, however, in the relation of form to the protein content of corn, but in making comparisons in the manner indicated, the few errors liable to occur are in assigning too low rather than too high a protein value to the sample. In the selection of seed corn a knowledge of the characteristic of the kernels as of high-or low-protein content will be found of value.

Experiment 72. - Select, from a sample of corn, kernels of highand kernels of low-protein content. Make longitudinal and cross sections of some of the kernels, and note the proportion of germ, aleurone, and floury parts in each. Make a drawing of a representative kernel of each kind of corn. Observe how your rating of the corn compares with the chemical analysis. Determine the weight per bushel and assign a grade to the sample.

395. Varieties of Corn. - The numerous analyses, which have been made of the different varieties of corn as dent or flint, do not show any wide variations in composition when they are grown under similar conditions. The main differences are in the amount of coloring matter and in the physical characteristics rather than in chemical composition. Yellow corn contains no more nutrients than white corn; there is coloring matter present in one and not in the other. Sweet corn contains more sucrose, 
but otherwise it has about the same general composition as the dent and flint varieties.

396. Moisture Content of Corn. - The keeping qualities of corn depend largely upon its moisture content. With more than I9 per cent moisture, corn cannot be considered safe for storage. With a sufficiently high temperature corn "heats" or ferments with less than I9 per cent moisture. The moisture in corn is determined for commercial purposes, in the following way:

One hundred grams of corn are placed in flask (a), with Ioo cc. of thin lubricating oil that has a high ignition point (a commercial grade known as "Atlantic red" being suitable for the purpose). The stopper with thermometer (b) and delivery tube (c) is inserted. The delivery tube is connected with condenser (d) and the graduated cylinder (e) is

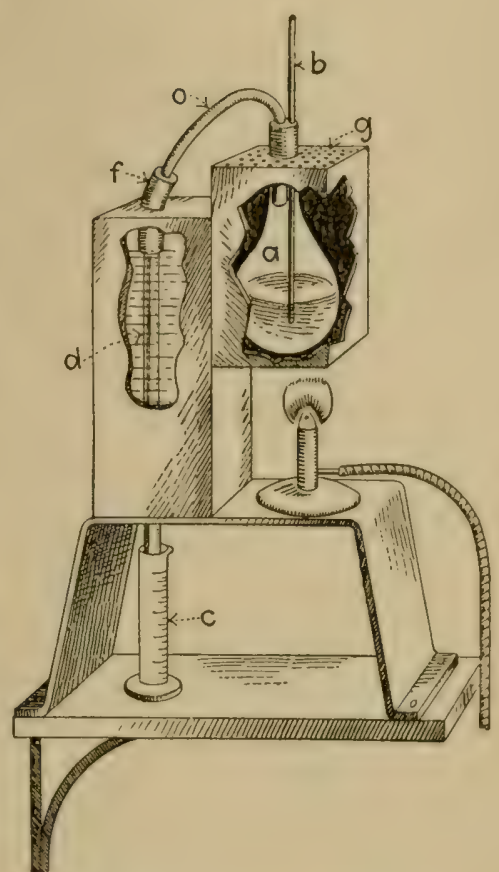

FIG. 90a.-Grain moisture.

Apparatus. A block tin pipe (d) passes through a condensing chamber filled with water. The flask (a) rests upon a triangle supported by a metal frame or box of galvanized iron with a perforated lid at $(\mathrm{g})$. The box is lined with asbestos paper. placed so as to receive the distillate. Heat is applied gradually until the thermometer registers $\mathrm{I} 88^{\circ} \mathrm{C}$. and then is shut off. The cc. of distillate in the graduate represents the per cent of moisture in the corn. This method, first used by a German chemist, has been 
modified, and is generally referred to as the "government" moisture method. It is extensively used in the testing of corn, and is also applicable to the testing of wheat for moisture content.

397. Corn Products. - When the entire kernel is ground, coarse corn meal is the product. When a part of the bran is removed, fine corn meal is obtained. Corn flour is made by removing the bran and germ and reducing the interior portion of the kernel, as in flour making. In the manufacture of starch, the proteid matter is removed, and with the germ and bran, forms the basis of a number of commercial feeds. Cornstarch is sold either as a commercial product, or is used in the preparation of glucose (see Experiment 49). The larger portion of the fat or oil of corn is present in the germ and is recovered as corn oil. A number of other products are also obtained from corn.

398. Corn as a Food. - Corn is extensively used both as human and animal food. Its proteids do not render it as valuable for bread-making purposes as wheat. It is, however, one of the cheapest foods that can be procured, and the prejudice against its use as human food because of its being fed to animals is gradually being overcome. Its value as animal food is too well known to require further discussion. 


\section{CHAPTER XXXI}

\section{Oats, Barley, Rye, Buckwheat, Rice, and Miscellaneous Seeds}

399. Structure of the Oat Kernel. - Oats are composed of two parts, the kernel and the hull. The hulls have the same general composition as straw, and make up about 30 per cent of the weight. The different parts of the oat kernel are: (I) seed pod, (2) aleurone layer, (3) germ, and (4) floury portion. The weight per bushel of oats depends largely upon the amount of hulls ; in some samples these make up 25 per cent, and in others 35 per cent of the weight.

400. Composition of Oats. - When the hulls are included, oats have a larger amount of fiber and ash than any other cereal. The per cent of fat is higher than in wheat, barley, or rye, and as high as in corn. Hulled oats have about the same general composition as wheat, with a tendency to a higher protein content. They are also characterized by a high per cent of fat. Variations in the composition of oats are, to a limited extent, noticeable. The ratio of hull to kernel influences the composition more than any other factor. There is not a great difference in the chemical composition of heavy- and light-weight oats. Experiments at the Maine Experiment Station show that the differences are mainly in the amount of nutrients in a given. volume of the grain, as a bushel, rather than in percentage composition. This emphasizes the importance of feeding oats by weight rather than by measure. 
40I. Oats as Human and Animal Food. - Oats are used more extensively as an animal food than as human food. When the hulls are removed and the oats are properly prepared, they make a valuable human food, because of the large amount of available protein, fat, and other nutrients. Oats are especially well adapted for the feeding of horses, because of their mechanical condition and the character of the available nutrients. Experiments at the Wisconsin Exp. Station show that when fed to dairy animals under similar conditions, high grade oats produce ıo per cent more milk and butter fat than the same weight of average bran.

402. Barley is used largely for brewing and for animalfeeding purposes rather than as a human food. There is less fat, fiber, and ash than in oats, but more protein and carbohydrates. Barley contains less protein than wheat. For brewing purposes, perfectly sound and fully matured barley with a high germination percentage is necessary, while that which has been slightly damaged in any way, as by rain, frost, or hot winds, is not suitable for this purpose. Such barley, however, can be used for feeding purposes, and is often the cheapest grain that can be fed by western farmers. Barley is suitable for feeding to all kinds of farm animals. The hull-less varieties contain less fiber and more protein and available carbohydrates. A study of the proteids of barley shows that there is about I part of nitrogen to every 5.7 parts of protein, which is practically the same in amount as is found in wheat proteids.

403. Rye. - Rye contains proteids similar to wheat, rendering it suitable for bread-making purposes. However, rye is more extensively used in this country for the manufacture of alcoholic beverages than for bread. Rye resembles wheat in chemical composition more than does 
any other cereal, although when grown under similar conditions it contains somewhat less protein than wheat. In the feeding of farm animals, rye must be used with more caution than wheat. If used in a dairy ration in too large amounts, it is believed to have a tendency to produce a slightly inferior quality of milk and butter, but when fed moderately no difficulty is experienced. In a mixed ration, rye has been found equal to barley and other cereals for meat production.

404. Rice. - Rice is characterized by a low protein and fat content, and a high per cent of carbohydrates. It is not used to any extent for the feeding of stock, although its by-products are employed for this purpose. Rice may furnish the carbohydrates of a ration at a low cost, but should be combined with foods rich in protein, as legumes.

405. Buckwheat. - The entire kernel contains quite an appreciable amount of fiber, which is removed in the preparation of buckwheat flour. There is somewhat less protein than in wheat and other cereals. Buckwheat is not extensively used for the feeding of animals, although some of its by-products are valuable for this purpose.

406. Flax is a type of oil seed, small in size but with a large amount of nutrients in the form of fat. Average flax contains about 38 per cent of fat, which is largely removed in the manufacture of linseed oil. A bushel of flax will yield about ig pounds of oil and 40 pounds of oil cake. Flax is too concentrated, and usually too valuable a market crop to be used much for animal feeding purposes. Should the price warrant, it may be combined with other grains. As much as 8 pounds a day have been fed in a dairy ration without apparent ill results. Unripe and immature flaxseed is often used for feeding 
purposes. Other oil seeds, as cotton and rape, are valuable for the oil they contain, and the oil cake which is used for feeding purposes.

407. Millet Seed has somewhat the same general composition as oats. However, when fed it should be ground and combined with other grains.

408. Peas and Beans. - Peas and beans, as well as other leguminous seeds, are characteristically rich in protein and contain variable amounts of fat. Peas and beans are valuable alike as human and animal food. When used as animal food, they should form a part of a grain ration. They are particularly good for pork production as well as for meat and milk, but their high price usually prevents their extensive use in animal feeding. When they can be produced cheaply and abundantly, they are among the best foods that can be used. The proteid of leguminous seeds is largely in the form of legumin, a casein-like body.

409. Grading of Grains. - Oats, barley, rye, and other grains are all graded commercially on the basis of their physical properties, as weight per bushel, maturity, amount of foreign weed seed, and any fungus disease, or injury caused by rust or excessive heat. As an example of rules for grading grain the following adopted by the Minnesota Board of Grain Appeals are given.

\section{NORTHERN SPRING WHEAT}

No. i Hard Spring Wheat. - Shall be dry, sound, bright, sweet, clean, and consist of over 50 per cent of the hard varieties, and weigh not less than $5^{8}$ pounds to the measured bushel.

No. I Northern Spring Wheat. - Shall be dry, sound, sweet, and clean, may consist of the hard and soft varieties of spring wheat, and weigh not less than 57 pounds to the measured bushel.

No. 2 Northern Spring Wheat. - Shall be dry, spring wheat, 
not clean enough or sound enough for No. I, but of good milling quality and must not weigh less than $5^{6}$ pounds to the measured bushel.

No. 3 Northern Spring Wheat. - Shall be composed of inferior, shrunken spring wheat and weigh not less than 54 pounds to the measured bushel.

No. 4 Northern Spring Wheat. - Shall include all inferior spring wheat that is badly shrunken or damaged and weigh not less than 48 pounds to the measured bushel.

Rejected Spring Wheat. - Shall include all varieties of spring wheat sprouted, badly bleached or for any other cause unfit for No. 4 .

Note. - Hard, flinty wheat, of good color, containing no appreciable admixture of soft wheat, may be admitted into the grades of No. 2 Northern Spring Wheat and No. 3 Northern Spring Wheat, provided weight of the same is not more than one pound less than the minimum test weight required by the existing rules of said grades, and provided, further, that such wheat is in all other respects qualified for admission into such grades.

Nore. - The variety of wheat known as "Humpback," owing to its inferior milling quality, shall not be graded higher than No. 3 .

\section{WHITE WINTER WHEAT}

No. I White Winter Wheat. - Shall include all varieties of pure, soft, white winter wheat, sound, plump, dry, sweet, and clean, and weigh not less than $5^{8}$ pounds to the measured bushel.

No. 2 White Winter Wheat. - Shall include all varieties of soft, white winter wheat, dry, sound, and clean, may contain not more than 5 per cent of soft red winter wheat, and weigh not less than 56 pounds to the measured bushel.

No. 3 White Winter Wheat. - Shall include all varieties of soft, white winter wheat, may contain 5 per cent of damaged grains other than mow-burnt wheat, and may contain ro per cent of soft red winter wheat, and weigh not less than 53 pounds to the measured bushel.

\section{HARD WINTER WHEAT}

No. I HARd Winter Wheat. - Shall include all varieties of hard winter wheat, sound, plump, dry, sweet, and clean, and weigh not less than 6r pounds to the measured bushel. 
No. 2 Hard Winter Wheat. - Shall include all varieties of hard winter wheat, dry, sound, and clean, and weigh not less than 59 pounds to the measured bushel.

No. 3 Hard Winter Wheat. - Shall include all varieties of hard winter wheat, of both light and dark colors, not clean and plump enough for No. 2, and weigh not less than 55 pounds to the measured bushel.

No. 4 Hard Winter Wheat. - Shall include all varieties of hard winter wheat not fit for a higher grade.

\section{RED WINTER WHEAT}

No. I Red Winter Wheat. - Shall be pure red winter wheat of both light and dark colors, dry, sound, sweet, plump, and well cleaned, and weigh not less than 60 pounds to the measured bushel.

No. 2 Red Winter Wheat. - Shall be red winter wheat of both light and dark colors, shall not contain more than 5 per cent of white winter; dry, sound, sweet, and clean, and weigh not less than $5^{8}$ pounds to the measured bushel.

No. 3 Red Winter Wheat. - Shall be sound red winter wheat, not clean and plump enough for No. 2 ; shall not contain more than 5 per cent of white winter, and weigh not less than 55 pounds to the measured bushel.

\section{WESTERN WHITE AND RED WHEAT}

No. I Western White Wheat. - Shall be dry, sound, well cleaned, plump, and composed of the western varieties of white wheat.

No. 2 Western White Wheat. - Shall be dry, sound, reasonably clean, and composed of western varieties of white wheat.

No. 3 Western White Wheat. - Shall be composed of all western white wheat fit for warehousing, weighing not less than 54 pounds to the measured bushel, and not sound enough or otherwise fit for the higher grades.

Rejected Western White Wheat. - Shall comprise all western white wheat fit for warehousing but unfit for higher grades.

Note. - Western Red Wheat and Western Wheat shall correspond in all respects with the grades of Nos. I, 2, 3, and Rejected. 


\section{DURUM (MACARONI) WHEAT}

No. I Durum Wheat.- Shall be bright, sound, dry, well cleaned, and be composed of durum commonly known as macaroni wheat and weigh not less than 60 pounds to the measured bushel.

No. 2 Durum Wheat. - Shall be dry, clean, and of good milling quality. It shall include all durum wheat that for any reason is not suitable for No. I Durum and weigh not less than $5^{8}$ pounds to the measured bushel.

No. 3 Durum Wheat. - Shall include all durum wheat bleached, shrunken, or for any cause unfit for No. 2, and weigh not less than 55 pounds to the measured bushel.

No. 4 Durum Wheat. - Shall include all durum wheat that is badly bleached or for any cause unfit for No. 3 .

\section{MIXED WHEAT}

In case of any appreciable admixture of Durum, Western, Winter or Western White and Red Wheat, with Minnesota grades of Northern Spring Wheat, or with each other, it shall be graded according to the quality thereof and classed as Nos. I, 2, 3, etc., Mrxed WHeat, with inspector's notation describing its character.

\section{CORN}

No. I Corn. - Shall be corn of various colors, sound, plump, and well cleaned, and shall contain not more than ${ }_{5}$ per cent of moisture.

No. 2 CoRn. - Shall be corn of various colors, sweet, reasonably clean, and shall not contain more than ${ }^{5} 5^{\frac{1}{2}}$ per cent of moisture.

No. 3 CORN. - Shall be corn of various colors, sweet, shall be reasonably sound and reasonably clean, and shall not contain more than I9 per cent of moisture.

No. 4 Corn. - Shall include all corn not wet and not in heating condition that is unfit for No. 3 corn.

\section{YELLOW CORN}

No. I Yellow Corn. - Shall be 98 per cent yellow, sweet, sound, plump, and well cleaned, and shall contain not more than I 5 per cent of moisture.

No. 2 Yellow CORn. - Shall be 90 per cent yellow, sweet, shall 
be reasonably clean and shall not contain more than $I^{\frac{1}{2}}$ per cent of moisture.

No. 3 Yellow Corn. - Shall be 90 per cent yellow, sweet, shall be reasonably clean and reasonably sound, and shall not contain more than ig per cent of moisture.

No. 4 Yellow Corn. - Shall include all yellow corn not wet and not in heating condition that is unfit for No. 3 Yellow.

Note. - Nos. I, 2, 3, and 4 White Corn shall correspond in all respects with the grades of Nos. I, 2, 3, and 4 Yellow Corn.

\section{OATS}

No. I White OAts. - Shall be white, dry, sweet, sound, clean, and free from other grain, and shall weigh not less than 32 pounds to the measured bushel.

No. 2 White OAts. - Shall be seven eighths white, dry, sweet, sound, reasonably clean, and practically free from other grain, and shall weigh not less than 3 I pounds to the measured bushel.

No. 3 White OAts. - Shall be seven eighths white, dry, sweet, sound, reasonably clean, and practically free from other grain, and shall weigh not less than 28 pounds to the measured bushel.

No. 4 White OAts. - Shall include all oats not sufficiently sound and clean for No. 3 White Oats and shall weigh not less than 24 pounds to the measured bushel.

Yellow OATs. - The grades of Nos. I, 2, and 3 Yellow Oats shall correspond with the grades of Nos. I, 2, and 3 White Oats, excepting that they shall be of the yellow varieties.

No. I OATs. - Shall be dry, sweet, sound, clean, and free from other grain, and shall weigh not less than 32 pounds to the measured bushel.

No. 2 OAts. - Shall be dry, sweet, sound, reasonably clean, and practically free from other grain and shall weigh not less than $3 \mathrm{I}$ pounds to the measured bushel.

No. 3 OATs. - Shall be all oats that are merchantable and warehouseable, and not fit for the higher grades.

No. I Clipped White OAts. - Shall be white, dry, sweet, sound, clean, and free from other grain, and shall weigh not less than 40 pounds to the measured bushel.

No. 2 Clipped White Oats. - Shall be seven eighths white, dry, 
sweet, sound, reasonably clean, and practically free from other grain, and shall weigh not less than 38 pounds to the measured bushel.

No. 3 Clipped White Oats. - Shall be seven eighths white, dry, sweet, sound, reasonably clean, and practically free from other grain, and shall weigh not less than 36 pounds to the measured bushel.

\section{RYE}

No. I Rye. - Shall be sound, plump, and well cleaned, and shall weigh not less than 56 pounds to the measured bushel.

No. 2 RYE. - Shall be sound, reasonably clean and reasonably free from other grain, and shall weigh not less than 54 pounds to the measured bushel.

No. 3 Rye. - All rye slightly damaged or from any other cause unfit for No. 2 shall be graded No. 3 .

\section{BARLEY}

No. I BARLEy. - Shall be plump, bright, clean, and free from other grain, and shall weigh not less than 48 pounds to the measured bushel.

No. 2 BARLEy. - Shall be sound and of healthy color, not plump enough for No. I, reasonably clean and reasonably free from other grain, and shall weigh not less than 46 pounds to the measured bushel.

No. 3 BARLEy. - Shall include all slightly shrunken and otherwise slightly damaged barley, not good enough for No. 2, and shall weigh not less than 44 pounds to the measured bushel.

No. 4 BARLEy. - Shall include all barley fit for malting purposes, not good enough for No. 3 .

No. I Feed Barley. - Must test not less than 40 pounds to the measured bushel and be reasonably sound and reasonably clean.

No. 2 Feed BARLey. - Shall include all barley which is for any cause unfit for the grade of No. I Feed Barley.

Chevalier Barley. - Nos. I, 2, and 3 Chevalier Barley shall conform in all respects to the grades of Nos. I, 2, and 3 Barley except that they shall be of a chevalier variety, grown in Montana, Oregon, and on the Pacific coast. 
No Grade. - All Wheat, Barley, Oats, Rye, and Corn in a heating condition, too musty or too damp to be safe for warehousing or that is badly bin burnt, or fire burnt, badly damaged, exceedingly dirty, or otherwise unfit for store, shall be classed as No Grade, with inspector's notation as to quality and condition.

\section{SPELTZ}

No. I Spelrz. - Shall be white, dry, sweet, sound, clean, and free from other grain, and shall weigh not less than 37 pounds to the measured bushel.

No. 2 Speltz. - Shall be dry, sweet, sound reasonably clean, and practically free from other grain, and shall weigh not less than 36 pounds to the measured bushel.

No. 3 Speltz. - Shall be all speltz that are merchantable and warehouseable, and not fit for the higher grades.

\section{FLAXSEED}

No. I Northwestern Flaxseed. - Shall be mature, sound, dry, and sweet. It shall be northern grown. The maximum quantity of field stack, storage or other damaged seed intermixed shall not exceed twelve and one half ( $12 \frac{1}{2}$ ) per cent. The minimum weight shall be fifty-one ( $5 \mathrm{I})$ pounds to the measured bushel of commercially pure seed.

No. I FlAXSEED. - Shall be northern grown, sound, dry, and free from mustiness, and carrying not more than twenty (20) per cent of immature or field stack, storage, or other damaged flaxseed, and weighing not less than forty-nine (49) pounds to the measured bushel of commercially pure seed.

No. 2 Flaxseed. - Flaxseed that is bin burnt, immature, field damaged or musty, and yet not to a degree to be unfit for storage, and having a test weight of not less than forty-seven (47) pounds to the measured bushel of commercially pure seed, shall be No. 2 Flaxseed.

No Grade Flaxseed. - Flaxseed that is damp, warm, moldy, fire burnt, very musty, or otherwise unfit for storage, or having a weight of less than forty-seven(47) pounds to the measured bushel of commercially pure seed, shall be No Grade. 
The following abbreviations to be used by inspectors in designating the grades:

R. Wt. for........................................... Winter

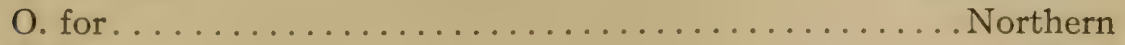

H. for . . . . . . . . . . . . . . . . . . . . . Hard

Wn. W. for . . . . . . . . . . . . . . Western White

Wn. R. for . . . . . . . . . . . . . . . Western Red

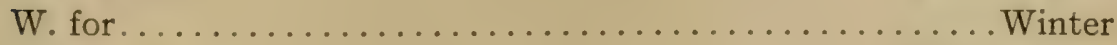

W. Wt. for. . . . . . . . . . . . . . . . . White Winter

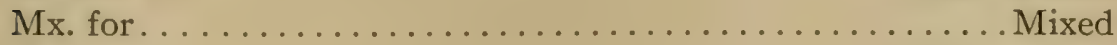

Y. Corn for ........................ Yellow Corn

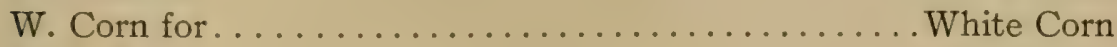

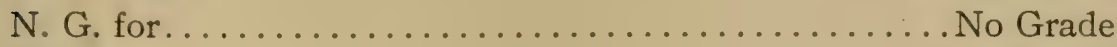

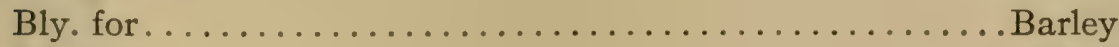

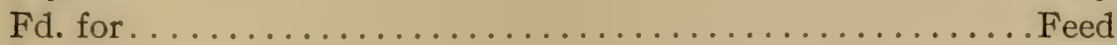

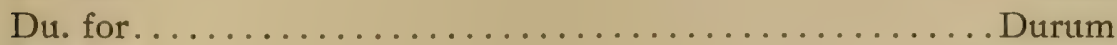

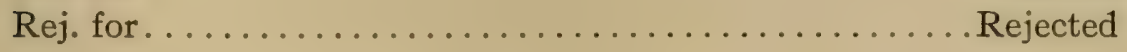

\section{MANNER OF TESTING}

Wheat, Flax, and Rye shall be tested after cleaning. The test kettle shall be placed where it cannot be jarred or shaken. From scoop, bag, or pan, held two inches from top of kettle, pour into middle of same at a moderate speed, until running over, striking off in a zigzag manner with the edge of beam held horizontally.

NoTE. - No grains shall in any case be graded above that of the poorest quality found in that lot when it bears evidence of being plugged or doctored.

Note. - Wheat scoured or otherwise manipulated, the test weight will not be considered in grading same.

Note. - The grades of "Purified Oats" or "Purified Barley" shall correspond with the other grades of Oats and Barley, except that same shall be designated as "Purified."

Grades are subject to change according to the character of the crops as influenced by climatic conditions. Wheat that grades No. I Northern one year might be assigned either a higher or a lower grade another year. Grades are relative rather than absolute. 


\section{- Composition of Grains and Seeds.}

(From Jenkins and Winton.)

\begin{tabular}{|c|c|c|c|c|c|}
\hline $\begin{array}{l}\text { Water. } \\
\text { Per cent. }\end{array}$ & $\begin{array}{l}\text { Crude } \\
\text { protein. } \\
\text { Per cent. }\end{array}$ & $\begin{array}{l}\text { Ether } \\
\text { extract. } \\
\text { Per cent. }\end{array}$ & $\begin{array}{l}\text { Nitrogen- } \\
\text { free ex- } \\
\text { tract. } \\
\text { Per cent. }\end{array}$ & $\begin{array}{c}\text { Crude } \\
\text { fiber. } \\
\text { Per cent. }\end{array}$ & $\begin{array}{l}\text { Ash. } \\
\text { Per } \\
\text { cent. }\end{array}$ \\
\hline Corn, dent. . . . . . . Io.6 & 10.3 & $5 \cdot 0$ & 70.4 & 2.2 & I. 5 \\
\hline Corn, dent (max.) ...19.4 & I 2.8 & $7 \cdot 5$ & $75 \cdot 7$ & 4.8 & 2.6 \\
\hline Corn, dent (min.)... 6.2 & $7 \cdot 5$ & $3 \cdot \mathrm{I}$ & $65 \cdot 4$ & 0.9 & I.O \\
\hline Corn, flint . . . . . . I I.3 & 10.5 & $5 \cdot 0$ & 70. I & I. 7 & I. 4 \\
\hline Corn, sweet. . . . . 8.8 & I I. 6 & 8. I & 66.8 & 2.8 & I.9 \\
\hline Oats............ I I.o & I I. 8 & $5 \cdot 0$ & 59.7 & $9 \cdot 5$ & 3.0 \\
\hline Barley .......... r 0.9 & I 2.4 & I.8 & 69.8 & 2.7 & 2.4 \\
\hline Rye............ I I.6 & Io. 6 & I. 7 & $72 \cdot 5$ & I. 7 & I.9 \\
\hline Rice............ I 2.4 & $7 \cdot 4$ & 0.4 & 79.2 & 0.2 & 0.4 \\
\hline Buckwheat........ I0.9 & 10.5 & $5 \cdot 4$ & 69.6 & 2.1 & I. 5 \\
\hline $\operatorname{Peas}^{1} \ldots . . . . .$. IO.I & $2 \mathrm{I} .6$ & 1.0 & 58.2 & $5 \cdot 7$ & $3 \cdot 4$ \\
\hline Flaxseed ${ }^{1} \ldots \ldots \ldots$. I & $27 \cdot 5$ & 38.6 & I 7.9 & $7 \cdot 4$ & $3 \cdot 5$ \\
\hline Millet seed ${ }^{1} \ldots \ldots$ I 2.5 & Io. 6 & 3.9 & $6 \mathrm{r} . \mathrm{r}$ & $8 . \mathrm{I}$ & 3.8 \\
\hline Navy beans........ I 2.4 & 22.2 & I. 4 & $53 \cdot I$ & $7 \cdot 2$ & $3 \cdot 7$ \\
\hline
\end{tabular}




\section{CHAPTER XXXII}

\section{Mill and By-PRoducts}

410. Sources. - Various by-products are obtained in the milling of wheat and in the preparation of cereal foods, malting of grain, extraction of oil from seeds, and manufacture of starch and glucose, and these are used for the feeding of animals.

4II. Wheat By-products. - In the milling of wheat, about 72 per cent of the grain is returned as straight grade or patent flour, .5 per cent as low grade, I. 50 per cent red-dog or feeding flour, and 25 per cent as wheat offal bran, shorts, or middlings. The mechanical losses and shrinkage due to drying amount to about I per cent. The separation of the wheat kernel into these various products is a mechanical operation effected by rolls for the reduction of the grain, and sieves and bolting cloths for the separation of the various products. The grades of flour and the percentage amounts of by-products recovered in milling vary with the character of wheat used and the individuality of the mill. (See Section 385.)

4i2. Wheat Bran is composed mainly of the outer layers of the wheat kernel removed in the manufacture of flour. Some of the floury portion and aleurone cells find their way into the bran and fine bran or shorts. Wheat bran varies in chemical composition and feeding value according to the composition and character of the wheat used and the process of milling. It may contain as low as 14 and as high as I 8 per cent of crude protein; 
average bran contains about 15 per cent. Two samples of bran may have about the same percentage amount of protein and not have the same feeding value. For example, one wheat containing I 3 per cent protein may be exhaustively milled and yield a bran of 15 per cent protein, while another wheat with $5_{5}^{\frac{1}{2}}$ per cent imperfectly milled may yield bran with I6 per cent protein. While both brans contain nearly the same amount of crude protein, the second sample would have more available non-nitrogenous nutrients and with the same per cent of crude protein would produce better results in feeding than the first sample. There is usually more protein in spring wheat bran than in winter wheat bran. This is due largely to the more nitrogenous character of the spring wheat. Bran should be practically free from weed seeds and all foreign matter.

Bran occupies a high position among animal foodstuffs. It is bulky in nature and can be fed in comparatively large amounts without injury to animals. Director Henry in "Feeds and Feeding" states: "Next to corn, wheat bran is the great cow feed of this country. Rich in ash and protein, carrying a fair amount of starchy matter, its light, chaffy character renders it the natural complement of heavy corn meal. Though its nutritive constituents approximate those of cottonseed meal, it mixes well with that feed, causing it to lie more lightly in the stomach.

" The large amount of mineral matter in bran is another factor of much importance in milk production. In milk there is much mineral matter, placed there for the framework of the calf, and bran supplies this more abundantly than most feeding stuffs.

"Middlings, like bran, are extensively fed to dairy 
cows. Being themselves heavy in character, they do not mix well with heavy feeds like cottonseed meal and corn meal. Dairymen will find middlings much relished by cows and yielding satisfactory returns. Bran and middlings are conceded by all who have fed them to favorably affect the flow of milk. Cows may be fed as much as 6 to 8 pounds of bran daily and from 4 to 6 pounds of middlings. Bran was at first regarded with favor only by dairymen. Gradually the steer feeder is learning. its value in connection with other grain in the feed box. Because of its bulky character and its cooling, slightly laxative properties, bran is a most excellent dilutent for corn meal, cottonseed meal, and other heavy food substances. Where it can be obtained at a reasonable price, the stockman will find much satisfaction in mixing one third its weight of bran with cornmeal."

In commenting upon the feeding value of wheat byproducts, Jordan, in the "Feeding of Animals," states: "No commercial feeding stuffs are regarded with greater favor, or are more widely and largely purchased by American feeders than the by-products from milling wheat. Wheat bran and middlings are cattle foods of standard excellence, whether we consider composition, palatableness or their relation to the quality of dairy products."

413. Wheat Shorts or Middlings consist of those outer portions of the wheat kernel which contain somewhat less crude fiber, protein, and ash than the parts which make up the bran. This product is practically the fine bran subjected to more complete pulverization and mixed with some "floury" stock. It is more variable in composition than bran, but for some purposes, as pig feeding, is more valuable. 
Standard middlings and flour middlings are products with different amounts of "floury" stock. Used in connection with animal feeding, middlings means an entirely different product from the purified middlings mentioned in Section 385, which form the basis of the patent grades of flour. Wheat germ is a part of the shorts or middlings and is rich in both protein and fat. About 6 per cent of the wheat offal is germ. It would impart poor keeping qualities if present in flour, and its proteids are not suitable for bread-making purposes.

4I4. Wheat Feed or Mixed Wheat Feed is composed of the bran, shorts, or middlings and the " red-dog" or feeding flour in the proportions obtained in the manufacture of flour. It is a mechanical mixture of all of the wheat by-products and has a high feeding value. It is particularly valuable for milk production, and because of its physical composition possesses some advantages over bran or middlings fed alone. A mixed wheat feed should contain 15 per cent or more of protein, 4.5 per cent fat, and less than 9 per cent fiber.

4I5. Wheat Screenings are a mixture of various seeds with occasionally broken and shrunken wheat kernels, and vary in composition and food value with the different kinds of weed seeds present. They should be finely ground so as to prevent the introduction of foul weeds on the farm. During recent years, mustard seeds have been removed from wheat screenings and sold as a separate product, the oil which they contain being extracted and used commercially.

4I6. Linseed Meal. - When the oil is extracted from flaxseed, linseed cake is obtained which, when ground, forms linseed meal. Linseed meal should contain 35 per cent crude protein. The darker-colored meals are 
those which contain most oil. Linseed meal is a concentrated nitrogenous animal food and is valuable for feeding all kinds of farm animals. It should be combined with other foods. Linseed meal is occasionally adulterated with flax screenings. Hence, if adulteration is suspected, the cake itself may be purchased and ground. The cake is not adulterated because weed seeds and impurities must be removed in order to produce a good quality of oil. When the oil is removed from the flaxseed by naphtha and other chemicals, the product is called "new process linseed meal," which differs from pressure process meal by having the oil more thoroughly extracted and by containing a larger amount of crude protein. There is but little new process meal found on the market.

4I7. Cottonseed Cake and Meal, obtained from cottonseed after removal of the hulls and extraction of the oil, are concentrated nitrogenous foods. The meal is lemon-yellow in color and is characteristically rich in crude protein and ether extract. It contains somewhat more crude protein than linseed meal. Cottonseed meal is a concentrated nitrogenous food and can be fed, when properly combined with other foods, to sheep and beef and dairy animals. It cannot safely be fed in large amounts nor for a long period to swine. When used in a dairy ration as the principal food, it influences the character of the butter fat, producing butter with a high melting point.

4I8. Oat Feed is a product obtained in the manufacture of oatmeal. It is variable in composition and consists of light-weight oats mixed with oat clippings. Oat hulls have about the same composition and feeding value as oat straw, and are frequently used for the adulteration of animal foods. In the purchase and use of oat feeds, 
particular attention should be given to their composition. High-grade oat feed is valuable, but when it contains any appreciable amount of hulls, the food value is proportionally lessened.

4I9. Gluten Meal is a by-product obtained in the manufacture of glucose. Soaked corn is broken open and the germ is liberated and floated off with water. The oil from the germ is extracted and the germ cake sold as a commercial product or used for mixing with other foods. The starch and gluten of the corn are separated by mechanical means. The starch being heavier separates and settles. The gluten product is dried, ground, and sold as gluten meal, which usually has about 35 per cent of protein and 3 per cent of fat. Gluten feed contains the corn hulls or bran along with the gluten meal. The hulls reduce the proportion of protein. Gluten feed usually contains about 25 per cent of crude protein, but is variable in composition.

420. Malt Sprouts. - When barley is subjected to the malting process, germination takes place, which results in changing the starch to maltose. The plantlets or sprouts are removed, dried, and sold as malt sprouts. They are nitrogenous in character and contain about 22 per cent of crude protein, the larger portion of which is in soluble form. Malt sprouts are valuable for feeding sheep and beef and dairy stock.

42r. Miscellaneous By-products. - There are a large number of miscellaneous by-products used for feeding animals as rye bran, buckwheat middlings, palm-nut meal, hominy chops, etc. Their composition and general feeding value may be noted from the table of analyses at the close of the chapter.

422. Inspection of Feeding Stuffs. - During recent 
years, many of the states have passed laws regulating the inspection and sale of animal feeding stuffs. The object of such laws is to prevent adulteration of animal foods by requiring manufacturers and dealers to guarantee the percentage amounts of crude protein and fat. Many of the European countries have had such laws in force for a number of years. It is noticeable that in those countries and states where feeding stuffs are subjected to inspection, the quality is better than where they are not inspected. The national pure food law is applicable to animal foods in that it requires all foods to properly correspond with their labels so that the purchaser may know what he buys.

Experiment 73. - Graphic composition of foods. Make a drawing of some human or animal food material and indicate graphically the percentage amount of the different nutrients. If a hundred millimeter rule is used in the construction of the drawing, each
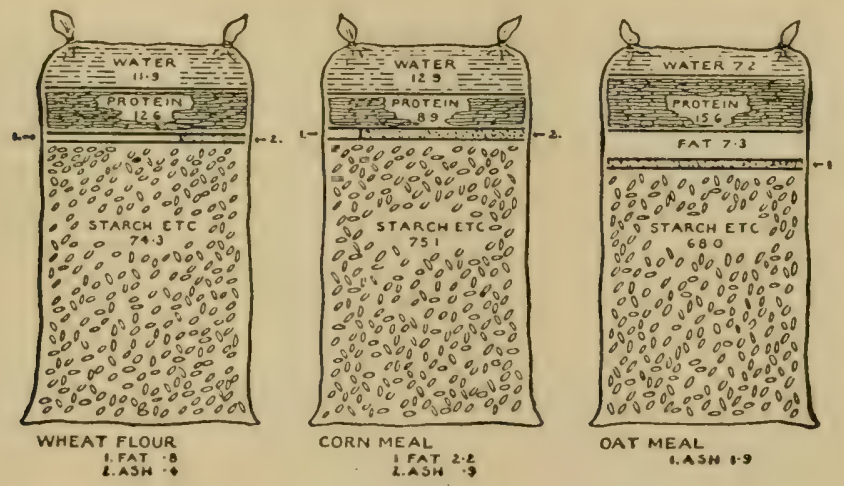

FIG, 91. - Graphic composition of foods.

linear millimeter will correspond to $\mathrm{I}$ per cent. If a food contains I 2 per cent water, 12 millimeters are measured off to represent the water in the material, and so for each class of nutrients an area corresponding to its percentage amount. 
Composition of Mill and By-products.

Linseed meal (old process). . 9.20

Linseed meal (new process) . ro.Io

Cottonseed meal......... 8.20

Malt sprouts.......... 10.20

Corn and cob meal........ I5.10

Gluten meal. ............. 9.60

Gulten feed........... 7.80

Oat feed............ 7.70

Oat hulls. $7 \cdot 30$

Sugar-beet pulp ${ }^{1} \ldots \ldots \ldots .88 .53$

Rye bran.

II. 60

Buckwheat middlings..... I 3.20

Palm-nut meal. ........ 8.30

Hominy chops............ II.IO

Apple pomace.......... 76.70

Wheat feed............ I 2.00

Wheat feeding flour (red

$\operatorname{dog}) \ldots \ldots \ldots \ldots \ldots$. I 2.00

Wheat bran, winter....... I 2.30

Wheat bran, spring ....... II.5O

Wheat shorts........... II.80

Wheat screenings......... Ir.60

Meat scrap........... I.33

Wheat flour (Minn.) . . . . . I I.90

Corn meal ............. I5.10

Corn flour. ........... I 2.57

Buckwheat flour......... I 4.60

Oatmeal............ 7.90

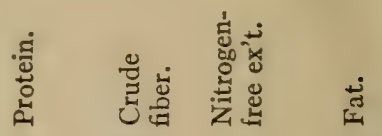

Per Per Per Per cent. cent. cent. cent. $\begin{array}{lllll}5.70 & 32.90 & 8.90 & 35.40 & 7.90\end{array}$

$\begin{array}{llllll}5.80 & 33.20 & 9.50 & 38.40 & 3.00\end{array}$

$\begin{array}{llllll}7.20 & 42.30 & 5.60 & 23.60 & \text { I3.10 }\end{array}$

$\begin{array}{llllll}5.70 & 23.20 & 10.70 & 48.50 & \text { I.70 }\end{array}$

$\begin{array}{llllll}I .50 & 8.50 & 6.60 & 64.80 & 3.50\end{array}$

$\begin{array}{llllll}0.70 & 29.40 & \text { I.60 } & 52.40 & 6.30\end{array}$

$\begin{array}{llllll}\text { I. } 10 & 24.00 & 5.30 & 51.20 & 10.60\end{array}$

$\begin{array}{lllll}3.70 & 16.00 & 6.10 & 59.40 & 7.10\end{array}$

$\begin{array}{llllll}6.70 & 3.30 & 29.70 & 52.10 & 1.00\end{array}$

$\begin{array}{llllll}4.85 & 9.45 & 22.40 & 62.62 & 0.68\end{array}$

$\begin{array}{llllll}3.60 & 14.70 & 3.50 & 63.80 & 2.80\end{array}$

$\begin{array}{llllll}4.80 & 28.90 & 4.10 & 41.90 & 7.10\end{array}$

$\begin{array}{llllll}3.70 & 14.40 & 21.40 & 38.90 & \text { I } 3.30\end{array}$

$\begin{array}{lllll}2.50 & 9.80 & 3.80 & 64.50 & 8.30\end{array}$

$\begin{array}{llllll}0.50 & 1.40 & 3.90 & \mathbf{1} 6.20 & \text { I.30 }\end{array}$

$\begin{array}{lllll}4.00 \quad & 16.00 \quad 8.00 \quad 55.00 \quad 5.00\end{array}$

$\begin{array}{lllll}3.00 & \text { I } 7.00 \quad 3.00 \quad 59.00 & 6.00\end{array}$

$\begin{array}{llllll}5.90 & 16.00 & 8.10 & 53.70 & 4.00\end{array}$

$\begin{array}{llllll}5.40 & \text { I6.10 } & 8.00 & 54.50 & 4.50\end{array}$

$\begin{array}{llllll}4.60 & 14.90 & 7.40 & 56.80 & 4.50\end{array}$

$\begin{array}{llllll}2.90 & \mathrm{I} 2.50 & 4.90 & 65.10 & 3.00\end{array}$

$\begin{array}{llllll}8.03 & 57.69 & \ldots & \ldots & 32.95\end{array}$

$\begin{array}{llllll}0.40 & \mathrm{I} 2.60 & \ldots & 74.30 & 0.80\end{array}$

$\begin{array}{lllll}1.40 & 9.20 & \text { I.90 } & 68.70 & 3.80\end{array}$

$\begin{array}{lllll}0.61 & 7.13 & 0.87 & 78.36 & \text { I.33 }\end{array}$

$\begin{array}{llllll}\text { I.00 } & 6.90 & 0.30 & 75.80 & \text { I.40 }\end{array}$

$\begin{array}{llllll}2.00 & 14.70 & 0.90 & 67.40 & 7.10\end{array}$

${ }^{1}$ Dry matter basis. 


\section{CHAPTER XXXIII}

Roots, Tubers, and Fruits

423. General Composition. - Roots, tubers, and fruits contain much water and but little dry matter. The dry matter is mainly non-nitrogenous compounds, as starch and sugar. All contain some nitrogenous compounds, of which the larger portion are amides and non-proteid forms. Mineral forms of nitrogen, as traces of nitrates and nitrites, are usually present. Organic acids in small amounts and essential oils are characteristic features.

424. Potatoes contain about 75 per cent of water. The dry matter is largely starch. About half of the nitrogen is present as proteids, of which the larger portion

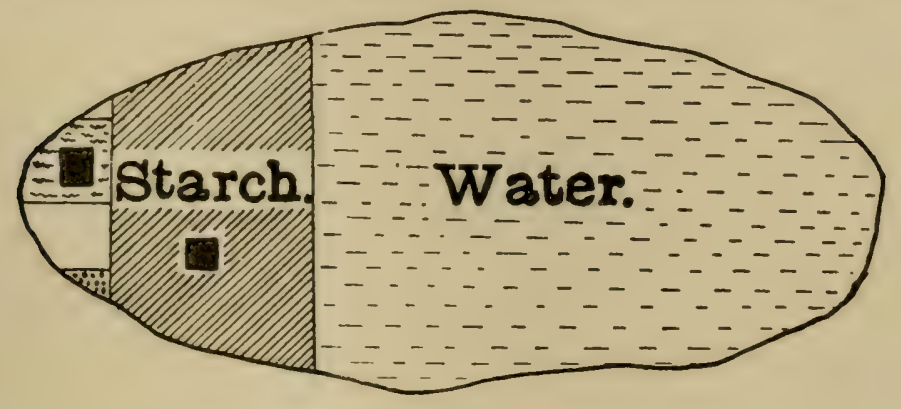

\section{Protein. Fat. Indigestible.}

FIG. 92.-Composition of potatoes.

is in the form of soluble albumin. The amount of fat is small, less than one tenth of one per cent. Potatoes contain tartaric and other organic acids, pectose substances, and other compounds in small amounts, and little 
cellulose. When potatoes are stored for any length of time and fermentation takes place, a portion of the starch is converted into glucose. In storing them, a low temperature and good ventilation are necessary to prevent fermentation. Potatoes are a concentrated, non-nitrogenous food.

425. Carrots contain approximately the same amount of water as milk, viz., 87 per cent, and about half as

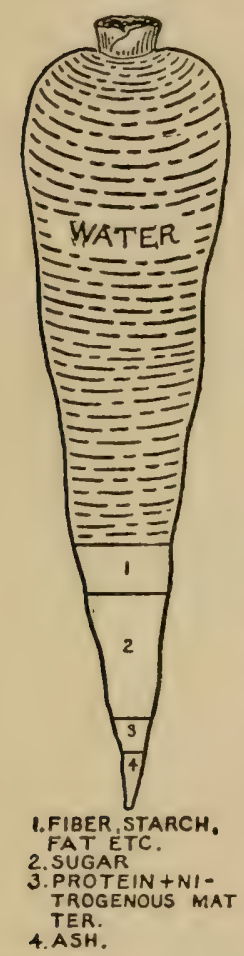

FIG. 93.-Composition of carrots. much dry matter as potatoes. The I 2 per cent of dry matter is nearly half sugar, 3 per cent being fruit sugar and 3 per cent other sugars. There is 1.20 per cent of total nitrogenous compounds given as crude protein in tables of analyses, of which 40 per cent is protein. Carrots contain more fat than potatoes.

426. Parsnips contain more dry matter than carrots and have nearly the same amounts of nitrogenous compounds, fat, and fiber, but less sugar and more starch. They have about the same general food value as carrots.

427. Mangel wurzels have more water and less dry matter than carrots. The dry matter, however, is richer in nitrogenous compounds than that of carrots, parsnips, potatoes, or beets, which makes the mangels a better balanced food. The ro per cent of dry matter is a little more than half starch, and contains about I.40 per cent of crude protein, of which half is protein. Mangels also contain about I per cent each of ash and fiber and a small amount of fat. 428. Apples vary in composition with the variety and 
physical characteristics. They contain from ro to 16 per cent solids, of which 75 per cent is sugar or allied carbohydrates, and about half a per cent each is fat and protein. Among the organic acids, malic predominates. The flavor and special characteristics depend upon the relative amounts of the different sugars, as sucrose, levulose, and dextrose, and the organic acids and essential oils which the apples contain. It is these compounds which give individuality to apples.

429. Oranges contain from io to I 5 per cent of solid matter, the larger portion, 80 per cent, being sugar. The citric acid content ranges from I to 2.5 per cent in different varieties. The amounts of protein, fat, and fiber are small. The ash or mineral matter averages about one half per cent, and is composed mainly of potash and lime with smaller amounts of other compounds. The iron and sulfur content is generally larger than is ordinarily found in fruits. The physical composition of average oranges is as follows: rind, 20 to 30 per cent; pulp, 25 to 35 per cent; and juice, 35 to 50 per cent.

430. Lemons differ from oranges in containing more citric acid and less sucrose, levulose, and dextrose. The average composition of lemons is as follows:

Physical Composition.

Chemical Composition.

Per cent.

Per cent.

Rind............ 25 to 35 Io to I 2

Pulp............ 25 to 35

Juice........... 40 to 55

Solids

$\begin{array}{ll}\text { Sugar.............. } & 2 \text { to } 4 \\ \text { Citric acid..... } & 6 \text { to } 9\end{array}$

The ash of the lemon is somerwhat similar in composition to that of the orange, but is present in larger amount.

43I. Strawberries are characterized by containing a high per cent of water, 90 to 92 per cent. Sugar and 
malic acid are the materials present in largest amounts, while protein, fat, ash, fiber, coloring materials, and essential oils form but a small part of the composition. While strawberries are valuable as a food adjunct, they do not supply any appreciable amount of nutrients. It has been estimated that it would require 13 pounds of strawberries to furnish the carbohydrates needed for a daily ration, to say nothing of the protein, which would require 65 pounds additional. The malic and other acids are valuable because of their antiseptic properties which, added to the appearance and palatability, make strawberries a valuable food adjunct.

432. Grapes vary in composition according to variety. They contain from ${ }_{5} 5$ to 20 per cent of solid matter. In the juice is from Io to 15 per cent or more of sugar in the form of sucrose, levulose, and glucose. Tartaric acid is found in grapes more liberally than in other fruits, and ranges from I to I.5 per cent. There is very little fat and protein, and while grapes add some nutrients, as sugar, to a ration, they do not contribute any large amount. There is some food value, but it is not so high as is occasionally claimed for them. Their value, as is the case with other fruits, is in palatability, and indirectly aiding in digestion, and thus adding value to other foods.

433. Olives, when fully matured and fresh, contain about I 5 per cent of oil. When preserved green, there is considerably less. Olives also contain small amounts of other compounds and essential oils. Pure olive oil is a valuable food, but it is frequently adulterated with refined cottonseed and other vegetable oils. Olive oil is slightly laxative in character and assists mechanically in the digestion of foods by preventing compaction of feces in the intestines. 
434. Dried Fruit. - Many fruits are preserved by drying. Dried fruit has a somewhat different composition from fresh fruit because of chemical changes which occur during the drying process and the slight loss of volatile and essential oils. Dried fruits, when free from objectionable preservative agents, are valuable, and can be used to advantage when fresh fruits are not obtainable.

435. Miscellaneous Fruits. - Since the list of fruits that could be discussed is large, only a few examples have been considered. For additional information upon the subject, or for data upon fruits not given, the student is referred to the bulletins of the California Experiment Station.

436. Food Value. - If judged entirely on the basis of nutrients, many vegetables and fruits would be assigned a low place in the list of foods, as they contain comparatively small amounts. Most fruits are used in the dietary not so much with the view of supplying nutrients as for other purposes. The organic acids, essential oils, and soluble mineral compounds, together with the digestible form in which the nutrients are present, are factors which give fruits their unique value. The organic acids and essential oils impart palatability and assist functionally in the digestive process. Some fruits, as figs and prunes, contain chemical compounds which are laxative in character. In the human ration, fresh fruits are as essential, and occupy the same position, as roots and vegetables in animal rations. 


\title{
CHAPTER XXXIV
}

\author{
FERMENTATION
}

437. Insoluble Ferments. - Fermentation is a chemical change produced by a class of bodies called ferments. Insoluble or organized ferments are single-celled, microscopic plants which have a definite structure. Many of them are bacteria, low forms of plant life. Nearly all secrete definite chemical products capable of producing fermentation. The insoluble or organized ferments are composed mainly of nitrogenous compounds, but they also contain non-nitrogenous and mineral matter. Some, as the tubercular organism, contain cellulose.

438. Soluble Ferments or Enzymes. - Enzymes are organic compounds, secreted by cells, and have the ability to produce chemical changes. They are also called soluble ferments, and chemical ferments. There are a great many different kinds of soluble ferments, some of which, as diastase and maltase, act upon carbohydrates, while others, as pepsin and pancreatin, act upon proteid bodies. Enzymes produce chemical change without entering into the composition of the substance or giving up any of their own material to the reacting compounds. A small amount of diastase will change a large amount of starch to soluble forms without losing its power of action. The enzymes are all soluble in water and are precipitated with strong alcohol. Their action is not generally retarded by antiseptics and chemicals 
which are capable of destroying organized ferments. When seeds are soaked in water, the diastase and proteose enzymes are extracted, and if precipitated with alcohol and recovered, they appear as a light gray powder. An organized ferment is a low form of plant, while a soluble ferment is a chemical product.

439. Aërobic and Anaërobic Ferments. - Ferments which require oxygen for their existence are aërobic, while those which are capable of working in the absence of oxygen are anaërobic. The aërobic ferments produce carbon dioxid, water, ammonia, and hydrogen sulfid as final products, while the anaërobic ferments usually produce intermediate products as organic acids.

440. Conditions Necessary for Fermentation. - The conditions necessary for fermentation are: (I) moisture, (2) favorable temperature, (3) a ferment body, and (4) a fermentable substance. Moisture is necessary in order that the chemical changes may take place. During fermentation water frequently enters into the chemical reaction, as in hydration changes, and is also necessary as a medium of exchange for the chemical products during the reaction. The most favorable temperatures for fermentation are between $15^{\circ}$ and $60^{\circ} \mathrm{C}$. Below zero and above the boiling point of water, ferments are inactive. Certain ferments require a different temperature for activity than others, and some have greater resistance to the action of heat. A ferment body is always necessary in order to start the fermentation change, and in the absence of a ferment either organized or unorganized, no fermentation can take place. A fermentable substance, with the right kind of ferment to act upon it, is also requisite, as a ferment which acts upon one class of bodies is incapable, unaided, of acting upon others ; for example, 
the peptic ferment is incapable of changing starch to soluble forms. When a substance is freed from all ferments and is protected from outside sources of contamination, it is in a sterile condition. Many forms of fermentation are produced by the spores of organized ferments gaining access to a material along with dust particles carried in the air. In the preservation of food, a knowledge of the conditions requisite for fermentation is made use of. The products formed by ferments are numerous, as there are ferment bodies capable of acting upon all forms of organic matter. Some of the ferments assist in the digestion of food and in the preparation of food products, while others take an important part in everyday life affairs, and in agriculture, as in the liberation of plant food. The growth of plants, the preparation of foods, their digestion, and the manufacture of food products all depend largely upon fermentation.

44r. Soil Ferments. - In the growth of plants, ferments take an important part, both in the preparation of the plant food and in the chemical changes which occur within the plant. Disintegration of the mineral food of the soil is assisted by ferment action. The nitrogenous food of the plant is prepared in the soil by ferments. The subject of soil ferments is bricfly considered in "Soils and Fertilizers."

442. Ferments in Seeds. - In the seeds of plants, particularly matured grains, there are a number of ferments which take an important part in the process of germination. These ferments change the insoluble nitrogenous and non-nitrogenous compounds to soluble forms, which are utilized by the young plant as food. If a seed were deprived of all of its soluble ferments, it would fail to germinate. 
Experiment 74. - Action of malt on starch. Crush in a mortar twenty malted barley kernels, transfer to a test tube, and add $\mathrm{x}_{5}$ cc. water. After twenty-four hours, filter off the solution, and add it to a flask containing 2 grams of flour and roo cc. water. Place the flask in the desk for twenty-four hours; then filter off the solution and test a portion for starch with iodin, as in Experiment 45 . Test another portion for glucose with Fehling's solution, as in Experiment 48.

Questions. - (1) What is malted barley? (2) What did the water extract from the barley contain? (3) What effect did this extract have upon the flour? (4) What did the tests with iodin and Fehling's solution show? (5) Would flour treated with water instead of malt extract give the same result?

443. Ferments in Bread-making. - - The yeast plant employed in bread-making secretes a number of soluble ferments which produce the desired chemical changes. The yeast plant requires as food, sugar or other soluble carbohydrates, mineral matter rich in phosphates, and available nitrogen rich in peptones, which are all present in grains. Yeast secretes diastase, alcoholic and acidyielding ferments. The diastase ferment changes the starch to soluble forms, the alcoholic ferment produces alcohol and carbon dioxid gas, which expand the dough and make the bread light, and acid ferments produce acids, which combine with the gluten proteids and modify their character. In short, bread-making is a series of chemical changes induced by soluble ferments.

Experiment 75. - Alcoholic fermentation. Weigh ro grams of flour into a flask, add $50 \mathrm{cc}$. water and a small piece of yeast (one tenth of a cake). Connect the flask by means of a delivery tube with the Woulff bottle containing enough clear lime water to cover the end of the tube. Place the flask on a warm sand bath, below $85^{\circ} \mathrm{F}$, for half an hour. Observe the bubbles of gas given off and the precipitate formed in the lime water. Do not overheat the sand bath. 
Questions. - (I) What is yeast and what does it contain? (2) What caused the gas to be given off? (3) From what was the gas formed? (4) Write the reaction with $\mathrm{Ca}(\mathrm{OH})_{2}$. (5) What becomes of the alcohol?

444. Ferment Action and Food Digestion. - The digestion of food is carried on largely by the soluble ferments. The digestive tract secretes a number of these, which act upon the insoluble nutrients and change them to soluble forms. In fact, the digestion of food is dependent upon the action of the different ferments in the digestive tract, as ptyalin in the saliva, pepsin in the stomach, pancreatin in the duodenum, and diastase and other ferments in the intestines.

445. Ferments and Food Preservation. - Preservation of food is dependent upon prevention of ferment action. The low temperature of cold storage is unfavorable to the development of ferments. Sterilization is likewise unfavorable. By means of heat, cold storage, chemicals, and protection from the spores in the air, perishable food products are preserved. Some ferments, however, are not destroyed by either high or low temperatures.

446. Ferments in Butter- and Cheese-making. - The processes of butter- and chcese-making are carried on with the aid of ferments. Milk contains enzymes or soluble ferments and, to a limited extent, is itself capable of acting as a digestive fluid. The ripening of cream is the result of the action of the lactic acid ferment which changes the lactose (milk sugar) into lactic acid. In cheese-making, the rennet used for coagulating the milk contains a number of ferments which take an important part in the process. The flavor and odor of butter as well as of cheese are the results of ferment action. In butter-and cheese-making, it is the object to control the 
action of the desirable ferments and to prevent the undesirable ones from developing. Ropy milk, red spots in cheese, and floating curds in cheese-making are all caused by fermentation. Butyric acid, one of the products found in foul milk and butter, is caused by the butyric acid ferment. Milk is exceedingly susceptible to the action of ferments.

Experiment $76 .-$ Lactic fermentation. Place 5 grams milk sugar, roo ce. water, 5 ce. slim milk, and two or three crystals of sodium phosphate in a flask. Leave the flask uncorked in the desk for twenty-four hours. Then add a few drops of phenolphthalein indicator, and determine the amount of lactic acid. I cc. alkali $=$ 0.009 gram acid.

Questions. - ( I) Why was milk used in this experiment? (2) What was produced from the milk sugar? (3) Why was sodium phosphate used? (4) How much acid was produced ?

447. Disease-producing Organisms. - Many diseases are caused by the action of microörganisms. The disease-producing organisms or bacteria invade the body and rapidly multiply, living upon the fluids and tissues of the body and producing poisonous products. Typhoid fever, smallpox, diphtheria, tuberculosis, cholera, and many other diseases are caused by specific bacteria. The products resulting from the action of the organism are poisonous, and death is often caused by these toxic bodies, and sometimes by the organisms' action upon the body tissues. The chemical products of organisms, when they accumulate, destroy the bodies which produce them, hence in combating some diseases these products, known as antitoxins, are used. Modern methods of sanitation are based upon the destruction of diseaseproducing organisms.

448. Beneficial Organisms. - While many discases are 
caused by microörganisms, not all microörganisms or bacteria are injurious. In nearly all foods there are large numbers of bacteria which are of a harmless nature. Some are valuable and beneficial to man, particularly those which assist in plant nutrition and in the preparation and digestion of foods. 


\section{CHAPTER XXXV}

\section{Chemistry of Digestion and Nutrition}

449. Digestion, a Biochemical Process. - In the digestion of food, the enzymes or soluble ferments take an important part. Although digestion is not well understood, it is known to be largely a chemical process brought about by ferment action, and hence is called a biochemical process. The cells in the different parts of the digestive tract secrete chemical products which produce chemical changes in the food, rendering it soluble so that the various nutrients can be absorbed and used by the body. Any compound which is capable of undergoing digestion and being utilized for food purposes is called a nutrient. The value of any food depends upon the kinds and amounts of its nutrients. During the process of digestion, a complex series of chemical changes take place, and as a result of digestion and of assimilation of food by the body, heat and energy are produced.

450. Digestion Experiments. - The digestibility of a food is determined by a digestion experiment. The percentage amount of a nutrient which is digested is called the coefficient of digestibility. Not all of the nutrients in foods are alike digestible. In clover hay, for example, 65 per cent of the organic matter is digested, while only 30 per cent of the crude fiber and 70 per cent of the nitrogen-free extract compounds are digested. Each compound has its own digestion coefficient. In order to determine the digestibility of a food, an animal 
is fed, for a number of days, a weighed amount of food which is analyzed. All of the feces or solid excrements produced during the experimental period are collected, reighed, and analyzed. After the food has undergone the process of digestion, the undigested portions, along with a small amount of digested products, are excreted as feces, while the liquid wastes of the body contain the products of the digested food. From the weight of the food consumed, and its analysis, the amount of each class of nutrients consumed is determined. From the dry matter of the feces, the undigested nutrients are likewise determined. The undigested nutrients subtracted from the total nutrients in the food consumed gire the amounts digested, which are calculated on a percentage basis. In the case of clover hay, an animal may consume 28 pounds per day, containing I 2 per cent protein; this is equivalent to 3.36 pounds of protein $(2 S \times 0.12=3.36)$. An account is opened with the animal, in which a charge for 3.3 pounds of protein is entered. From the $2 S$ pounds of food, 40 pounds of feces or excrements are obtained, as a large amount of water is added during the process of digestion. The feces, which are composed largely of the indigestible portions of the food, are analyzed and found to contain 20 per cent of dry matter; this is equiralent to $S$ pounds of indigestible matter yielded by the 28 pounds of clorer $(40 \times 0.20$ $=S)$. The dry matter is analyzed and found to contain I 5 per cent of the protein; this is equivalent to I. 2 pounds of protein $(8 \times 0.15=1.2)$. The animal is charged with 3.36 pounds of total protein; I.2 pounds are found to be indigestible, leaving a balance of 2.I 6 pounds of digestible protein, equivalent to 64 per cent of the total $(2.16 \div 3.36 \times 100=64)$. Sixty-four is the digestion 
coefficient of the crude protein in this clover hay. In like manner, the digestion coefficients of all the nutrients are determined.

Exumple. - From the following figures, calculate the digestion coefficients of the organic matter, ether extract, crude fiber, and nitrogen-free extract of the clover hay. The figures for the composition of clover hay are on the basis of the food as fed, while those for the feces are on the basis of the dry matter.

\section{COMPOSITION OP \\ Clover.}

(Hay as fed.)

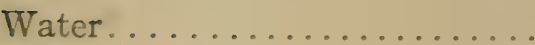

Ash.

Ether extract

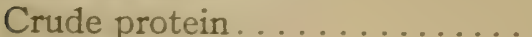

Crude fiber.

Nitrogen-free extract
10.00

6.90

3.10

I 2.00

26.00

42.00
CoMposmion of

Feces.

(Dry matter.)

$9 \cdot 50$

2.10

15.00

30.00

43.40

45I. Caloric Value of Foods. - During the process of digestion, heat is produced in proportion to the calories contained in the food and the nutrients digested. By the caloric value of a food is meant the amount of heat measured in calories which the food yields. A calorie is the amount of heat required to raise I kilogram of water $\mathrm{I}^{\circ} \mathrm{C}$. or I pound of water about $4^{\circ} \mathrm{F}$. The caloric value of a food is determined by means of the calorimeter (Fig. 94). The calorimeter consists of a steel bomb in a metal cylinder $(\mathrm{Q})$ (Fig. 95). The bomb is surrounded by water as indicated in the illustration, and the cylinder containing the bomb and water is placed within a doublewalled fiber receptacle ( $\mathrm{T}$ and $\mathrm{U}$ ). The bomb itself consists of three parts: the cylinder, which is lined with platinum, the corer, and a collar to hold the corer in place and tightly seal the bomb. These three parts of the apparatus are shown in Fig. 96. 
The principle involved in determining the caloric value of a food is simple. A weighed amount of the substance

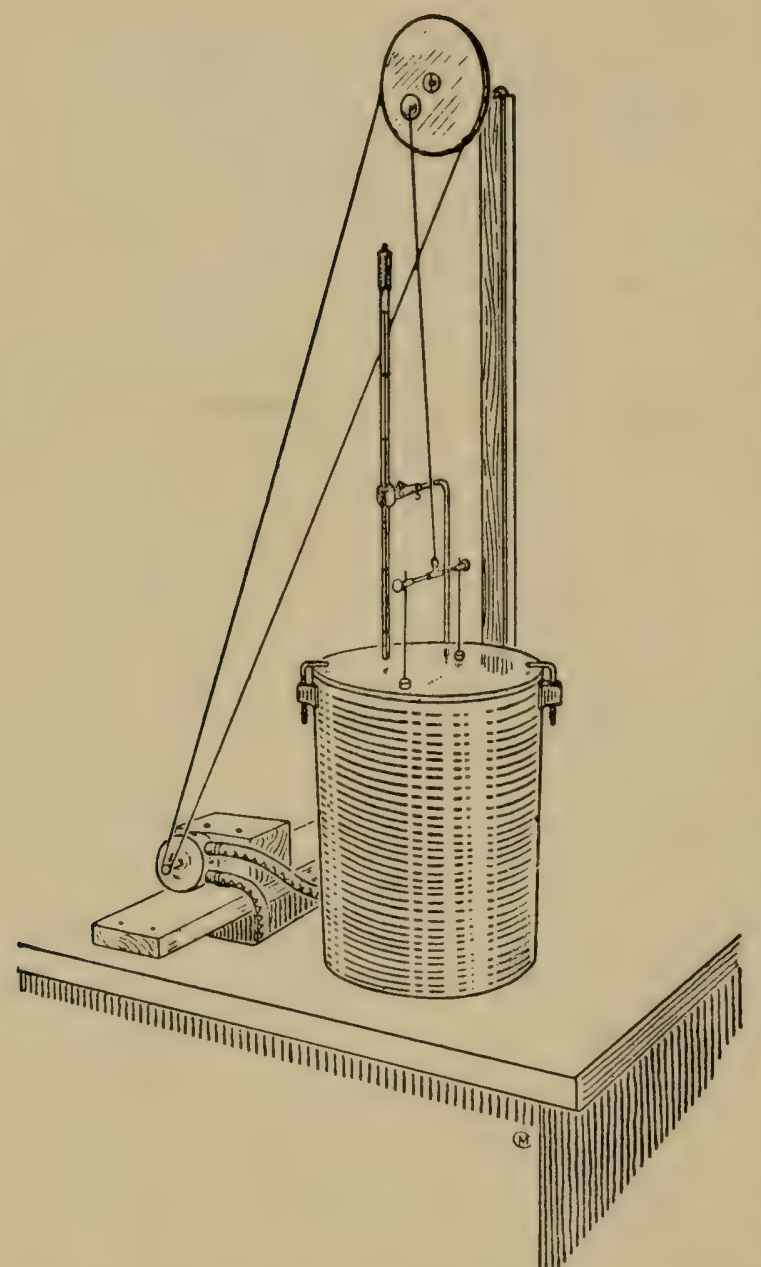

FIG. 94. - Bomb calorimeter used for determining the caloric or heat-producing value of foods. is burned in the calorimeter and the rise in temperature of the water that surrounds the bomb is noted. The combustion is carried on in oxygen so as to be complete, and all means possible are employed to secure accuracy of results. The substance to be burned, if it is a material like flour, is made into a pellet by means of a press, so that it may form a compact mass and burn evenly and not be scattered about in the calorimeter cylinder and be only partially burned. The pellet is placed in the small platinum crucible O (Fig. 95). This crucible is supported by platinum wires attached to the cover of the calorimeter. Above the crucible a small coil of fine iron wire 


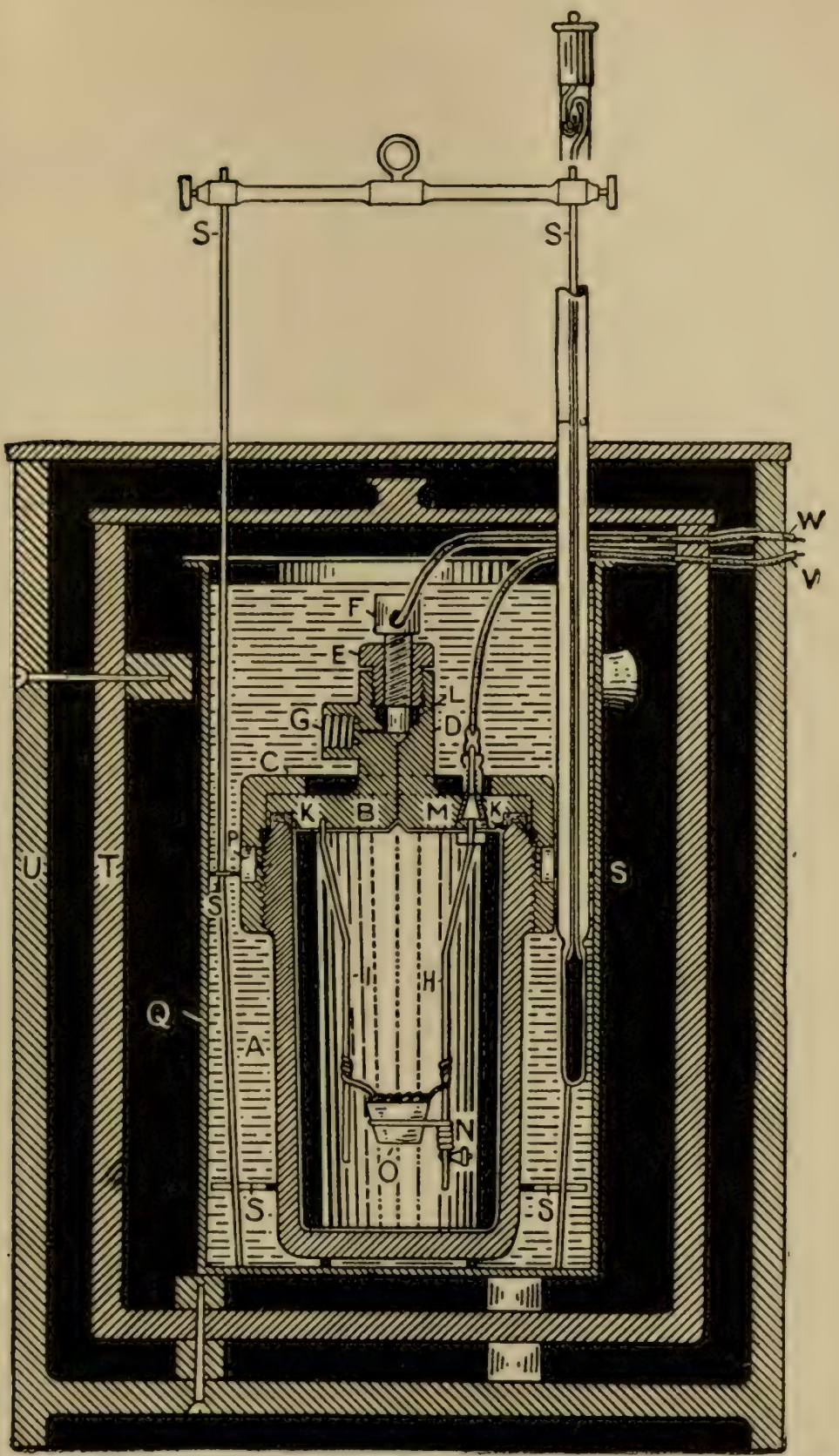

FIG. 95. - Bomb calorimeter, showing interior structure and working parts. Atwater, Conn. (Storrs) Agr. Expt. Station, Annual Report, I897. 
is stretched from the platinum wires. The cover is screwed tightly upon the cylinder of the bomb and oxygen is admitted from an oxygen tank through valve $\mathrm{G}$ of the cover until a pressure of twenty atmospheres is secured, when the valve is securely closed. The bomb, with the substance to be burned, and charged with oxygen, is placed in the metal cylinder $Q$, which contains a definite amount of water, the temperature of which is carefully determined by means of a thermometer that reads to $0.005^{\circ} \mathrm{C}$. The water is kept at an even temperature by means of the metal stirrer SS, operated by a motor. Connection is made with a storage battery which ignites the small iron wire that is suspended above the substance. The burning wire falls upon and ignites the material in the platinum crucible $\mathrm{O}$ and the heat from the combustion of the material raises the temperature of the water in the calorimeter cylinder. A number of readings are taken so as to secure the actual rise in temperature, caused by the combustion of the substance. Due allowances are made for the heat contributed by the combustion of the iron wire, the heat absorbed by the steel bomb, and for other factors that are known and under control.

The approximate amount of energy which a food will yield can be determined by the use of the following factors: ether extract 4225 , and fiber, nitrogen-free extract, and crude protein 1860 . These are the numbers of calories which a pound of each of the nutrients yields.

452. Available Energy of Foods. - Since only a portion of the nutrients of foods is digestible, not all of the total caloric value is rendered available to the body. The digestion process is more complete with non-nitrogenous compounds than with the proteids. The final products of oxidation in the case of starch, sugar, and digestible 


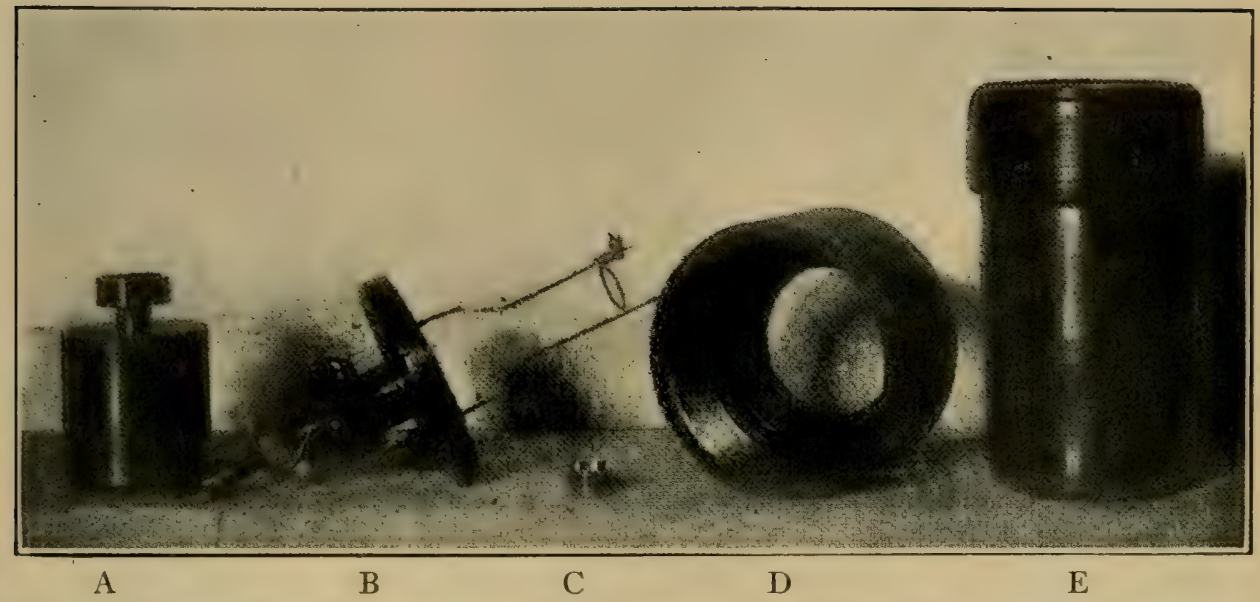

FIG. 96. - Parts of bomb calorimeter and accessories: A, pellet mold; B, cover to bomb; C, platinum dish, holding substance burned; D, collar; E, steel bomb - platinum-lined. 

carbohydrates are carbon dioxid and water. These compounds undergo complete combustion. The final products of digestion of the proteids are amides, the larger portion of which is excreted as urea in the liquid waste. This compound, urea, $\mathrm{CH}_{4} \mathrm{~N}_{2} \mathrm{O}$, does not undergo complete oxidation in the body. If burned in the calorimeter, it would yield an additional amount of heat. The term available energy of a food means simply the energy available to the body and measured in calories. The available energy is obtained by deducting from the total digestible energy the calories from the residue product, as urea, which are not completely oxidized. In the determination of the available energy of foods, the principle is the same as explained in the section relating to the digestibility of nutrients. The total number of calories in a food is determined by the calorimeter; the number of calories in the feces is likewise determined and deducted from the total, as well as the caloric value

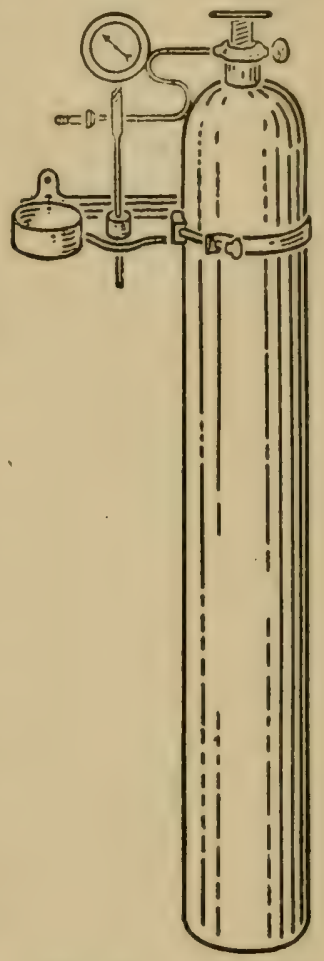

FIG. 97. - Oxygen tank and pressure gauge for charging the bomb. of the liquid excrements containing urea. This gives the energy of the food which is available to the animal.

453. Net Energy of Foods. - In the process of digestion, particularly of coarse fodders which contain much crude fiber, energy varying with the density of the tissue is required to render the food available to the body. Of the total available energy, a portion, and in some cases, a large amount, is used in rendering the food available; 
that is, in carrying on the process of digestion. Means have been devised whereby the approximate amount of work required on the part of the animal to render the food available can be determined. When the energy used in this way is deducted, it leaves the net energy. In the case of coarse fodders, a considerable portion of the energy is used in the digestion of the food, leaving, in some cases, only comparatively little net energy. Less force is required to digest the grains, and thus a larger amount of energy is available to the body. A knowledge of the total, available, and net energy which different foods produce is important, because one of the objects of foods is to supply nutrients for the production of energy.

454. Digestion of Proteids. - The insoluble proteids are acted upon by the pepsin ferment secreted by the gastric juice in the stomach of animals. Peptones are produced by this action. Proteids which escape the action of the peptic ferment are later brought into contact with the tryptic ferment in the pancreas and lower parts of the digestive tract. This ferment acts in an alkaline solution, while pepsin requires one slightly acid in character. The proteids which fail to be digested by either the peptic or tryptic ferments are usually expelled as undigested proteids. In normal digestion, the fluids of the stomach are slightly acid, while those of the pancreas and intestines are alkaline. For the formation of acids and alkalies, sodium chlorid is essential. From this compound, hydrochloric acid, present in the gastric juice, is formed, also the alkaline products in the biliary and other fluids. Sodium chlorid is a normal constituent of the blood and of many of the vital fluids of the body.

After serving various purposes in the body, as noted in Section 305, the proteids are expelled as amides in 
either the solid or the liquid excrements, the larger portion being in the form of urea. From the time the proteids are acted upon by the soluble ferments in the digestive tract until their products are expelled from the body as amides, a large number of intermediate substances are formed. Should the proteids fail to undergo normal digestion, poisonous products, called ptomaines, are produced.

455. Digestion of the Carbohydrates. - Digestion of the carbohydrates begins with the ptyalin ferment of the saliva. Carbohydrate digestion takes place mainly in the lower part of the digestive tract, where diastase and other ferment bodies are secreted which change the insoluble carbohydrates to soluble forms. When completely digested, carbon dioxid and water are the final products. Between the soluble carbohydrates formed by the diastase and other ferments, and the final products of oxidation, carbon dioxid and water, a large number of intermediate products are formed. Glycogen is one of these bodies, and is a carbohydrate present in small amounts in the blood, but stored up largely in the liver. The process of carbohydrate digestion is one in which the soluble ferments take an important part, changing the insoluble compounds to soluble and assimilable forms.

456. Digestion of Fats. - Bile and the intestinal fluids are the main factors which assist in the digestion of fats. After emulsion or separation into fine particles, the fats are changed to glycerin and fatty acids by the action of a ferment body. They are then absorbed, and undergo slow oxidation, whereby carbohydrate-like bodies are produced. These products then undergo the same general changes as the carbohydrates.

457. Oxygen Necessary for Digestion. - In order that 
digestion may proceed in a normal way, a liberal supply of air is necessary to oxidize the nutrients and to prevent the formation of poisonous waste products in the body. In the absence of a liberal supply of air, normal digestion fails to take place. Oxygen is equally as important as protein, fat, carbohydrates, and water.

458. Factors Influencing Digestion. - There are a number of factors which influence the completeness of the process of digestion. Some of these factors are: (I) mechanical condition of the food, (2) combination of foods, (3) amount of food consumed, (4) palatability of the food, and (5) individuality of the animal. A digestion coefficient is a variable factor capable of being influenced by these and other conditions.

459. Mechanical Conditions. - The mechanical condition of ' a food, as fineness of division and density of particles, materially influences digestion. As a general rule, the finer the division, the more complete is the digestion. For example, experiments with pigs show that wheat meal is ro per cent more digestible than whole wheat. Experiments with other animals, recorded in Bulletin No. 77, U. S. Department of Agriculture, Office of Experiment Stations, giving the digestibility of American feeding stuffs, show equally large differences. The finer the division of the particles, the larger is the surface exposed to the action of the digestive fluids. The density of a material also influences its digestibility. Many foods contain a fair amount of nutrients, but their mechanical condition is such that the nutrients are not easily rendered available because of the presence of a large amount of cellulose inclosing and protecting the nutrients, and as a result, digestion and assimilation fail to take place. This is particularly true of many coarse fodders, as timothy 
hay and clover when allowed to become overripe and fibrous. Digestion experiments with such forage, and with that cut in early bloom, show that when cut in early bloom, it is more digestible than when overripe and woody. In the case of human foods also, fineness of division of the particles favorably affects the completeness of the digestion process. Graham or coarsely granulated flour, although it contains more nutrients, is less digestible and furnishes less total available nutrients than finely granulated flour. The advisability of grinding animal foods depends entirely upon the cost of the grinding. Where it can be done on the farm at slight expense, it invariably pays to grind grains, particularly wheat, barley, millet, and others which have a hard seed coat. In the feeding of coarse fodders, their mechanical condition is an important factor. When shredded corn fodder is fed, less energy is required on the part of the animal to render the nutrients available. This results in the return of a larger amount of net energy from the food.

46o. Combination of Foods. - The way in which a food is combined and fed in a ration influences its digestibility. When foods are fed singly, they are not as completely digested as when fed in a well-balanced ration. For example, experiments show that corn alone when fed to pigs is not as completely digested as when combined with shorts and other foods. Some foods assist in the digestion of other foods. Whenever milk is added to the ration for pigs, a larger amount of pork is secured than when the same amount of nutrients in other form is added. The milk assists in the digestion of the grains with which it is combined. Exact experiments to show the full extent to which one food influences the digesti- 
bility of another have not as yet been made. In the feeding of farm animals, however, the practical results which have been obtained show that this is an important factor.

46r. Amount of Food Consumed. - In human digestion experiments, results show that too large an amount of food is not so completely digested as a smaller amount. With farm animals, the experiments have not been so decisive. In some cases, large rations have been digested as completely as smaller ones. This is undoubtedly due to individual differences of animals. Excessive amounts of foods, however, have a tendency to interfere with normal digestion, and the results are not so satisfactory as when medium rations are fed.

462. Palatability. - In order to obtain the best results, the food should be relished by the animals. Palatability exerts a favorable influence upon digestibility and also upon the returns in animal products. Overripe and fibrous fodders generally lack palatability, because in the later stages of growth there is a smaller amount of the essential oils and other products that impart palatability. Mechanical condition and palatability of coarse fodders are closely associated, and the highest degree of digestibility of grains and fodders usually accompanies the best mechanical condition.

463. Individuality. - When a number of animals are fed the same ration, individual differences are observed. Some animals are capable of digesting all foods more completely than are others, and some can digest one food more completely than another food. This is due to individuality in digestive power and is particularly noticeable in experiments with sheep, where it has been found that all do not digest the different foods equally well. Also, 
digestion coefficients obtained in experiments with one kind of animal, as sheep, are not always applicable to other animals. Experiments with swine show that fiber is not so completely digested as with sheep or cows.

464. Miscellaneous Factors Influencing Digestibility. - Experiments in cooking foods for animals show that cooked foods are no more completely digested by farm animals than uncooked foods. Cooking, however, is sometimes desirable in order to encourage animals to consume a larger amount of food. The wetting of food, causing fermentation, has been found to be slightly beneficial. However, if wetting is practiced, great care should be exercised to prevent excessive fermentation or the action of undesirable ferments. Drying and curing of fodders do not appear to exert any unfavorable influence upon digestibility, provided leaching and excessive bleaching are avoided. Green fodders, as a rule, appear to be slightly more digestible than cured fodders. In some cases, the laxative nature of a food prevents complete absorption of the nutrients before the material is expelled from the body.

465. Application of Digestion Coefficients. - Too close application of digestion coefficients should not be made, but general comparisons where the experiments have been performed under similar conditions are allowable and give valuable results. The methods used for the determination of digestion coefficients have not been perfected, and a number of sources of minor error are introduced. In the case of the feces, the ether extract contains bile nitrogen, cleavage products, and a number of other non-fatty compounds. Hence the figures for the digestibility of the ether extract are invariably too low. Not all of the nitrogen of the feces is in indigestible form, 
thus there is a tendency for the digestibility of the crude protein to be too low. Then, too, it is difficult to assign an absolute nitrogen factor for the determination of the crude protein. Notwithstanding these known imperfections in determining the digestibility of foods, the general results are of great value to the farmer, as they indicate ways by which the largest returns, due to the highest degree of digestibility, can be secured. Some of the digestion coefficients of the more common food materials are given in the following table, which is taken from Bulletin No. 77, U. S. Department of Agriculture, Office of Experiment Stations:

\section{Digestion Coefficients.}

Green Fodders.

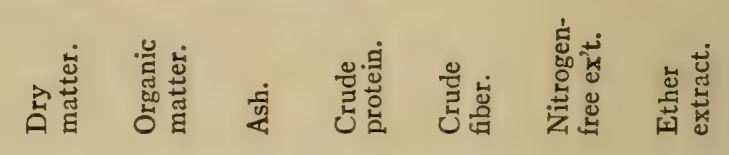

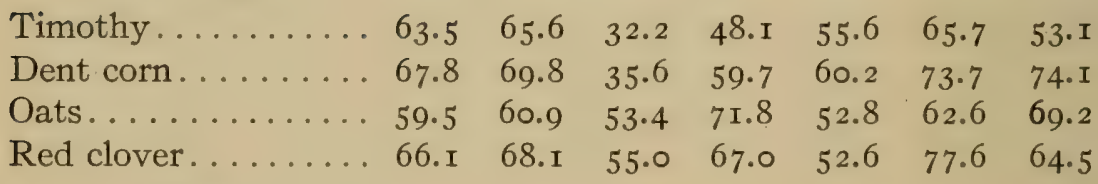

\section{Silage.}

$\begin{array}{llllllll}\text { Dent corn silage. . . . } & 65.1 & 67.1 & 32.2 & 48.3 & 66.7 & 68.6 & 80.0\end{array}$ $\begin{array}{lllllllllll}\text { Flint “ “ } & \ldots & \ldots & 73 . \mathrm{I} & 76 . \mathrm{I} & 32.9 & 62.8 & 75 . \mathrm{I} & 76.9 & 8 \mathrm{I} .8\end{array}$ Dent “ " (im$\begin{array}{lllllllll}\text { mature }) \ldots \ldots & \ldots & 65.6 & 67.4 & 34.3 & 51.3 & 70.6 & 67.4 & 80.2\end{array}$

Cured Fodders.

$\begin{array}{lllllllll}\text { Timothy (average) } \ldots & 56.6 & 57.9 & 32.8 & 46.9 & 52.5 & 62.3 & 52.2\end{array}$

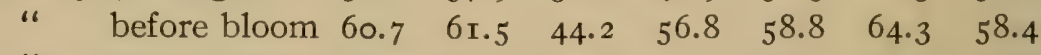

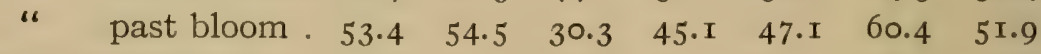

$\begin{array}{lllllllll}\text { Dent corn fodder.... } & 64.3 & 66.1 & 30.7 & 50.4 & 62.2 & 68.0 & 73.6\end{array}$

$\begin{array}{llllllllll}\text { Flint “. " } & \ldots & \ldots 8.6 & 7 \mathrm{x} .7 & 42.6 & 60.0 & 74.9 & 70.3 & 7 \mathrm{I} .4\end{array}$

Dent and flint (imma$\begin{array}{llllllll}\text { ture }) \ldots \ldots \ldots \ldots & 63.9 & 65.7 & 37.2 & 51.7 & 66.0 & 66.2 & 72.2\end{array}$

Dent and flint (ma$\begin{array}{llllllll}\text { ture }) \ldots \ldots \ldots \ldots & 68.2 & 70.7 & 30.6 & 56.7 & 65.8 & 72.2 & 73.9\end{array}$ 
Cured Fodders (cont.).

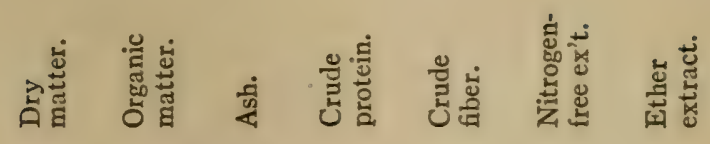

$\begin{array}{llllllll}\text { Corn stover....... } & 57.2 & 59.1 & 32.6 & 35.9 & 64.2 & 57.9 & 70.4\end{array}$ $\begin{array}{llllllll}\text { Red clover........ } & 57.4 & 59.7 & 29.1 & 58.0 & 54.2 & 64.4 & 55.2\end{array}$

Grains and Seeds.

$\begin{array}{llllllll}\text { Corn meal ... } \ldots .6 & 89.4 & 89.6 & \ldots & 67.9 & \ldots & 94.7 & 92.1\end{array}$

$\begin{array}{llllllll}\text { Gluten feed . . . . . . } & 86.3 & 87.3 & \ldots & 85.6 & 78.0 & 89.2 & 84.4\end{array}$

$\begin{array}{llllllllll}\text { “ meal...... } & 89.7 & 90.4 & \ldots & 88.2 & \ldots & 89.8 & 94.4\end{array}$

$\begin{array}{lllllllll}\text { Malt sprouts...... } 67.1 & 67.2 & \ldots & 80.2 & 32.9 & 68.1 & \ldots\end{array}$

$\begin{array}{lllllllll}\text { Wheat bran ....... } 62.3 & 65.7 & \ldots & 77.8 & 28.6 & 69.4 & 68.0\end{array}$

Oil-bearing Seeds.

$\begin{array}{llllllll}\text { Cottonseed meal.... } & 73.7 & 76.1 & 23.7 & 88.4 & 55.5 & 60.6 & 93.3\end{array}$

Linseed meal (old

process).

$78.7 \quad 81.2$

$\begin{array}{llll}88.8 & 57.0 & 77.6 & 88.6\end{array}$

Roots.

$\begin{array}{lllllllll}\text { Mangels . . . . . . . } & 78.5 & 84.8 & \text { I6.4 } & 74.7 & 42.8 & 9 \text { I.3 } & \ldots\end{array}$

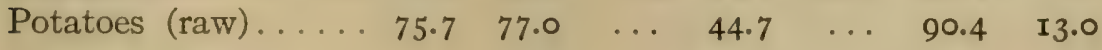

Some of the facts noticeable in the table are as follows: The highest degree of digestibility of a nutriment is usually obtained with foods which contain the largest amount of that nutrient. For example, clover hay contains more crude protein than timothy hay, and in general the protein of clover is more completely digested than that of timothy. In potatoes, there is a large amount of nitrogen-free extract compounds (starch), and in the table it will be observed that they are more completely digested than the crude protein which is present in smaller amount. Whenever a food contains nutrients in small amounts they are in dilute forms, and are not so completely extracted as when present in larger amounts. The coarse fodders are not so completely digested as the grains and milled products. In the coarse fodders, the digestion coefficients range from 30 to 65 , 
while in grains and milled products, the range in digestibility is from 70 to 95 .

466. Digestible Nutrients of Foods. - When the total nutrients in a food are multiplied by the digestion coeffcients, the available nutrients are secured. For example, clover hay contains I 2 per cent crude protein, which is 60 per cent digestible. The available or digestible crude protein of the clover hay is 7.2 ( I $2 \times 0.6=7.2$ ). In like manner, all the digestible nutrients of foods are ascertained. The per cent of each nutrient is multiplied by its digestion coefficient, which gives the total available or digestible nutrients. When the average composition of American feeding stuffs and the average digestion coefficients are used, the average digestible or available nutrients are obtained. Such a table is given at the end of the chapter. In using this table, it should be remembered that the figures are those of average conditions, and may not be applicable to all cases, and while the amounts of nutrients given are fairly constant, they nevertheless vary. It is possible by giving due care to the production of crops to secure those containing the maximum nutrients, and then to feed the crops so as to secure the highest degree of digestibility and thus more nutrients than are given in the tables at the close of the chapter. For example, timothy hay may contain from 5 to 9 per cent protein. That which contains 5 per cent is less completely digested than that containing 9 per cent. From the timothy with the highest degree of digestibility, there is about 7 per cent of the protein digestible and available, while from that with 5 per cent of crude protein there is from 2.5 to 3 per cent available. The availability of the other nutrients also is in favor of the timothy hay with the larger amount of protein. In the feeding 
of farm animals, particular attention should be given to the production of foods which contain the largest amounts of the most valuable nutrients and to combining and using them so as to secure the highest degree of digestibility. Digestion experiments have pointed out ways in which these results may be accomplished, and the experiments are valuable in indicating how the largest returns can be secured from the fodders and grains raised and fed upon the farm.

Experiment 77. - Digestible nutrients of foods. Take the dimensions of one of the measures given out for the experiment and calculate its capacity in quarts, dry measure ( $\mathrm{r}$ quart $=67.2$ cubic inches). Weigh the measure, fill it with oats and weigh again. From the tables, calculate the pounds of digestible fat, protein, and carbohydrates in one quart of each of the foodstuffs. Tabulate the results as follows:

Digestible Nutrients in Foods.

\begin{tabular}{|c|c|c|c|c|c|}
\hline \multirow{2}{*}{ NAME of Food. } & \multicolumn{2}{|c|}{$\begin{array}{l}\text { Net Weight of } \\
\text { Measure. }\end{array}$} & \multicolumn{3}{|c|}{ Digestible Pounds Per QUART. } \\
\hline & Grams. & Pounds. & Fat. & Protein. & C'bhydr'ts. \\
\hline $\begin{array}{l}\text { Oats... . . . . } \\
\text { Bran . . . . . . } \\
\text { Corn . . . . . . } \\
\text { Oil meal. . . . . } \\
\text { Flour. . . . . } \\
\text { Shorts . . . . . }\end{array}$ & & & & & \\
\hline
\end{tabular}




\section{CHAPTER XXXVI}

\section{Rational Feeding of Animals}

467. Balanced Rations. - A balanced ration is one which contains sufficient nutrients from a variety of foods to meet the requirements of the animal. Since the different classes of nutrients serve different purposes in the body, it is the object of rational feeding to combine foods so as to supply the nutrients in the right proportion for growth and work or for the production of milk, meat, or wool. Rational feeding is based upon (I) the food requirements of animals, and (2) the amount of digestible nutrients in foods. The food requirements of animals are determined by experiments.

468. A Maintenance Ration is one which furnishes all of the nutrients required for maintaining the weight of the body and for performing all its functions without allowing any nutrients for growth, work, or other purposes. A maintenance ration simply sustains the animal, and makes no allowance for growth or work. When an animal is fed a maintenance ration, it neither gains nor loses in weight; an equilibrium is established between the income and outgo of the food. The nitrogen in the proteids of the food consumed is all returned in the various waste products of the body. Since nitrogen is the characteristic element of protein, it is taken as the index for determining the maintenance requirements of animals. When the nitrogen in the waste products equals that in the food consumed, and no work has been 
performed, a maintenance ration has been fed, as the body has neither gained nor lost protein. Growth, work, and animal products are all produced from the excess of nutrients over those required for maintenance purposes. For example, a pig weighing 200 pounds requires about five pounds of grain per day for maintenance. If 5.5 pounds per day are fed, an increase in weight is secured only from the half pound in excess of the maintenence ration.

469. Standard Rations. - For feeding purposes standard rations have been proposed, giving the amounts of nutrients required by different classes of animals for different purposes. These tables have been prepared largely as the result of digestion experiments and feeding trials. The table in most common use is that prepared by Woulff and modified from time to time by various investigators. This table is given at the close of the chapter.

470. Food Requirements of Animals. - In the feeding of balanced rations, tables of feeding standards should be used largely as guides. It is not necessary that the rations should, in all particulars, absolutely conform to the standards given. On the other hand, it is not advisable to have the amounts of nutrients in the rations vary in any large degree from the standards. It is difficult to specify the amounts of nutrients which, under all conditions, will meet the food requirements of all classes of animals. In previous chapters, it has been shown that the composition of forage crops is subject to variation, as is also their digestibility. Hence, tables giving the amounts of digestible nutrients are only approximately correct, and if assumed for all fodders and conditions, the calculated amounts of nutrients would, in some cases, 
exceed, and in others fall short of, the standards given. On this account, it is not well to adhere too closely to fixed rules in the rational feeding of farm animals. When foods containing the largest amounts of nutrients are produced and so fed as to secure the highest degree of digestibility, smaller amounts are required than when foods low in available nutrients are used and injudiciously fed.

\section{I. Food Supply at Different Stages of Growth. -} The amount and nature of the food consumed should vary with the period of growth. Rations for young and growing animals should contain more protein and less of the non-nitrogenous compounds than rations for mature animals. This is because more food is required for building purposes in the early stages of growth than in later stages, when more is required for heat and energy. These facts may be observed from the table of feeding standards. For example, a calf three months old that weighs $\mathrm{r} 50$ pounds requires per day 0.6 pound digestible protein and 2.4 pounds digestible non-nitrogenous compounds. When the animal is a year old and weighs 500 pounds, it requires $\mathrm{I} .3$ pounds of digestible protein and 6.9 pounds of digestible non-nitrogenous compounds. The animal has increased in weight more than three times, while the additional demand for digestible protein has only doubled, but for the non-nitrogenous compounds it is four and one half times as great.

When an excess of starchy and non-nitrogenous foods is fed to a young and growing animal, there is a tendency toward the production of a poor muscular and bony framework and premature fattening. To produce balanced growth in young animals, careful attention should be given to the amount and nature of the nutrients supplied in the food. 
472. Food Requirements of Horses. - In feeding work horses, the object is to provide available nutrients for the production of energy, because it is the energy from the food which enables the horse to do his work. Experiments show that for maintenance purposes, a rooo-pound horse requires about $\mathrm{I} 7.5$ pounds of hay per day containing a half pound of digestible protein and 7 to 7.5 pounds of digestible non-nitrogenous compounds. Such a ration does not provide any nutrients for work. In the table at the close of the chapter are given the amounts of nutrients required for average work. Any increase in work should be followed by a corresponding increase of food. Average work is best accomplished with a ration containing 22 to 24 pounds of dry matter per day, of which about I. 8 pounds are digestible protein and II to II.5 pounds are digestible nitrogen-free extract. It is estimated that about one third of the energy derived from the food is utilized as energy in the performance of work. The best results are obtained when an even draft is made upon an animal, as experiments show that less energy is required for average work continuously than for severe work for a short time followed by rest.

473. Selection of Food for Horses. - For light work, 5 to 7 pounds per day of mixed grains are usually sufficient if combined with I 2 to 15 pounds of coarse fodder, as timothy hay. For average work more food is required, and the amount of grain should be about equal in weight to the coarse fodder. For heaviest work, the grain should exceed the fodder in weight. Pure clover hay, on account of its mechanical condition, is not suitable for the feeding of horses. Timothy hay, blue grass, and the different varieties of prairie hay are all good if cut and cured when medium ripe. Early cut fodders are not so satisfactory 
for horses as for other kinds of animals. There is a tendency to confine the ration of horses too largely to one grain, oats, which usually makes an expensive ration. Experiments show that a larger variety of foods is desirable. Corn, barley, ground wheat, bran, and other milled products may form a part of the ration for work horses. For purposes of variety, carrots or potatoes in small amounts may be fed. Oil meal also to the extent of about one fourth pound per day is valuable. For average work, grinding of grains is not necessary; for hard work, coarse grinding results in availability of a larger amount of the net energy of the foods.

474. Foods required for Beef Production. - According to the table of feeding standards from 25 to 30 pounds dry matter containing 2.5 to 3 pounds digestible protein, and about ${ }_{5}$ pounds digestible carbohydrates are required for a rooo-pound animal. As pointed out by Jordan, in "Feeding of Farm Animals," these standards are too high for economic feeding. As the result of feeding trials, I 5 pounds digestible organic matter per day for a rooo-pound animal have been found sufficient. A ration containing 15 pounds digestible dry matter, about 1.80 pounds digestible protein, I 3 pounds digestible nitrogen-free extract compounds, and 0.7 pound digestible ether extract was found satisfactory. When too little protein is supplied in a ration, the meat is of poorer quality than when more is available, so as to produce a normal amount of circulatory proteids in the system. In beef production, the aim should be to supply sufficient available protein for maintenance purposes, and a small amount for the other needs of the body, the fat being produced from the less expensive nutrients, as carbohydrates and ether extract. When the fat is produced 
from an excess of protein in the food, the cost of production is unnecessarily large. The protein supply in beef production should vary with the stage of fattening. Experiments at the Pennsylvania Station show that 0.42 pound digestible protein, 6.77 pounds digestible nonnitrogenous compounds, and O.I3 pound digestible ether extract are required for maintenance purposes. At different stages of growth, different amounts of food are required to produce a pound of gain. This fact is particularly noticeable in experiments at the Kansas Station from which the following data are taken:

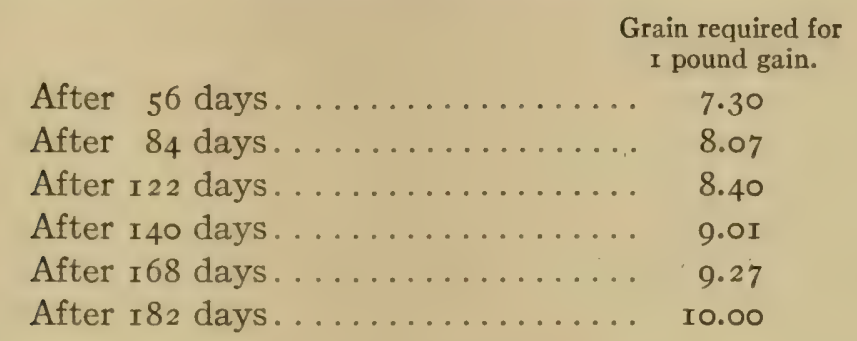

In the production of beef, palatability of the ration is an important factor; this is best secured by combining a number of grains and coarse fodders.

475. Selection of Foods for Beef Production. - Foods which are valuable for milk production are likewise valuable for beef production; bran, oil meal, cottonseed meal, corn, barley, shorts, middlings, and screenings are among the best grain and milled products. Pasture grass, clover hay, alfalfa, corn silage, corn fodder and mixed hays are all valuable coarse fodders. Roots and tubers, to the extent of Io to I 5 pounds per day, may also be added to a beef ration. The amount of grain should range from ro to $\mathrm{I} 8$ pounds per day, with from I 2 to $\mathrm{I} 8$ pounds of coarse fodder. Occasionally heavy grain 
feeding is resorted to in the fattening of steers. When grains and milled products are cheap, this practice is often economical, as it converts a cheap grain into a more valuable marketable product. Ordinarily the cost of production is greater with a heavy grain ration than with a light or medium one, and when more than I 2 pounds of grain per day are fed, the additional amount is fed at a loss. When grains and feeding stuffs are high in price, heavy grain feeding is not economical. It should be the aim, in the production of beef, to secure the larger portion of growth, as well as the larger portion of the increase during the fattening, from high-grade coarse fodders, and supplement them with medium amounts of grain and milled products. The amount of grain that can be fed economically is regulated by its cost and the market price of the beef product.

476. Food Requirements of Dairy Cows. - For the production of milk, a more liberal supply of digestible protein is required than for beef production. From 0.4 to 0.5 pound of digestible protein and from 7 to 7.5 pounds of digestible carbohydrates are required for maintenance. A ration should contain, in addition, I.2 to I.8 pounds digestible protein and 4 to 6 pounds digestible carbohydrates, because milk cannot be produced economically on too scant an amount of nutrients. According to the standard feeding tables, a ration for a cow giving a heavy yield of milk should contain 32 pounds dry matter, 3.3 pounds digestible protein, and I3 pounds carbohydrates. This is a larger amount of protein than is necessary for economical milk production. Under average conditions, a ration containing about 27 pounds dry matter, I. 8 to 2 pounds digestible protein, and II to $\mathrm{I} 3$ pounds digestible carbohydrates will prove more economi- 
cal than one containing larger amounts of protein. In a milk ration, proteids must be furnished for the production of the albumin and casein in the milk. In I 5 pounds of milk there is about one half pound of proteids, as albumin and casein, and this must be supplied from the food. About as much more protein is necessary to supply the energy to produce the milk as is required for maintenance and the milk proteids. In an ordinary dairy ration, practically one fourth of the proteids is recovered in the milk as casein and albumin, one fourth is indigestible, while one half is present in the liquid waste and represents the protein required for maintenance and the production of milk. The nutrients in a dairy ration should vary with the milk yield, as given in the table of feeding standards, but it is not necessary to adhere too closely to the figures.

In calculating a dairy ration, it will be found that when ordinary foods are combined, the amount of ether extract or crude fat will exceed the figures given in the table. Provided the ration contains the requisite digestible protein, and does not yield more than 32,000 calories, there is no objection to the crude fat amounting to 0.6 pound per day. It ought not, however, in an average ration, exceed 0.8 pound.

477. Selection of Foods for Dairy Cows. - The amount of grain which a dairy cow should receive varies from 7 to 12 pounds per day. Occasionally I 5 pounds can be fed economically, but, as a rule, medium grain rations of from 7 to $\mathrm{I} 2$ pounds produce milk and butter more economically than either light or heavy rations. As in beef feeding, when more than $\mathrm{I} 2$ pounds per day of grain are fed, the additional amount is not used economically, and is generally a loss. The coarse fodder in a dairy ration 
may vary from is to 50 pounds per day, according to the amount of water in the foods. The ration should contain from 25 to 30 pounds of dry matter. When silage is fed, 20 to 40 pounds may be used because of its high water content. In feeding roots, from $5_{5}$ to 20 pounds per day will be found economical. It is not desirable to restrict dairy cows to a ration of one grain or milled product. Better results are secured from a mixture of two or three grains. No great differences have been observed in the milk-producing value of the different grains and milled products. A pound of one grain in a mixed ration will produce about as good results as a pound of another grain. For example, wheat has been found to have practically the same feeding value as corn, oats, or barley. Common farm grains will give about the same yield of milk and butter-fats as average mill feeds like bran or shorts. Mixed wheat feed consisting of bran, shorts, or middlings and red-dog or feeding flour is a valuable dairy feed. Oil meal in medium amounts in a ration produces from 20 to 25 per cent better results than bran. Oil meal, cottonseed meal, and gluten meal all have about the same milk-producing value.

Clover hay, corn silage, corn fodder, alfalfa, and oat hay are among the most valuable coarse fodders for milk production, preference being usually given to clover hay when cut in early or full bloom. When silage is not fed, roots should always form a part of a dairy ration. Roots are valuable largely because of their palatability and the favorable influence which they exert upon digestion, rather than for any large amount of nutrients.

478. Food Requirements of Swine. - The nutrients required by swine vary with the stage of growth more than in the case of other animals. In the earlier stages of 
growth, particular attention should be given to furnishing a liberal supply of available protein and mineral matter. A ration for a roo-pound animal should contain about 0.5 pound digestible protein and 2.5 pounds digestible carbohydrates, while that for a 200-pound animal should contain about 0.6 pound digestible protein and nearly 4 pounds digestible carbohydrates. For growing pigs, a mixture of shorts and corn or shorts and barley with skim milk will be found preferable to any single grain. Skim milk should not be used in greater amounts than 3 pounds for each pound of grain. Five pounds of skim milk will produce as much gain in weight as one pound of grain. For fattening pigs the grain mixture should contain more corn than shorts. Coarsely ground barley is a valuable food and produces a good quality of pork. Peas may form about one third of the grain mixture. For fattening purposes, foods with a large amount of digestible protein are not as essential as for growing animals because the excess of protein is used for the production of fat, which can be produced from less expensive nutrients, as carbohydrates. The food should not be too concentrated in character. Many of the grains are so highly digestible that they leave in the digestive tract only a little insoluble matter to dilute the waste products. This is particularly true of peas and corn. Charcoal and a small amount of corn and cob meal are found useful to correct such deficiencies. Also some forage crop, as chopped, steamed, or soaked clover, should be at the disposal of the animal. Wheat, barley, and rye, if fed, should be coarsely ground, but with corn, grinding is not so essential. Bone meal, dried blood, and meat scrap are valuable in a ration for pigs, particularly if corn is the principal grain used. Among the forage crops, rape, clover, alfalfa, sorghum, 
and corn will be found most valuable for pork production.

479. Food Requirements of Sheep. - The standard for the rations of sheep, as given in the tables, can be adhered to more closely than the standards for any other class of farm animals. This is because a large number of feeding trials and experiments have been made with sheep. They require more nutrients than do beef animals, and they are capable of making equally good returns from the food consumed. Experiments by Lawes and Gilbert show that during the process of fattening only a slight increase in nitrogen takes place; the gain in weight is largely an increase in fat. During the growing period, a more liberal allowance of available protein is required than for fattening. Farm foods need but little reënforcement with mill and other products for the production of mutton. Henry, in "Feeds and Feeding," states that about 500 pounds of corn and 400 pounds of clover will produce roo pounds of gain in live weight of lambs, and he gives these figures for calculating the cost of production. The grinding of grains is not so necessary in sheep feeding as in dairy feeding. Among the grains, corn, barley, wheat, and oats have all been found valuable. Wheat screenings are extensively utilized in the production of mutton. Oil meal and other mill by-products also are suitable, provided their cost is not too high. Among the coarse fodders, clover hay, alfalfa, corn fodder, and silage are particularly valuable. Roots should form a part of the ration. Variety and palatability should be considered.

480. Calculation of Balanced Rations. - In calculating a balanced ration, first the food requirements of the animal, as given in the table of feeding standards, are noted. 
Then a reasonable variety of coarse fodders, grains, and roots is selected on the basis of cost, as explained in Sec. 483 , and a trial ration is calculated, using the approximate amounts of foods as given in the various sections relating to the food requirements of animals. The amounts of digestible nutrients in the foods selected are calculated and the totals of the different nutrients determined. If these correspond with the figures given in the table, a reasonably well-balanced ration is secured. In case the nutrients are present in the right proportion but deficient in amounts, the weights of foods used are increased; if excessive, they are reduced. Should the ration be deficient in digestible protein, a small amount of some food containing a liberal supply of this nutrient may be added. Finally, when the requirement as to nutrients is satisfied, the various other factors, as bulk, suitable combinations, cost, and labor involved in preparation are to be considered.

Example. - Calculate a ration for a dairy cow giving a large milk yield. The standard ration calls for 1.8 to 2 pounds digestible protein and from to to $\mathrm{I} 2.5$ pounds digestible carbohydrates. It is necessary to combine the coarse fodders and grains so as to secure approximately these amounts of nutrients. A trial ration is calculated, composed of ro pounds each of clover hay and corn fodder, 20 pounds of mangels, 5 of bran, and 3 of oats. The digestible nutrients in these materials, as given at the close of the chapter, are as follows:

Digestible Nutrients.

\begin{tabular}{|c|c|c|c|}
\hline & Protein. & Fat. & $\begin{array}{l}\text { Carbohy- } \\
\text { drates, etc. }\end{array}$ \\
\hline Wheat. & & $3 \cdot 4$ & 40. I \\
\hline Mangel beets............. & I.I & O.I & $5 \cdot 4$ \\
\hline Clover hay ............. & 6.8 & I.7 & 35.8 \\
\hline Corn fodder............. & 2.5 & I. 2 & 34.8 \\
\hline Oats................. & 9.2 & 4.2 & $47 \cdot 3$ \\
\hline
\end{tabular}


These figures are on the basis of roo pounds. The amounts of nutrients in one pound are found by moving the decimal point two places to the left. Multiplying the pounds of food by the per cent of digestible nutrients, the pounds of digestible nutrients will be found to be as follows:

Pounds of Digestible Nutrients.

\begin{tabular}{|c|c|c|c|}
\hline $\begin{array}{l}\text { Pounds. } \\
\text { ro Clover hay. . . . . }\end{array}$ & $\begin{array}{l}\text { Protein. } \\
0.68\end{array}$ & $\begin{array}{l}\text { Fat. } \\
\text { O.I7 }\end{array}$ & $\begin{array}{c}\text { Carbohy- } \\
\text { drates, etc. } \\
3.58\end{array}$ \\
\hline ro Corn fodder. . . . . . . . & 0.25 & 0.12 & 3.48 \\
\hline 20 Mangel-wurzels....... & 0.22 & 0.02 & 1.08 \\
\hline 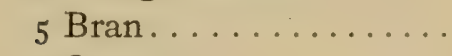 & 0.64 & O. I6 & 2.00 \\
\hline 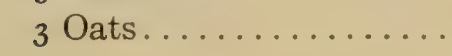 & 0.28 & 0.13 & $\mathrm{I} .42$ \\
\hline & 2.07 & 0.60 & II. 56 \\
\hline
\end{tabular}

Compared with the standard ration, it will be observed that the amounts of nutrients are approximately as given in the table, suggesting that as far as total nutrients are concerned, the ration is a reasonable one. The coarse fodder, grain, and roots are about in the proportions given in Section 477. As to the effects of the various foods, the bran, mangels, and clover hay might possibly prove somewhat laxative in character, and while the ration supplies all of the requisites as to dry matter and amount of nutrients, it would be necessary to note the effect upon the animal, before concluding it satisfactory in all respects.

48I. Nutritive Ratio. - The nutritive ratio is the ratio which exists between the digestible protein and the digestible non-nitrogenous compounds. A nutritive ratio of I to 6.7 means that for every I pound of crude protein there are 6.7 pounds of digestible non-nitrogenous compounds. A wide nutritive ratio means a large amount of non-nitrogenous to nitrogenous compounds, while 
a narrow nutritive ratio means a small amount of nonnitrogenous to nitrogenous compounds.

To calculate the nutritive ratio, first determine the pounds of digestible protein in the food, then the pounds of digestible carbohydrates, etc. Multiply the pounds of digestible ether extract by 2.2 , because the fat produces 2.2 times as much heat, consequently is considered 2.2 times more concentrated than the nitrogen-free extract compounds. Add the digestible fiber, nitrogen-free extract, and corrected ether extract and divide the sum by the digestible protein; the result is the nutritive ratio. The nutritive ratio of the ration given is $6.23(0.6 \times 2.3$ $=\mathrm{I} .32)(\mathrm{I} .32+\mathrm{II} .56=\mathrm{I} 2.88)(\mathrm{I} 2.88 \div 2.07=6.23)$. 482. Caloric Value of Rations. - The caloric value of a ration is determined by multiplying the pounds of digestible ether extract by the factor 4225 and adding this to the number secured by multiplying the sum of the digestible protein and carbohydrates by 1860 . As used in the calculation of rations, the carbohydrates include the nitrogen-free extract compounds and the digestible fiber. The term carbohydrates is used in the broad rather than the restricted sense.

Problem 1 . - Calculate a ration for a I 200-pound horse at light work. Use any foods desired.

Problem 2. - Calculate a ration for a I 200-pound horse at heavy farm labor.

Problem 3. - Calculate a ration for a pig weighing 100 pounds.

Problem 4. - Calculate a ration for a pig weighing 250 pounds.

Problem 5. - Calculate a ration for a dairy cow giving a full flow of milk.

Problem 6. - Calculate a dairy ration for average milk yield.

Problem 7. - Calculate a ration for a sheep weighing roo pounds.

Problem 8. - Calculate a ration for a growing steer weighing 500 pounds.

Problem 9. - Calculate a ration for a I 200-pound steer, fattening period. 
483. Comparative Cost and Value of Grains. - The market value of grains frequently differs from their actual food value. That is, a given sum of money if invested in one food article will often procure a larger amount of digestible protein and other nutrients than if invested in other foods. To illustrate: If corn is 50 cents and oats 30 cents per bushel, \$I will purchase either II 2 pounds of corn or Io7 pounds of oats. Which is the cheaper and more valuable for fceding purposes? The digestible nutrients in Ioo pounds of corn and oats are as follows:

\begin{tabular}{|c|c|c|c|}
\hline & \multicolumn{2}{|c|}{ Digestible nutrients. } & \multirow{2}{*}{$\begin{array}{l}\text { Pounds per hundred. } \\
\text { Carbohydrates, etc. }\end{array}$} \\
\hline & Protein. & Fat. & \\
\hline Corn. & $7 \cdot 9$ & $4 \cdot 3$ & 66.7 \\
\hline Oats.......... & 9.2 & 4.2 & $47 \cdot 3$ \\
\hline
\end{tabular}

The amounts of digestible nutrients in II 2 pounds of corn and 107 pounds of oats obtained by multiplying by the per cent of digestible nutrients are:

$\begin{array}{lccccc} & \text { Pounds. } & \text { Protein. } & \text { Fat. } & \begin{array}{c}\text { Carbohy- } \\ \text { drates. }\end{array} & \text { Calories. } \\ \text { Corn...... } & \text { II } 2 & 8.85 & 4.82 & 74.7 & \text { I75,684 } \\ \text { Oats...... } & \text { I07 } & 9.84 & 4.50 & 50.6 & \text { I3 } 3 \text { I, } 407\end{array}$

There is a difference of about I pound of digestible protein in favor of the oats and 24 pounds of digestible carbohydrates in favor of the corn; the dollar's worth of corn would also contain about 44,000 more calories. At the prices given, corn rather than oats should form the larger portion of a grain ration for work horses, beef and dairy animals, and swine and sheep. For growing animals, however, a large amount of corn is not desirable.

In deciding the comparative value of foods on the basis of their nutrient content, preference should usually be given to the protein, but when the difference in digestible protein is small, the preference should be given to the food containing the largest amount of available carbo- 
hydrates and number of calories. Comparisons between foods which are very unlike in character of nutrients cannot safely be made. It is not possible to assign an absolute value to any food upon the basis of any one or all of its digestible nutrients, because the comparative value of the different nutrients has not, as yet, been definitely ascertained. In the selection of foods, it will frequently be found that a given sum of money can be invested in the purchase of two foods, one nitrogenous and the other nonnitrogenous, better than in the purchase of one. The results of actual feeding tests should also be considered before definitely selecting foods. When both the available nutrients and the results of feeding experiments are considered, an accurate idea of the comparative cost and value of grains and milled products can be formed.

Problem. - Complete the following table and calculate the available nutrients and calories that can be procured for $\$ \mathrm{I}$ when the various foods are at different prices. In making the calculations, use the prices of your local or home market. Select three of the cheapest and three of the most expensive foods from the list.

\begin{tabular}{|c|c|c|c|c|c|c|}
\hline & \multirow{2}{*}{$\begin{array}{c}\text { PRICE } \\
\text { PER } \\
\text { BUSHEL } \\
\text { OR TON. }\end{array}$} & \multirow{2}{*}{$\begin{array}{c}\text { Pounds } \\
\text { FOR } \$ 1 . \infty 0\end{array}$} & \multicolumn{4}{|c|}{$\begin{array}{l}\text { Nutrients PROCURABle FOR } \$ 1.00 \text {. } \\
\text { Pounds Digestible NutrLENTS. }\end{array}$} \\
\hline & & & Protein. & $\begin{array}{l}\text { Carbohy- } \\
\text { drates. }\end{array}$ & $\begin{array}{l}\text { Ether } \\
\text { extract. }\end{array}$ & Calories. \\
\hline $\begin{array}{l}\text { Corn.......... } \\
\text { Oats......... } \\
\text { Wheat feed.... } \\
\text { Wheat bran ... } \\
\text { Wheat shorts ... } \\
\text { Oil meal....... } \\
\text { Linseed meal... } \\
\text { Cottonseed meal } \\
\text { Gluten meal... }\end{array}$ & & & & & & \\
\hline
\end{tabular}


484. Sanitary Conditions. - Satisfactory results in the feeding of animals can be secured only under the best sanitary conditions. When animals are kept in crowded quarters, deprived of pure air and sunlight, they fail to make the best use of the food consumed. Carbon dioxid thrown off from the lungs and ammonia produced from decaying manure form ammonium carbonate, a volatile and irritating compound. Sunlight is an important factor for promoting animal growth. Experiments with growing calves show that under the same conditions of food and management, animals reared with an abundance of sunlight make better gains in weight, and are more vigorous than those confined in dark quarters. The best results are obtained in the feeding of animals when their surroundings are most sanitary. A large amount of available energy is often lost in warming up cold, wet bedding. Pure water, pure air, sunlight, clean quarters, and dry bedding are as necessary to animals as is a well-balanced ration.

Table of Feeding Standards.

Per 1000 lbs. live weight, daily.

Digestible organic substances.

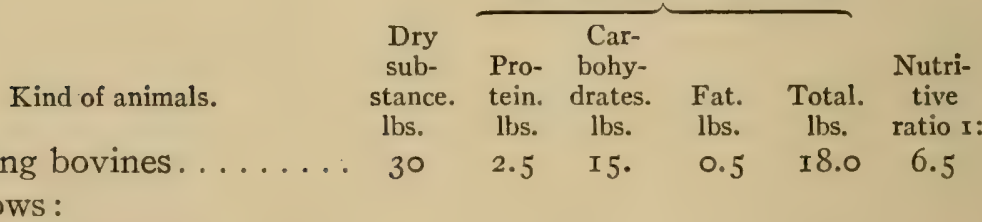

Milk cows :

Daily milk yield, I r lbs. . . 25

$\begin{array}{lllll}\text { I.6 IO. } & 0.3 & \text { II.9 } & 6.7\end{array}$

Daily milk yield, $\mathrm{I} 6 \frac{1}{2} \mathrm{lbs} \ldots 27$

$2.0 \quad$ II.O

$0.4 \quad \mathrm{I} 3.4$

6.0

Daily milk yield, 22 lbs... . 29

$2.5 \quad 13.0$

$0.5 \quad 16.0$

$5 \cdot 7$

Daily milk yield, $27 \frac{1}{2} \mathrm{lbs} . . \quad 32$

$3.3 \quad 13.0$

$0.8 \quad$ I 7.1

$4 \cdot 5$

Sheep.............. 22

I. 3 II.O

$0.3 \quad 13.5$

$3.0 \quad I 5.0$

$0.5 \quad \mathrm{I} 8.5$

$5 \cdot 4$

Horses :

Light work......... 20

Moderate work........ 24

$\begin{array}{lllll}\text { I. } 5 & 9.5 & 0.4 & \text { II. } 4 & 7.0\end{array}$

$\begin{array}{lllll}2.0 & \text { II.0 } & 0.6 & \text { I } 3.6 & 6.2\end{array}$

Severe work......... 26

$2.5 \quad I 3.3$

$0.8 \quad$ I6.6

6.0 
Per 1000 lbs. live weight, daily.

Digestible organic substances.

Fattening swine:

$\begin{gathered}\text { Dry } \\ \text { sub- }\end{gathered}$ Pro- bohy-
bub-

Kind of animals. $\quad \begin{gathered}\text { stance. tein. drates. Fat. Total. tive } \\ \text { strite }\end{gathered}$

First period........ $36 \quad 4.5 \quad 25 . \quad 0.7 \quad 30.2 \quad 5.9$

$\begin{array}{lllllll}\text { Second period......... } 32 & 4.0 & 24 . & 0.5 & 28.5 & 6.3\end{array}$

Third period.......... $25 \quad 2.7$ I8. $0.4 \quad 21.1 \quad 7.0$

Growing cattle (dairy breeds) :

Age in Live weight

months. per head, lbs.

$\begin{array}{rlllllll}2-3 & \text { I } 50 & 23 & 4.0 & \text { I3.0 } & 2.0 & 2 \text { I.O } & 4.5 \\ 3-6 & 300 & 24 & 3.0 & \text { I 2.8 } & \text { I.0 } & \text { I6.8 } & 5.1 \\ \text { 6-I2 } & 500 & 27 & 2.0 & \text { I2.5 } & 0.5 & \text { I 5.0 } & 6.8 \\ \text { I 2-I } 8 & 700 & 26 & \text { I.8 } & \text { I 2.5 } & 0.4 & \text { I4.7 } & 7.5 \\ \text { I8-24 } & 900 & 26 & \text { I.5 } & \text { I2.0 } & 0.3 & \text { I } 3.8 & 8.5\end{array}$

Beef breeds :

$$
\begin{array}{r}
2-3 \\
3-6 \\
6-12 \\
\text { I } 2-18 \\
\text { I8-24 }
\end{array}
$$

Sheep :

$$
\begin{aligned}
& 4-6 \\
& 8-\text { I I }
\end{aligned}
$$

\section{...}

$\begin{array}{llllll}23 & 4.2 & \text { I } 3.0 & \ldots & \text { I } 9.2 & 4.2 \\ 24 & 3.5 & \text { I } 2.8 & \cdots & \text { I } 7.8 & 4.7 \\ 25 & 2.5 & \text { I } 3.2 & \cdots & \text { I6.4 } & 6.0 \\ 24 & 2.0 & \text { I } 2.5 & \cdots & \text { I } 5.0 & 6.8 \\ 24 & \text { I.8 } & \text { I } 2.0 & \cdots & \text { I } 4.2 & 7.2\end{array}$

Swine :

$\begin{array}{rrrrrrrr}2-3 & 45 & 44 & 7.6 & 28.0 & \text { I.0 } & 35.7 & 4.0 \\ 3-5 & \text { IIO } & 35 & 5.0 & 23.1 & 0.8 & 28.9 & 5.0 \\ 5-6 & \text { I } 50 & 33 & 4.3 & 22.3 & 0.6 & 27.2 & 5.5\end{array}$

Digestible Nutrients in Fodders

Digestible nutrients in $100 \mathrm{lbs}$.

\section{Name of feed.}

\section{S}

Co

Dent corn.

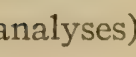

s).

Dry matter in $100 \mathrm{lbs}$.

Flint corn

Corn cob.

Corn and cob meal
65
I00

$\begin{array}{lll}26 & 4.4 & \text { I } 5 \cdot 5 \\ 24 & 3.0 & \text { I } 4.3\end{array}$

$\begin{array}{ll}0.9 & 20.8\end{array}$

4.0

0.5 I 7.8

5.2

$\begin{array}{ccc}\text { Protein. } & \begin{array}{c}\text { Carbohy- } \\ \text { drates. }\end{array} & \begin{array}{c}\text { Ether } \\ \text { extract. }\end{array} \\ 7.9 & 66.7 & 4.3 \\ 7.8 & 66.7 & 4.3 \\ 8.0 & 66.2 & 4.3 \\ 8.8 & 63.7 & 7.0 \\ 0.4 & 52.5 & 0.3 \\ 4.4 & 60.0 & 2.9\end{array}$


Digestible nutrients in roo lbs.

\section{Name of feed.}

Corn bran . . . . . . . . . . 90.9

Gluten meal. . . . . . . . . . . 9r.8

Germ meal. . . . . . . . . 89.6

Hominy chops . . . . . . . . 88.9

Wheat.............. 89.5

Wheat bran ........... 88.

Wheat bran (spring wheat) $\quad 88.5$

Wheat bran (winter wheat). 87.7

Wheat feed........... 88.0

Wheat shorts......... 88.2

Wheat middlings....... 87.9

Wheat screenings ........ 88.4

Rye................ 88.4

Rye bran............ 88.4

Rye shorts............ 90.7

Barley............... 89.1

Malt sprouts . . . . . . . . . 89.8

Brewers' grains (wet)..... 24.3

Brewers' grains (dried) . . . . 9 9 9

Oats............... 89.0

Oat feed or shorts....... 92.3

Oat hulls.............. 90.6

Buckwheat........... 87.4

Buckwheat bran ......... 89.5

Flaxseed ............. 90.8

Linseed meal (old process). . 90.8

Linseed meal (new process). $\quad 89.9$

Cottonseed meal......... 9r.8

\section{Coarse Fodders.}

Fodder corn (green)....... 20.7

Fodder corn (field-cured) . . $\quad 57.8$

Corn stover (field-cured) . .. 59.5

Fresh Grass.

Pasture grasses (mixed).... 20.0

Kentucky blue grass..... 34.9

Timothy, different stages... $\quad 38.4$

Oat fodder............ 37.8

Peas and oats.......... I6.0

\section{$\overbrace{\text { Carbohy- Ether }}$}

Protein. drates. extract.

$\begin{array}{lll}7.4 & 59.8 & 4.6\end{array}$

$25.8 \quad 43.3 \quad$ II.O

$9.0 \quad 6 \mathrm{I} .2 \quad 6.2$

$\begin{array}{lll}7.5 & 55.2 & 6.8\end{array}$

I0.2 $69.2 \quad$ I.7

$\begin{array}{lll}\text { I } 2.2 & 39.2 & 2.7\end{array}$

I $2.9 \quad 40 . I \quad 3.4$

I $2.3 \quad 37 . \mathrm{I} \quad 2.6$

I $3.3 \quad 40.5 \quad 4.0$

$\begin{array}{lll} & \\ \text { I } .2 & 50.0 & 3.8\end{array}$

I $2.8 \quad 53.0 \quad 3.4$

$9.8 \quad 51.0 \quad 2.2$

$9.9 \quad 67.6 \quad$ I.I

II. 5 50.3 2.0

II.9 $45 . \mathrm{I} \quad$ I. 6

$\begin{array}{lll}8.7 & 65.6 & \text { I. } 6\end{array}$

I8.6 $37 . \mathrm{I} \quad \mathrm{I.7}$

$\begin{array}{lll}3.9 & 9.3 & \text { I. } 4\end{array}$

I $5.7 \quad 36.3 \quad 5 . I$

$9.2 \quad 47.3 \quad 4.2$

$\begin{array}{lll}\text { I } 2.5 & 46.9 & 2.8\end{array}$

I. 3 40.I 0.6

$\begin{array}{lll}7.7 & 49.2 & \text { I. } 8\end{array}$

$\begin{array}{lll}7.4 & 30.4 & \text { I.9 }\end{array}$

$20.6 \quad$ I $7.1 \quad 29.0$

$29.3 \quad 32.7 \quad 7.0$

$28.2 \quad 40.1 \quad 2.8$

$\begin{array}{lll}37.2 & \text { I } 6.9 & \text { I } 2.2\end{array}$

I. $\quad$ I I. $6 \quad 0.4$

$2.5 \quad 34.6 \quad$ I. 2

$\begin{array}{lll}\text { I. } & 32.4 & 0.7\end{array}$

$2.5 \quad$ IO. $2 \quad 0.5$

$\begin{array}{lll}3.0 & I 9.8 & 0.8\end{array}$

I.2 I9.I 0.6

$2.6 \quad I 8.9 \quad$ I.O

$\begin{array}{lll}\text { I. } & 7 . \mathrm{I} & 0.2\end{array}$


Digestible nutrients in $100 \mathrm{lbs}$.

Name of feed. $\quad \begin{gathered}\text { Dry matter } \\ \text { in roo lbs. }\end{gathered}$ Protein. $\begin{gathered}\text { Carbohy- } \\ \text { drates. }\end{gathered} \quad \begin{gathered}\text { Ether. } \\ \text { extract. }\end{gathered}$

$$
\text { Hay. }
$$

Timothy............. 86.8

Redtop............ 9 91.9

Kentucky blue grass...... 78.8

Hungarian grass........ 92.3

Mixed grasses.......... 87.I

Rowen (mixed)........ 83.4

Oat hay............. 9 I.I

Straw.

Wheat............ 90.4

Oat............. 90.8

Fresh Legumes.

Red clover, diff. stages.... 29.2

Alsike, bloom.......... 25.2

Crimson clover......... I9.I

Legume, Hay, and Straw.

Red colver, medium..... . 84.7

Red clover, mammoth..... $\quad 78.8$

Alsike clover......... 90. 90.3

Alfalfa.............. 9 r.6

Cowpea ........... 89.3

Silage.

Corn.............. 20.9

Roots and Tubers.

$\begin{array}{lll}2.8 & 43.4 & \text { I.4 } \\ 4.8 & 46.9 & \text { I.O } \\ 4.8 & 37.3 & 2.0 \\ 4.5 & 51.7 & \text { I.3 } \\ 5.9 & 40.9 & \text { I.2 } \\ 7.9 & 40 . I & \text { I.5 } \\ 4.3 & 46.4 & \text { I.5 }\end{array}$

$0.4 \quad 36.3 \quad 0.4$

I. $2 \quad 38.6 \quad 0.8$

$2.9 \quad \mathrm{I} 4.8 \quad 0.7$

$2.7 \quad$ I3.I $\quad 0.6$

$2.4 \quad$ I $3.9 \quad 0.5$

$\begin{array}{lll}6.8 & 35.8 & \text { I. } 7\end{array}$

$\begin{array}{lll}5.7 & 32.0 & \text { I.9 }\end{array}$

$8.4 \quad 42.5 \quad$ I. 5

II.O $39.6 \quad$ I. 2

I6.8 $38.6 \quad$ I.I

$\begin{array}{lll}0.9 & \text { II.3 } & 0.7\end{array}$

Potato.............. 2I.I

Sugar-beet............ I 13.5

Mangel beet.......... 9. I

Rutabaga............ II.4

Carrot............... II.4

Miscellaneous.

Pumpkin (field)........ 9. 9.

Beet pulp............ I0.2

Cow's milk . . . . . . . . . . 2.8

Skim milk (gravity)...... $\quad 9.6$

Skim milk (centrifugal) .... 9.4

Buttermilk........... 9.9

Whey............... 6.6

$\begin{array}{lll}0.9 & I 6.3 & \text { O.I }\end{array}$

I.I IO.2 O.I

I. I $5.4 \quad$ O.I

I.O $8 . \mathrm{I} \quad 0.2$

$\begin{array}{lll}0.8 & 7.8 & 0.2\end{array}$

$\begin{array}{lll}\text { I.O } & 5.8 \quad 0.3\end{array}$

$0.6 \quad 7.3 \quad \ldots$

$\begin{array}{lll}3.6 & 4.9 & 3.7\end{array}$

3.I $\quad 4.7 \quad 0.8$

$\begin{array}{lll}2.9 & 5.2 & 0.3\end{array}$

$3.9 \quad 4.0 \quad$ I.I

$\begin{array}{lll}0.8 & 4.7 & 0.3\end{array}$




\section{CHAPTER XXXVII}

\section{Composition of Animal Bodies}

485. Water and Dry Matter. - About half of the live weight of an animal is water. In fat animals, the proportion of water is less than in lean animals. The same. general classes of organic compounds present in plants, as non-nitrogenous and nitrogenous, are found also in animal bodies; the animal forms, however, are usually somewhat more complex than the plant forms. Animal bodies are characterized by containing a high per cent of fat and proteid materials and a low per cent of nonnitrogenous compounds other than fat.

486. Mineral Matter. - The ash elements in the animal body are the same as those found in plants, and are nearly all furnished from vegetable sources. The body of an animal, live weight basis, contains from two to four per cent of mineral matter, from half to three fourths of which is present in the bones, while the remainder is in solution in the various fluids, as the blood, chyle, etc., and deposited and combined with the solid and fleshy tissues of the body. Silicon in animal bodies is found mainly in the hair, wool, and feathers. Sodium and chlorin, while unnecessary to plants, are absolutely necessary to animals. A thousand parts of blood yield about 4 parts of mineral matter, of which I.2 are sodium chlorid. In the blood, salt is necessary as a solvent for the proteids.

The per cent of ash in the carcasses of different animals 
varies, being greatest in the half-fat steer or ox and least in the fat pig. In the process of fattening, the percentage amount of ash is decreased.

As in the case of the plant, the mineral matter of the animal body must be secured and assimilated in the early stages of growth. Young pigs, or other young animals, fed exclusively on food which, like corn, is poor in digestible mineral matter, have bones which are weak and do not furnish a framework strong enough for the perfect development of the body in its last stages of growth. The same elements which are essential for plant growth are also essential for animal growth.

487. Fat. - The per cent of fat in the carcasses of animals ranges from I 4 to 45 per cent of the live weight. The carcasses of fattened steers of good quality are about one third fat; in moderately fat sheep there is somewhat more, while the largest amount is present in the body of the very fat pig, with the very fat sheep as a close competitor. "It is thus seen that animal food of reputed high quality as sold by the butcher, and to which such a highly nitrogenous character is

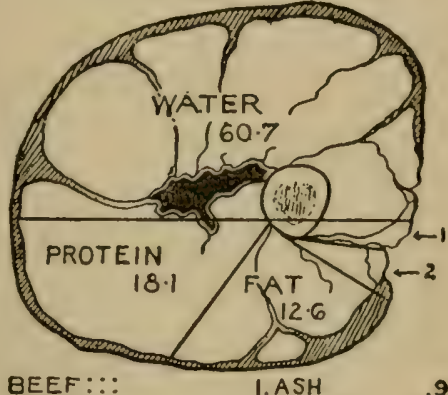
-ROUND.. usually attributed, will consist of fat to the extent of one third to one half of its total weight." (Lawes and Gilbert.)

488. Nitrogenous Matter is present to the extent of Io to I 8 per cent in the live animal, being least in the very fat pig and most in the half-fat ox. The offal parts, as the head, feet, tail, hair, wool, and horns, are rich in nitrogen, but not so rich as the flesh. Beef-yielding 
animals, on the whole, contain rather more nitrogenous compounds than sheep, which in turn contain more than pigs. A large amount of the nitrogenous compounds of sheep and lambs is found in the wool ( 50 to 55 per cent). About 75 per cent of the carcass of the sheep is consumed as food; thus it will be seen that much less than half of the total nitrogen is really made use of as human food. Of the fattened pig, about three fourths of the nitrogenous compounds are in the edible carcass, from 6 to 7 parts are in the bone, and about one quarter is in the offal. About 8 per cent of the nitrogenous compounds of the offal and a little over three fourths of the total nitrogenous compounds of the pig are consumed as food. About two thirds of the entire nitrogen of the calf and steer are in the butcher's carcass, and about I 2 per cent in the bones. From 5 to 7 per cent of the nitrogen of the offal parts and about 60 per cent of the total nitrogen of the steer are utilized as human food.

In the table of relative composition of animal bodies, it will be noticed that the mineral matter increases and decreases with the nitrogenous matter. In the carcasses of all animals, it will be observed that the fat always exceeds the nitrogenous matter, except in the case of the lean calf. In the bodies of animals in good condition, there is usually twice as much fat as protein. The following table is from the extensive work of Lawes and Gilbert.

489. Proteids of Meat. - Lean meat, fat-free, is a concentrated nitrogenous material composed mainly of proteids, but containing also small amounts of amides, albuminoids, and, in some cases, alkaloidal bodies. The proteids are mainly in insoluble forms; a small amount, however, is soluble. The principal soluble meat proteids are albumin and syntonin. 


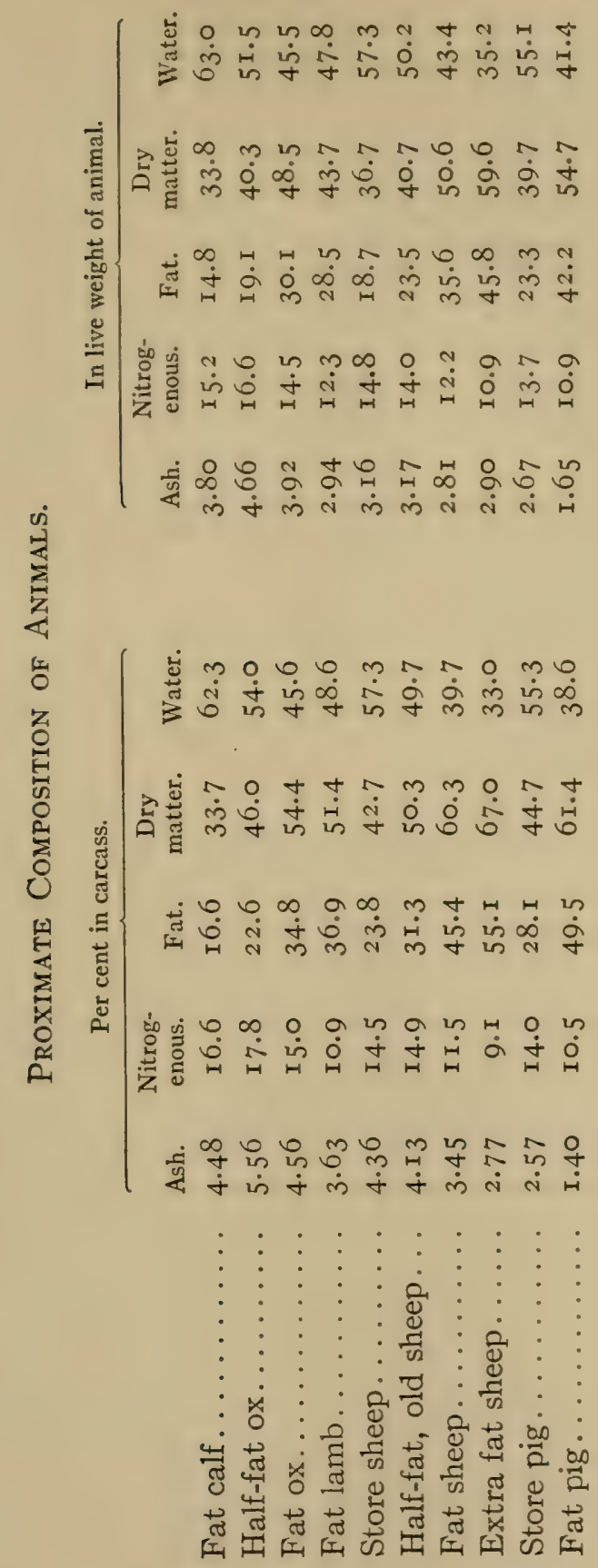


490. Albumin. - The formula $\mathrm{C}_{72} \mathrm{H}_{112} \mathrm{~N}_{18} \mathrm{SO}_{22}$ has been tentatively assigned to albumin. The albumin in meats ranges from 0.6 to 5 per cent. Liebig gives as a mean 2.96 per cent. The lean meat of the pig as well as that of poultry contains a relatively large amount. Albumin is soluble in cold water, and is coagulated at a temperature of $\mathrm{I} 57^{\circ}$ to $\mathrm{I} 63^{\circ} \mathrm{F}$. and of $69^{\circ}$ to $75^{\circ} \mathrm{C}$. Dilute acids convert albumins into acid albuminates, while alkalies produce alkali albuminates. The albuminates are proteids derived from albumins and other proteids by the action of acids or alkalies.

49I. Myosin. - Myosin is obtained from meat by extraction with a weak solution of common salt. The myosin dissolves in the salt solution and is precipitated by heat and chemicals (see Experiments 6o and 6r). Myosin is a globulin, and in the living animal is largely in soluble forms.

492. Syntonin has the same general relationship to myosin as dextrin has to starch. Dextrin is derived from starch and syntonin is derived from myosin. Syntonin is an acid albuminate formed by the action of dilute acids. The amount of syntonin and myosin in meats is small, never exceeding, according to Hoffman, 2 or 3 per cent.

493. Hemoglobin. - When fresh meat is soaked in cold water, the solution becomes red in color on account of the hemoglobin extracted. Hemoglobin is a proteid which imparts the red color to the blood and is coagulated by heat at a temperature of $\mathrm{I} 28^{\circ}$ to $\mathrm{I} 32^{\circ} \mathrm{F}$. There is enough of the various salts in the blood to dissolve some of the fibrin proteids which are precipitated at a temperature of about $140^{\circ} \mathrm{F}$. or $60^{\circ} \mathrm{C}$.

494. Insoluble Proteids. - The larger portion of the 
nitrogenous material of the muscles is in the form of insoluble muscular fiber. From 90 to 95 per cent or more of the total nitrogenous matter of fat-free lean meat is in insoluble forms. In the grains there are various insoluble protcids; and in the different meats different kinds of insoluble proteids are present. Meats differ both as to the kinds and proportional amounts of the several proteids which they contain.

495. Peptones. - When muscular fiber is acted upon by some ferments, peptones are produced. Only a small amount of peptones is present in meat. When meat is in cold storage to undergo the curing process before it is placed upon the market, the peptonizing process takes place to a slight extent. If the process is too long continued, ptomaines, which are poisonous compounds, may develop. With meat of the best quality long curing is unnecessary.

496. Keratin is an amide compound found in meat juices in small amounts; roo pounds of meat contain from 0.07 to 0.32 of a pound. Like other amides, it possesses less food value than protein. Keratin, sarkin, and allied bodies are not coagulated by heat, but are gradually decomposed, and when meat is being cooked, pass off with characteristic odors. Keratin and sarkin are present in large amounts in beef extracts, and although they possess no direct food value, they impart palatability and are valuable mainly on this account

497. Albuminoids, Gelatin. - When bone or muscular tissue is subjected to the action of boiling water, gelatin separates upon cooling and standing. Gelatin is quite different in chemical composition from albumin, muscular fiber, and other proteids. Hoffmeister gives the formula as $\mathrm{C}_{102} \mathrm{H}_{151} \mathrm{~N}_{6} \mathrm{O}_{39}$. It contains no sulfur, while proteids 
contain from I to 2 per cent. Gelatin may prevent the rapid depletion of the protein of the body, but cannot take its place as a nutrient. The approximate amounts of the nitrogenous compounds in lean meat are given in the following table, from which it will be observed that only a small part is in the meat juices.

The Nitrogenous Compounds of Meat.

Per cent.

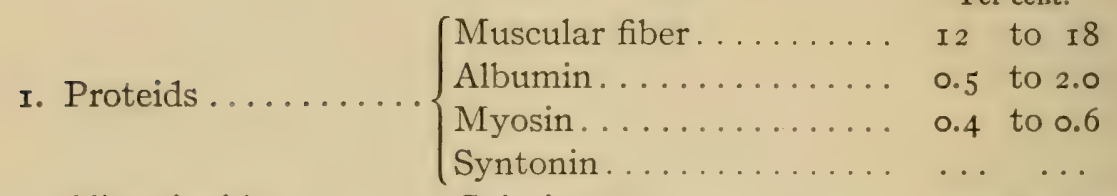

2. Albuminoids....... Gelatin, etc. ......... 2.0 to 5.0

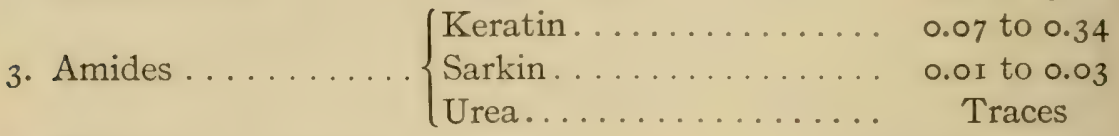

4. Alkaloids (ptomaines) .............. Occasionally traces

\section{Influence of Food upon the Composition of Ani-} mal Bodies. - The nature of the food consumed has a noticeable effect upon the composition of the animal body. The food affects both the amount of meat produced and its composition. As a general rule, an unbalanced ration, particularly one with a large amount of non-nitrogenous compounds, produces flesh that is poor in circulatory proteids. But few systematic experiments have been made in regard to the influence of food upon the composition of animal bodies.

499. Composition of the Human Body. - Halliburton states that the human body contains 58.5 per cent water. The amount at different stages of life varies; in later life, the body contains less than during youth. Water is present in all parts of the body; enamel contains 2 per cent, the gray matter of the brain 85 to 86 per cent, 
bone about 50 per cent, and muscle 75 per cent. The amount of fat varies between wide limits; Moleschott states that normally it makes up from 4 to 5 per cent of the weight of the body. Adipose tissue contains about 85, marrow 96, and nerves 22 per cent fat. Twentyfive per cent of the muscle is solid matter, of which 2 I per cent is proteid and albuminoid material, and 4 per cent are fat and nitrogenous extractive bodies. Mineral matter is present in small amounts combined with the muscular and other tissues and in solution in the various fluids and secretions. 


\section{CHAPTER XXXVIII}

\section{Rational Feeding of Men}

\section{Similarity in the Principles of Human and Animal}

Feeding. - The rational feeding of men is founded upon the same principles as the rational feeding of animals. It is the object in each case to supply the body with the right kinds and amounts of nutrients to meet all its demands. It is not possible in either human or animal feeding to establish inflexible standards.

50r. Dietary Standards. - Some of the proposed standard rations call for about one fourth of a pound each of fat and protein and a pound of carbohydrates in the daily ration of a man at average muscular labor. Such a ration should yield about 3200 calories. The actual amount of nutrients consumed by laborers does not always conform to this standard. For example, studies show that the negro laborer in the South often, by choice, consumes about o.I pound per day of protein, while a well-fed mechanic frequently consumes over 0.5 pound per day. While only tentative standards are proposed, experiments and dietary studies show that the best results are obtained in the feeding of men, as in the feeding of animals, when the ration conforms within reasonable limits to the standard. By a dietary standard is meant the approximate amounts of nutrients which the daily ration should contain. Such a standard as proposed by Atwater is as follows: 


$$
\begin{array}{cccc}
\begin{array}{c}
\text { Protein. } \\
\text { Fat. } \\
\text { lb. }
\end{array} \text { lb. } & \begin{array}{c}
\text { Carbohy- } \\
\text { drates. } \\
\text { lb. }
\end{array} & \begin{array}{c}
\text { Fuel } \\
\text { value. } \\
\text { Calories. }
\end{array} & \begin{array}{c}
\text { Nutri- } \\
\text { tive } \\
\text { Ratio. }
\end{array}
\end{array}
$$

$\begin{array}{llllll}\text { Man with little physical exercise } & 0.20 & 0.20 & 0.66 & 2450 & 5.5\end{array}$

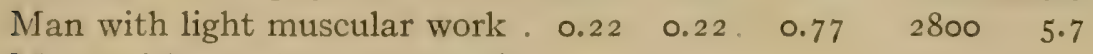

Man with moderate muscular

work. . . . . . . . . . $0.28 \quad 0.28 \quad 0.99 \quad 3520 \quad 5.8$

$\begin{array}{llllll}\text { Man with active muscular work } & 0.33 & 0.33 & \text { I.ro } & 4060 & 5.6\end{array}$

$\begin{array}{llllll}\text { Man with hard muscular work } & 0.39 & 0.55 & 1.43 & 5700 & 6.9\end{array}$

\section{Amounts of Foods consumed per Day. - In} combining foods to form human rations, there should be, as in animal rations, a variety of foods, and no food article should be used in excess. The approximate amounts of foods consumed per day by a man at average labor are as follows:

\begin{tabular}{|c|c|c|}
\hline & $\begin{array}{l}\text { Range. } \\
\text { Ounces. }\end{array}$ & $\begin{array}{c}\text { Average. } \\
\text { Pound. }\end{array}$ \\
\hline 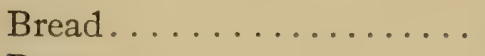 & 6 to $\mathrm{I} 4$ & 0.50 \\
\hline Butter................. & 2 to 5 & 0.12 \\
\hline Potatoes................ & 8 to 16 & 0.75 \\
\hline Cheese................. & I to 4 & 0.12 \\
\hline Beans................. & I to 4 & 0.12 \\
\hline Milk................. & 8 to 32 & $\cdots$ \\
\hline Sugar. ................ & 2 to 5 & 0.20 \\
\hline Meat................. & 4 to I 2 & 0.25 \\
\hline Oatmeal.............. & I to 4 & 0.12 \\
\hline
\end{tabular}

In a balanced ration, it is the aim to obtain from all of the foods approximately 0.25 pound each of fat and protein and a pound of carbohydrates. In case of severe work, larger amounts of nutrients, as indicated in the table, are necessary. The composition of human foods is given in the tables at the close of the chapter.

To calculate the amounts of nutrients in fractions of a pound, the percentage composition of the food is multiplied by the weight used. as in calculating animal rations (see Section 480). 


\section{Calculating a Balanced Ration. - The various} articles of food should be selected according to cost, nutritive value, purposes for which they are desired, amount and kind of work to be performed, and individual preferences. When bread, butter, milk, potatoes, sugar, oatmeal, corn meal, beef, ham, and eggs are to be combined to form a ration, such amounts are taken as will yield approximately 0.25 pound each of protein and fat, and a pound of carbohydrates. Such a combination would be as follows:

\begin{tabular}{|c|c|c|c|c|c|}
\hline \multirow[b]{2}{*}{ Foods. } & \multirow[b]{2}{*}{$\begin{array}{l}\text { Amount } \\
\text { per day. } \\
\text { Ounces. }\end{array}$} & \multicolumn{3}{|c|}{ Nutrients. } & \multirow[b]{2}{*}{$\begin{array}{c}\text { Calories. } \\
480\end{array}$} \\
\hline & & $\begin{array}{l}\text { Protein. } \\
\text { Pound. } \\
0.04\end{array}$ & $\begin{array}{c}\text { Fat. } \\
\text { Pound. } \\
0.09\end{array}$ & $\begin{array}{c}\text { Carbohy } \\
\text { drates. } \\
\text { Pound. } \\
\text {... }\end{array}$ & \\
\hline$\ldots \ldots \ldots$ & $\ldots$ & 0.03 & 0.02 & . & I36 \\
\hline$\ldots \ldots \ldots$ & 8 & 0.05 & 0.01 & 0.28 & 650 \\
\hline$\ldots \ldots \ldots$ & 2 & $\ldots$ & O. I I & $\ldots$ & $45^{\circ}$ \\
\hline$\ldots \ldots \ldots$ & I 2 & 0.02 & $\ldots$ & 0.14 & 285 \\
\hline$\ldots \ldots \ldots \ldots$ & I6 & 0.04 & 0.04 & 0.05 & 325 \\
\hline$\ldots \ldots \ldots \ldots$ & 2 & $\ldots$ & $\ldots$ & 0.12 & 200 \\
\hline$\ldots \ldots \ldots$ & 2 & 0.02 & 0.01 & 0.09 & 230 \\
\hline$\ldots \ldots \ldots$ & 4 & 0.04 & 0.05 & $\cdots$ & 250 \\
\hline$\ldots \ldots$ & 4 & 0.02 & $0.0 r$ & O.I 8 & 420 \\
\hline & & 0.26 & 0.34 & 0.86 & 3426 \\
\hline
\end{tabular}

This ration contains 0.26 pound protein, 0.34 pound fat, 0.86 pound carbohydrates, and yields 3426 calories. While there is somewhat more fat and slightly less carbohydrates than the standard the ration is sufficiently near for all practical purposes. Some vegetables and fruits should be added, not so much with the object of increasing the nutrients as for the purpose of greater variety and palatability. In this ration, the nutrients are secured from a variety of sources, the largest amount of protein coming from the bread. About one third of 
the protein is furnished by the meat, one fourth by the eggs and milk, while the balance comes from the vegetable foods. Bread, potatoes, corn meal, and sugar supply most of the carbohydrates, the two ounces of sugar supplying nearly I4 per cent.

In combining foods to form balanced rations, meats, beans, cheese, milk, bread, and oatmeal supply protein, while pork, ham, bacon and other fat meats, butter, cheese, and milk supply the fats. Carbohydrates are provided liberally by bread, rice, corn meal, cereals, potatoes, sugar, and vegetables.

504. Comparative Cost and Value of Foods. - With human as with animal foods, the market price does not, as a rule, correspond with their nutritive value. When foods differ widely in cost, their relative values can be
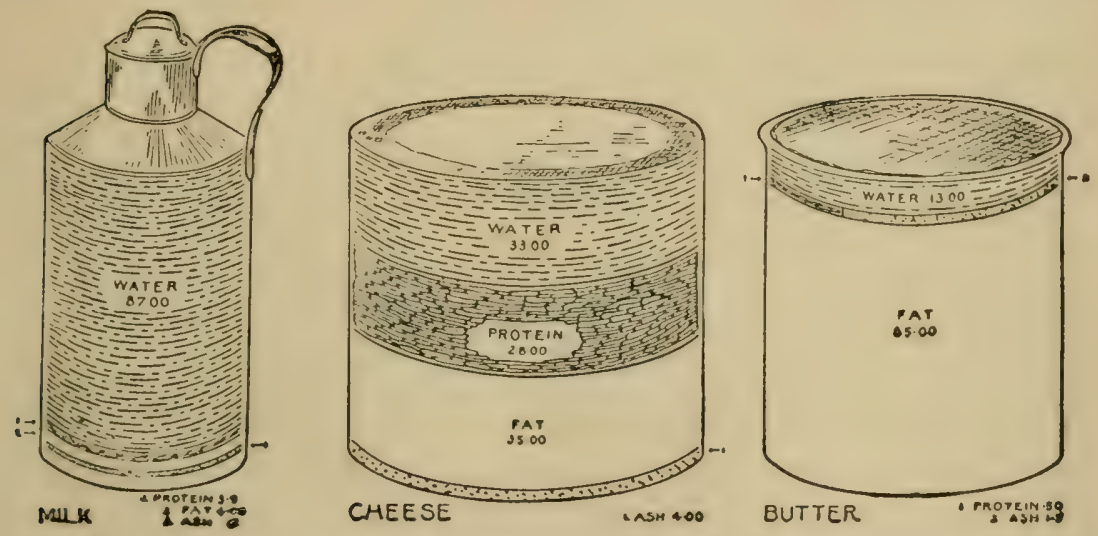

FIG. I00. - Comparative composition of milk, cheese, and butter

approximately determined by comparing the amounts of nutrients which a given sum of money will procure in each case. The principle is the same as in the comparison of cost and value of animal foods, Section 483 .

In making comparisons, preference cannot be given to any single nutrient. In general, however, foods which 
supply the largest amount of protein for a given sum of money are cheapest and most economical, provided there is no great difference in the amounts of fat and carbohydrates. When there is but little difference in protein content, preference should be given to foods yielding the largest number of calories.

In order to calculate the nutrients which can be procured for a given sum of money, first determine the pounds of food, then multiply the weight by the percentage composition, using the figures in the tables.

When round steak is ${ }_{5}$ cents per pound and milk 5 cents per quart, the amounts of nutrients which can be purchased for i 5 cents are as follows :

\begin{tabular}{|c|c|c|c|c|c|}
\hline \multirow[b]{2}{*}{ Round steak. } & \multirow[b]{2}{*}{ lbs. } & \multicolumn{3}{|c|}{ I5 cents will buy } & \multirow[b]{2}{*}{$\begin{array}{c}\text { Calories } \\
870\end{array}$} \\
\hline & & $\begin{array}{l}\text { Protein. } \\
\text { lb. } \\
\text { o. I } 8\end{array}$ & $\begin{array}{l}\text { Fat. } \\
\text { lb. } \\
\text { O. I } 2\end{array}$ & $\begin{array}{c}\begin{array}{c}\text { Carbo- } \\
\text { hydrates. } \\
\text { lb. }\end{array} \\
\ldots\end{array}$ & \\
\hline Milk. & 6 & $0.2 \mathrm{I}$ & 0.24 & 0.30 & I050 \\
\hline
\end{tabular}

Three quarts of milk or six pounds contain 0.03 pound more protein and 0.12 pound more fat and yield over I000 calories more than a pound of round steak costing the same. Milk at 5 cents per quart should be used liberally in the ration when steak is $\mathrm{I} 5$ cents or more per pound. It does not follow that meat should be entirely excluded from the ration in favor of milk, but the nutrients indicate that milk should be used in liberal amounts.

Problem I. - Calculate a balanced ration for a man at hard muscular labor and give the cost of the food articles required.

Problem 2. - Calculate a ration for a man with little physical exercise, giving cost of ration.

Problem 3. - Calculate the amounts of foods and the nutrients required for a family of seven for ten days, three of the family to be considered as consuming each 0.8 as much as an adult. Calculate 
the cost of the food. Then calculate, on the same basis, the probable amounts of food for one year with cost, adding 20 per cent additional for fluctuations in market prices and foods not included in the ten-day list.

Problem 4. - How do beef and mutton compare as to nutrients when they are the same price per pound?

Problem 5. - Calculate the comparative amounts of nutrients that can be procured in cheese and loin steak at current market prices.

Problem 6. - How do the nutrients in chicken at 16 cents per pound compare with those in round steak at 18 cents per pound?

Problem 7. - How does flour at $3 \frac{1}{2}$ cents per pound compare in nutritive value with a cereal breakfast food at Io cents per pound, and having the same composition as whole wheat?

505. Factors Influencing Digestibility. - The factors discussed in Chapter XXXV, which influence the digestibility of animal foods, also influence the digestibility of human foods. The mechanical condition of the food and the method of preparation have a more pronounced effect in a human than in an animal ration. The term digestibility has, by some physiologists, been used to designate ease of digestion rather than completeness of the process, foods which are easily digested and require but little work of the digestive tract being termed digestible, while those which require a larger amount of work are said to be indigestible. Some confusion has arisen from this use of the term digestible. For example, rice is frequently called a digestible food and cheese an indigestible food. Digestion experiments show that cheese is more completely digested than rice. A food which is easily digested is not necessarily completely digested. Variations in the digestive power of individuals influence digestibility; for example, digestion experiments show differences of over I4 per cent in digestibility of the protein in a mixed ration of bread, milk, and beans. 
There is a greater difference between individuals as to the ease of digestion than as to the completeness. Since digestion is largely a biochemical process, its completeness is necessarily influenced by the activity of the cells in the digestive tract. The combining of foods influences digestibility. For example, milk in a ration exerts a favorable influence upon the digestibility of the other foods with which it is combined. This is because of the presence in milk of enzymes or soluble ferments. Experiments show that I 2.5 per cent of the protein in a sterile food, as toast, is capable of. being digested by the soluble ferments of milk.

The method of cooking and preparing foods also exerts an influence upon their digestibility. Cooking changes both the physical and chemical composition of foods; the cell walls of vegetables and cereals are broken and the starch granules ruptured, thus exposing them to more thorough action of the digestive fluids. Cooking influences the ease or rapidity of digestion to a greater extent than it does the completeness of the process. The carbohydrates are favorably influenced by the action of heat, while, in some cases, prolonged heat may make the proteids less digestible. In pasteurized milk, for example, the proteids are slightly less digestible than in pure fresh milk, while in sterilized milk the digestibility is noticeably lessened. As in the case of animals, the mechanical condition of a food influences both the ease and the completeness of the process. With persons of sedentary habits, the best results are secured when a small amount of some coarsely granulated food is present. A large amount of such foods is not suitable in the ration of a hard-working man because of lack of availability of the nutrients. 
506. Requisites of Ration. - Reasonable combinations should be made in forming balanced rations. A number of foods which are slow of digestion or require much intestinal work should not be combined. Neither should a number of foods which are easily digested and leave but little indigestible residue. Two foods which are either laxative or costive should not be combined. After formulating a ration, it should be critically examined to see if it satisfies the following conditions: (I) foods economical and suitable to the work to be performed, (2) foods combined so as to secure balanced work of the digestive tract, (3) foods not too laxative or too costive in effect, (4) requisite bulk, (5) sufficient amount of indigestible residue to dilute the waste products in the intestinal tract.

507. Dietary Studies. - A dietary study considers the cost and amount of nutrients consumed by individuals and families. It is an investigation in which men are used and human foods are studied instead of farm animals and animal foods. Dietary studies show that frequently money is injudiciously spent in the purchase of highpriced foods which contain but a small amount of nutrients. In a dietary study, the amounts of nutrients in the foods exclusive of the refuse parts are determined, and from the weight of the foods, the nutrients contained are calculated, using the tables, or they are determined by chemical analysis.

The purchasing of food is frequently done without regard to nutritive value. Erroneous ideas as to the value of foods are often the cause of extravagance in their purchase and use. As, for example, it has been claimed that the banana is as valuable as beef, and mushrooms have been erroneously called vegetable beefsteak. Many 
other foods are assigned fictitious values. Too frequently, choice is made on the basis of palatability; but cost of nutrients and kind of work to be performed should be considered as well as palatability. Dietary studies of the United States Department of Agriculture show that lack of knowledge in regard to the value of foods has frequently resulted in whole families being underfed, not from necessity, but from lack of judgment in the selection of foods. While it is not practicable or desirable to confine the ration to an absolute standard, dietary studies show that for long periods the best results are obtained when foods are combined so as to secure nutrients in approximately the amounts given as dietary standards. By means of a careful study of the dietary, it is possible to reduce the cost of food without impairing its nutritive value, and in many cases, as the cost is decreased, the nutritive value is increased.

508. Chemical Changes in the Cooking of Foods. - The chemical changes which take place in cooking are brought about by the action of heat, water, and ferments, and occasionally by the use of chemicals. 'The various compounds of which foods are composed, namely, carbohydrates, proteids, and fats, are all susceptible to the action of these agencies, and the chemical changes which they undergo are briefly discussed in Chapters XXIII and XXIV, treating of the composition of the nitrogenous and nonnitrogenous compounds. Some of the changes are physical rather than chemical in character.

All of the different nutrients of foods are influenced by the action of heat. Starch, in the presence of water and heat, undergoes partial hydration, so that the material is in condition both chemically and mechanically to undergo readily inversion changes. In the cooking and 
preparation of foods, starch rarely undergoes more than the hydration change. In bread-making, for example, only a small portion of the original starch is converted into soluble forms.

The action of heat upon cellulose and cellular tissue

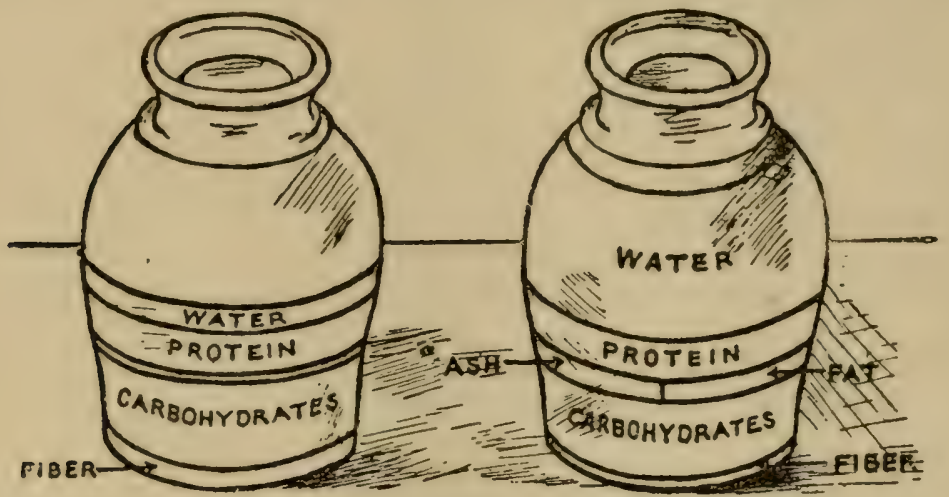

FIG. Ior. - Comparative composition of raw and baked beans.

is mechanical rather than chemical. The mass is partially disintegrated, and in the case of some of the cellulose, hydration takes place to a limited extent. Human foods, however, contain comparatively little of the cellulose group of compounds. The sugars are partially caromelized by heat, provided it is sufficiently intense, but in ordinary cooking operations, they undergo little or no chemical change unless associated with acids, alkalies, or ferment bodies, in which case they may be converted into a number of chemical products.

In the cooking of fruits, as the baking of apples, a portion of the levulose is partially carbonized. If the fruit is not fully matured, the pectose substances or jellies are converted into a more soluble condition by the action of heat. When heat is sufficiently intense, the essential or volatile oils are expelled. Fats, as a class, undergo 
slight oxidation changes by the action of heat. For example, the fat extracted from the bread is different in character from that in the original flour. It is darker in color, and chemical tests show that it is slightly oxidized.

Heat causes the proteids to undergo more complex changes than any other class of nutrients. The soluble albumins are coagulated, the globulins also are coagulated, and if the heat is sufficiently intense, molecular changes take place, in which the elements composing the proteid molecule are rearranged, forming, practically, a new molecule with different chemical and physical properties. Since the proteid compounds contain fatty acid radicals, carbohydrate-like bodies, amides, and radicals of other compounds, a number of chemical changes may take place, varying with the degree of heat employed.

The chemical changes which occur in the process of cooking influence, to a limited extent, the digestibility of the foods. As a rule, the total digestibility of the carbohydrate nutrients is changed but little by the action of heat. For example, experiments show that the carbohydrates in toast are no more completely digested than the carbohydrates in bread, but the action of heat in the preparation of toast produces chemical and physical changes which render the nutrients more susceptible to the action of the digestive fluids, and while toast is no more completely digested than bread, it is more readily acted upon by the digestive fluids. Prolonged heat has a tendency to decrease the digestibility of the proteid compounds as a class. In toast, the proteid nutrients are slightly less digestible than in bread.

In general, it can be said that cooking affects ease of digestion rather than completeness of the process, that the carbohydrates are practically as digestible before the 
action of heat as after, and that the proteids are slightly less digestible after the action of prolonged heat. Experiments in the feeding of animals show that when foods are cooked, the total digestibility of the nutrients is not increased, and in some cases, a smaller amount of nutrients was absorbed after cooking than before. This does not mean that the cooking of foods is undesirable, because ease of digestion is equally as important as completeness of digestion. Also cooking sterilizes the food, which is desirable. Many foods, if consumed uncooked, would be unwholesome because of the presence of ferment bodies or poisonous compounds as ptomaines. When acted upon by heat, the ferment bodies are destroyed and the ptomaine compounds decomposed.

When salt, soda, or other chemicals are used, chemical changes, to a limited extent, take place. Soda, for example, combines with the proteid compounds of foods, forming alkali proteids, and the acids form acid proteids. In cooking and preparing foods, the physical changes which occur often precede and are necessary to the chemical changes. In boiling potatoes, for example, heat changes the physical character of the cells but does not alter the solubility of the starch. The albumin is coagulated, and small amounts of the mineral compounds and other bodies are extracted. In cooking of some of the cereals, as oatmeal, if the process is continued for only a few minutes, the starch is not acted upon to any appreciable extent because of the gelatinous proteids which protect the starch particles. If the cooking is continued for three or four hours, they are disintegrated, the starch cells are ruptured, and instead of masses of starch, small particles of disintegrated starch may be observed. This starch is partially hydrated. Oatmeal cooked in the 
two ways, for a few minutes, and for four hours, contains practically the same percentage amount of total starch.

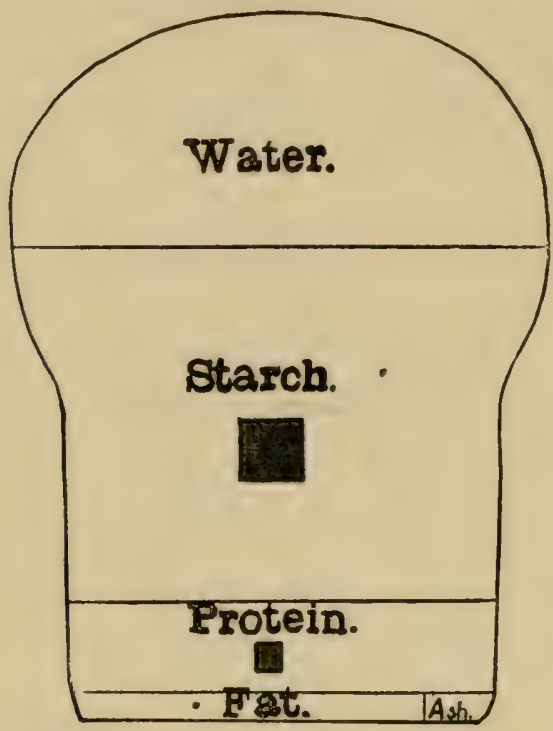

FIG. 102. - Composition of bread. In the one case, however, the starch is in large masses, unruptured and unaltered, while in the other, the starch masses have been ruptured, the particles are in a finer state of division, and are partially hydrated. Oatmeal which has been cooked for only a few minutes does not readily undergo digestion, but four hours' cooking produces physical and intermediate chemical changes that cause the starch to yield readily to the action of the diastase ferment.

In cooking meats, the heat liquefies a portion of the fat and oxidizes a portion of that exposed to the air, while the proteids undergo complex molecular changes. In cooking and preparing foods, it should be the object to bring about physical rather than chemical changes. Cooking influences the ease rather than the completeness of digestion.

509. Refuse and Waste Matters. - Nearly all foods contain some refuse material which cannot be consumed as food. Of average meat, as purchased in the market, from 7 to 56 per cent is refuse; round steak has least, while shank has most. Tables showing the average amounts of refuse in meats are given at the close of the chapter. The waste of a food is frequently enough to 
make the nutrients of the edible portion quite expensive even in apparently cheap foods. In vegetables, the refuse ranges from I 5 to 50 per cent. About I 5 per cent of the weight of potatoes is lost as parings; of fresh peas, one half of the weight is pods, and of squash, one half the weight is rind and seeds. In calculating the nutrients of foods, the refuse and waste parts should be considered, as there is nearly always a smaller percentage amount of nutrients in the edible portion than in the food as purchased.

510. Loss of Nutrients in the Preparation of Foods. In the cooking of vegetables, as potatoes, carrots, and cabbage, some of the soluble nutrients, as albumin, sugar, and mineral matter, are extracted and lost in the water. In the case of potatoes, experiments show that over 57 per cent of the total nitrogenous matter is extracted and lost when potatoes are cut in small pieces and soaked in cold water. When the cleaned, unpeeled potatoes were placed directly in hot water, the loss amounted to only I per cent. In the case of carrots and cabbage, the loss is great if the pieces are small and much water is used. There need not be much loss of nutrients incident to cooking meats, provided mechanical losses are avoided. In the boiling of meat, there is a decrease in weight of about 30 per cent, due largely to loss of water. About 5 per cent of proteid matter is extracted, also I 3 to I 5 per cent of fat and 5 I per cent of mineral matter. With small pieces of meat, the total loss of weight may be over 50 per cent. The amount of nutrients dissolved varies with the size of the pieces. From experiments made at the University of Illinois, there does not appear to be any great difference in the amount of nutrients extracted from meats by hot or cold water. If the broth is utilized 
for soup, the nutrients extracted during cooking are not lost.

5II. Mineral Matter in a Ration. - In the calculation of human as well as animal rations, the mineral content of the food is not considered along with the other nutrients. This is not because the mineral nutrients are of insignificant value, but because nearly all combinations of foods contain sufficient, both in amount and variety, for nutritive purposes. Phosphates, compounds of iron, potassium, and magnesium are required only in comparatively small amounts. It is estimated that with a man at hard labor from 2 to 3.5 grams per day of phosphoric acid are eliminated through the kidneys. Since this includes all of the soluble mineral phosphates of the food, and not all of those are used for functional purposes, it is not necessary that the food should contain even 2 to 3.5 grams of available phosphates per day. A ration consisting entirely of white bread contains enough phosphates to supply the body and establish a phosphate equilibrium. An average daily ration of mixed foods contains from 5 to 8 grams or more. Meats and nearly all animal foods contain about I per cent of mineral matter, of which about half is phosphoric acid. Milk and eggs contain phosphates and mineral matter in liberal amounts. In a mixed ration of three or more food articles, there is always enough phosphates and mineral matter for purposes of nutrition. A part of the excess of phosphates in a ration is eliminated through the kidneys. The feces also contain phosphoric acid. Inability of the organs to assimilate phosphates, due to malnutrition and lack of available forms of other nutrients, is more frequently a source of trouble than lack of phosphates in the food. 
"It is evident, however, that a large part of the mineral constituents of cereals is not required for nourishment of the body. Feeding experiments have confirmed this theoretical view, and the ash of food materials has the lowest coefficient of digestion of any constituents thereof with the possible exception of cellulose.

"In grinding and reducing to merchantable flour a considerable portion, as a rule more than half, of the mineral ingredients is removed in the waste products of the meal. Enough is left, however, not only to supply the need of the body for mineral constituents but also for condimentary purposes." (H. W. Wiley, Bul. I3, Part 9, Div. Chem., U. S. Dept. Agr.)

It is estimated that in the ration of an adult, about 20 grams per day of sodium chlorid are necessary. This compound takes an important part in nutrition and is a normal constituent of all the fluids of the body.

5I2. Digestibility of Foods. - The digestibility of foods is a subject which belongs for investigation alike to the chemist, the physiologist, and the bacteriologist. The physiologist considers the structure of the digestive tract and the functions of the various organs; the chemist studies the chemical changes which occur while the food is undergoing digestion, the completeness of the digestion process, and the extent to which the nutrients of the food are made available to the body; the bacteriologist deals with the ferment bodies which assist in the process of digestion.

5r3. Digestibility of Meats. - The nutrients of meats, particularly the fats and proteids, are more completely digested than the same classes of nutrients in vegetables. From 93 to 95 per cent or more of the proteids and fats from foods of animal origin are completely digested, 
while of vegetables not more than 85 per cent of the proteids are completely digested except in the case of finely ground flour. Meats are concentrated foods, as they furnish large amounts of nutrients in digestible forms. There is less difference in the completeness with which the various meats are digested than in the ease of digestion. Some meats, as pork, veal, and mutton, which are called indigestible, are slow of digestion but are quite completely digested. The nutrients of meats can, for all practical purposes, be considered entirely digestible.

\section{I4. Digestibility of Vegetable Foods. - Vegetable} foods are less completely digestible than animal foods. The larger the amount of cellulose or fiber, the less completely digested is the food. Only a very small amount of the cellulose, even hydrated cellulose, of human foods is available to the body. In many vegetables the nutrients are inclosed in cellular tissue, and thus, to a certain extent, are protected from the solvent action of the digestive fluids. The starches and carbohydrates of vegetables are more completely digested than the proteids. Frequently 95 per cent of the starch and only 80 per cent or less of the proteids are digested. There is a wide range in the digestibility of the nutrients of vegetable foods. The nutrients of fruits are, as a rule, more completely digested than those from other vegetable sources, but fruits contain little nutritive material.

515. Relation of Food to Health. - Since the function of food is to supply the body with nourishment, the subjects of food and health are necessarily closely related. If too long continued, either an abnormally large or too scant an amount of food affects the health. And not only is the amount important to health but also the quality of the food, as nature of nutrients and sanitary 
condition. Many diseases result from malnutrition, while many others are caused by the use of foods in an unsanitary condition. Food may cause disease either on account of its being unsanitary or because of an excessive or deficient amount of nutrients, or because the nutrients are unbalanced. 


\section{Composition of Human Foods.}

(From Bulletins Nos. 28 and 34, Office of Experiment Stations.)

\begin{tabular}{|c|c|c|c|c|c|c|c|}
\hline \multirow[b]{2}{*}{ KiND OF FoOD. } & \multirow[b]{2}{*}{ 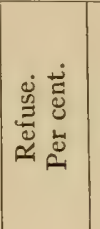 } & \multirow[b]{2}{*}{ 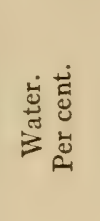 } & \multicolumn{4}{|c|}{ NUTRIENTS. } & \multirow{2}{*}{ 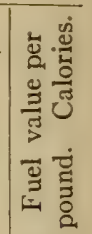 } \\
\hline & & & 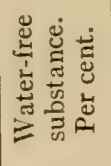 & 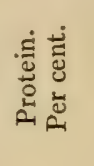 & 永泀 & 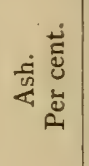 & \\
\hline BEEF - Chuck ribs : & & & & & & & \\
\hline Edible portion. . . . . . . & & $57 \cdot 3$ & 42.7 & I $7 \cdot 4$ & $24 \cdot 4$ & 0.9 & I355 \\
\hline $\begin{array}{l}\text { As purchased ......... } \\
\text { Loin : }\end{array}$ & I 3.8 & $49 \cdot 3$ & 36.9 & I 5.0 & $2 \mathrm{I} . \mathrm{I}$ & 0.8 & I I 70 \\
\hline Edible portion ........ & .. & 60.5 & $39 \cdot 5$ & I 8.3 & 20.2 & I.O & I I 90 \\
\hline $\begin{array}{l}\text { As purchased ...... } \\
\text { Neck: }\end{array}$ & I 3.0 & 52.6 & $34 \cdot 4$ & I 5.9 & I 7.6 & 0.9 & 1040 \\
\hline Edible portion . . . . . . . & . . & $63 \cdot 4$ & 36.6 & I9.2 & I6.5 & 0.9 & 1055 \\
\hline $\begin{array}{l}\text { As purchased ......... } \\
\text { Ribs: }\end{array}$ & 27.6 & $45 \cdot 9$ & 26.5 & I $3 \cdot 9$ & I I.9 & 0.7 & 760 \\
\hline Edible portion....... & & $55 \cdot 4$ & 44.6 & I6.9 & 26.8 & 0.9 & I 445 \\
\hline $\begin{array}{l}\text { As purchased ......... } \\
\text { Round: }\end{array}$ & 20.8 & 43.8 & $35 \cdot 4$ & $13 \cdot 4$ & $2 \mathrm{I} \cdot 3$ & 0.7 & I I 50 \\
\hline Edible portion....... & $\cdots$ & 65.8 & 34.2 & I9.7 & I $3 \cdot 5$ & 1.0 & 935 \\
\hline $\begin{array}{l}\text { As purchased ........ } \\
\text { Rump : }\end{array}$ & $7 \cdot 7$ & 60.7 & 31.6 & I 8. I & I 2.6 & 0.9 & 870 \\
\hline Edible portion . . . . . . & $\ldots$ & 56.7 & $43 \cdot 3$ & I6.8 & 25.6 & 0.9 & I395 \\
\hline $\begin{array}{l}\text { As purchased....... } \\
\text { Shank, fore: }\end{array}$ & $2 \mathrm{I} .4$ & $44 \cdot 5$ & $34 \cdot I$ & 13.2 & 20.2 & 0.7 & 1095 \\
\hline Edible portion.... & $\ldots$ & $67 \cdot 9$ & $32 . I$ & I9.6 & I I. 6 & 0.9 & 855 \\
\hline $\begin{array}{l}\text { As purchased....... } \\
\text { Shank, hind: }\end{array}$ & 36.9 & 42.9 & 20.2 & I 2.3 & $7 \cdot 3$ & 0.6 & 535 \\
\hline Edible portion........ & $\ldots$ & 67.8 & 32.2 & I9.8 & I I. 5 & 0.9 & 855 \\
\hline $\begin{array}{l}\text { As purchased......... } \\
\text { Fore quarter : }\end{array}$ & 53.9 & $3 I \cdot 3$ & I 4.8 & 9.I & $5 \cdot 3$ & 0.4 & 395 \\
\hline Edible portion...... & $\cdots$ & $6 \mathrm{r} .4$ & 38.6 & 17.5 & 20.2 & 0.9 & I I 80 \\
\hline $\begin{array}{l}\text { As purchased ....... } \\
\text { Hind quarter : }\end{array}$ & I9.4 & $49 \cdot 5$ & $3 I . I$ & I 4.1 & I6.3 & 0.7 & 9.50 \\
\hline Edible portion ........ & $\cdots$ & 61.0 & 39.0 & I 8.0 & 20.1 & 0.9 & I 8 I 5 \\
\hline
\end{tabular}


Composition of Human Foods (Continued).

BEEF (Contin'd) :

As purchased........

Cooked, corned, and canned:

As purchased

Dried and smoked:

As purchased.

VEAL - Leg, whole:

Edible portion

As purchased

Rump :

Edible portion..........

As purchased

Fore quarter :

Edible portion

As purchased

Hind quarter:

Edible portion

As purchased.

LAMB - Leg, hind :

Edible portion.

As purchased.

Loin :

Edible portion

As purchased.

Neck:

Edible portion

As purchased.

Shoulder:

Edible portion

As purchased.

\begin{tabular}{|c|c|c|c|c|c|c|}
\hline \multirow[b]{2}{*}{ 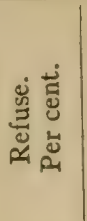 } & \multirow[b]{2}{*}{ 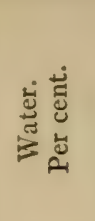 } & \multicolumn{4}{|c|}{ Nutrients. } & $\dot{y}$ \\
\hline & & 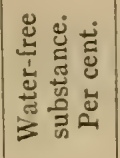 & 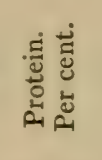 & 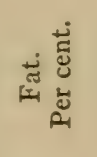 & 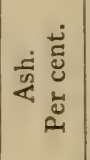 & 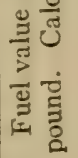 \\
\hline I 5.8 & $5 \mathrm{I} \cdot 3$ & 32.9 & I 5.2 & I 7.0 & 0.7 & 1000 \\
\hline & $53 . I$ & 46.9 & 28.5 & I 4.0 & $4 \cdot 4$ & I I 20 \\
\hline & 50.8 & $49 \cdot 2$ & 31.8 & 6.8 & $\cdots$ & 845 \\
\hline & 70.4 & 29.6 & 20.1 & 8.4 & I. I & 730 \\
\hline I 5.6 & 59.4 & 25.0 & I6.9 & 7.2 & 0.9 & 620 \\
\hline$\ldots$ & 62.6 & $37 \cdot 4$ & 20.1 & I6. 2 & I.I & 1055 \\
\hline 30.2 & $43 \cdot 7$ & 26. I & 14.0 & I I. 3 & 0.8 & 735 \\
\hline$\cdots$ & 71.7 & 28.3 & I9. 4 & 8.0 & 0.9 & 700 \\
\hline $24 \cdot 5$ & $54 \cdot 2$ & $2 \mathrm{I} \cdot 3$ & I 4.6 & 6.0 & 0.7 & 525 \\
\hline & 70.9 & 29. I & I 9.8 & 8.3 & I.O & 720 \\
\hline 20.7 & 56.2 & $23 . I$ & I $5 \cdot 7$ & 6.6 & 0.8 & 570 \\
\hline & 63.9 & $36 . \mathrm{I}$ & I 8.5 & I 6.5 & I. I & 1040 \\
\hline I $7 \cdot 4$ & 52.9 & 29.7 & I 5.2 & I 3.6 & 0.9 & 855 \\
\hline & $53 . \mathrm{I}$ & 46.9 & 17.6 & 28.3 & 1.0 & I 520 \\
\hline I 4.8 & $45 \cdot 3$ & $39 \cdot 9$ & I 5.0 & $24 \cdot I$ & 0.8 & I 295 \\
\hline$\cdots$ & $5^{6.7}$ & $43 \cdot 3$ & I $7 \cdot 5$ & 24.8 & I.O & 1375 \\
\hline I 7.7 & 46.7 & 35.6 & I 4.4 & 20.4 & 0.8 & I I 30 \\
\hline & 51.8 & 48.2 & I 7.5 & $29 \cdot 7$ & 1.0 & I 580 \\
\hline 20.3 & $4 \mathrm{I} \cdot 3$ & 38.4 & 14.0 & 23.6 & 0.8 & I 255 \\
\hline
\end{tabular}


Composition of Human Foods (Continued).

KIND OF FOOD.

Mutron - Leg, hind : Edible portion........ As purchased

Loin :

Edible portion As purchased

Neck :

Edible portion As purchased

Shoulder :

Edible portion........ As purchased.

Fore quarter:

Edible portion As purchased.

Hind quarter:

Edible portion As purchased.

Side, without tallow :

Edible portion As purchased.

PORK - Flank:

Edible portion As purchased

Ham, smoked :

Edible portion As purchased.

Shoulder, fresh :

Edible portion As purchased.

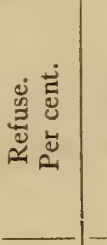$$
\text { ( }
$$$$
\text { I } 8.0
$$

I 8.0

.

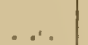

I $5 \cdot 3$

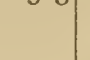

3. 4

28.4

58.2

41.6

50. I

42.2

62.8

$$
37.2
$$

$$
30.6
$$

NUTRIENTS.

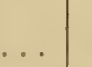

21.7

6r.9

48.5

$$
7
$$

$5 \mathrm{I} .7$

2I. I

40.6

...

- 54.8

I6.7 45.6

45.6

45.

37.

38. I

I 7.3

29.8

I 3.5

48.3

I 5.0

38.3

I I.9

32.4

25.7

33.2

28.6

$0.8 \times 695$

0.7 I 450

24.5

I 7.6

ฯ.० 1335

\begin{tabular}{l|l}
0.7 & 960
\end{tabular}

I9.9

0.9 I 160

I 5.6

0.79 10

0.9 I 645

0.7 × 305

28.2

$0.8 \times 490$

23.5

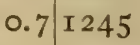

53.1

46.9

…

42.9

37.9

(5)

I 5.4

30.7

0.71580

I.

5.

...

59.0

I 7.0

$$
41.0
$$

I

I 2.5

24.7

0.71275

40.7

I $4.4 \quad 34.9$

...

57.5

46.6
30.4
50.7

I $3 \cdot 3$

42.5

$\mathrm{r} 5.6$

8.3

23.0
4I.0 $\quad$ I 7.8

22.2

I I. 8

$5 . \mathrm{I}$

59.3

I $5 \cdot 5$

6.4

I. 1265

$0.3 \quad 365$

39. I

4.7 1940

$33.4 \quad 4.0 \quad 1655$

26. I

0.8 I 390

I 4.3
0.4760 
Composition of Human Foods (Continued).

\begin{tabular}{|c|c|c|c|c|c|c|c|}
\hline \multirow[b]{2}{*}{ KIND OF FOOD. } & \multirow[b]{2}{*}{ 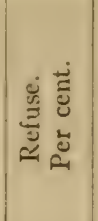 } & \multirow[b]{2}{*}{ 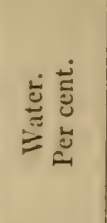 } & \multicolumn{4}{|c|}{ NUTRIFNTS. } & \multirow{2}{*}{ 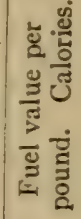 } \\
\hline & & & 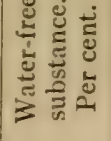 & 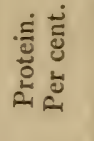 & 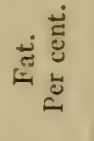 & 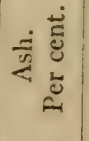 & \\
\hline $\begin{array}{l}\text { Pork (Contin'd) : } \\
\text { Salt, clear fat: }\end{array}$ & & & & & & & \\
\hline $\begin{array}{l}\text { As purchased....... } \\
\text { Salt, lean ends: }\end{array}$ & & $7 \cdot 3$ & 92.7 & I. 8 & 87.2 & $3 \cdot 7$ & 37 I 5 \\
\hline Edible portion....... & & I9.9 & So.I & $7 \cdot 3$ & 67.1 & $5 \cdot 7$ & 2965 \\
\hline $\begin{array}{l}\text { As purchased ........ } \\
\text { Bacon, smoked: }\end{array}$ & I I.2 & 17.6 & 71.2 & 6.5 & 59.6 & 5.1 & 2635 \\
\hline Edible portion...... & $\cdots$ & I 8.2 & $8 \pi .8$ & I0.0 & 67.2 & $4 \cdot 6$ & 3020 \\
\hline $\begin{array}{l}\text { As purchased } \ldots . . . \\
\text { Side: }\end{array}$ & 8.0 & I6.8 & 75.2 & $9 \cdot 2$ & $6 \mathrm{r} .8$ & 4.2 & 2780 \\
\hline Edible portion....... & $\cdots$ & $29 \cdot 4$ & 70.6 & 8.5 & $6 \mathrm{r} \cdot 7$ & 0.4 & 2760 \\
\hline $\begin{array}{l}\text { As purchased.......... } \\
\text { Poultry - Chicken : }\end{array}$ & II. 2 & 26.1 & 62.7 & $7 \cdot 5$ & 54.8 & 0.4 & 2455 \\
\hline Edible portion........ & & 74.2 & 25.8 & 22.8 & I.8 & I. 2 & 500 \\
\hline $\begin{array}{l}\text { As purchased........ } \\
\text { Turkey: }\end{array}$ & 34.8 & 48.5 & r6.7 & I 4.8 & I.I & 0.8 & 325 \\
\hline Edible portion....... & $\cdots$ & $55 \cdot 5$ & $44 \cdot 5$ & 20.6 & 22.9 & I.O & I350 \\
\hline $\begin{array}{l}\text { As purchased . . . . . . } \\
\text { Fish, fresh - Cod, } \\
\text { dried: }\end{array}$ & 22.7 & 42.4 & $34 \cdot 9$ & I $5 \cdot 7$ & I 8.4 & 0.8 & 1070 \\
\hline Edible portion ........ & $\cdots$ & 82.6 & I $7 \cdot 4$ & I 5.8 & 0.4 & I.2 & 310 \\
\hline $\begin{array}{l}\text { As purchased ........ } \\
\text { Mackerel, ent. rem'd: }\end{array}$ & 29.9 & 58.5 & I 1.6 & I0.6 & 0.2 & 0.8 & 205 \\
\hline Edible portion ....... & $\cdots$ & $73 \cdot 4$ & 26.6 & I8. 2 & $7 \cdot I$ & I.3 & 640 \\
\hline $\begin{array}{l}\text { As purchased .......... } \\
\quad \text { Salmon, Cal., sections: }\end{array}$ & 40.7 & $43 \cdot 7$ & I 5.6 & I I. 4 & $3 \cdot 5$ & 0.7 & 360 \\
\hline Edible portion ........ & . & 63.6 & 36.4 & I 7.5 & 17.9 & 1.0 & I080 \\
\hline $\begin{array}{l}\text { As purchased ......... } \\
\text { Salmon trout, whole: }\end{array}$ & 10.3 & 57.9 & 31.8 & I6.I & I 4.8 & 0.9 & 925 \\
\hline Edible portion ........ & & $69 . x$ & 30.9 & I 8.2 & I I.4 & I.3 & 820 \\
\hline As purchased ... .. & $56 \cdot 3$ & 30.0 & $13 \cdot 7$ & $7 \cdot 7$ & $5 \cdot 4$ & 0.6 & 985 \\
\hline
\end{tabular}


Composition of Human Foods (Continued).

\begin{tabular}{|c|c|c|c|c|c|c|c|}
\hline \multirow[b]{2}{*}{ Kind of Food. } & \multirow[b]{2}{*}{ 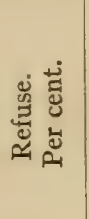 } & \multirow[b]{2}{*}{ 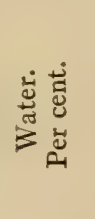 } & \multicolumn{4}{|c|}{ Nutrients. } & \multirow{2}{*}{ 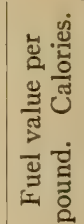 } \\
\hline & & & 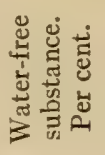 & 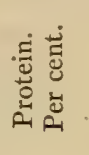 & 芯 & 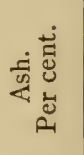 & \\
\hline $\begin{array}{l}\text { Fish (Contin'd) : } \\
\text { Trout, brook, whole: } \\
\text { dible portion ........ }\end{array}$ & $\ldots$ & 77.8 & 22.2 & I 8.0 & 2. I & I. 2 & 440 \\
\hline $\begin{array}{l}\text { As purchased ........ } \\
\text { Fish, pres'v'd, Cod, } \\
\text { salt: }\end{array}$ & $48 . I$ & 40.4 & I I. 5 & 9.8 & I. I & 0.6 & 230 \\
\hline dible portion $\ldots . .$. & . & 53.6 & 46.4 & $2 \mathrm{I} \cdot 4$ & 0.4 & 24.6 & 410 \\
\hline $\begin{array}{l}\text { As purchased ........ } \\
\text { Mackerel, salt : }\end{array}$ & 24.9 & 40.3 & 34.8 & I6.0 & 0.4 & I 8.4 & 3 I 5 \\
\hline dible portion ... & $\cdots$ & 42.2 & 57.8 & 22.0 & 22.6 & $\mathrm{I} 3.2$ & 1360 \\
\hline $\begin{array}{l}\text { As purchased ......... } \\
\text { Salmon, canned, as pur- }\end{array}$ & 22.9 & $32 \cdot 5$ & $44 \cdot 6$ & I 7.0 & I 7.4 & IO.2 & 1050 \\
\hline $\begin{array}{l}\text { chased } \ldots . . . . \\
\text { Sardines, canned, as }\end{array}$ & .. & $64 \cdot 5$ & $35 \cdot 5$ & 20.1 & I I. 6 & 2.4 & 890 \\
\hline $\begin{array}{l}\text { purchased ....... } \\
\text { Shell fish, clams, } \\
\text { round: }\end{array}$ & $\ldots$ & 56.4 & 43.6 & $25 \cdot 3$ & I 2.7 & 5.6 & 1010 \\
\hline Edible portion ....... & $\cdots$ & 86.2 & I3.8 & 6.5 & 0.4 & 2.7 & 2 I 5 \\
\hline $\begin{array}{l}\text { As purchased ........ } \\
\text { Oysters, "solids," as }\end{array}$ & $67 \cdot 5$ & 28.0 & $4 \cdot 5$ & 2. I & O.I & 0.9 & \\
\hline $\begin{array}{l}\text { purchased....... } \\
\text { DAIRY PRoducts : }\end{array}$ & . . & 88.3 & I I. 7 & 6.1 & I. 4 & 0.9 & 235 \\
\hline Cheese - Cheddar.... & $\cdots$ & 33.0 & 67.0 & 28.0 & 35.0 & 4.0 & I999 \\
\hline Butter. . & $\cdots$ & $13 \cdot 0$ & 87.0 & 0.5 & 85.0 & I. 5 & 3600 \\
\hline Milk......... & $\cdots$ & 87.0 & I 3.0 & $3 \cdot 5$ & $4 \cdot 0$ & 0.7 & 323 \\
\hline $\begin{array}{l}\text { Cream } \ldots . . . . . \\
\text { EgGs : }\end{array}$ & ... & $\ldots$ & $\ldots$ & 2.5 & 20.0 & 0.5 & $\cdots$ \\
\hline n shell..... & I 3.7 & $63 \cdot 1$ & 23.2 & I $2 . \mathrm{J}$ & 10.2 & 0.9 & 655 \\
\hline Edible portion . & $\ldots$ & 73.8 & 26.2 & I 4.9 & 10.5 & 0.8 & $72 \mathrm{I}$ \\
\hline
\end{tabular}

${ }^{1}$ Milk also contains 4.8 per cent carbohydrates. The fat content of cream ranges from io to 30 per cent. 
Composition of Human Foods (Continued).

\begin{tabular}{|c|c|c|c|c|c|c|c|}
\hline KIND of Food. & 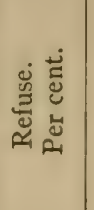 & 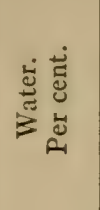 & 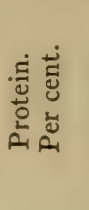 & 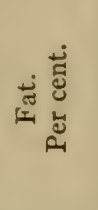 & 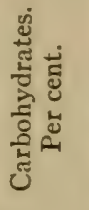 & 造苞 & 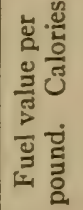 \\
\hline $\begin{array}{l}\text { Wheat flours, meals, } \\
\text { etc: }\end{array}$ & & & & & & & \\
\hline${ }^{1}$ Roller process flour ... & $\cdots$ & I 2.9 & I 2.2 & I.O & $74 \cdot 3$ & 0.5 & 1665 \\
\hline Spring wheat flour ... & $\cdots$ & I I. 6 & I I. 8 & I. I & $75 \cdot 0$ & 0.5 & I 660 \\
\hline Winter wheat flour ... & $\cdots$ & I 2.5 & IO. 4 & 1.0 & $75 \cdot 6$ & 0.5 & I 640 \\
\hline Buckwheat flour ..... & $\cdots$ & $\mathrm{I} 4 \cdot 3$ & 6.I & 1.0 & 77.2 & I. 4 & I 590 \\
\hline Corn meal, bolted... & $\cdots$ & I 2.9 & 8.9 & 2.2 & $75 \cdot \mathrm{I}$ & 0.9 & 1655 \\
\hline Oatmeal ......... & . . & $7 \cdot 2$ & I 5.6 & $7 \cdot 3$ & 68.0 & I.9 & I 860 \\
\hline Rice ........ & . . & I 2.4 & 7.8 & 0.4 & 79.0 & 0.4 & 1630 \\
\hline Rice, boiled ... & . . & 52.7 & 5.0 & O.I & 41.9 & 0.3 & 875 \\
\hline${ }^{1}$ White bread .... & . . & 31.0 & $9 \cdot 9$ & I.4 & $57 \cdot 1$ & 0.6 & 1306 \\
\hline${ }^{1}$ Graham bread ... & . & 32.2 & $9 \cdot 5$ & 2.5 & $54 \cdot 7$ & I. I & $\ldots$ \\
\hline Crackers ... . . . . . & $\cdots$ & 8.2 & 10.7 & $9 \cdot 9$ & 68.8 & $2 \cdot 4$ & I 895 \\
\hline Sugar, granulated .... & $\cdots$ & $\cdots$ & $\cdots$ & $\cdots$ & 98.0 & $\cdots$ & I600 \\
\hline $\begin{array}{l}\text { Sugar, maple ......... } \\
\text { Vegetables - Aspara- } \\
\text { gus: }\end{array}$ & . . & $\cdots$ & $\cdots$ & $\ldots$ & 82.8 & $\cdots$ & I 540 \\
\hline $\begin{array}{l}\text { As purchased ........ } \\
\text { Beans, dried : }\end{array}$ & . & 94.0 & I.8 & 0.2 & $3 \cdot 3$ & 0.7 & 105 \\
\hline $\begin{array}{l}\text { As purchased ....... } \\
\text { Beets : }\end{array}$ & - & I 3.2 & 22.3 & I. 8 & 59.1 & 3.6 & I 590 \\
\hline Edible portion ...... & $\ldots$ & 87.6 & I. 6 & O.I & 9.6 & I. I & 210 \\
\hline $\begin{array}{l}\text { As purchased ........ } \\
\text { Cabbage: }\end{array}$ & 20.0 & 70.0 & I. 3 & $0 . I$ & $7 \cdot 7$ & 0.9 & 170 \\
\hline Edible portion ........ & $\ldots$ & 90.3 & 2.I & 0.4 & 5.8 & I. 4 & I65 \\
\hline $\begin{array}{l}\text { As purchased } \ldots \ldots \ldots \text {. } \\
\text { Carrots : }\end{array}$ & I 5.0 & 76.8 & I. 8 & 0.3 & 4.9 & $\mathrm{I} .2$ & 140 \\
\hline Edible portion ........ & $\cdots$ & 88.2 & I. I & 0.4 & 9.2 & I.I & 210 \\
\hline As purchased ........ & 20.0 & 70.5 & 0.9 & 0.3 & $7 \cdot 4$ & 0.9 & I 70 \\
\hline
\end{tabular}

1 From Minnesota analyses. 
Composition of Human Foods (Continued).

\begin{tabular}{|c|c|c|c|c|c|c|c|}
\hline KIND OF Foods. & 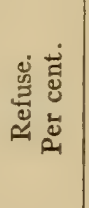 & 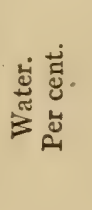 & 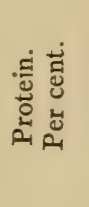 & 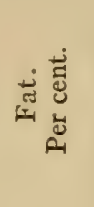 & 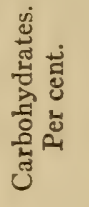 & 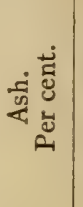 & 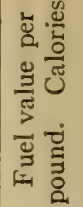 \\
\hline $\begin{array}{l}\text { Vegetables (Contin'd) : } \\
\text { Parsnips: }\end{array}$ & & & & & & & \\
\hline dible portion........ & $\cdots$ & 79.9 & I. 7 & 0.6 & I6. I & I.7 & 553 \\
\hline $\begin{array}{l}\text { As purchased.......... } \\
\text { Peas, dried : }\end{array}$ & 20.0 & 63.9 & I. 3 & 0.5 & I 2.9 & I. 4 & 528 \\
\hline $\begin{array}{l}\text { As purchased.......... } \\
\text { Peas, green : }\end{array}$ & . & I0.8 & $24 . I$ & I. I & $6 \mathrm{I} \cdot 5$ & 2.5 & I 640 \\
\hline dible portion........ & $\cdots$ & 78.1 & $4 \cdot 4$ & 0.5 & I6.I & 0.9 & 400 \\
\hline $\begin{array}{l}\text { As purchased.......... } \\
\text { Potatoes, raw: }\end{array}$ & 50.0 & $39 \cdot 0$ & 2.2 & 0.3 & 8.0 & 0.5 & 200 \\
\hline dible portion........ & $\cdots$ & 78.9 & 2.1 & O.I & I 8.0 & 0.9 & 380 \\
\hline $\begin{array}{l}\text { As purchased.......... } \\
\text { Potatoes, sweet: }\end{array}$ & 15.0 & $67 \cdot I$ & I. 8 & O.I & I $5 \cdot 3$ & 0.7 & 325 \\
\hline dible portion......... & $\cdots$ & $69 \cdot 3$ & I. 8 & 0.7 & $27 . I$ & I.I & 565 \\
\hline $\begin{array}{l}\text { As purchased ......... } \\
\text { Squash: }\end{array}$ & I 5.0 & 58.9 & I.5 & 0.6 & $23 \cdot I$ & 0.9 & 480 \\
\hline dible portion........ & $\cdots$ & 86.5 & r.6 & 0.6 & 10.4 & 0.9 & 245 \\
\hline $\begin{array}{l}\text { As purchased } \ldots . . . \\
\text { Turnips: }\end{array}$ & 50.0 & $43 \cdot 3$ & 0.8 & 0.3 & 5.2 & 0.4 & I 25 \\
\hline dible portion........ & $\cdots$ & 88.9 & r. 4 & 0.2 & 8.7 & 0.8 & I95 \\
\hline $\begin{array}{l}\text { As purchased......... } \\
\text { Tomatoes: }\end{array}$ & 30.0 & 62.2 & I.० & O.I & 6.I & 0.6 & I35 \\
\hline Edible portion......... & .. & 96.0 & 0.8 & 0.4 & 2.5 & 0.3 & 80 \\
\hline Green corn . . . . . . . . & . . & $8 \mathrm{r} \cdot 3$ & 2.8 & I.I & I $4 . \mathrm{I}$ & 0.7 & 360 \\
\hline Cucumber........... & . . & 96.0 & 0.8 & 0.2 & 2.5 & 0.5 & 70 \\
\hline Spinach. ............ & . & 92.4 & 2.I & 0.5 & $3 \cdot I$ & I.9 & 120 \\
\hline Sauerkraut.......... & .. & 86.3 & 1.5 & 0.8 & $4 \cdot 4$ & 7.0 & 145 \\
\hline
\end{tabular}




\section{INDEX}

Acid, citric

hydrochloric

malic.

oxalic

phosphoric

salts

silicic

sulfuric

tannic

tartasic

Acids .

basicity of

fatty

naming of

organic

Aërobic ferments .

Air

a mechanical mixture

ammonium compounds of .

as plant food

carbon dioxid of

impurities in

liquid

moisture in

Albumin in meat

Albumins

Albuminates

Albuminoids

Alfalfa

food value of

Aliphatic series

Alkaloids

Allotropism

Aluminum

Alums

in plants

Amides

food value

occurrence in animals

plants

$\begin{array}{rr}r & 197 \\ 76-79 \\ . \quad 196 \\ . \quad 197 \\ . \quad 90 \\ . \quad 72 \\ . \quad 98 \\ . \quad 94 \\ . \quad 197 \\ . \quad 196\end{array}$

69

72

I9I

7 I

I95

319

63,68

63

65

74

63,65

67

67

66

352

208

209

$215-217$

216 253

I08

220

47

I38

I6 I

I38

2I 7-220

22 I

2 I 8

$2 \mathrm{I} 7$
Ammonia . . . ... 84

properties of . . 85

uses of . . . 85

Ammonium compounds in air . 65

Anaërobic ferments . . . . 305

Anhydrids . . . . . . . 86

Animal bodies, composition of $348-355$ fat in . . 349 mineral matter in 348 nitrogenous matter of

Animal life, chemical change . 8

Antitoxins . . . . . . 309

Apatite . . . . . . . . 87, I30

Apparatus, names of . . I7, 20

Apples . . . . . . . 300

Argon . . . . . . . 67

Aromatic series . . . . . 108

Arsenic, occurrence . . . . . I44

poisoning . . . . I 45

Ash determination . . . . . I54

Ash elements, essential . . . . 155

of animal bodies . . . 348

of plants . . . . $153-167$

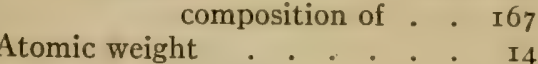

table of . . I 12

Bacteria, disease-producing . . 309

Balanced rations . . . . . 328

calculation of 338

Barley . . . . . .280, 290

grading of . . . . . . 287

Bases . . . . . . . . . 69

naming of . . . . 7 I

Beans . . . . . . . 282

Beef production, foods for . . . 332

Benzine . . . . . . . 103

Beri beri . . . . . . 210 
Bessemer process . . . . . . I35|C

Blast-furnace . . . . . . . I34

Bleaching-powder . . . . . 130

Bordeaux mixture . . . . 142

Bread . . . . . .32I, 37I

Brick . . . . . . . . I39

British thermal units . . . I IO

Bromus Inermis . . . . . . 252

Buckwheat . . . . . . $28 \mathrm{I}$

Burette . . . . . . . 73

Calcium . . . . . . . $\quad{ }_{12} 8$

carbonate . . . . 128

chlorid . . . . . I30

compounds . . . . . I 28

hydroxid . . . . . I29

hypochlorite . . . I30

in plants . . . . . I59

oxid . . . . . . I29

phosphate . . . . I30

sulfate . . . . . I30

Caloric value of rations . . . 34I

Calorie . . . . . . . II 1 , 313

Calorimeter . . . . 3 I 4

Candle, chemistry of . . . 50 power . . . . . . 107

Capillarity of plant tissue . . 229

Carbids . . . . . . . . 109

Carbohydrates . . . . 169-188

Carbon digestibility of . . 319

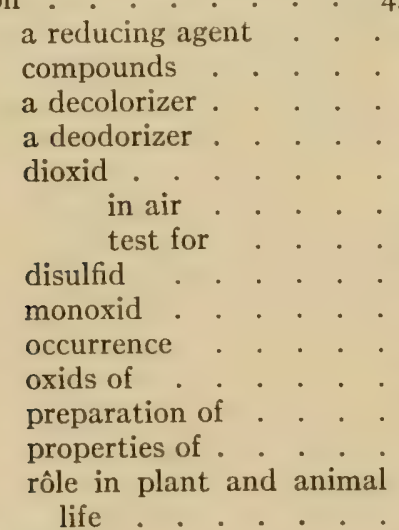

Carbonates :

45-54

47

52

5 I

$5 \mathrm{I}$

IO2

63

I 29

109

I03

45

I 29

45

46

53

IO2

Carrots . . . . . . . 300

Cellulose
Cellulose, chemical properties of . I 7 I food value of . . . 17 I function of . . . I 7 I physical properties of . I 70

Chemical affinity . . . . 7 analysis . . . . 8 changes . . . . 3 properties defined . IO-II

Chemistry . . . . . . . 4

Chlorids . . . . . . . 80

Chlorin . . . . . . . . 78

family . . . . . 80

preparation . . . . 78

properties . . . . . 79

Chlorophyll . . . . .231-234

function of . . 233

production .... 232

Citric acid . . . . . . . 197

Clay . . . . . . . . 100

Cleaning apparatus . . . . 28

Climate and plant growth . . 247

Clover, composition of . . . 236

early and late cut . . 237

hay . . . . . 252

rapidity of growth . 236

Coal . . . . . . . . 47

Combination of elements . . . 16

Combustion . . . . . . . 48

products of . . 5 I

spontaneous . . 50

Composition of matter . . . 3-8

Compounds . . . . . . . 7

Cooking of foods, changes during carbohydrates . . 364 fats . . . . 365

proteids . . . . 366

losses during . . . . 369

Copper . . . . . . . . I4I

compounds . . . $14 \mathrm{I}-\mathrm{I} 42$

sulfate . . . . . I I I

Corks, perforation of . . . 22

Corn (see maize).

fodder . . . . . . 254

Cottonseed cake and meal . . 295

Creosote. . . . . . . 109

Crop growth and soils . . . 246

Crops, improvement of . . . . 249

Crude fiber . . . . . . . 172 
Crude protein

Crystallization, water of

Cyanids

Dairy cows, food for . . . . 335

requirements of . . 334

Definite proportion, law of . . 15

Dextrin . . . . . . 178

Dextrose . . . I82

chemical and physical properties of . . $\quad 182$

Dialysis . . . . . . . 99

Dietary standards . . . . . 356

studies . . . . 363

Digestibility, factors influencing $36 \mathrm{I}$ influence of cooking upon . . 364

Digestible nutrients . . . . 326 in fodders and grains 346,347

Digestion, a biochemical process 3 II chemistry of . . $3 \mathrm{II}-328$ coefficients . . . 3II not constant 323 experiments . . . 3II factors influencing $\quad 320$

Disease, air . . . . . . 67 and water supply . 56-60

Double salts . . . . . . . 72 Dry matter . . . . . . . . I5I

Elastin . . . . . . . 216

Elements and compounds, properties . . . 6-18 classification of . . 69 combination of . . I2, I8 cycle of . . . . . II4

Energy, available, of foods . . 3 I 6 net, of foods . . . 3I7

Epsom salt . - 132

Equations . . . . II5-II8

for classroom . . II $19-120$

Essential oils . . . . . $198-200$ food value . . 200 synthetic production of . . 200

Ether extract . . . . . . . I94

Fat in animal bodies . . . 349 Fats . . . . . . 188-195
Fats, amounts of, in foods . . 193 chemical properties . . . 189 digestion of . . . . . 316 food value of . . . . . 192 formation in plants . . . 188 heat from . . . . . 192 physical properties . . 189

Fatty acids . . . . . . 192

Feeding of animals . . . 328-348 ard sanitary conditions 344 standards . . . . 344 stuffs, inspection of . . 297

Feldspar . . . . . . . . . 100

Fermentation . . 305-310 conditions necessary for . . . 305

Ferments, aërobic . . . 305 anaërobic . . 305 and bread-making . . 307 in butter- and cheesemaking . . . 308 disease-producing . . 309 and food digestion . 308 preservation 308 in seeds . . . . 306 soils . . . . 306 insoluble . . . . 304 soluble . . . . 304

Fertilizers, phosphate . . . . 90 Fiber, crude . . . . . . 172

Filter-paper, folding of . . . . 25

Flame, structure of . . . . . 50

Flax, rapidity of growth . . . 239

Flaxseed, grading of . . . . : 288

Fodders, composition of . . 257-258 cutting of . . . . 260

Food, relation of, to health . . 378 requirements of animals . 329 supply and stage of growth 330

Foods, caloric value of . . . . 313 combination and digestibility of . . . $32 \mathrm{I}$ cost and value of . . 359 factors influencing digestibility . . . 320, 36r influence of cooking upon digestibility . . . 323 mechanical condition of, and digestion . . . 320 
Foods, palatability of refuse and waste matters of .

Formula .

Formulas, structural

I 78

Fruits

dried

300-303

food value . . . . . 303

Fuels

IIO

Galvanized iron . . . . . $\mathrm{I}_{42}$

Gasoline, use of . . . . . 105

Gelatin . . . . . . . 216

Germination of seeds . . 225-227 conditions necessary for $\begin{aligned} & 227 \\ & - \\ & 0\end{aligned}$ tubing, bending . . . 22

Gliadin . . 260

Globulins . . . . . . 208

Glucose, test for . . . . . . I4I

Gluten . . . . . . . 260 meal . . . . . . 296

Glutenin . . . . . . $26 \mathrm{I}$

Grains, composition of . . . 290 cost and value of . . 343 grading of . . . 382

Grapes . . . . . . . 302

Grass, pasture . . . . . 254 Gypsum . . . . . . . 130

Helium . . . . . . 67

Hemoglobin . . . . . 352

Horses, foods for . . . . . 33I

food requirements of . . 33I

Human and animal feeding compared body, composition of $\quad 354$ food problems . . . 360 foods, composition of $374-380$ cost and value of 359 rations $\begin{array}{r}359 \\ -358 \\ \hline\end{array}$ calculation of . $\quad 35^{8}$ requisites of . 363

Hydrated cellulose . . . . I7 I

Hydrocarbons . . . . . . 104

Hydrochloric acid . . . 76-80 preparation . 76
Hydrochloric acid, properties . 78 Hydrogen . . . . . 36-40 importance . . . 39 occurrence . . . 36 preparation . . 36-37 properties . . . . 38 peroxid . . . . . 67 sulfid . . . . . 96

Hydroxyl . . . . . . 69, 7 I

Illuminating gas . . . . . 106

Indestructibility of matter . . 5

Insecticides . . . . . . . 145

Insoluble proteids . . . . . 2 II

Invert sugars . . . . . . I8I

Iron . . . . . . . . . 133

compounds . . . . $133-137$

galvanized . . . . . I42

in plants . . . . . . . I6I

ores, reduction . . . . . 133

rusting of . . . . . 137

wrought . . . . 135

Keratin . . . . . . . . 353

Kerosene oil, testing of . . . 105

Laboratory manipulation . . 19-30

practice, important . I9

Lactose . . . . . . . . 180

Law of definite proportion . . I7

multiple proportion . . 89

Lead . . . . . . . . I43

carbonates . . . . . I43

compounds . . . . I43, I46

oxids . . . . . . . . I43

uses of . . . . . . . 144

Lecithin . . . . . . . 234

Lemons . . . . . . 301

Levulose . . . . . . . . $\mathrm{I}_{3}$

Ligno-cellulose . . . . . . 172

Lime kiln . . . . . . . I 28

Lime, slaking of . . . . . I3I

Limestone . . . . . . . . 128

Linseed meal . . . . . . 294

Magnesium, occurrence . . . 132

in plants. . . $16 \mathrm{I}$

salts . . . . . 132 
Maintenance ration

Naming of acids . . . . . $7 \mathrm{I}$

Maize, as food. . . . . 278

as forage . . . 254

composition of . . . 273

kernel . . 273

glutinous and starchy . . 275

grading of . . . . 285

husk . . . . 242

leaves ....24I

moisture . . . . 277

products . . . 278

proteids of . . . 274

roots . . . . 240

stalk . . . . $24 \mathrm{I}$

structure of kernel . . 273

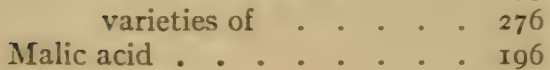

Malt sprouts . . . . . 296

Maltose . . . . . . . I80

Mangels . . . . . . 300

Marsh gas . . . . . $\mathrm{IO}_{4}$

Matter, indestructibility of . . 5

Measuring liquids

Meats, albumin of

albuminoids of

rc -pposition of

digestibility of

Mechanical mixtures

Mercury compounds . : 155

Metric equivalents . . . . 23

Mica . . . . . . . I00

Milk solids . . . . . . . ${ }_{152}$ sugar . . . . . . I80

Mill and by-products . . 29I-298

Millet . . . . 252, 290

Mineral food, assimilation of, by plants 235 matter of crops . . 153-168 oils . . . . . . I07 in a ration . . . 370

Minium

Molecular weights . . . I4

Molecules

Mortar . . . . . I30

Mucin . . . . . . 216

Multiple proportion, law of . . 89

Neutralization . . . . 7I, 73

Nitrates . . . . . 82

Nitric acid . . . . $82-84$

importance . . 84

preparation . . . 82

properties . . . 83

Nitrogen . . . . 4 $4 \mathrm{I}^{-44}$

assimilation of, by plants 235 compounds, importance of . . . 44,89

determination of . . $2 \mathrm{I}_{4}$

occurrence ". . . 4 $4 \mathrm{~T}$

oxids of . . . 86

preparation . . 4I-42

properties . . . 43

rôle in plant and animal life . . . . 44

Nitrogen-free extract . . . . 188

Nitrogenous compounds . . 204-223

matter, animal bodies 349

value . . . . . 202

Non-nitrogenous compounds, general relationship . . . 202

Note-book, laboratory . . . . 27

Nuclein . . . . . . . 326

Nutrients, digestible, of foods $\quad 326$

Nutrition . . . . . 3II 348

Nutritive ratio . . . 340

Oat feed . . . . . 295

hay . . . . . 252

Oats, composition of . . . 279

as food . . . . 280

grading of . . . . 286

structure of kernel . . . 279

Olein . . . . . . I I I

Olives . . . . . 302

Oranges . . . . . 30I

Organic compounds in plants . III

matter . . . 168

decay of . . III3

production of . 236

6 Osmosis . . ..... 229 
Oxids .

Oxygen importance . . . . 34 occurrence . . . . 30 preparation . . . . 30 properties . . . . . 33

\section{Ozone}

Palmitin

Paris green . . . . . . . . 145

Parsnips . . . . . . . . 300

Pectin bodies . . . . . . . 187

Pentosans . . . . . . . . 186

Peptic ferments . . . . . 318

Peptones . . . . . . 210

Petroleum . . . . . . . . 104

Phosphates .

fertilizers

in human foods

Phosphoric acid

Phosphorus .

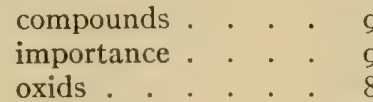

in plants. . . . 162

properties . . . 89

Physical change . . . . . 3

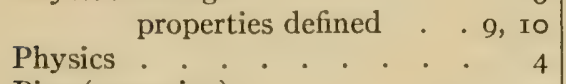

Pigs (see swine).

Plant ash

growth .

juices, movement of

life, chemical change physical change

Plaster of Paris

153-167

. $224^{-234}$

. 229

8

8

Plumbing

Polariscope

Porcelain

Potassium

carbonate. . . . I 22

chlorate . . . . . I 23

compounds . . . I $2 \mathrm{I}-\mathrm{I} 23$

hydroxid . . . . . I 2 I

nitrate . . . . . . 122

in plants . . . . 158

sulfate . . . . . I23

Potatoes . . . . . . . . 299

Pottery
Prairie hay . . . . . . 252

Properties, chemical . . . IO-I I of elements and compounds . . . 9-18 physical . . . . 9-10

Proportion, law of definite . . I7

Proteids . . . . . . . 205

amount in plants . . $2 \mathrm{I} 3$

chemical properties . 206

classification . . . 207

digestibility of . . 318

food value . . . 212, 262

insoluble . . . . 2 II

of meat . . . . 350

physical properties . . 206

of wheat . . . . 260

Protein, crude . . . . . $2 \mathrm{I} 3$

Proteoses . . . . . . $22 \mathrm{I}$

Protoplasm . . . . . . $23 \mathrm{I}$

Quartz . . . . . 98

Radicals . . . . . . . 7 I

naming of . . . $7 \mathrm{I}$

Rape . . . . . . . . 254

Rational feeding of animals . 328-347

men . .356, 380

Rations, balanced . . . 328

caloric value of . . . 34 I

maintenance . . . 328

standard . . . . 329

Reactions . . . . . II $5-120$

illustrated . . . II6-II7

impossible . . . . II8

Reagent bottles, handling of . . 25

Reduction . . . . . . . 47

Rice . . . . . . . . . $28 \mathrm{I}$

Roots . . . . . . 299, 300

Rye . . . . . . . 280

grading of . . . . . 287

Salts . . . . . . . . 69

acid . . . . . . 72

double. . . . . . 72

naming of . . . . 72,73

Sand culture . . . . . . . 157

Sanitary conditions and feeding 344

Saponification . . . . . . I9I

Seeds . . . . . . .224-229 
Seeds, and crop growth . . . 245 ash of . . . . . . 224

nitrogenous compounds of . 225 Sheep, food requirements of . $\quad 338$

Silage

Silica .

Silicates

Silicic acid

Silicon

compounds, importance of

Silo, losses in

Sodium

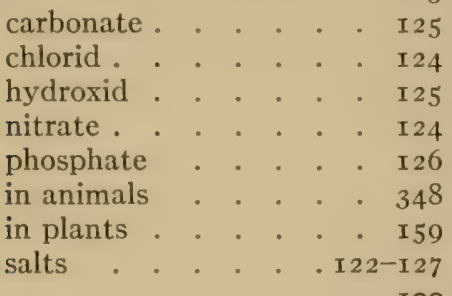

Soils . . . . . . 100

Spontaneous combustion . . 50

Starch .. . . . . I73-I79

chemical properties . . . 175

food value . . . . . 176

function . . . . 176

physical properties . . I73

in seeds . . . . . 226

Stearin . . . . . . . 190

Steel . . . . . . . . . . I35

Steer-feeding . . . . .330-334

Stover . . . . . . 254

Straw . . . . . . 250

Strawberries . . . . . 30I

Sucrose . . . . . . . 180 chemical properties . . I80 physical properties . . I8o

Sugar . . . . . . I79-187 Sulfeets . . . . 185

Sulfates . . . . . . 95

Sulfids . . . . . . . . 96

Sulfur . . . . . . . . 92 dioxid . . . . . 93

preparation . . . . 92

properties . . . . . 92

uses . . . . . . . 93

in plants . . . . . 163

Sulfuric acid . . . . . . 93

properties . . . 94
Swine, food requirements of . $\quad 336$

Symbols . . . . . . . II

Syntonin . . . . .210, 352

Tartaric acid . . . . . 196

Timothy hay . . . . . 25I

Tin . . . . . . 143

salts . . . . . . 143

Trypsin . . . . . . 318

Tubing, glass, bending . . . . 22

cutting . . . 2 I

Turpentine . . . . . . 107

Typhoid bacillus . . . . 57

Valence ... . . . . . . I7

table of . . . . . I2

Vegetable foods . . . . 379,380

digestibility of $\quad 372$

Ventilation of rooms . . 64-66

Water . . . . . 54-62

borne diseases . . . . . 57

contamination of . . 56,60

culture . . . . . . 156

of crystallization . . . . 56

distillation of . . . . 62

electrolysis . . . . 54

filters . . . 60, 6I

mineral matter of . . . 60

natural . . . . . 56

organic matter in . . 57

oven . . . . . . . I49

physical properties . . . 58

in plants . . . . . $15 \mathrm{I}$

purification of . . . $6 \mathrm{I}, 62$
Waxes

Weighing . . . . 23, I52

Weights, atomic . . . . I4

molecular . . . . I4

Wheat . . . . 259-272

American and foreign . . 272

as animal food . . . 270

as human food . . . . 27 I

bran . . . . . . 29I

bread-making properties of $26 \mathrm{I}$

by-products . . . . 29I

composition of varieties . 269

feed . . . . . . 294

flour, grades of . . . 268 
Wheat, germ . . . . . . $268 \mid$ Wheat, shorts . . . . . . 293 gluten of . . . . . 26r storage of . . . . 267 grading of . . . . $283 \quad$ structure of kernel . . 259 influence of climate upon . 263 unsound . . . . . 268 fertilizers upon 264 variations in composition . 265 middlings ..... 293 White lead ...... I44 nitrogen content of, and flour . . . . . 263 proteids of . . . . 260 Zeolites . . . . . . I00 rapidity of growth . . . 235 Zinc compounds . . . . . . 142 screenings . . . . . 294 occurrence . . . . . I42 
THE following pages contain advertisements of a 1 few of the Macmillan books by the same author and on related subjects. 

BY HARRY SNYDER, B.S.

Professor of Agricultural Chemistry, University of Minnesota, and Chemist of the Minnesota Agricultural Experiment Station

\section{Human Foods}

Cloth, I2mo, illustrated, 362 pages, $\$ 1.25$ net

A discussion of the composition and physical properties of foods, the main factors which affect their nutritive value, etc.

\section{Dairy Chemistry}

Illustrated, rgo pages, $\$$ T.Oo net; by mail, $\$$ T.IO

"The book is a valuable one which any dairy farmer, or, indeed, any one handling stock, may read with profit." - Rural New Yorker.

\section{Soils and Fertilizers}

Third edition, illustrated, $\$ 1.25$ net; by mail, $\$ 1.38$

A book which presents in a concise form the principles of soil fertility and discusses all of the topics relating to soils as outlined by the Committee on Methods of Teaching Agriculture. It contains 350 pages, with illustrations, and treats of a great variety of subjects, such as Physical Properties of Soils; Geological Formation, etc.; Nitrogen of the Soil and Air; Farm Manures; Commercial Fertilizers, several chapters; Rotation of Crops; Preparation of Soil for Crops; etc.

\section{THE MACMILLAN COMPANY}

Publishers 64-66 Fifth Avenue New York




\title{
Chemistry and Its Relations to Daily Life
}

\author{
By LOUIS KAHLENBERG \\ Professor of Chemistry
}

AND

EDWIN B. HART

Professor of Agricultural Chemistry in the University of Wisconsin

Cloth, r2mo, illustrated, 393 pages, \$I.25 net

This book is intended to represent a year's work for students of agriculture and home economics in secondary schools. The subject matter is thoroughly practical in character and it is presented in a simple, interesting manner. Although the content is scientifically accurate, useful facts have been placed in the foreground and no more theory has been presented than seemed necessary. Chemical formulas are introduced, but merely as an aid in expressing facts in simple, compact, and convenient form. Questions follow each chapter and there are abundant laboratory exercises. While the book is not intended to provide a preparatory course for colleges, yet the students who have completed it successfully will doubtless have gained information and sound scientific training which will compare favorably with that received in courses usually taken in preparatory schools.

The practical character of the book and its adaptability to meet the needs of the home and the farm are indicated by the chapter headings, among which are: The Composition and Use of Water; Carbon and Its Compounds; The Metals of the Alkalies and the Alkaline Earths; Paints, Oils, and Varnishes; Leather, Silk, Wool, Cotton, and Rubber; The Soil ; Commercial Fertilizers; Farm Manures; The Animal and Its Feed; Human and Animal Foods; Milk and Its Products; Poisons for Farm and Orchard Pests.

\section{THE MACMILLAN COMPANY}

Publishers

64-66 Fifth Avenue

New York 


\section{Exercises in Elementary}

\section{Quantitative Chemical Analysis for Students of Agriculture}

By AZARIAH THOMAS LINCOLN, Ph.D. Assistant Professor of Chemistry, University of Illinois AND

JAMES HENRY WALTON, Jr., Ph.D. Assistant Professor of Chemistry, University of Wisconsin

New York, 1907. Third Reprint, 1910. Cloth, 8vo, 218 pages, $\$ 1.50$ net

This book is the outgrowth of several years' experience in teaching Quantitative Analysis to students specializing in Agriculture, Chemistry, Medicine, and Household Science. No attempt has been made to present a complete treatise on Quantitative Analysis; but a few typical exercises have been chosen to illustrate the fundamental principles of the most important methods of manipulation.

Owing to the importance of calculating the amount of various elements in substances analyzed, a special part of the book (Part V) deals with this subject (Stoichiometry). A large number of problems have been here introduced for the sake of practice.

\section{THE MACMILLAN COMPANY \\ Publishers 64-66 Fifth Avenue New York}


$5 \quad 1918$ 





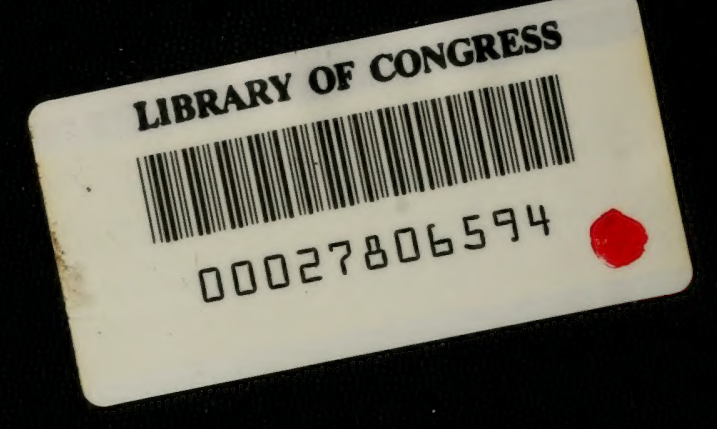

